\title{
Co-Creation in Higher Education
}

Mollie Margaret Dollinger

Submitted in total fulfilment of the requirements of the degree of Doctor of Philosophy

August 2018

Centre for the Study of Higher Education

Faculty of Education

University of Melbourne 


\section{$\underline{\text { Declaration }}$}

This is to certify that:

(i) the thesis comprises only my original work towards the $\mathrm{PhD}$;

(ii) due acknowledgement has been made in the text to all other materials used,

(iii) the thesis is less than 100,000 words in lengths, exclusive of tables, maps, bibliographies and appendices.

Mollie Dollinger

August 2018 
Publications based on this research include:

Dollinger, M., Lodge, J., \& Coates, H. (2018). Co-creation in higher education: towards a conceptual model. Journal of Marketing for Higher Education, 1-22.

Dollinger, M. \& Brown, J. (accepted at Journal of Teaching and Learning for Graduate Employability). An Institutional Framework to Guide the Comparison of WorkIntegrated Learning.

Dollinger, M. (2018, July). Higher Education's Value: In the Experience Itself. In Higher Education Research and Development Society Association (HERDSA) conference papers. (Best Paper by a New Researcher)

Dollinger, M. (2018). Technology for the Scalability of Co-Creation with Students. Australasian Society for Computers in Learning in Tertiary Education (ASCILITE).

Dollinger, M., \& Lodge, J. M. (2018, March). Co-creation strategies for learning analytics. In Proceedings of the 8th International Conference on Learning Analytics and Knowledge (pp. 97-101). ACM.

Mahat, M., \& Dollinger, M. (2018). Mind the gap: co-created learning spaces in higher education. In K. Fisher (Ed.). The translational design of bigher education learning environments and campuses: an evidenced based approach. Rotterdam: Sense.

Dollinger, M. (under review). Can Co-Creation Enhance Value in Higher Education?

Dollinger, M. (under review). Designing for Student-Staff Co-Creation: A Guide for Practice in Higher Education.

Dollinger, M., \& Lodge, J. (under review). Applying Students-as-Partners to Learning Analytics. 


\section{Acknowledgements}

I would like to thank my wonderful supervisors, Professor Richard James and Associate Professor Jason Lodge, for always challenging me and pushing me to do better. My dissertation, and my development as a researcher, has greatly benefited from you both.

I would also like to acknowledge the wisdom and feedback I received from my initial supervisor, Professor Hamish Coates, who encouraged me to take on this ambitious project. I also drew on continual support from my board members, Professor Sophia Arkoudis and Professor Christopher Ziguras.

I also would like to thank the many researchers, professional staff, and scholars who helped and supported me during my candidature including: Chi Baik, Peter Bentley, Julie Blasioli, Cassandra Colvin, Linda Corrin, Camille Dickson-Deane, Sarah French, Wendy Green, Helen Hu, Paula Kelly, Gregor Kennedy, Gabriele Lakomski, Danny Liu, Gail Maddigan, Marian Mahat, Kelly Matthews, Samantha Marangell, Peter McPhee, Ken Moore, Romina Mueller, Allan Patience, Douglas Proctor, Sylvia Schaffarczyk, Christian Schneijderberg, Ian Teo, Dina Uzhegova, Umesha Weerakkody, Tom Whitford, Paul Wiseman and David Wolf.

Outside of my professional network, I would also like to thank my family, including my parents, Marc and Mimi Dollinger, and my siblings, Matt Dollinger and Marisa Boevers. Mom, you once told me that if I studied hard enough in high school I might become a manager of a McDonalds (where I currently worked), I hope I have exceeded your expectations ${ }^{1}$.

To my future husband ${ }^{2}$ and partner in crime, Charles Dangibeaud, thank you for always believing in me and providing me the support I needed to finish this in a relatively sane state.

I have lost some friends in my life and I have many other friends who do not have the means to study towards a PhD. I dedicate this dissertation to them, as we should all have the opportunity in life to spend three years thinking about something we care about.

\footnotetext{
${ }^{1}$ My mother wanted it to be noted in text that her response to this comment was, "You might still end up a manager at McDonalds from what I hear about PhD graduates these days."

${ }^{2}$ Charlie, this is a reviewed text, therefore, this is pretty much fact now.
} 


\section{Table of Contents}

Co-Creation in Higher Education ....................................................................

Acknowledgements ................................................................................................. 5

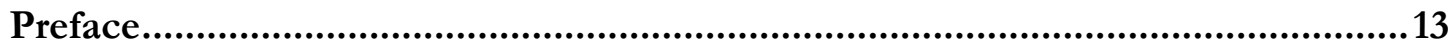

Chapter 1. Introduction to Dissertation.............................................................17

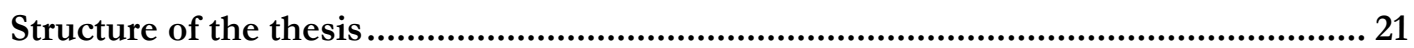

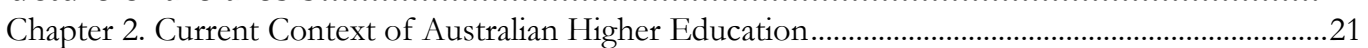

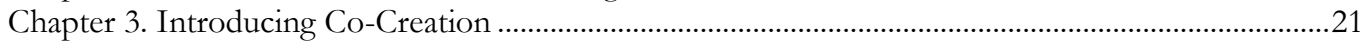

Chapter 4. Conceptual Framework for Co-Creation in Higher Education ..............................................22

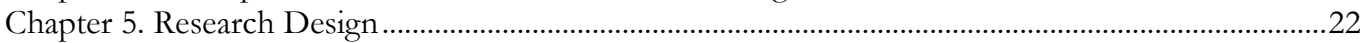

Chapter 6. Overview of Cases .............................................................................................................22

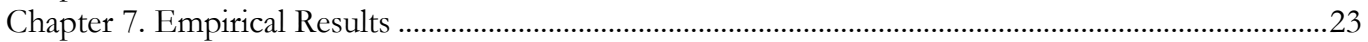

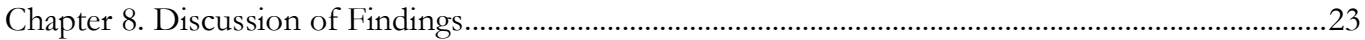

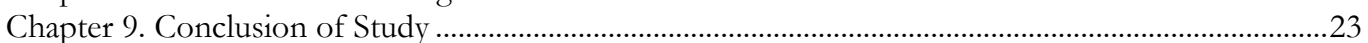

Chapter 2. Current Context of Australian Higher Education ................................24

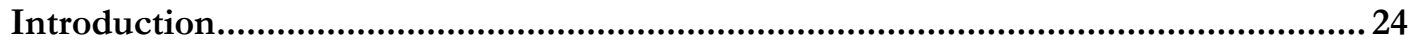

Factors Changing the Higher Education Context ...........................................................2 25

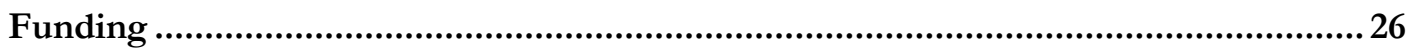

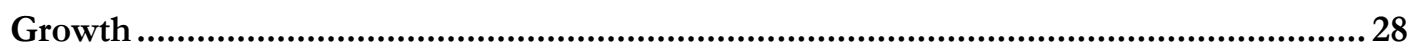

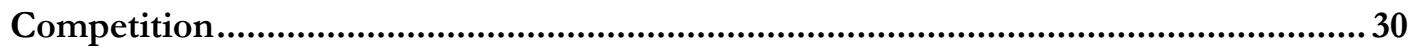

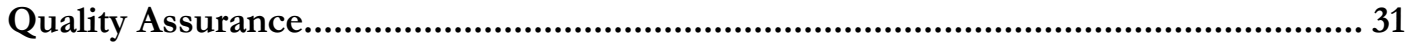

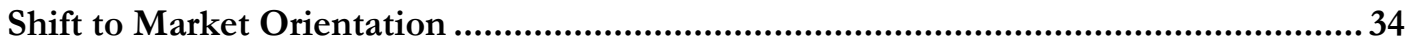

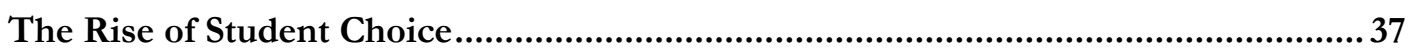

Redefining the Role of Universities for the Future ....................................................... 39

The Student Experience ................................................................................................. 42

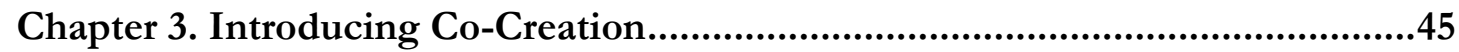

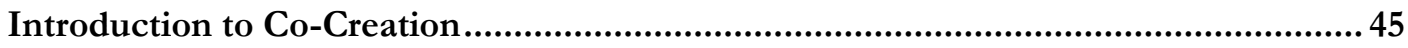

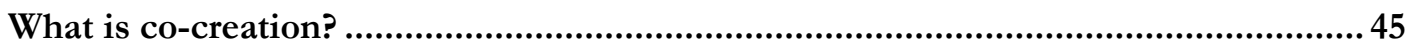

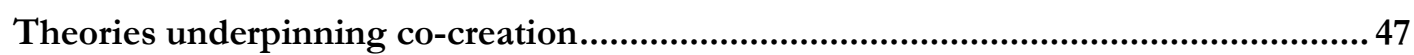

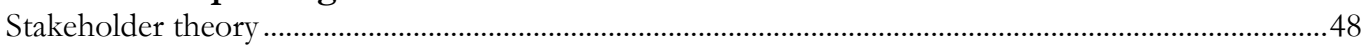

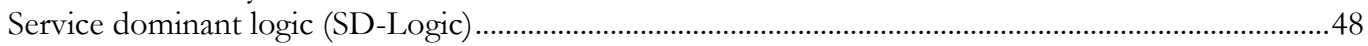

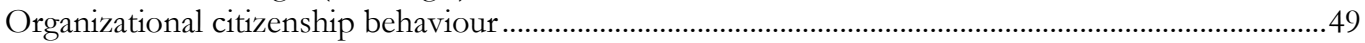

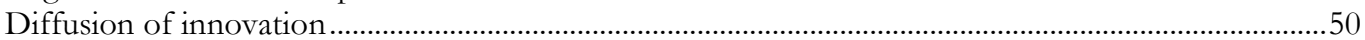

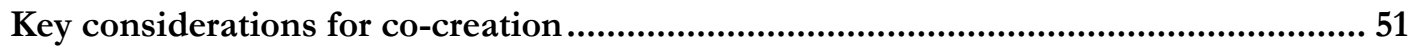

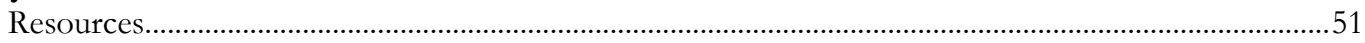

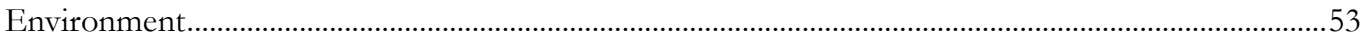

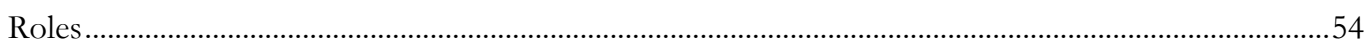

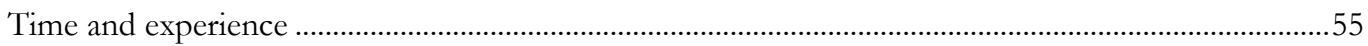

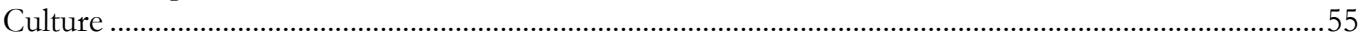

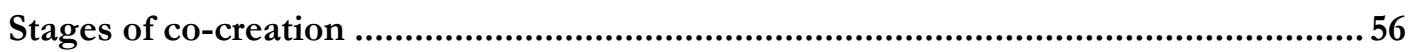

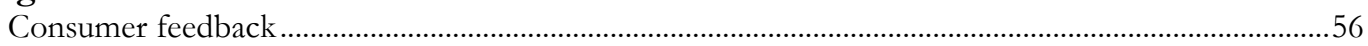

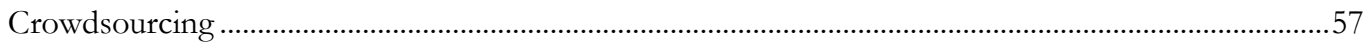

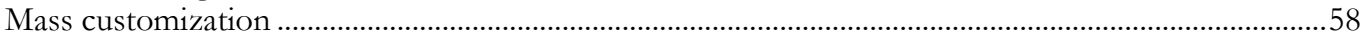

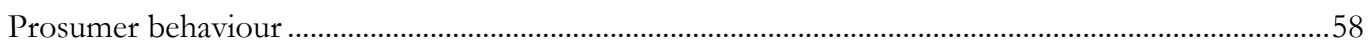

Co-creation as participatory design..............................................................................59 


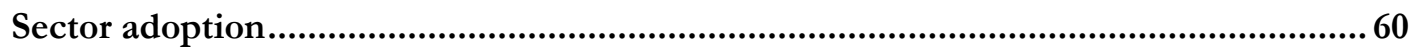

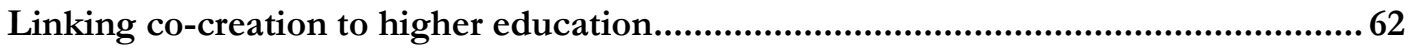

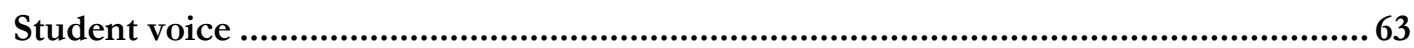

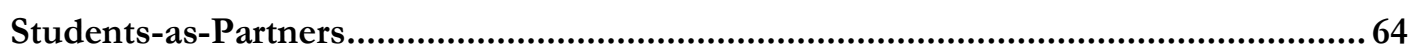

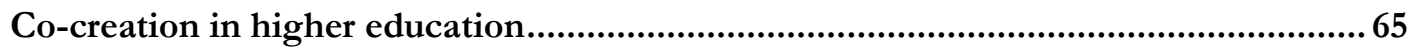

Challenges to co-creation in higher education..............................................................67 67

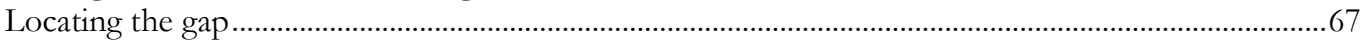

Chapter 4. Conceptual Framework of Co-Creation for Higher Education.............70

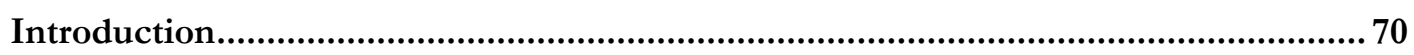

Previous relevant models on co-creation............................................................... 70

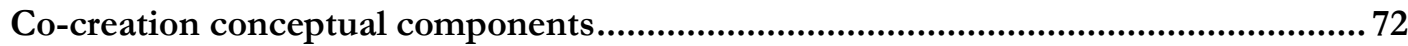

Table 1. Summary of Indicators for Co-Creation .............................................................. 73

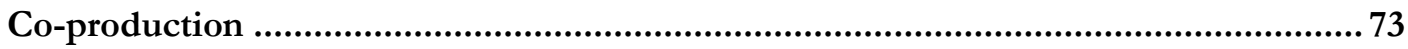

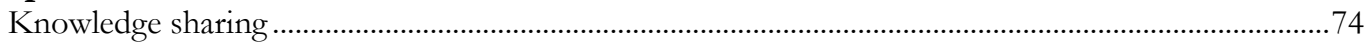

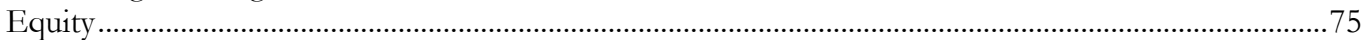

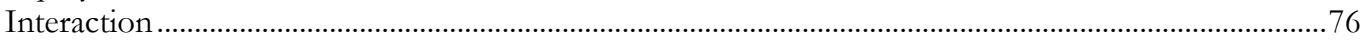

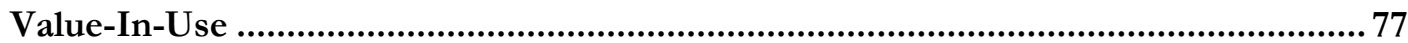

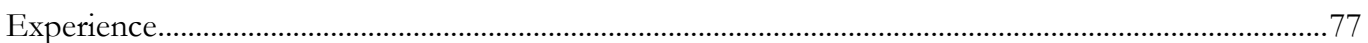

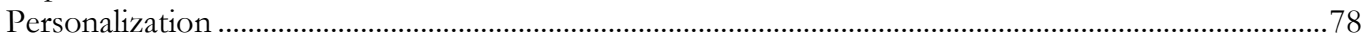

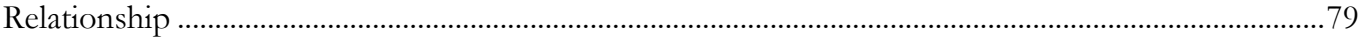

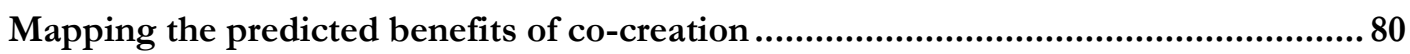

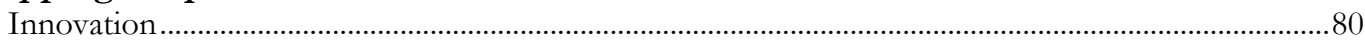

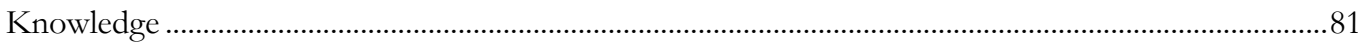

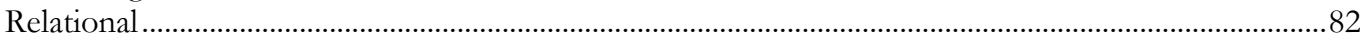

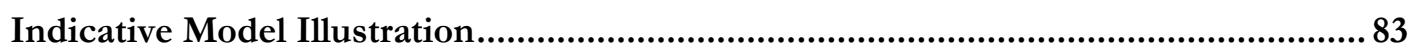

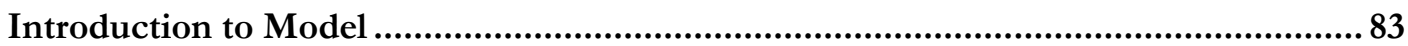

Figure 1. Model for Exploring Co-Creation in Higher Education..................................86

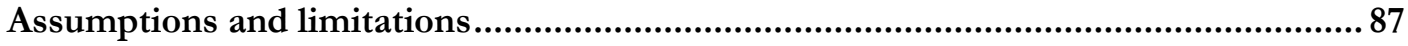

Summary of Conceptualization of Co-Creation ............................................................. 87

Chapter 5. Research Approach and Design ....................................................89

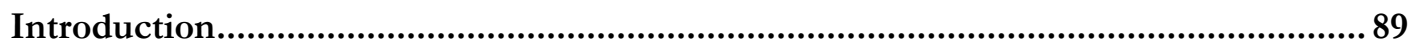

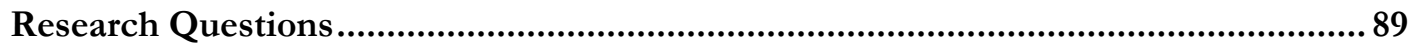

Researchers' Worldview ................................................................................................90

Research Methodology: case study ............................................................................... 91

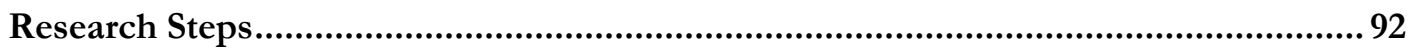

Literature review and research question formation ................................................................................93

Expert consultation and review...........................................................................................................93

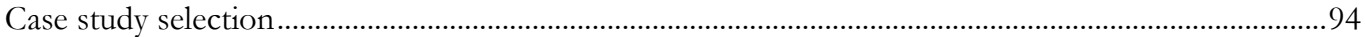

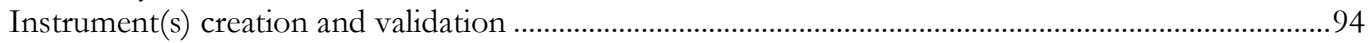

Data collection I: qualitative (online) survey ………………………………………………………………...95

Table 2. Summary of online questionnaire instrument ...................................................99

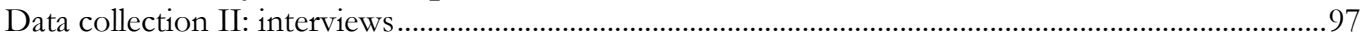

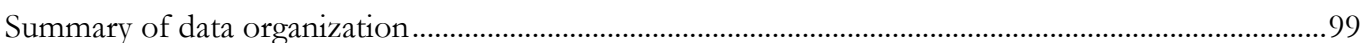

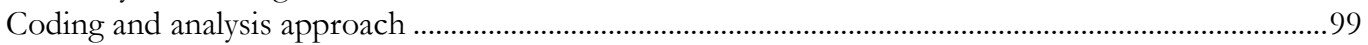

Table 3. Example of Gioia Method ..............................................................................100 
Implications and Limitation of Research Design ............................................101

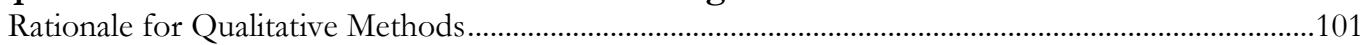

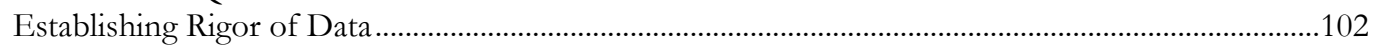

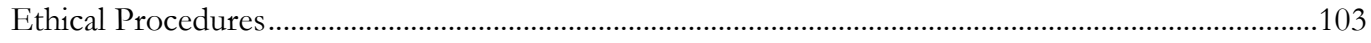

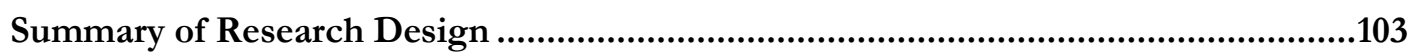

Chapter 6. Overview of Case Studies and Results of Descriptor Data.................. 105

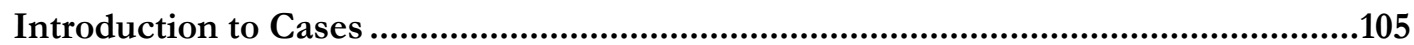

Table 5. Location and Type of Institution of Case Studies...........................................106

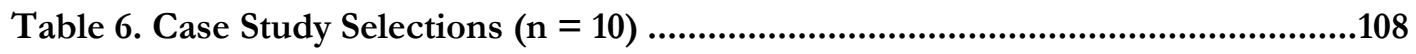

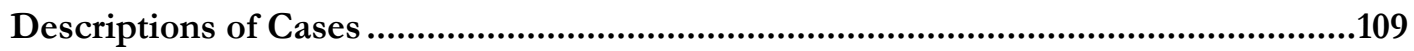

Case 1. Student-Staff Co-Designed Magazine ...................................................................................110

Case 2. Work-Integrated Learning (WIL) Course ...............................................................................110

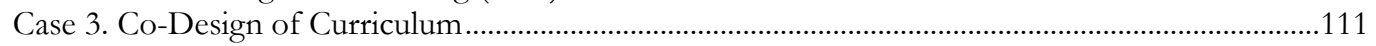

Case 4. Student-Staff Customer Experience Project ...............................................................................112

Case 5. Student-Staff Creation of Learning Resources ............................................................................113

Case 6. Student-Staff Program Implementation ...............................................................................113

Case 7. Student-Staff Peer Mentor Program (A) ....................................................................................114

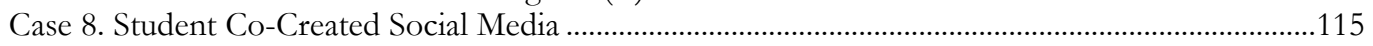

Case 9. Student-Staff Governance .....................................................................................................115

Case 10. Student-Staff Peer Mentor Program (B) ....................................................................................116

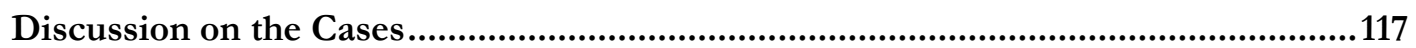

Table 7. Expert Consultation on Co-Creation Potential $(n=19)$................................120

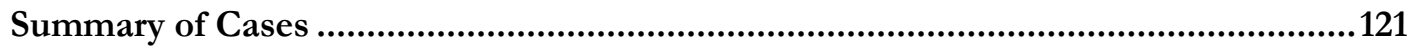

Chapter 7. Exploring the nature of co-creation through empirical data...............122

Introduction to empirical data .....................................................................................122

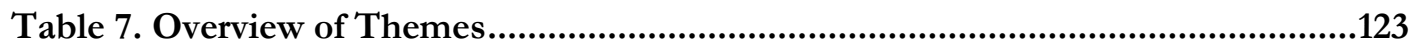

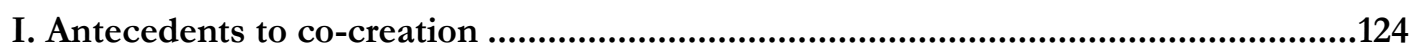

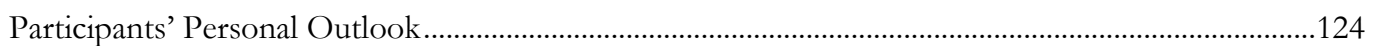

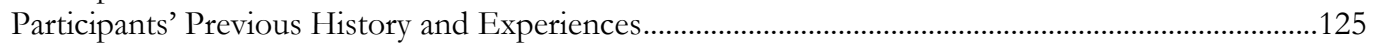

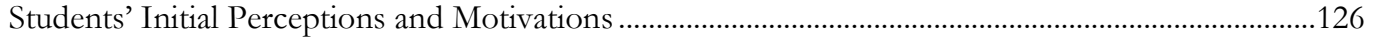

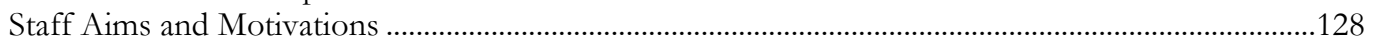

II. Environmental factors .............................................................................129

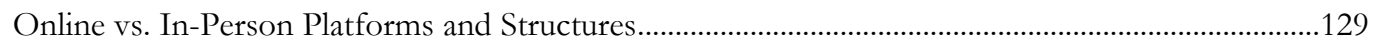

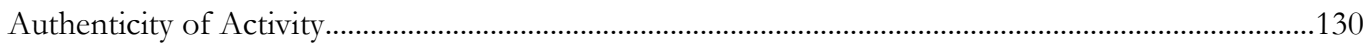

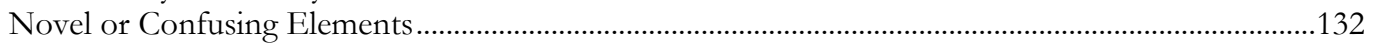

III. Barriers to co-creation......................................................................134

Need for Staff Guidance and Direction ................................................................................................134

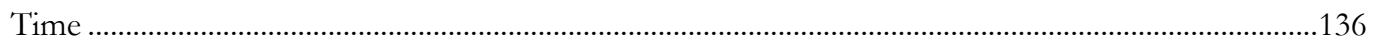

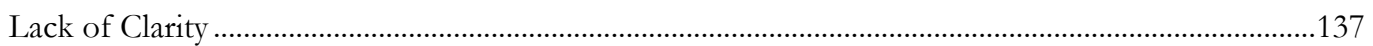

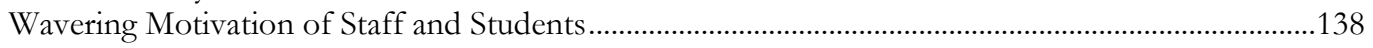

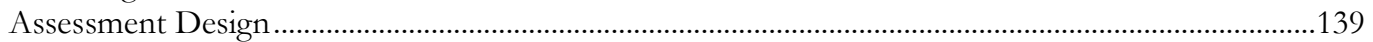

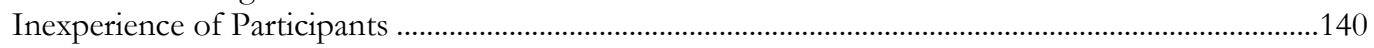

Power Imbalance between Staff and Students .......................................................................................141

Disengagement or Lack of Motivation from Participants.....................................................................145

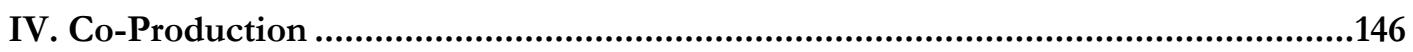

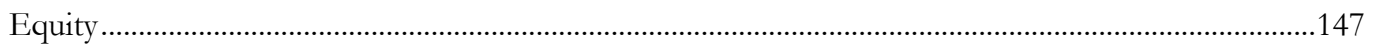

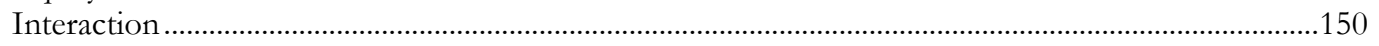

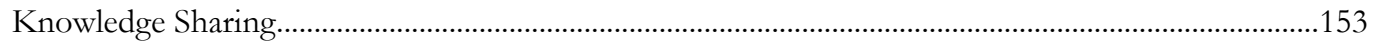

V. Value-in-Use ......................................................................................155 


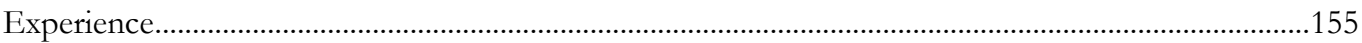

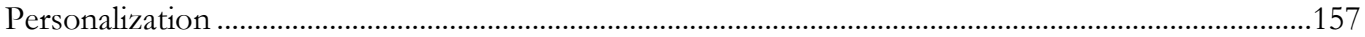

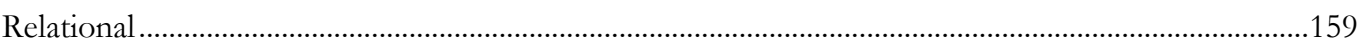

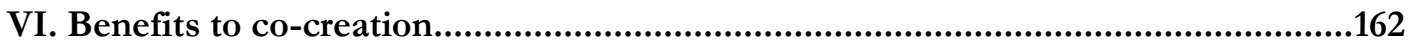

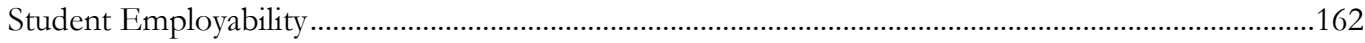

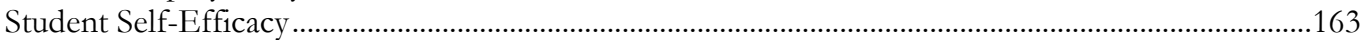

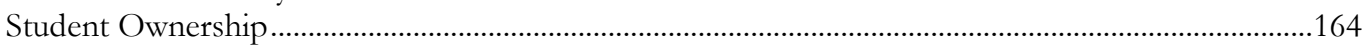

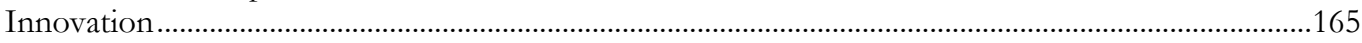

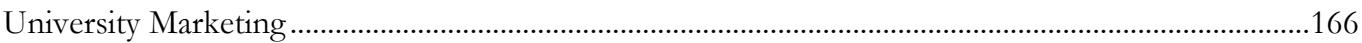

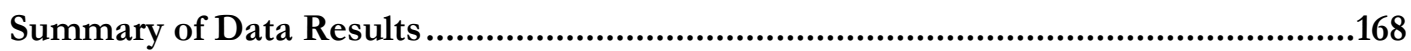

Chapter 8. Discussion of Findings ..................................................................169

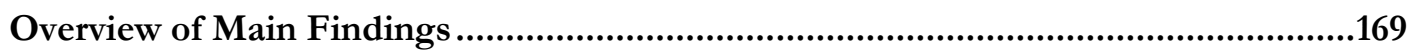

Discussion of Six Major Findings .................................................................169

Finding 1. Antecedents have a significant impact ....................................................................................170

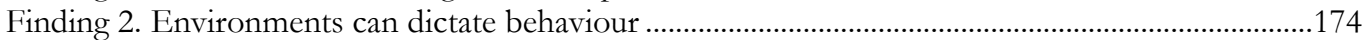

Finding 3. Barriers to co-creation come in many shapes and sizes ....................................................177

Finding 4. The first step to co-creation is co-production........................................................................181

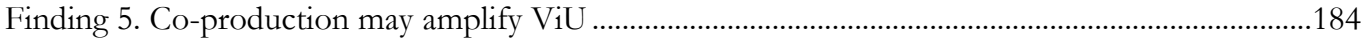

Finding 6. When benefits outweigh costs ..........................................................................................187

Discussion of Less Anticipated Findings......................................................189

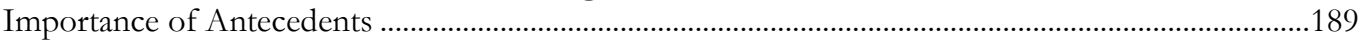

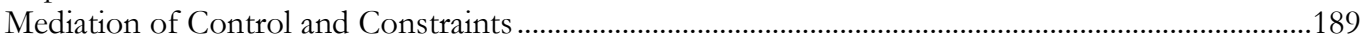

Large Variation Across Cases ......................................................................................................190

Overview of the places, stages and key considerations of co-creation in higher

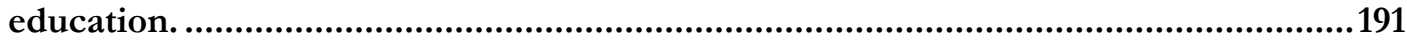

Places of Co-Creation in Higher Education ..........................................................................................191

Table 8. Example of Co-Creation Participation Matrix ...............................................194

Key Considerations of Co-Creation in Higher Education ......................................................................194

Summary of Major Findings...........................................................................................195

Chapter 9. Conclusion of the Study .................................................................197

Overview of Study ............................................................................................................197

Figure 2. Empirically Informed Model for Co-Creation in Higher Education........... 200

New Insights for Higher Education Research ........................................................201

New Directions for Research on Co-Creation........................................................... 204

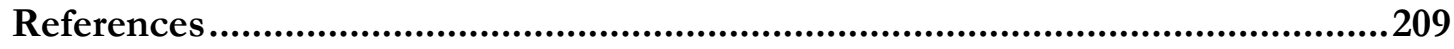

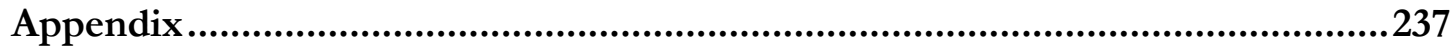

Expert Review on Co-Creation in Higher Education .................................................. 237

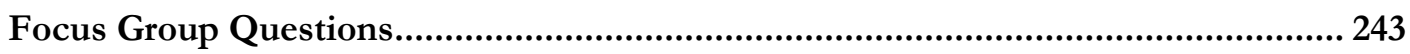

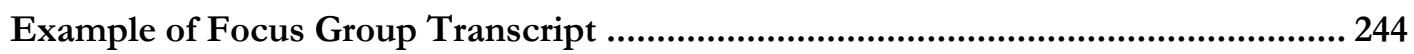

Example of Instrument Pilot ...................................................................................... 245

Copy of Qualitative Survey ........................................................................................... 248

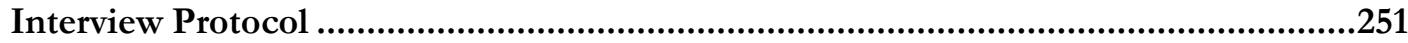

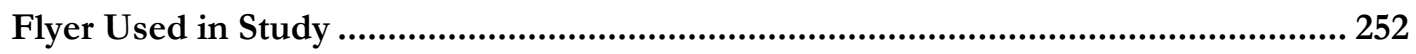

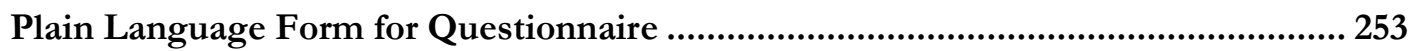

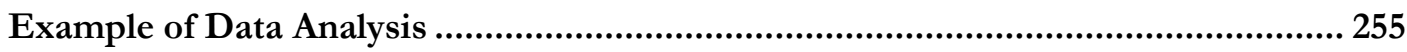


Summary of Data Analysis ..................................................................................... 260

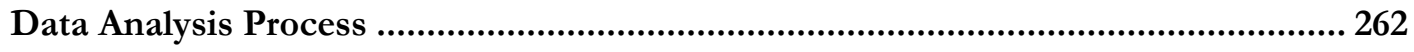

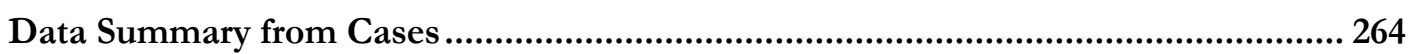

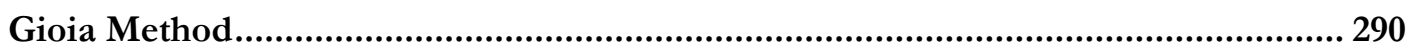




\section{Preface}

Within this dissertation, I will present and discuss my research on student-staff co-creation in higher education. My decision to research the topic came firstly from my understanding and perspective on the current higher education context. Universities in modern times have various pressures, including funding, growth and competition. It is central to my thesis that these pressures are compelling universities to increase their focus on the student experience (see Chapter 2). Yet improving the student experience is not a straightforward task. Students are diverse, as are universities, and enhancing the student experience can be achieved in a multitude of ways. One dissertation could not even begin to research all the mechanisms to improve the student experience. However, co-creation stood out immediately as an interesting lens to study, evaluate and even improve the student experience. Originally developed in organisational literature, co-creation activities and interventions encourage organisations to break down their traditional production and supplier structures and allow for users to change and modify services and products. In higher education, this would mean allowing students not only to consume higher education but also to help produce their own higher education experience. In this study, I have defined co-creation as an interaction between two or more unique stakeholders to jointly integrate their respective resources to provide greater benefits for the both the organisation and the user. Critical in this definition, is the emphasis on unique stakeholder groups working together (in this case students and staff) and recognition that their resources are similarly unique. Further, as this study will discuss, I will explore co-creation as both a benefit to the university and to the student.

Anecdotally, co-creation makes sense. Organisations can create better services and products by involving users in the process, understanding their needs and perspectives more deeply, and thus co-creating greater value together. Yet, applying co-creation to higher education is not simple, as what works in industry does not always align to the context of universities. Industry is profit-driven, universities are not. This is where the challenge of the dissertation stood.

To illustrate, when I first began presenting and sharing my work on student-staff cocreation in higher education I was often questioned by other researchers who wanted to hear my argument why students were consumers. However, 'students as consumers' is not something I hold to be accurate. Students cannot be consumers, as a consumer, defined 
by Oxford dictionary is "a person who purchases good and services for personal use." Education and subsequently learning are not individual endeavours, at least not in the current model of universities where students interact with each other and their teachers regularly. From an educational psychology perspective, learning is a social act (Lave \& Wenger, 1991). Further, despite tuition fees that charge for entry, an education cannot be bought. Universities may provide paying students subjects to choose from, however, if students do not learn and pass these subjects they do not get the credential, nor do they get their money back. Yet it seemed at times no matter how much I explained this to audience members or colleagues, my use of term 'co-creation' and 'co-production' and 'value' always led them to believe that my thesis was to argue that universities should treat students as consumers, something, in fact, I do not at all believe.

There are two points I would like to make here, which I will expand on later in the thesis. The first is the recognition that students do take on consumer type roles within their university experience (Woodall, Hiller \& Resnick, 2015). Which, as McCulloch (2009) has noted, does have some benefits to the sector, including incentivising institutions to recognise the important financial undertaking a university degree is for many students. And yet, as McCulloch and others (e.g. Single-Jackson, Jackson \& Reinhardt, 2010) also acknowledge, consumer roles are only one part of the student experience. In this thesis, I will therefore use a different metaphor to view students, not as consumers, but that students are 'users'. The definition of a user by Oxford dictionaries is, of course, far broader than a consumer. Defined as 'a person who uses or operates something' it is a general term, and it would be hard to argue that students do not fit this description in their university experiences. Yet while the definition is simple, its meaning immediately implies something that the term 'consumer' failed to, active participation. Students do not consume education as they would a chocolate bar, they use it, interact with, sometimes even add to it and improve it. Therefore, contained in this dissertation are many terms, such as customer, consumer, and user. When quoting others work I refer to the term(s) they used, to convey their perspectives, however, it is my argument that students are not consumers, but users of universities.

In the over three years from when I started my dissertation to now I have seen a remarkable level of interest in my chosen topic. Not only is co-creation increasingly mentioned in higher education discourse, but my own project has elicited interest from 
many university scholars and leaders. As a PhD student, I have been invited to two interstate conferences to either give a presentation on co-creation or speak on a panel. Additionally, I remember sitting in the audience of the Higher Education Research and Development Australasian Society (HERDSA) in 2017 to have the keynote speaker mention, mid-speech, how he looked forward to attending my session (he did, and he asked a good question, for the record). This speaks, I think, to the general level of interest many have in higher education about how we can expand past the concept of student engagement and begin to discuss in more finite terms how we encourage students to actively participate. It was also with great pride that I found two of my conference papers in 2018 nominated for best paper awards, first at the International Learning Analytics and Knowledge (LAK) conference and then a few months later at HERDSA 2018, where I won the best paper from a new researcher. To me, this success speaks more to my chosen topic, and its relevance, than to my own ability.

Like most PhD students, I did not have a specific aim in mind when I started my dissertation other than to complete it. However, three years on now, I am still pleased with my topic choice, and even more surprisingly, I am excited by the results. As this dissertation will discuss, co-creation is happening in higher education. These opportunities are varied, and yet they hold in common an ability to allow for students to participate in their own student experiences as never before. By co-creating with students, universities also have an opportunity to innovate and understand their increasingly diverse student population to deliver better student experiences and raise the calibre of their university. This is not to say co-creation is easy, there are numerous barriers, as will be discussed. However, it is my belief, and hopefully yours at the end of this dissertation, that co-creation will only continue to grow and develop in higher education. And that is something we should all be excited about. 


\section{Chapter 1. Introduction to Dissertation}

Higher education is changing. Today, the context of Australian higher education, and much of the Western world, is one of decreased government funding, growth and expansion, heightened competition, and questions over the value of universities in the modern age. These factors have led universities to become increasingly market-orientated. The market, of course, being the millions of students who are considering attending university. Which, too, is changing. More people are considering higher education than ever before, across the globe. These potential students are diverse and range in age, background, socio-economic status, future career goals, expectations, and preferences. Therefore, as the market of higher education intensifies, the audience is also diversifying. How does a modern university handle these dual pressures?

It the argument of this dissertation that a potential solution is through co-creation. Cocreation is a term that has been used across a broad range of literatures and sectors, but in this dissertation, it is conceptualised from its original form that occurred in organisational business literature. Co-creation began as a resource integration approach. It was realised by scholars (e.g. Prahalad \& Ramaswamy, 2000) that users or customers (or in this dissertation students) are underutilised in current business practices. They suggested that users' 'resources' such as their ideas, preferences, past experiences and time could be integrated into the creation of key value offerings. In essence, they argued that by cocreating with users, organisations could understand their audience better and provide them more value, while at the same time better predict the preferences and needs of their potential future audience. It was referred to as a 'win-win' (Ramaswamy, 2009).

This dissertation set out to explore the nature of co-creation in the unique context of higher education, using these guiding research questions:

I. What is the nature of co-creation in higher education?

A. How is co-creation occurring in higher education within the Australasian context?

B. What are the outcomes (i.e. benefits) and barriers of co-creation in higher education within the Australasian context? 
The study explored these questions and the phenomenon of co-creation within the Australian context mostly, with one case study originating from New Zealand. To achieve this, extensive literature reviews and a collection of ten case studies on student-staff cocreation were analysed. The main contributions of the study included:

- The first empirically informed model of co-creation in higher education,

- Further conceptualisation of the two underpinning constructs of co-creation (co-production and value-in-use),

- An overview of key considerations and stages of co-creation in a range of literature and how they compared to the higher education sector,

- A conceptualisation of where co-creation takes places in higher education,

- Analysis and discussion on the antecedents, barriers, and benefits of cocreation in higher education.

These contributions are important first steps in the continued evaluation of co-creation in higher education. The model, in particular, will allow for teachers and researchers to understand their specific type and corresponding considerations of co-creation, depending on the activity, and serve as a foundation to continue to explore this complex area. Additionally, conceptualisation of co-creation across two constructs, may help the research area generally, as definitions over the term are diverse and can lack theoretically underpinnings.

Through the literature review and analysis within this study, it was revealed that the need for co-creation was very much present in the higher education sector. However, as Chemi and Krogh (2018) write, while co-creation in higher education can be intuitive, the awareness and approaches on how to develop and implement co-creation are less so. The research aimed to address this, and to offer practical and relevant contributions and findings that help future research in the area.

Ten case studies were included in this study on a range of activities that integrated purposeful student-staff co-creation and included:

- Student-staff co-designed magazine,

- Work integrated learning course, 
- Co-design of curriculum,

- Student-staff customer experience project,

- $\quad$ Student-staff creation of learning resources,

- Student-staff program implementation,

- $\quad$ Student staff peer mentoring program (2 cases),

- $\quad$ Student co-created social media, and

- $\quad$ Student-staff governance.

These activities do not exhaust all the possibilities of co-creation in the area. They further, only investigate student-staff co-creation, yet co-creation could also be applied to other stakeholders such as industry and community members. Yet from these cases, rich data is drawn. Using qualitative surveys and interviews, students and staff involved in these activities discussed their motivations supporting their participation, what their experiences were like, and the challenges and benefits to co-creation. Using the Gioia method (Gioia, Corley \& Hamilton, 2013), student and staff quotes were thematically mapped first and then organised by aggregate dimensions. These aggregate dimensions, as well as themes, laid the foundation for the empirical model, presented in Chapter 9.

To give a brief overview of the dimensions, six dimensions were uncovered. They included antecedents, environmental factors, barriers to co-creation, co-production, value-in-use, and benefits to co-creation. Each of these dimensions gave way to a critical finding. For example, it was found that antecedents, including participants' personal outlook and previous history and experiences, played a major factor in determining the individuals' participation in the co-created activity. This finding further raises questions about how universities can encourage all students and staff, not just those with past experiences that are similar and/or already highly engaged, to co-create? Another finding, about the environments of co-creation, found that the authenticity of the activity heavily impacted the students' participation in the co-creation activity. To summarise, if the student did not believe the intent to co-create with students was genuine, the risk of the student dismissing the activity loomed large. This then relates to staffs aims in the co-creation activity, and how to ensure that students feel their voices are truly valued.

A major contribution of this study was uncovering that the definition of co-creation through two underpinning constructs, co-production and value-in-use (ViU) applied to the 
higher education context. First revealed by Ranjan and Read (2016) through a meta-study, co-creation occurs both during production in the value chain (co-production) and onwards past production (value-in-use). While co-production, such as the design and processes of co-creating during the activity, was well known in regard to co-creation, ViU was far less applied in current research, and especially so in the field of higher education. Yet through this study, these two constructs not only served as the lens to evaluate co-creation, thus highlighting then relevance and functionality, but also served as a lens to understand value in higher education. Through co-production elements students and staff communicated, interacted, and shared knowledge, all benefits in themselves. But also, through the lens of $\mathrm{ViU}$, student-staff enhanced relationships, experiences, and were able to personalise aspects of the student experience. These benefits were conceptualised as 'processual benefits' as they occur naturally through the process of co-creation. However, in this study it was also found that co-creation can result in outcomes-based benefits as well. Benefits of this kind included student employability, student self-efficacy, student ownership, innovation, and university marketing. These benefits further relate to the 'win-win' term mentioned earlier, or how co-creation allows not only for greater benefits for students, but also universities.

Yet this study was designed to not only to reveal the benefits of co-creation, but also the barriers. Barriers were wide ranging across the ten cases and included the need for staff guidance and direction, time, lack of clarity, wavering motivation, assessment design, inexperience of participants, power imbalance between staff and students and disengaged or lack of motivation from participants. These barriers have serious implications for cocreation in higher education. They call into question whether co-creation can ever truly be an equal partnership between students and staff (or should it be), and whether co-creation has a place in the classroom regarding the need for assessment. The barriers revealed in the study also again call into question the equity of co-creation across all student populations. While it is wonderful to integrate the voices and perspectives of highly engaged students through co-creation, how can co-creation bring in students who are disengaged? How can we hear all student voices, not just the few? That question, and many more, are also contributions of this study, as the study offers new insights and directions for research on co-creation in the future. 
The research and outputs of this study will be of interest to many teachers, university staff and administrators, and students. Higher education is relationship between students and staff, and a mutual dependency. We need each other. Co-creation may not be the panacea for all of higher education's challenges, but through its approaches, stages, and key considerations, it is a way to enhance the relationship between students and staff, and ultimately, the value of higher education.

\section{$\underline{\text { Structure of the thesis }}$}

The following chapters are listed here which will give a summary to their individual contribution and help guide the reader through the argument of the dissertation.

\section{Chapter 2. Current Context of Australian Higher Education}

Within this chapter, it was argued that the due to the current context of higher education, the exploration of co-creation has critical relevance and importance. Contextual factors, such as funding, expansion and competition within the higher education sector, have highlighted the importance of market orientation. Additionally, questions over value of higher education, have led many students to become increasingly aware of their power to choose between universities and select universities based on their preferences towards the student experiences. This chapter set the foundation for why co-creation, or collaboration between students and staff, is important in today's higher education context.

\section{Chapter 3. Introducing Co-Creation}

This chapter aimed to continue the argument for how co-creation can relate to the higher education context by presenting an overview of the main literature on co-creation to date. Introduced in this chapter was the conceptual background to co-creation, through various definitions and theoretical underpinnings. Key literature reviews that helped form the crux of the dissertation were also presented in this chapter, for example, the key considerations and stages of co-creation. Also, sector examples such as in healthcare and industry were included to give the reader some background into how co-creation has been explored in other industries. These literature reviews showcase to the reader the applicability of cocreation in the context of higher education, as well as note the difference between cocreation and other similar concepts such as student engagement and student voice. 


\section{Chapter 4. Conceptual Framework for Co-Creation in Higher Education}

This chapter was designed to showcase the lens in which co-creation in this study was defined and explored. It was argued in this chapter that co-creation consists of two constructs, co-production and value-in-use, and that these constructs allow for value creation both during the value chain and afterwards. Please note, this conceptual model has been peer-reviewed and published since its formation (Dollinger, Lodge \& Coates, 2018). However, the model discussed in this chapter is not empirically informed (as the study was not yet conducted) and the empirical model is presented in Chapter 9.

\section{Chapter 5. Research Design}

As the dissertation intended to explore the nature of co-creation in higher education, this chapter discussed the methodological decisions and justifications for adopting a qualitative case study-based approach. Co-creation, a relatively new phenomenon in higher education, it is argued is best investigated through multiple case studies as they draw the greatest possible variation of how the concept can and may occur in the sector. In this chapter, the data analysis approach was also presented and justified, as the aim of the study was to take an existing concept (co-creation) and analyse it under the new context of higher education.

\section{Chapter 6. Overview of Cases}

In some dissertations, the overview of cases or sample population descriptions are included in an appendix, however, the cases were part of the story to understand the nature of co-creation in this study, and as such, they were included and described in the body of the dissertation. This was decided because before empirical results can be interpreted by a reader, the context and background to each of the cases needs to be understood. Also, one of the contributions of this study was to give examples into how co-creation occurred in the higher education context. This was achieved by showcasing cases that included: a student-staff co-created magazine, student-staff co-created social media, student-staff cocreated curriculum. 


\section{Chapter 7. Empirical Results}

Within this chapter, empirical results of the study were presented according to theme and aggregate dimension, which later informed the empirical model of co-creation. Integrating key quotes and relevant data, this chapter showcased how the themes and dimensions were formed.

\section{Chapter 8. Discussion of Findings}

Within this chapter, the major findings of the study were distilled and summarised for the reader. Further, with each of the six major findings, relating literature was presented alongside to help demonstrate the unique contributions of this study.

\section{Chapter 9. Conclusion of Study}

In this final chapter, the empirical model of co-creation was presented and discussed. Critically, this study also transformed the findings of the study into new insights for higher education as well as future directions of research as it relates to co-creation. From these insights and questions, the contributions of the study, such as the model, the conceptualisation, and the barriers of co-creation, will be clear to the reader and serve as a foundation for future research. 


\section{Chapter 2. Current Context of Australian Higher Education}

\section{Introduction}

Higher education is a critical economic asset in the Australian context, with over $\$ 25$ billion as a direct benefit to the economy and an estimated $\$ 160$ billion impact from the knowledge, research and technology developed through university stakeholders (Deloitte Access Economics, 2015). However, while the economic benefits of the university sector are important nationally, in the sector itself there is a growing competition over revenue streams (Raciti, 2010). The vying for funds has in many ways transformed the higher education landscape, with simultaneous expansion and competition and a move to market orientation. Market orientation, and the new focus on students as independent actors of choice, akin to consumers or clients, is a hotly debated topic (e.g. see overview in Woodall, Hiller \& Resnick, 2014). Discussion arising from market orientation include questions of the value of higher education, the employability of graduates, the purpose of university degrees, and the quality of the system. From this discussion, many scholars have emerged wary of market orientation occurring in the context, with concerns that students will be treated as customers (Brunce, Baird, Jones, 2017; Molesworth, Scullion \& Nixon, 2010) or the universities may become vocational-focused factories that could lose their intellectual traditions (Coffield \& Williamson, 2011).

These concerns are valid. And yet, as the University of Melbourne's Vice-Chancellor Glyn Davis wrote in an essay titled 'Dissolving the University' Australian higher education institutions do not want to take the same path as the monasteries in English during the reign of Henry VIII (Davis, 2016). At this time, monasteries, like universities now, were criticised by outsiders as out of touch with modern concerns and the needs of people. And their inability to orientate themselves to their present market led them to upheaval and transformational reforms. Therefore, while concerns over market orientation are reasonable, similarly reasonable is the need for universities to connect more closely with society and the needs of its students. As this chapter discusses, the major changes in higher education, funding cuts, growing competition, are unlikely to disappear. Market orientation or repositioning an organisation or institution to more closely align to the needs of its users may help support higher education through the tumultuous times ahead. Further, as market orientation expands, so will the need to integrate student preferences and ideas, as 
research increasingly focuses on the student experience through the perspective of students (e.g. Jungblut \& Vukasovic, 2015; Mittelmeier, Rienties, Tempelaar \& Whitelock, 2018; Mulder, Pearce \& Baik, 2014). Thus, this chapter aimed to make that the case the traditional higher education model cannot continue in the current climate. As factors, such as funding and growth, place new challenges on the higher education market, universities' relationships towards students, and subsequently how they view student roles and responsibilities, will likely need to evolve to match the current context.

\section{$\underline{\text { Factors Changing the Higher Education Context }}$}

Both in Australia and globally, higher education has been going through a period of significant change for quite some time. These changes include reforms in funding, with less government funding overall, expansion of the sector with new universities, increased competition amongst institutions for students and quality researchers, and the emergence of new quality assurance mechanisms and benchmarking platforms (Hazelkorn, 2015; Norton, Norton \& Cakitaki, 2016; Pucciarelli \& Kaplan, 2016). These changes are interconnected, as one can trace the changes principally to the funding reforms beginning in many Western countries, such as Australia, in the 1980s. Yet while the changes within higher education have been put forth in motion for a couple decades, they are still manifesting in novel ways today. Manifestations of the changes in higher education include emerging private sector higher education institutions, the casualisation of workers, and the increased focus on evaluative teaching measures, to name a few.

Most notably, and relevant to this research, the changes within the sector continue to shift universities to become increasingly market orientated and consider the needs of the student in innovative ways. Market orientation, moreover, has not only been confined to an internal shift that universities have adopted, but also manifested through the rise of student choice, with students more aware of their status as prospective consumers of higher education (Tomlinson, 2017). From these forces, higher education has also undergone a reflection of its identity and gradually began to question the role of universities in the coming future. For example, as student enrolment capacity limits in Australia are still under debate and likely to change, as well as course pricing structures, universities are going to need to be ready for a dynamic and quickly changing market context. These challenges, 
such as funding, however may mitigated through a strong and loyal student population, reiterating the importance of student choice and market orientation.

\section{Funding}

Starting in the late 1980's the Australian government began to adopt principles of New Public Management (NPM) (Guthrie \& Neumann, 2007). As consistent with NPM policies, the Australian government adopted many management practices common in the private sector, including decentralising management of public services, increasing competition within markets and introducing new performance measures and benchmarking (Larbi, 1999). Notably, the adoption of NPM has also decreased the amount of the funding that Australian institutions receive. Government funding per student as a proportion of GDP has been trending downwards since the 1970s in Australia (Jongbloed \& Vossensteyn, 2001). More cuts occurred in 1996 under John Howard and again in 2012 under the Labor government. The repercussions of which pushed Australian higher education to operate in a market-based model, much like a private firm does. The assumption being that by placing higher education in a market-based model they will make rational decisions based on the current market and this will provide better outcomes than if universities were regulated by government (Baldwin \& James, 2000; Hemsley-Brown, 2011). This assumption is, in fact, common in the Anglo-American university system (Altbach, Reisberg \& Rumbley, 2009; Liefner, 2003). Relying on private funds, especially student tuition, assumes that it is in the universities' best interest to offer high-quality educational experiences (Liefner, 2003), thus leading to focus on the student perspective and satisfaction. However, even though government funding has decreased, universities in Australia are not fully autonomous of government policies (Guthrie \& Neumann, 2007). This stands in contrast to universities in the USA who receive comparatively more money from private donors and/or alumni, to supplement student tuition, that allows them to be less reliant on government funds, and thus, more autonomous (Huisman \& Currie, 2004). Yet Australian higher education is still uniquely tied to government and also expected to search for new forms of revenue.

In the near future, the funding situation in Australia is unlikely to return to the old system, instead more funding cuts are likely to occur as Australian economy is not growing as quickly as it once was. Harold Hovey in 1999 noted that higher education gets targeted in 
times of bad economy for two reasons, first because they have tuition mechanisms in place, making government funds not their sole reliance, and secondly, college students are not the neediest group of the population (Doyle \& Delaney, 2009). Unsurprisingly, therefore, more reforms and funding cuts are currently discussed now in Australia, with the Turnbull government suggested over a billion in additional cuts (Deloitte Access Economics, 2015). These reforms are underpinned by the belief that the higher education system is no longer appropriate for the modern environment. John Dawkins, a former politician in Australia and once-architect of the Dawkins Reforms writes that the current system, implemented in 1987, is completely out of date, and was never meant to last 30 years (Krause, 2017). Likely, changes in the sector are yet to be fully realised.

One of the largest consequences of the funding reforms within Australia and the adoption of NPM is through the increased focus on individual-needs rather than public needs (English, Guthrie \& Parker, 2005). This shift has profoundly impacted the higher education sector, with universities thinking of each student as an entity, and has, therefore, given support for the introduction of student fees. This had led many in the sector to refer to the growing neoliberalism in higher education, which pushes the sector to reflect on their performance mechanisms such as efficiency and productivity (Levin, 2005). Neoliberalism in higher education is also often frequently discussed alongside discussion of student fees. Once a fee-free system, all Australian students (with the exception of those on scholarships) are charged fees (White, 2007). A student supported by the commonwealth is either funded by the Commonwealth Grant Scheme or pays a student contribution directly to the university, based on the field of study and unit of study (Carrington, O’Donnell, Prasada Rao, 2018; Norton, Norton \& Cakitaki, 2016). Beginning in 2005, universities were allowed to set the student contribution, albeit with a government legislated maximum amount, which quickly became the standard for all institutions (Norton, Norton \& Cakitaki, 2016). However, universities can also bring in student fee revenue through full-fee paying students (often international and postgraduate students), a structure that is less regulated with no legislated maximum on the fees universities can charge. Averages of fees range from $\$ 24,000$ to $\$ 31,000$ a year depending on the discipline (Norton, Norton \& Cakitaki, 2016). It is possible the Australian higher education will also soon introduce deregulation of fees for domestic students, allowing universities to charge what amount they deem reasonable to students. However, as funding for government 
supported places will decrease, and perhaps also extend to private institutions, students will also have more choice on where to attend (Carrington, O'Donnell, Prasada Rao, 2018).

These changes have had a significant impact on Australian higher education recruitment of full-fee paying students and ultimately changed the behaviour of universities. Liefner (2003) writes:

"Changes in funding methods, that is shifts in income sources, or in the forms of resource allocation will likely have a major impact on the behaviour of universities as well as their international process of resource allocation... but changes in resource allocation also affects individual faculty, who are directly responsible for carrying out teaching and research duties." (p.470).

Liefner (2003) goes on to conclude that most essential in the changing funding environment is for universities to attract qualified and motivated faculty. However, it is not only through student fees and encouraging more 'motivated' faculty that higher education has changed due to the reforms in funding. Globally, funding cuts to universities has meant that higher education has at its core shifted from a government dependency and public good mindset to a more private entrepreneurial mindset (e.g. Gibb \& Hannon, 2006). As universities grow increasingly reliant on student fees, universities are more concerned with increasing the student population, and thus, collecting more revenue. Therefore, as the reforms have deregulated the sector, they have also supported unprecedented growth.

\section{Growth}

In 1975 there were just 19 universities in Australia (Favaloro, 2015). Now Australia is currently home to 43 universities and an additional 170 higher education providers. As the government funding for these universities have been greatly reduced, the Australian higher education sector, as seen globally as well, have encouraged universities to think of new revenue streams and the increasingly globalised world that allows for a higher influx of students (Hemsley-Brown, 2011). This has meant universities are focused on enrolment growth to supplement the lack of government funding. In terms of student numbers, enrolments have grown considerably, with full-time enrolments approximately half a 
million at the turn of the century to over 1 million since 2014 (Carrington, O'Donnell, Prasada Rao, 2018; Norton, Norton \& Cakitaki, 2016). Estimates predict as many as 40\% of all young people in Australia will participate in some type of higher education by 2020 (Forsyth, 2014). Yet growth in recent years has level off and instead remained stable or even shifted with small declines as the Australian government re-introduced student caps (Norton, Norton \& Cakitaki, 2016).

Overall, the trend of university and student growth in Australia is not particularly unique. Globally, there are more students enrolled in tertiary education than ever before, with significant increases in countries with an upper middle or upper income average (Altbach, Reisberg \& Rumbley, 2009). This upwards trend towards higher education participation has been occurring since post World War II, as many countries have shifted to knowledgebased economies that require more highly skilled workers. However, growth has also occurred in less developed countries, especially those that value educational status and outcomes such as in Asia (Altbach \& Knight, 2007). In Australia, the growth in student number is most directly linked to the 2012 removal of student caps on student enrolments (with the exception of medical places) and Australia adapting to a demand-driven system (Carrington, O’Donnell, Prasada Rao, 2018; Norton, Norton \& Cakitaki, 2016). This change cannot be understated for Australia universities. Going from a system where student caps were in place, to a demand-driven system has had profound impacts on enrolment and recruitment. In short, the shift from a tightly regulated system by the state towards more privatisation has allowed universities the freedom to adhere to market demands (Hemsley-Brown \& Oplatka, 2006; Jongbloed, 2003). For example, more students since the shift are likely to receive an offer to enrol from their first-choice university, from 77\% in 2009 to 85\% in 2015 (Norton, Norton \& Cakitaki, 2016). This statistic is not unexpected, as universities are enrolling more students, more students will be accepted into their first choice, and therefore, where students choose to go is more important than ever before.

It is not only domestic students that universities are attracting in record numbers. International students are also a major avenue of growth for Australian higher education. Beginning in the late 1980s universities were permitted to accept international students at fees they set for themselves, and huge growth quickly followed (Marginson, 2015). Growth has expanded international student full-time enrolments from 100,000 around the turn of 
the century to approximately 350,000 in 2013 (Norton, Norton \& Cakitaki, 2016). These students fill a critical need in funding and also allow for the universities to market their expansion on a global level (White, 2007). Countries sending the largest numbers of students include China, Singapore, Malaysia, and India and Vietnam, showing a strong Asian centered growth pattern (Ortiz, Chang \& Fang 2015). However, attracting full-fee paying students costs money as well, for example, with marketing and administration costs and services (Marginson, 2003, 2015) All of which, further emphasises student choice and student preferences. This means at the same time higher education is growing, the competition (and subsequent student choice) is growing, too.

\section{Competition}

It was not only the Australian government that adopted NPM. Universities have also begun to re-think and re-design policies and practices to support strategic management and deregulation (Marginson, 2013; Parker \& Guthrie, 2005). This has been witnessed through introduction of many business practices within higher education including budgeting, resource allocation decisions, changing incentives, and a focus on performance indicators (Guthrie \& Neumann, 2007). Additionally, universities' responsibilities have changed, from simply providing education, to profit-making through commercialisation, and strategic management and marketing practices (Bok, 2009; Brandenburg \& De Wit, 2015). Universities as a consequence have begun to invest resources into the sale of their “...courses, programs, degrees, certificates, and ideas” (White, 2007, p.594). This does not mean that higher education services are akin to those in industry, however, it may allude to a general re-positioning of higher education's activities to align with student preferences and desires, with an emerging amount of scholarly research exploring students' needs and satisfaction levels (e.g. Allen, Bourhis, Burrnell \& Mabry, 2002; Bonnema, Van der Waldt, 2008).

Marketisation and subsequent competition of higher education have been developing alongside government funding decreases since the 1970s (Hemsley-Brown, 2011). Marginson (1997) defined marketisation as the "introduction or extension of some or all the forms of competitive economic markets" (p.6). The higher education sector as such can be conceptualised as a 'quasi-economic market' where not all aspects operate on market-based model (Marginson, 1997). As universities in Australia are still partially 
publically funded and this have societal expectations, despite operating in a market-based model (Baldwin \& James, 2000). Young (2002) defines marketisation of higher education as a "compromise between privatisation, academic autonomy and state control" (p.79).

The compromise that Young refers to often places pressure in universities to stay traditional in their image, yet concurrently adopt more competitive and business focused marketing and/or management practices (Carey, 2013; Hemsley-Brown \& Oplatka, 2006; Ribes-Giner \& Peralt, 2014; Ramachandran, 2010). Marketing practices can enhance institutions' appeal and brand profile (Ramachandran, 2010), help institutions differentiate themselves in an increasingly crowded market (Pucciarelli \& Kaplan, 2016) and encourage student engagement through student-centric activities and programs (Carey, 2013; Edwards, Rowe, Barnes, Anderson \& Johnson-Cash, 2015). Thus, by adopting marketing practices institutions can create demand and also improve and innovate their specific institutional-offered products and services. Marginson and Considine (2000) write that as funding cuts and expansion have created a demand-driven system where universities now operate as enterprises and their educational offerings are now distributed as products.

Yet while in the private sector marketing practices of products are ubiquitous, in the higher education sector, adoption of such practices has been slower (Cuthbert, 2010). However, as the higher education market continues to expand, and competition as noted by numerous scholars continues to grow (Altbach, 2015; Pucciarelli \& Kaplan, 2016), it may become necessary for institutions to transform to a new market orientated context (Bowden \& D’Alessandro, 2011; Helgesen, 2008; Thomas \& Cunningham, 2009). Further, as competition grows other impacted areas will likely be institutional image and reputation, branding, service differentiation, market segmentation, market positioning, and so forth (Hazelkorn, 2015; Hemsley-Brown \& Oplatka, 2006; Marginson, 2013). Yet central to competition and attracting students, is also the discussion of the quality of the institution itself.

\section{Quality Assurance}

Changes in the market-based model of higher education have called into question the quality assurance of the sector. Pervasive throughout government and the general public in Australia is that the university sector is not sufficiently regulated or accountable which 
erodes trust in the current system (Baldwin \& James, 2000; Vidovich \& Currie, 2011). In a 2014 poll it was found that higher education in Australia is less trusted than the defence forces and the police (McCamish, 2016). As higher education has been forced to grow and become more market-orientated due to less government funding, it appears the general public has not been able to reconcile the changes in the role of higher education itself. This mismatch causes a chasm between those within universities and students and the general public that ultimately, if left as is, will cause students to question the value of a university degree. Already within the for-profit sector of higher education the lack of quality has led to the closure of many underperforming schools (Shah \& Nair, 2013).

In Australia, higher education institutions are registered and regulated by the Tertiary Education Quality and Standards Agency (TEQSA). Through TEQSA, higher education institutions' qualifications are evaluated against the Australian Qualifications Framework (AQF). Yet there are concerns that there is not enough information on the quality of higher education (Coates, 2005; Hemsley-Brown, 2011; Kift, Nelson \& Clarke, 2010). As quality assurance is a complex area, that can be both multi-dimensional and multi-level, and heavily mediated by the context including the system, the institution, the program and the discipline (Vlascean \& Barrows, 2004) designing and translating benchmarks can be difficult. Further, quality assurance mechanisms need to find a way to be accessible to stakeholders, including students who are increasingly concerned about their services and experiences they expect to receive (Johnson \& Hirt, 2011). In a study by White (2007) it was found that undergraduate students were critical of the way universities were being run and suspected that the attention placed on generating revenue was coming at the cost of their own quality experiences. Students were quoted as noting that since they were paying a lot of money to attend university they should have more say in what they are expected to do and how they are taught (White, 2007).

Examples of changes to quality assurance in Australia include the creation of The Higher Education Standards Panel (HESP) an advisory committee set up under the Tertiary Education Quality and Standards Agency Act in 2011 (TEQSA, 2011). Established partly for the aim of increasing the transparency of the higher education experience and outcomes for students, the panel's existence reiterates to institutions in Australia their responsibility to meet the needs and expectations of students (Whitelaw \& Wranthall, 2015). However, current quality assurance mechanisms and benchmarking practices still 
struggle to capture student engagement and satisfaction (Coates, 2005; Kift, 2004; Norton, Norton \& Cakitaki, 2016). Kwong (2000) writes that universities will likely never be able to perfectly capture their value to students in the quantitative terms that often utilised through quality assurance. And yet quality assurance is still a growing and increasingly important area for universities (Knight, 2015). Not just nationally, but globally, there are new discussions on how quality assurance can capture graduate employability and the complex competencies they develop in higher education, and further measure those gains across borders (Knight, 2015; Altbach, Reisberg \& Rumbley, 2009).

Universities in Australia compete and compare themselves not only nationally but increasingly globally as well (Hazelkorn, 2015). Thus, the major changes in higher education, decreases in government funding, the growth and expansion of the sector, the increased competition and the introduction of quality assurance has ultimately pushed universities to embrace their market-based model and shift to market orientation in new ways.

Many of the changes occurring in Australia have also been seen in other countries, including increased competition, quality assurance, and funding. Useful examples include Reem, Hillyard, Reed and Reed's (2007) discussion of managerialism in the UK higher education system and Mok's (2003) research on quality assurance and globalisation in China. Several scholars have noted that the expansion of higher education globally has led many systems to become similar in their challenges and contexts (Marginson, 2006; Schofer \& Meyer, 2005). In fact, the growing similarities across markets is not entirely novel, as the American, European, and Australian systems have shared commonalities for some time (De Wit, 2002; Luijten-Lub, Van der Wende \& Huisman, 2005).

Due to these shared similarities, it may be pertinent to adopt a global perspective in regard to emerging research (Hemsley-Brown \& Oplataka, 2006; Marginson \& Rhoades). To illustrate this, recent literature on student partnership in higher education has already traversed several regions including the USA (e.g. Felten \& Clayton, 2011), Canada (e.g. Marquis et al., 2016), UK (e.g. Healey, Flint \& Harrington, 2016) Australia (e.g. Matthews, 2016), and Macau (Hao, 2018). Within these contexts, several universities have also enacted student partnership practice to further support research and theory development. For example, at McMaster University they have a student partnership program (McMaster 
University, 2018), while University of Western Sydney has a students as curriculum partners program (University of Western Sydney, 2018). This highlights that trends and changes occurring in higher education are now capable of having international repercussions and complexities.

\section{$\underline{\text { Shift to Market Orientation }}$}

Market orientation is the ability to meet the needs and wants of specific target population(s) and deliver more efficiently and effectively than competitors (Kotler \& Armstrong, 2010). However, when discussing market orientation in the higher education context, direct applications from private firms do not perfectly translate. As previously noted, higher education does not operate in a true market place. First conceived through economic theory the market has been defined as "a means of social coordination whereby the supply and demand for a good or service are balanced through the price mechanism" (Hemsley-Brown, 2011, p.11). Therefore, the discussion of the "marketisation" or market orientation of higher education is already an altered version of a true marketplace context, as universities' in nearly all countries lack the autonomy to dictate their price mechanism without government influence (Nedbalova, Greenacre, Schulz, 2014). In fact, for all the debate of the marketisation of higher education (e.g. Altbach, 2015; Hemsley-Brown \& Oplatka, 2006; Judson \& Taylor, 2014; Pucciarelli \& Kaplan, 2016), scholars rarely note that the discussion should first be clarified by two important facts. Firstly, higher education is still considered to be a public good (Altbach, 2015) and one that should inherently benefit society thus cannot and will not hold the same principles of unregulated goods and services. Secondly, marketisation of higher education is far from a new or novel concept with remarks of the competition between universities dating back to medieval times (Byrd, 2001).

Kotler and Armstrong (2010) noted there are five concepts within marketing activity: production, the product, the selling, the marketing, and the societal marketing concept. Nicolescu (2009) highlights that within the higher education sector the last two are of relevancy. The marketing concept holds that instrumental to organisations is the ability to meet the needs and wants of specific target populations and deliver more efficiently and effectively than their competitors (Kotler, 1991). In essence, organisations should design their services or products to satisfy the needs of customers (Levy \& Luedicke, 2012). This 
includes adopting approaches in their marketing strategy such as: eliciting consumer behaviour, market segmentation, strategic positioning, and marketing a mix of activities such as product policies, pricing policies, distribution and promotion policies (Nicolescu, 2009). Given the growing competition in the higher education sector it is unsurprisingly that many of these approaches have already been seen throughout the sector (e.g. Allen, Bourhis, Burrell \& Marby, 2002; Hemsley-Brown \& Oplatka, 2006; Temple \& Shattock, 2007).

To detail, one example of a marketing practice growing in higher education is positioning or the organisation's strategy for diversifying itself within the marketplace (Kotler, 2011). Mohrman, Wa and Baker (2008) write that global institutions are beginning to meld into a specific type of university, the Emerging Global Model (EGM). The model has eight characteristics which the institutions strive to achieve: global mission, research intensity, new roles for professors, diversified funding, worldwide recruitment, increasing complexity, new relationships with government and industry, and global collaboration with similar institutions (Mohrman, Wa \& Baker, 2008). These goals encompass not only characteristics that help provide funding for the institution, but also relate to current ranking systems that can improve institutional marketing and branding. But as institutions continue to compete for each other through similar models such as EGM, the ability of institution to distinctly brand itself apart from other institutions will become increasingly important. In essence, by universities catering to general student preferences, they all become similar. By uniquely branding itself a university can operate more competitively in the marketplace and create a university image (Joseph, Mullen \& Spake, 2012; Lowry \& Ownes, 2001; Pinar, Trapp, Girard \& Boyt, 2011). However, in order to achieve this, a university must deeply understand the needs of its specific student cohort and audience, and simply not compare itself to other universities.

Yet branding in higher education is a contentious issue. Students are often also swayed by 'image' (Baldwin \& James, 2000; Jospeh, Mullen \& Spake, 2012). As Brown and Mazzarol (2009) found institutional image is a clear antecedent to value perception, and thus, also satisfaction and loyalty. Yet students making decisions based solely on image for their education is likely not always in their best interest. Part of the push to help students make informed choices is through objective performance indicators found in quality assurance initiatives (Baldwin \& James, 2000; Knight, 2015). Examples of performance indicators 
including evaluations of teaching quality, as measured through the Course Experience Questionnaire (CEQ) (Wilson, Lizzio \& Ramsden, 1997). However, examples of performance indicators are still met with scrutiny by many within higher education who are concerned with their validity and that the measures will force universities to conform to a single perspective of 'quality' (Baldwin \& James, 2000).

Additionally, scholars argue whether institutional branding is related to institutional reputation (i.e. relating to quality in some way), or whether the two are entirely distinct (Bennett \& Ali-Choudhury, 2009; Schofield, Cotton, Gretsy, Kneale \& Winter, 2013, Temple, 2011). For example, scholars such as Temple (2011) argue that institutional branding is superficial and short-term and ultimately has no impact on the reputation of institution over a long period of time. Reputation improvement can only be increased through quality publications, quality teaching, and quality graduates (Temple, 2011). However, while Temple (2011) may be correct that branding and reputation are two separate factors, the two concepts have a complex relationship (Shenkar \& YuchtmanYaar, 1997). To illustrate, when branding strategy aims to increase prestige, institutions often raise the admissions standards, thus raising the quality of the student body (Pucciarelli \& Kaplan, 2016). Therefore, the actual reputation and perceived prestige are both improved within just one action. The two factors also often correlate to the same outcomes. For example, studies show that students that held positive images of their institution through prestige (i.e. branding) and reputation were more likely to hold supportive attitudes towards their institution (Sung \& Yang, 2008). One was not more significantly influential than the other in determining student support.

Thus, while marketing practices and branding theories (e.g. the Four P's, product, place, price and promotion) (McCarthy, 1960) might begin as short-term strategies implemented under NPM they can have long-term consequences, as branding often strives to reimagine the relationship between the institution and the student through relational marketing (Bowden, 2011; Helgesen, 2008). By adopting principles of relational marketing institutions are refocusing on their relationship with students and in essence participating in trust building (Bowden, 2011). Trust built through student relationships to faculty and staff is a strong predictor of loyalty (Carvalho \& Mota, 2010). Loyalty further impacts alumni behaviours, and eventually, prestige and reputation (Carvalho \& Mota, 2010). However, universities should still be mindful of how they adopt market practices and orientation strategies. Strong relationships are built on long-term fulfilment of 
expectations and goals (Wong \& Sohal, 2002). Judson and Taylor (2011) call on institutions to focus not on perceived value of branding, and instead focus on relationship building strategies. Therefore, before a university can engage in positioning they may choose to first better understand how students judge and compare institutions and also what they want from the university experience. This requires further implementation of marketorientated practices that seek to better understand students' wants, needs and their goals in higher education. In summary, a universities ability' to attract students through a strong brand and reputation requires universities to reflect on the type of student experience they offer students and align the experience to the desires of its targeted student body.

\section{The Rise of Student Choice}

Altbach (2015) writes that the competition and adoption of marketing practices in higher education has transitioned the sector from a sellers' market to a buyer's market. This has been seen already within the higher education sector through the adoption of more active participatory roles, as students are being framed not only as the consumers of higher education, but also as members of the university, sources of production, and even partial employees (Bowden \& D’Alessandro, 2011; Cuthbert, 2010; Woodall, Hiller \& Resnick, 2012). Marketing practices, from brochures, websites and open-days further speak to Altbach's shift from the sellers' market to a buyer's market for students.

Yet students having more say and power in their roles is not without its debate. Frank Furedi (2009) in an analysis of the marketisation of higher education thoroughly argued against the transition of student to consumer. He forewarned that students as consumers would create an environment when the customer is always right, ergo, the student must always be right. That teachers would succumb to flattery or worse in an effort to gain favourable student satisfaction or student experience marks. He went so far as to paint a picture that institutions 'worship' students and are 'obsessed' with pleasing them (Furedi, 2009, p.4). He isn't alone in his fear. Many academics, in fact, are pessimistic that students as consumers could result in any long-term benefits for the institution much less the sector (McCulloch, 2009; Molesworth, Nixon, Schullion, 2009). While other scholars take a more objective stance and argue that students cannot be classified as consumers because their failure in the higher education service (i.e. retention) is not necessarily the fault of the provider (Schofield, Cotton, Gresty, Kneale, Winter, 2013). In a study conducted by 
Bunce, Baird and Jones (2017) it was found that students who paid fees were more likely to identify with consumer orientation, as well as students who had lower levels of learner identities. The authors highlighted that the student as consumers debate, therefore, also needs to consider how students see themselves and perhaps acknowledge that the context as well as the individuality of the student may play an important role in fostering consumer attitudes and behaviours (Bunce, Baird \& Jones, 2017).

It is important to recognise the significance of the students as consumer dialogue within higher education. Students pay increasing large fees to attend university, forgo possible income, and put forth their own time and energy into completing the degree (Altbach, 2015; Bowen, 2018). It is further credible to see that with rising fees and increased marketisation of higher education, that many within higher education are likely to perceive students as consumers more so than ever before (Tilak, 2015). However, while students may take on consumer-type roles, and universities may perceive students as consumers, there are still a few key points of differentiation which make the role of student distinct from that of consumer. As McCulloch (2009) found in his review of literature, students as consumers as metaphor would assume that students themselves are products. It could further encourage an entertainment model of learning which could hinder the quality of education (McMillian \& Cheney, 1996; Single-Jackson, Jackson \& Reinhardt, 2010). McCulloch (2009) concluded that, while the metaphor has some select alignment to the higher education context, it is an inappropriate metaphor overall for the sector.

Yet given the changes to the higher education sector and the now market-based model in which universities sit, student choice will continue to be a critical area for universities to explore. Universities are not alone, either, in their effort to understand their users. In governance, numerous scholars have also noted a general trend towards active community participation and collectivist principles (Bice \& Sullivan, 2014; Cova, Dalli \& Zwick, 2011; Newman, Barnes, Sullivan, Knops, 2004). By reframing students as those empowered by choice and potential innovators who can influence and even co-create their experiences, higher education is undergoing a foundational change not only by entering the marketplace (as they have for a long time) but by seeking to understand the value of student centric perspectives. Value is no longer created for the student, but instead created with the student (Dollinger \& Lodge, 2018; Vargo \& Lusch, 2004). Service-dominant logic as put forth by Vargo and Lusch (2004) argues that in modern service industries, including higher 
education, there is an increased importance on relationships and mutual value creation. Moreover, value is created in real time, with both the production and consumption of the higher education experience occurring simultaneously (Bowden \& D'Alessandro, 2011). Therefore, as the service of the higher education experience evolves to include more participants, those participants will increasingly reshape it. This allows for increased opportunities to engage students through novel and innovative ways.

Outside of higher education, the trend in user choice and preferences can already be seen through market practices which often encourage users to have more active participation and choice in their services. To attract potential consumers, firms and organisations have long adopted customer-centric strategies that are designed to attract consumers and also meet the needs and wants of the consumer populations they serve (Frow, Nenonen, Payne \& Storbacka, 2015; Neuhofer, Buhalis \& Ladkin, 2013; Ramaswamy \& Ozcan, 2014). These strategies include practices and policies that facilitate consumers to have more active participatory roles, which allow for organisations to better understand their consumers, and subsequently better serve them (Fagerstrøm \& Ghinea, 2013; Prahalad \& Ramaswamy, 2004; Ramaswamy \& Ozcan, 2014). Von Hippel (2005) notes that this shift towards active participation of consumers to allow for more customer-centric strategies is the 'democratisation' of innovation. In other words, where once innovation was confined to include only the firm or organisations' perspectives, now consumers themselves can contribute to innovation. It has been written that the shift in democratisation of innovation is also driven by the younger generations of consumers. Younger generations may no longer be satisfied with simple consumption in any sector, with scholars noting the younger generations desire to design, influence and produce their products and services growing (Ramaswamy \& Ozcan, 2014; Ritzer \& Jurgenson, 2010). As the higher education student population in many places is still young, how the new generational expectations will impact the market will be of continued interest (Jones, Ramanau, Cross \& Healing, 2010).

\section{Redefining the Role of Universities for the Future}

When leaders of higher education speak of the purpose of universities it is often in lofty measures. For example, Sir David Derham, who served as Vice-Chancellor of University of Melbourne from 1968 to 1982 noted that the objective of higher education was the pursuit and dissemination of knowledge, "not to the local community, not to the state, nor 
to the nation, but to the world" (Poynter \& Rasmussen, 1996, p.8). However, higher education also greatly impacts the lives of the students and the local community. Australia first initiated universities for the educated and privileged children of Sydney and Melbourne, but it later became a great societal equaliser, especially after World War I (Forsyth, 2014). As different populations have utilised higher education, the purpose of higher education has morphed. What began as small elite institutions geared for the select individuals of society has turned into a mass system that serves as a gatekeeper not only for professional jobs such as doctors and lawyers, but increasingly for most middle-class employment (Forsyth, 2014). In 2013, Universities Australia Policy statement explicitly wrote that universities' contribution was a more vibrant economy with more opportunities for better jobs, and thus more products and industries. Therefore, while a goal of universities might be the pursuit and dissemination of knowledge on a global scale, on a national scale, and on a community level scale, its purpose can be far humbler.

Some scholars argue that higher education is still a public good its underlying aim should be benefiting the society in which it is located (Nedbalová et al., 2014; Pucciarelli \& Kaplan, 2016). However, higher education also shares characteristics with private goods. The most obvious transition from a public good to a private good is the introduction of fees, as discussed in this chapter. Higher education fees are now common, and increasingly free of government regulation. Further, international higher education has been monetised to the point where it is now included within 12 services in the General Agreement on Trade in Services (GATS) through the World Trade Organisation (WTO) (Caruso \& de Wit, 2015).

However, international education pursuits and the introduction of fees into higher education is not necessarily a sign that higher education has become closer to a traditional economic marketplace. Higher education is unique to other forms of education as research shows that university graduates earn more than those without higher education degrees (Norton, 2013). Therefore, by introducing fees to the same citizens that will eventually earn more money, the government has an opportunity to further distribute wealth. Actually, the money collected from student tuition can help create scholarships and funds for students who cannot afford the tuition and further the distribute wealth. In this respect, a private good for some becomes a public good to others. 
Moreover, higher education adopting some private good characteristics does not mean it must abandon all of its public good benefits. By adopting private good characteristics higher education may also see societal benefits. For example, Tilak (2008) argues that public goods can no longer keep up with increasing privatised and liberalised market context. In effect, they cannot change and innovate as quickly as the market demands. Through marketisation though higher education can progress more efficiently. This is important for many nations, including Australia, where higher education has been repositioned from a public good only for the domestic population to a critical export and major part of foreign policy (Knight, 1999, 2015). For example, Australian international education as an export is worth $\$ 15$ billion annually and graduates are assumed to contribute to sustained economic growth across industries (Ritzen, 2016).

It is not what the 'what' of higher education that is changing, it is the 'bow'. Students influencing higher education either through the choice the institutions they choose to attend or through their choices once they are enrolled at the university not only impacts their own personal experiences but also impacts the university and the entire sector (Bowden, 2011; Neary, 2012). To explain how student perspectives can change and improve quality of higher education further, Von Hippel (2005) has noted that producers and consumers have different perspectives, resources, and information, and tend to innovate in different ways. The tension that lies between producer and consumer perspectives is further complicated because different groups, such as institutions and students, often have knowledge that is not easily transferable to non-group members. Von Hippel (1994) writes that this is known as 'sticky' information, which can be rooted deep within the perspective of the student or institution in the form of a personal bias or a shared experience and may be costly or difficult to transfer to another group. Therefore, as competition grows within higher education, students' participating in novel and active ways may further help universities understand students' perceptions and needs which can help the university implement new ideas or policies that will improve student satisfaction and loyalty (Bowden, 2011; Elsaharnouby, 2015; Ribes-Giner \& Peralt, 2014), which in turn, may guard against the current challenges in the sector.

Student participatory and producing roles are also being driven by students' increased desire to express their identities, creativity, and impact the higher education experience to better align with their own goals (Gambetti \& Graffigna, 2010). Ng and Forbes (2009) 
note that students increasingly expect their voices to be noticed by faculty and administrators. Through active partnership and collaboration with students and faculty, faculty have been shown to display a 'deep shift in perspective' that can better serve students (Cranton, 2011, p 76) although current standard academic practices rarely integrate student voices into development of pedagogy (Bovill, Cook-Sather \& Felten, 2011). In the market-based model of higher education, students will also increasingly expect their higher education experiences to reflect an environment where that can have a high degree of participation (Bowden, 2011; Pucciarelli \& Kaplan, 2016). As information and assessment of higher education has increased, so has students' ability to act as rational actors within their student experience (Baldwin \& James, 2000; Bowden, 2011). Thus, the major changes shaping higher education today, such as funding cuts, expansion, competition, quality assurance and the subsequent market orientation has placed more emphasis on understanding what the student needs and expects. Students and universities alike have become concerned with what literature refers to as 'the student experience.'

\section{The Student Experience}

The challenges facing higher education, funding, growth, and competition have led to a growing focus on the student experience. The massification of the Australian system has redirected attention to three imperatives, retention, academic quality, and the student experience (Altbach, Reisburg, Rumbley, 2009; Marginson, 2015; Van Damme, 2001). However, the student experience is hard to define and therefore hard to capture or analyse. Neary and Winn (2009) write that the two core functions of a university are teaching and research, however, students' experiences often extend much wide than these two functions. Krause (2007) further highlights that the student experience is not only what is achieved inside the classroom, but also outside the classroom. Other scholars also add to the discussion by noting that the student experience often relates to the all the relationships and interactions student have experienced through their university (Klem \& Connell, 2004). As such, defining the student experience is complicated. For example, when does the student experience begin? Is it from the moment the student prospectively considers the university, or the moment they apply, or the moment they arrive? Is the student experience only what occurs on campus, or does it also include what occurs online, or even, what is provided for through the students either through internships, study abroad or mentorships, many of which, occur off campus? These questions only begin to touch 
on the many questions that need to be considering when conceptualising the student experience.

Astin (1984) writes there is no typical student. Students come into higher education with diverse backgrounds and perspectives, as well as goals, all of which are negotiated with the university to ultimately form their student experience. However, the complexities of defining the student experience has not stopped scholars from investigating the area. Specific streams relating to the student experience have included first year experiences (e.g. James, Krause \& Jennings, 2010), line and digital experiences (e.g. Ellis, Goodyear, O’Hara \& Prosser, 2007), and the international student experience (e.g. Hellstén \& Prescott, 2004). McInnis (2003) writes that within the area of the student experience, however, a common shift has occurred in all sub-streams. He writes that students increasingly expect universities to fit with their lives and priorities, rather than the other way around. He goes on to note that this has given rise to a 'negotiated engagement' where students and universities must work together to co-create the student experience (2003, p.3).

A number of studies have shown that when students are involved in the research functions of universities benefits exist, including inquiry skills (Soohoo, 1993) and life-long learning (Brew, 2006). Similarly, student engagement in teaching and learning activities additionally yields positive results (Carini, Kuh, Klein, 2006; Nelson, Kift \& Clarke, 2008; Kahu, 2013; Trowler \& Trowler, 2010). Therefore, it is plausible to assume that students actively engaged in their student experiences (both inside and outside the classroom) can also have beneficial value. Already, in fact, literature on students-as-partners has shown that students and staff working together across a range of activities can improve both student and staff outcomes (e.g. Bovill, Cook-Sather \& Felten, 2011; Cook-Sather, Bovill \& Felten, 2014; Matthews, 2016). Bovill, Cook-Sather and Felten (2011) summarise a few as, a deeper understanding of learning, enhanced engagement, motivation and enthusiasm and relationships. They further note that already to academic developers the benefits of including students as partners in curriculum design should lead to significant change in curriculum design and for pedagogy considerations.

Neary and Winn (2009) argue that the basis of student life may be "reconstructed [towards] the student as producer" (p.193). In this scenario, students could work alongside university staff and faculty to re-imagine the university and help co-create their own experiences. The 
distinction between university staff and faculty and students would be blurred, as all members of the university community could contribute and even add values to others. By supporting students as producers, higher education may be able to improve the student experience overall (Neary \& Winn, 2009). University staff and faculty no longer would need to assume what students expect or desire from their experiences and would to discuss and interact with students to co-create experiences that match the students' needs. Encouraging students as producers would not be altering all university aspects to only meet the demands of students though (a popular assumption in the student as consumer discourse) but rather, it would support students and staff/faculty to interact and negotiate as McInnis (2003) alluded to. Student co-creation would further not be elevating students above staff/faculty, but it may mean making them increasingly equal partners in a range of activities. Moving forward, student experience research and discourse may want to address more innovative ways for students to actively participate in the shaping of their own student experiences. However, as this study showcases, while student participant may have the ability to enhance higher education experiences, there are also many considerations and barriers that additionally need to be considered. The next chapter addresses these issues and introduces the concept of co-creation. 


\section{Chapter 3. Introducing Co-Creation}

\section{Introduction to Co-Creation}

The concept of co-creation is still predominantly discussed in organisational literature, rather than higher education literature. However, within this chapter, an argument is made for why co-creation could a useful lens to understand student-staff interactions in higher education. Included within this chapter therefore are definitions, key considerations, stages, and underpinning theories of co-creation and how they relate to the higher education sector. This chapter aimed to set the scene for the following chapter (Chapter 4), where a conceptual model for co-creation in higher education is presented.

\section{What is co-creation?}

In this study, co-creation was defined as an interaction between two or more unique stakeholders to jointly integrate their respective resources to provide greater benefits to both the organisation and the user. As this definition highlights, within the process of cocreation stakeholders are often delineated between 'organisational members' and 'users'. This is because co-creation originally emerged from business literature. Often credited to Prahalad and Ramaswamy in a series of articles on co-creation from 2000-2005, cocreation is based on a similar concept known originally as a core competence model. A core competence model was a framework that encouraged organisations to understand their strengths and their resources across organisational boundaries (Hamel \& Prahalad, 1990). Yet arising from the core competence model it was demonstrated that a commonly ignored core competence and potentially transformative resource within organisations was users' perspectives and knowledge (Hamel \& Prahalad, 1990). Thus, identifying nontraditional capabilities including user-contributed resources would later pave the way for developing and theorising the process of co-creation and how to include users in production and delivery (Prahalad \& Ramaswamy, 2000, 2002, 2003, 2004).

The process of co-creation emphasises the social interaction and relationship between organisations and users and has been occurring in pockets of business and industries for some time (Nonaka \& Takeuchi, 1995; Ramaswamy \& Ozcan, 2014). In fact, even organisations that operate in a closed system, where non-employees are not allowed to 
contribute and there exists little transparency other than limited communication to consumers, have never been able to shut out users' opinions altogether (Berthon, Pitt \& Campbell, 2008). Any organisation or business that accepts money from users, for example, have to at least acknowledge user's purchasing power, and thus, production has swayed to their changing needs. Yet the recent tide of user involvement is now stronger than in the past (Prahalad \& Ramaswamy, 2000, 2002) and users expect to be included more in the production of their products and services. Before organisational production often blindly guessed what potential users wanted, yet through processes such as cocreation, users can jointly create alongside production, minimalising organisational assumptions (Ramaswamy \& Ozcan, 2014).

While co-creation is neither a new concept, nor an uncommon phenomenon, varying definitions have complicated the concept (Ranjan \& Read, 2016). For example, Sanders and Stappers (2008) write broadly that co-creation "refers to any act of collective creativity, i.e. creativity that is shared by two or more people" (p.8). However, McColl-Kennedy, Vargo, Dagger, Sweeney and Kasteren (2012) have identified in the literature as many as 27 different definitions of co-creation. Some definitions align more closely to conceptualising co-creation as co-design or co-production of a single activity or product, while others view co-creation more holistically. Other definitions such as Vargo and Lusch $(2004,2008)$ write that co-creation is the users' use of the service/product, known as valuein-use. McColl-Kennedy et al. (2012) after reviewing the literature on co-creation define it as "the benefits realised from integration of resources through activities and interactions with collaborators" (p. 375). This definition is useful for several reasons. For example, the definition does not denote a specific kind of benefit, which is key as research has found various benefits of co-creation including relationship building, market or consumer orientation, and innovative products and services through co-design (Kale, Dyer \& Singh, 2001; Perks, Gruber \& Edvardsson, 2012; Ranjan \& Read, 2016; Vargo, Maglio \& Akaka, 2008). Second, the definition refers to resource integration. Resource integration occurs when consumers are either allowed and/or also incentivised to share their resources with organisations (Frow, McColl-Kennedy \& Payne, 2016) and it is important for the cocreation process to be able to continually add value (Prahalad \& Ramaswamy, 2003). Third, the definition uses the term 'collaborators' referring to co-creation as not only a closed relationship between fixed organisational members and select consumers, but instead an 
open process that elicits resource integration from a range of stakeholders (Fleischman, Raciti \& Lawley, 2015; McColl-Kennedy et al., 2012).

There are several aspects of co-creation that make it a unique process to other similar usercentric approaches. Firstly, co-creation redefines user involvement and ownership. For example, services or products that are co-created with users are likely to result in a shift in consumer attitudes or perceptions. Consumers may feel like they have more ownership in the final result (Prahalad \& Ramaswamy, 2004) or that they helped create meaning and value to the process with their integration of preferences (Ind \& Coates, 2013). The cocreation process additionally may influence co-creators' feelings towards the organisation or each other through team building or alliances (Kale, Dyer \& Singh, 2001; Vargo, Maglio \& Akaka, 2008). Co-creation is also unique because it is much more than simply eliciting feedback from consumers. Instead, co-creation deviates from previous producerconsumer exchange logic that the interaction between a producer and consumer occurs just once at the time of exchange (Vargo, Maglio \& Akaka, 2008). Co-creation recognises the possibility that the traditional point of exchange can be redefined to a series of ongoing interactions where both parties can continuously add value (Prahalad \& Ramaswamy, 2003; Vargo \& Lusch, 2004). This notion of continuous communication, therefore, sets an important parameter of what constitutes co-creation: ongoing interaction. Co-creation is not a single exchange; it is a continuous process that when applied to an organisation may fundamentally change how the organisation perceives the role of the consumer.

\section{Theories underpinning co-creation}

Underpinning co-creation are several key theories including stakeholder theory, servicedominant logic, organisational citisenship behaviour and diffusion of innovation. These theories together form a logical foundation for grounding co-creation and have commonly been used by other scholars to help further breakdown the process of co-creation (Frow, McColl-Kennedy \& Payne, 2016; Pluijm, 2010; Reypens, Lievens \& Blazevic, 2016; Yi \& Gong, 2013). 
Stakeholder theory is a contributing theory to co-creation as it conceptualises how organisations integrate various stakeholders to create shared value (Freeman, Harrison \& Wicks, 2007). Like co-creation, stakeholder theory acknowledges that various stakeholders have different perspectives that, if ignored, can undermine the production, delivery or consumption. However, traditionally, stakeholder theory conceptually focuses more on managing the stakeholder process, and less so on how stakeholders can create shared value (Jensen, 2010; Tantalo \& Priem, 2014). For example, Freeman (2010) proposes that as stakeholders have varying and perhaps conflicting goals, organisations could use shifting incentives or trade-offs to balance stakeholder interests. More recently, Tantalo and Priem (2014) have coined the term 'stakeholder synergy' to discuss how different stakeholder goals can be aligned to increase total shared value. Jensen (2010) additionally discusses how stakeholder theory could be a mechanism to achieve value maximisation, however, notes that because this is not the only aim of stakeholder theory (it also relates to governance for example), it is overall an inefficient theory to apply when seeking to amplify the co-creation of value. Thus, while co-creation differs from stakeholder theory, as it does not discuss value creation by combining goals of stakeholder groups, rather co-creating the services and products to jointly integrate value early on in the production. Yet stakeholder theory can be useful to inform the co-creation process. By understanding the difference between stakeholders, research can seek to understand how differences drive value creation (Reypens, Lievens \& Blazevic, 2016).

\section{Service dominant logic (SD-Logic)}

Commonly discussed alongside co-creation is service-dominant logic (SD-Logic) originally put forth by Vargo and Lusch (2004, 2008). SD-Logic comes from services literature that has contended since the late 1970s that services are unique from goods for 4 major reasons including 1) intangibility, 2) inseparability, 3) heterogeneity, and 4) perishability (Fisk, Brown \& Bitner., 1993). However, while at first, service literature set to distinguish itself from goods literature, it increasingly took on the perspective that all goods were also services (Ballantyne \& Varey, 2006). SD-Logic contends that organisations no longer solely provide value (e.g. through a product) but rather organisations and consumers both play active roles within their interactions as a joint process to co-create value (Diaz-Mendez \& Gummesson, 2012) (also conceptualised as value-in-use, discussed later in the chapter). 
Regardless of whether the organisation is offering a product or a service, the true value of exchange is the application of the resource by the consumer (Vargo, Maglio \& Akaka, 2008). Vargo, Maglio \& Akaka (2008) use the analogy of a car to demonstrate. To illustrate, before the consumer drives the car, it has no value, only when the consumer combines his/her ability to drive, plus the need to travel to a location, does the car incur value. Therefore, the car, through its service experience, is co-created with the consumer. And yet, the car is not co-produced. For example, using Vargo, Maglio and Akaka's (2008) analogy of the car one could also argue that the consumer had no input on the design of the car. Therefore, while the consumer may have bought the car and possibly derived value from it, because of the lack of consumer resource integration in the car's design, the car is not customer-centric designed. Therefore, the car's co-creation process only occurred post-production, yet as the next chapter will later demonstrate co-creation can occur both pre and post production (Ranjan \& Read, 2016).

\section{Organisational citizenship behaviour}

Important to co-creation is also what motivates organisations and consumers to participate in resource integration (discussed in relation to this study in Chapter 7). Organisational Citizenship Behaviour (OCB) is a theory that conceptualises the behaviour of people within an organisation that is outside of their mandatory roles yet carried out regardless. OCB was originally drawn from the broader theory of social exchange. Social exchange theory stipulated that social “...exchange generates an expectation of some future return... however, unlike economic exchange, the exact nature of that return is unspecified (Konovsky \& Pugh, 1994, p. 657). Additionally, the definition of OCB states that it is only in the aggregate of all OCB interactions can true value for the organisation or institution be calculated (Organ, 1988).

OCB was first introduced within the field of organisational behaviour to explain employee behaviour (Organ, 1988), then applied to consumer behaviour (Yi \& Gong, 2013), and now, more recently, has begun to have application to explain the behaviour of students (Elsharnouby, 2015). OCB theory explains that employees, consumers, or students, participation in non-mandatory behaviours is, "discretionary, not directly or explicitly recognised by the formal reward systems and that in the aggregate promotes the effective functioning of the organisation" (Organ, 1988, p. 4). Organ's definition later clarifies that by discretionary behaviour it is referring to "...behaviour [that is] a matter of personal 
choice, such that its omission is not generally understood as punishable (Organ, 1988, p. 4). OCB, therefore, may help explain why stakeholders choose to engage in the co-creation process (Yi \& Gong, 2013). However, it is important that OCB and customer engagement behaviour (CEB) are distinct from co-production or co-creation. To illustrate, CEB is what users or consumers do in addition to their assumed roles, also known as extra-role behaviour (Brodie, Hollebeek, Jurić \& Illić, 2011). Co-production on the other hand is a built-in design process, where users co-produce processes or design elements with the organisation (Auh, Bell, McLeod \& Shih, 2007). Finally, co-creation, as described in more detail in Chapter 4, includes both elements of co-production and the co-creation of value post-production (value-in-use). Though, interesting to note, is research that has previously explored the link between $\mathrm{CEB}$ and co-creation and found that four types of CEB (augmenting, co-developing, influencing, and mobilising behaviour) can impact subsequent co-creation (Jaakkola \& Alexander, 2014).

\section{Diffusion of innovation}

The co-creation process may also be analysed by how and why it is adopted in certain contexts, similar to individual motivation but on a larger scale. Diffusion of Innovation (DOI), first published in the 1990s is a theory to explain the spread of practices in novel contexts (Lyytinen \& Damsgaard, 2001; Rogers, 1995). The theory posits that variables of innovation including the availability of information, past experiences of stakeholders, and characteristics of the social system all help explain whether the innovative practice is eventually adopted (Lyytinen \& Damsgaard, 2001). The theory further breaks down the adoption decision factors into two categories, initiation and implementation (Rogers, 1995). Yet while DOI has mostly been applied in information technology (IT) fields, it can be applied to any innovation, including co-creation. However, due to the broad nature of DOI theory, it leaves itself open for criticism. For example, the attributes or conjectures that are significant for one innovation may not be relevant for another (Lyytinen \& Damsgaard, 2001). Thus, its application to co-creation is only to broadly understand why some contexts may develop co-creation differently than others.

Also related to DOI is lead user innovation, where users of products or services can drive the innovation progression (Morrison, Roberts \& von Hippel, 2000). Whereas DOI sought to explain why some innovations are adopted and others are not, user innovation seeks to explain why some users innovate further and others do not. Urban and von Hippel (1988) 
defined lead users as those who expected innovation-related profits from a solution to their needs and who experience needs unmet by the larger market. Further, Morrison, Roberts and von Hippel (2000) note the lead user must be in an environment where they believe they will be able to benefit in the innovation, as opposed to being punished or ignored. Therefore, lead users emerge in a gap between the needs of a consumer and the existing market, but also as a result of users who believe they can innovate and improve existing products or services. This relates to co-creation as in order for co-creation to occur, users must be motivated to participate (Nambisan \& Baron, 2009; Pluijm, 2010; Roberts, Hughes \& Kertbo, 2014). It is not enough to have unmet needs; stakeholders must also have the knowledge and support to believe that they can contribute and add value to the existing product and service.

The theories listed above are important antecedents to understand how and why cocreation occurs. Theoretical underpinnings also guide direction and research to what practical considerations need to be analysed to develop co-creation.

\section{$\underline{\text { Key considerations for co-creation }}$}

Literature relating to co-creation has highlighted various factors that are important to the co-creation process, implementation or results. This section reviews the most commonly cited key considerations from previous literature including resources, environment, roles, time and experience, and culture. These factors are important because they also shed light on the dynamic nature of co-creation. Co-creation is not an isolated process, but rather a process that involves both the changing creation and the capture of value (Reypens, Lievens \& Blazevic, 2016). Key considerations, therefore, further allow the value creation and capture process to evaluated and understood, guiding future research (Bizzi \& Langley, 2012; Gros \& López, 2016; Reypens, Lievens \& Blazevic, 2016). These key considerations were integrated into the model of co-creation in higher education presented in the next chapter.

\section{Resources}

In co-creation, the term 'resources' is applied not only to physical resources such as space and money but also as intangible resources, such as opinions, information, or even 
experiences (Breidbach \& Maglio, 2016). For example, in the tourist industry Mathis, Kim, Uysal, Sirgy and Prebensen (2016) describe consumer co-creation resources as time, effort, money and/or knowledge. However, scholars such as Mele, Russo-Spena and Colurcio (2010) also point out that simply acknowledging consumer resources is not enough to provide benefit. Resources do not have intrinsic value and need agile and supportive environments and processes to be integrated for co-creation (Frow, McColl-Kennedy \& Payne, 2016). Co-creation, therefore, is the use of consumer resources through a facilitating environment for a specific benefit (Lusch, Vargo \& Wessels, 2008). There are numerous forms or types of resources that can be integrated during co-creation. Examples include stakeholders' ideas, past experiences, opinions, specific knowledges, and preferences (Gummesson \& Mele, 2010; Kazadi, Lievens \& Mahr, 2016). As resources can vary in co-creation, in this study, during the qualitative survey, participants were asked to specify which resources students integrated during the co-creation process (results highlighted in Chapter 6).

However, important to consider, is that user resources can be integrated in two ways. The first way is the through the typical co-production process. For example, users give ideas or feedback on how a service can be improved, the organisation listens and makes corresponding changes, and thus, the users' resources are integrated. However, the second way users can integrate their resources is post-production where their resources help contribute to the perspective or ability to gain value from the service. As Vargo and Lusch (2004) write that in this second way "resources are not, they become" (p.4). Meaning that users resources such as time, effort and money should also be integrated after initial 'consumption' to continue to co-creation value. Prebensen, Vittersø and Dahl (2013) use an example of a vacation, which a family could purchase and then go on. Their additional effort to climb a nearby mountain or relax by the beach reading a book, or even after the fact, create a family photo album are all ways they are co-creating with their own resources post-production (i.e. after the hotel was built, trip was purchased, etc.). In higher education, this additional lens on what is value and how students can integrate their resources to cocreate value is also well-known and yet unexplored in current literature. Students not only co-create value of services in higher education themselves by choosing to attend, listen and later utilise their potential value, but have the ability to do so for many years after their student experience has ended (this concept of value will be discussed further in Chapter 4). 


\section{Environment}

The environment of co-creation is important for resource integration to occur (Frow, McColl-Kennedy \& Payne, 2016) however; there are various discussions on how a supportive environment can be achieved. For example, some researchers note that organisational leadership may lay the foundations to creating a beneficial co-creation environment and building other environmental capabilities such as trust, empathy and mentality (Pluijm, 2010; Ramaswamy, 2009). While other research emphasiaes that cocreation must be voluntary and naturally motivated from the onset with all stakeholders (Cova, Dalli \& Zwick, 2011).

Transparency and accessibility are other factors for the co-creation environment (Prahalad \& Ramaswamy, 2004). The process of jointly creating value between consumers and organisations may rest heavily on its ability to provide transparency (Leavy, 2012; NavarroGarcia, Peris-Ortiz \& Rueda-Armengot, 2015). Transparency builds an atmosphere of trust and helps further establish authenticity (Coates, 2016; Leavy, 2012). Further, accessibility for consumers is integral for co-creation as it allows all consumers to participate (Navarro-García, Peris-Ortiz \& Rueda-Armengot, 2015; Vargo \& Lusch, 2008). Accessibility also helps support other aspects of co-creation such as continuous interaction and dialogue (Prahalad \& Ramaswamy, 2004). Frow, McColl-Kennedy and Payne (2016) have discussed the environment for co-creation as the 'service ecosystem' which influences what resources are available for consumers to share and when/how they are integrated. Other scholars such as Grönroos (2012) previously also discussed the importance of environment in co-creation through organisational structure and internal support systems as requirements for consumer resources to be turned into actionable information.

While there is much discussion on the importance of the co-creation environment for the process to occur, there are few frameworks or scales for critically evaluating environment. One scale that does exist is the DART (Dialogue, Accessibility, Risk Assessment, Transparency) developed by Prahalad and Ramaswamy (2004). The scale is intended to be a diagnostic measure of the firm's environmental readiness (Albinsson, Perera, Sautter, 2016). The DART scale has been used and adapted by subsequent research (e.g. Restuccia \& Ouellet, 2009), yet debate remains whether a scale to measure environmental ability to co-creation is feasible. For example, service ecosystems concepts like the ones put forth by Frow, McColl-Kennedy and Payne (2016) denote the constantly changing and perhaps 
difficult to assess environmental factors of co-creation. Vargo and Lusch (2011) further point out that service ecosystems are self-adjusting systems that are dependent on exchanges, thus often re-adjusting to new experiences and novel contexts. Therefore, while it is important that environmental factors be considered, and may be crucial to organisations ability to adopt co-creation (Sawhney, Verona \& Prandelli, 2005), comprehensive measures of the co-creation environment are more difficult in practice to achieve.

Interesting, there are also questions of whether environmental factors for co-creation should be online or in-person. This is of relevance to this study, in particular, as while the majority of co-creation examples in industry are information telecommunication (ICT) supported (see Ramaswamy \& Ozcan, 2014), most cases included in this study were not. This may be due to co-creation in higher education being a relatively new mechanism, and therefore, as it is in its more infant stages, perhaps scalable ICT supported options are not yet fully explored (Dollinger, under review). This finding is discussed further in Chapter 9 as well as down below in the 'stages of co-creation'.

\section{Roles}

Co-creation is a redefining of roles, previously producer and consumer, therefore, role formation and identity may be important considerations as well (Humphreys \& Grayson, 2008). When Porter (1985) first outlined the 'value chain' he spoke about a series of interactions and activities that take place to make a product and eventually to deliver to an end user. In this, he pictured roles such as the factory man or woman producing something and a consumer later using it. However, as scholars have noted (e.g. Prahalad \& Ramaswamy, 2000; Ramirez, 1999), the distinction between producers and consumers is misleading, as consumers still 'produce' with the product/service after purchase or consumption. To illustrate, a consumer may purchase a light bulb, and then go home, coproduce light by screwing the light bulb in, and then continue to gain value from the light as they cook dinner. Ramaswamy and Ozcan (2014) write that co-creation strives for balanced roles among organisations and consumers, as the balancing of roles helps facilitate transparency, dialogue and trust which can impact other aspects such as environment and resources. Prahalad and Ramaswamy (2004) also note that through balanced roles, stakeholders can share responsibility throughout the co-creation process. However, the balancing of roles and shared responsibility that comes with it is difficult to 
achieve for multiple reasons. First, the organisation rather than the consumer usually still largely controls the environment of co-creation. In fact, Grönroos (2012) writes that cocreation is not the consumers' opportunity to interact with the organisation, but rather cocreation first begins with organisation's decision to interact with the consumer. Coinciding with this, organisations may need to have more flexible structures to allow for the change and development that occurs during co-creation (Pluijm, 2010; Prahalad \& Krishnan, 2008).

\section{Time and experience}

As the co-creation process through resource integration, environment, and roles can be difficult to achieve, time and experience have also been shown to be important considerations when developing co-creation (Albinsson, Perera \& Sautter, 2016; Gros \& López, 2016). Either through leadership perspectives (e.g. Thomke \& von Hoppel, 2002), building trust between stakeholders (e.g. Gros \& López, 2016) or for users to understand how and why they might integrate their resources (e.g. Bovill, Morss \& Bulley, 2009) cocreation often involves changes over time and experiences. Co-creation as a process also takes time and experience because it is not a single interaction between multiple stakeholders (Prahalad \& Ramaswamy, 2002, 2004). Since the process allows for numerous interactions (Prahalad \& Ramaswamy, 2004) many instances of co-creation occur of an extended period of time. Aspects of co-creation such as continuous dialogue between stakeholders also denote the importance of sustained interaction over time (Jaworski \& Kohli, 2006; Pluijm, 2010). And again, to reiterate, co-creation of value can occur past production, and therefore, value continues changes over time. In higher education, this is evident as the value of the student experience and the university degree may continue to gain value as time goes on.

\section{Culture}

Emerging co-creation research is also beginning to emphasise the importance of culture as a mediator within the co-creation process (Akaka, Schau \& Vargo, 2013). First, culture is a key consideration of co-creation because it takes a culture-shift in order for co-creation to be recognised and supported (Sanders \& Strappers, 2009). But also, as Reypens, Lievens and Blazevic (2016) found in their case study of co-creation that organisational cultural components such as working style, language and perspective were large influencers in how 
the communication unfolded between multiple stakeholders. Thus, the converging of cultures within the co-creation process has the ability to impact the outcomes. Further, applying consumer culture theory that understands culture as the basis of meaning and action (Geertz, 1973), Akaka, Schau and Vargo (2013) posit that all social norms and culture guide interaction between stakeholders and is an important aspect of the value cocreation process.

The key considerations highlighted here showcase the complex and inconsistent nature of the co-creation process. When researching co-creation, it is important that these key considerations are integrated both into the analysis of the co-creation process and structure, but also how they further impact the benefits or outcomes of the co-creation process. Therefore, an analysis of the key considerations of the cases included in this study are presented in Chapters 8 and 9.

\section{$\underline{\text { Stages of co-creation }}$}

As the key considerations discussed above show, co-creation can be difficult to design, implement and assess. But actually, even the most basic organisation and consumer interaction through market research can be a form or style of co-creation according to some (Ranjan \& Read, 2016). This does not mean it is an efficient form of co-creation. However, as simple market research still encourages consumer integration of their resources such as opinions and experiences to provide a benefit to both the organisation and the consumer it could be considered to fall under the umbrella of co-creation. Still, not enough research has tried to discuss the stages towards an efficient and effective cocreation process. This section, therefore, goes through common stages or styles of cocreation and discusses which elements relate to co-creation.

\section{Consumer feedback}

Feedback through questionnaires or other forms of market research has long been common in practice with the aim of organisations improving their products, services or marketing (Wei, Chen, Yang \& Yang, 2010). However, more recently the expansion of ecommerce has meant that consumers now have various platforms to offer feedback, not only through the organisation sponsored questionnaires but through social media or 
websites that collect consumer opinions on a wide range of products like Amazon (Wei et al., 2010). However, framing co-creation as a means to elicit consumer feedback is largely ineffective. Consumers can only give feedback on products or services that already exist, meaning the organisation has already spent considerable amounts of time and money designing and testing their core offer (Thomke \& von Hippel, 2002). Thus, while market research can be a form of co-creation, it overlooks many potential benefits of co-creation and opportunities to create new products and services (Thomke \& von Hippel, 2002).

\section{Crowdsourcing}

Crowdsourcing is one mechanism to engage a larger audience in co-creation. Using online technology, crowdsourcing is a distributed problem-solving and production model that encourages users to actively participate (Brabham, 2008). Crowdsourcing often supports user-generated ideas and suggestions and can be applied through various means and along various points of the value chain. In higher education, universities could ask potential students to crowdsource ideas for orientation activities, or they could ask students to crowdsource ideas for new building on campus. Using either a mobile application and/or a website portal, crowdsourcing is a relatively easy way to collect data on students' opinions and perspectives. Crowdsourcing further touches upon both concepts of co-creation, coproduction and ViU. As students crowdsource they contribute resources and innovate the service, but they also can derive more value from the service or activity if it is tailored to their specific needs and preferences (Vargo \& Lusch, 2002).

However, important to note are some of the drawbacks to the crowdsourcing model. First, as some scholars have pointed out, crowdsourcing is actually more co-creation between users and technology, as organisations do not input their own resources (except for choosing the topic to crowdsource) (Anderson, 2011). Anderson (2011) uses the example of a stagnant online course, where students can integrate their resources (i.e. time, energy) to learn from the online content, in some ways co-creating the learning experience and yet never involved a university staff member. Another pitfall of crowdsourcing is that often crowdsourcing models separate user- generated ideas from professional designers, researcher, and industry experts (Anderson, 2011). Therefore, these multiple stakeholder populations do not work together, but almost, rather against one another, which can limit innovation. 


\section{Mass customisation}

Another process that has some elements of co-creation is mass customisation. Companies selling apparel or technology such as computers can now allow for the customer to select certain characteristics of their products to fit their size, budget, or needs. However, mass customisation is not cheap (Ogawa \& Piller, 2006; Zipkin, 2001). It takes years to develop a technology or business model that can help companies achieve customisation on a large scale. Therefore, not all organisations can utilise mass customisation either because of time or money to integrate the complex coordination and planning that is necessary (Ogawa \& Piller, 2006). This problem only becomes worse if after participating in costly consumer feedback, and costly mass customisation adoption, the organisation learns that their consumer feedback no longer meets the needs of the market. Moreover, like consumer feedback, organisations are usually only allowing the customer to give their opinion or change small aspects of the product or service, framing the choice options, thus limiting innovation (Wind \& Rangaswamy, 2001). In some forms, customisation in higher education as already begun to occur, such as through teachers customising dashboards and sending out personalised emails to students (Arthars et al., 2018).

\section{Prosumer behaviour}

Prosumer behaviour (in some literature also known as prosumption) occurs when consumers are expected to help produce the product or service earlier in the value chain (Toffler \& Alvin, 1980). Recent examples include websites such as Facebook and Twitter that rely on prosumer behaviour to produce their core offering (Muñiz \& Schau, 2011; Ritzer, 2013). Yet prosumer behaviour still limits what consumers can alter about the existing structure of the organisation. For example, on Twitter (a social media website) users can post about any topic they like, as long as it is limited to 140 characters.

Prosumer behaviour is also closely related to brand communities. Brand communities are groups of consumers who strongly identify enough with a brand that they willingly donate resources to improving and sharing it. Yet much of why customers choose to engage in brand communities or prosumption behaviour is unknown (Muñiz \& Schau, 2011; Von Hippel, 2009). Scholars have hypothesised that users participate to express brand attachment, social interaction, or intrinsic rewards (Muñiz \& Schau, 2011). For example, people who engage in prosumer behaviour through open source models such as Linux (an 
open-source database) may be hobbyists and therefore the satisfaction of working out a problem of source code will entice them and offer more intrinsic rewards for them (Brabham, 2008).

Yet while consumer feedback, crowdsourcing, mass customisation and prosumer behaviour could be considered forms of co-creation, they are not the only forms of cocreation. Prahalad and Ramaswamy (2004) write that co-creation is unique from market research and superficial customisation because the joint problem-solving process strives towards balanced roles and shared transparency. Yet in many examples of market research and customisation, the power still lies largely with the organisation (Tsigkas, 2013). Further, co-creation allows for the consumer to participate in design, knowledge production, and feedback, and therefore, consumers only giving opinions or knowledge to other consumers (e.g. Twitter) does not represent a fundamental change in traditional consumer roles (Di Gangi \& Wasko, 2009; Humphreys \& Grayson, 2008).

\section{$\underline{\text { Co-creation as participatory design }}$}

While the majority of research on co-creation from organisation literature includes a discussion of the applicability of the concept or the benefits (e.g. Alves, Fernandes \& Raposo, 2016; Ramaswamy \& Ozcan, 2014), there is not a great deal of research aimed on how it links to other similar areas. Instead, co-creation literature often highlights the uniqueness of the construct (e.g. see Prahalad \& Ramaswamy 2000, 2002, 2003, 2004). Yet one way to link co-creation to existing literature is to analyse it as a form of participatory design. Participatory design is a series of actions, including investigation, reflection, development and support, towards mutual learning between multiple and unique participants (Schön, 1983). Therefore, while participatory design literature rarely conceptualises users' resources or value creation to the same extent as co-creation literature, they are in fact, by their very definition, quite similar. Yet, participatory design, unlike co-creation, does not have the objective to integrate all users into the design process, with instead interventions taking place between research and designers or designers and users (Schuler \& Namioka, 1993). Participatory design further has very specific activities that literature describes such as various tools, toolkits that may include 2-D collages, 2-D mappings, and 3-D mock-ups (Sanders, Brandt \& Binder, 2010). Though, this is not actually significantly different from co-creation, where specific strategies have also been 
outlined. For example, Frow, Nenonen, Payne and Storbacka (2015), write in details about 12 different types of co-creation including co-promotion and co-outsourcing. To complicate matters further, another literature stream, user-centered design, is also similar to participatory design and co-creation and advocates for specific strategies such as interviews, focus groups, and usability testing (Abras, Maloney-Krichmar \& Preece, 2004).

The similarities between co-creation, participatory design frameworks, and user-centered design have not gone unnoticed in this research. For reasons of time and clarity, other literature streams were not exhaustively searched, and it is suggested that future work help integrate these overlapping and similar streams as there is likely much to be gained from learning from one another. Sanders and Strappers (2008) attempt this as they note cocreation and other similar forms are all forms of collaborative design. Thus, all the different terms (e.g. co-creation, participatory design) are just different strategies to achieve the same aim, to collaborate with users. Participatory design framework literature arose namely from technology industries (e.g. Verbert et al., 2014), while co-creation came from organisational business literature (e.g. Prahalad \& Ramaswamy, 2000), and co-design from design and architecture (e.g. Sanders \& Strappers, 2008) which is likely why the literature streams have remained separate. Yet these disparity between industries and contexts is support that a literature review on sector adoption of co-creation needed to be conducted within this study, as seen in the next section, as co-creation was likely to confer distinct meanings and arise in unique applications depending on the context.

\section{$\underline{\text { Sector adoption }}$}

Thus far, this chapter has discussed what co-creation is, underlying theories, key considerations, and stages or styles of co-creation. However, to better understand cocreation, industry examples can also be useful. Companies such as LEGO, Apple and Starbucks have all successfully integrated co-creation into their management and/or marketing practices (Ramaswamy \& Ozcan, 2014). For example, in LEGO all three million LEGO sets produced each year are now co-created with their consumers (Pluijm 2010; Prahalad \& Ramaswamy, 2004). To do so, the firm has a variety of platforms (LEGO.com, LEGO Club, and an online LEGO factory) where consumers can interact and share ideas for new LEGO designs and uses. Many of these ideas relate directly to some of the stages of co-creation discussed earlier such as crowdsourcing and prosumer behaviour. 
In their book, The Co-Creation Paradigm (2014) Ramaswamy and Ozcan also describe how major companies such as Starbucks and Apple have adopted co-creation. For example, Apple encourages consumer creativity and co-production through their Software Development Kit (SDK) that helps users develop their own applications based on consumer ideas and then upload those applications to peers. Toolkits such as Apple's SDK may help users participate in co-creation as they provide tools that enable users to innovate more effectively in line with the organisation's needed tasks or issues (Von Hippel, 2009). Apple, in an effort to further boost transparency of their innovation process and learn from consumers, also holds an annual World-Wide Developers Conferences where participants can interact with over 1,000 Apple engineers to hear keynotes, learn new skills, and participate in design labs and workshops (Ramaswamy \& Ozcan, 2014). Additionally, Starbucks has launched an online platform for co-creation called MyStarbucksIdea (MSI). Similar to traditional feedback, customers can submit ideas on how to improve Starbucks products, services, processes, or environments. However, the platform differs from traditional consumer feedback in several ways. MSI is fully endorsed by the senior management, with even the CEO of Starbucks, Chris Bruzzo supporting the program (Ramaswamy \& Ozcan, 2014). Further, the platform gives as much information as possible to the consumer to help the consumer generate constructive feedback. Starbucks employees and customers are also allowed to see each other's feedback and additionally vote up or down in endorsement (Ramaswamy \& Ozcan, 2014).

However, co-creation has also been adopted within other contexts, such as health care provision (Frow, McColl-Kennedy \& Payne, 2016). Porter, Pabo and Lee (2013) found that the health care industry increasingly encourages patients to be active contributors to their health care practices. This has stemmed from diseases shifting from the majority as acute, to the majority as chronic and relating directly to patient demographics and lifestyle choices (Freire \& Sangiorgi, 2010). Freire and Sangiorgi (2010) write that within healthcare, patients have growing opportunities to co-design, co-produce or co-create their health services. For example, in an effort to encourage active lifestyles, Kent County Council in the UK created with residents the idea of Activmobs or self-organising groups can participate in shared healthy activity such as dog walking. To stay motivated participants would get discounts at local shows or have personal statements to show their time exercising to others (Freire \& Songiorgi, 2010). Other cases have shown examples of 
patients keeping diaries to help collect ideas and better understand patient experiences (Elg, Engström, Witell \& Poksinska, 2011).

Co-creation is also developing within public policy reform as a process that allows citizens to actively engage in the planning and delivery of public services (Osborne, Radnor \& Strokosch, 2016). In the United States, several initiatives including the Veterans Benefits Administration Innovation Initiative and Innovation.ed.gov encourage individuals to put forth ideas, feedback, and harness their collective intelligence to create value (Wise, Paton, Gegenhuber, 2012). However, co-creation may not develop within the public sector along the lines it has developed in the private sector. This is because in the public sector, individuals may contribute because of financial rewards or notoriety, yet research in the public sector has shown individuals are motivated more by intrinsic rewards such as civic duty (Wise, Paton, Gegenhuber, 2012). Moreover, Osborne, Radnor and Strokosch note that co-creation within public services is unique to other forms as it is not a supplementary service or process, but rather public service delivery stands on the basic premise that it should be co-creation and/or co-produced with the community.

As discussed, co-creation, or forms of co-creation have also appeared in literature relating to architecture (Dossick \& Neff, 2011), tourism (Binkhorst \& Den Dekker, 2009), technology for aged care (Karahasanović et al., 2009), and industry from everything from the furniture market (Andreu, Sánchez \& Mele, 2010) to global brands such as Nike (Ramaswamy, 2008). Therefore, while examples help illuminate how co-creation can take unique forms in different contexts, it also helps build evidence that co-creation is a flexible enough concept that it can be useful to a variety of environments. In the next section, therefore, co-creation is linked to the higher education context.

\section{Linking co-creation to higher education}

Aspects and concepts similar to co-creation are increasingly being adopted within the higher education context (Díaz-Méndez \& Gummesson, 2012; Elshanouby, 2015; Fagerstrøm \& Ghinea, 2013; Judson \& Taylor, 2014). As this chapter highlighted, there is a wide variation in co-creation definitions, contexts, types and stages. Therefore, as the aim of the study was to explore the nature of co-creation in the higher education context, 
the study design needed to careful to explore all forms of co-creation so as to be able to ascertain how it occurs in the higher education context.

To achieve this, a literature review on similar terms such as student voice and students-aspartners was conducted, along with a literature review on co-creation. As mentioned previously, this is due to co-creation having considerable crossover with other terms. A literature review was further conducted to understand the challenges of investigating cocreation in higher education context. The section, and chapter, then concludes with a discussion the gap in the literature to date, and the importance of the study. From this, in Chapter 4, a model to explore co-creation in higher education is presented.

\section{$\underline{\text { Student voice }}$}

The term student voice often underpins other concepts such as students-as-partners or student-staff co-creation. As McLeod (2011) notes, defining student voice is difficult, as the term is often interpreted in various ways. She identifies four common usages of student voice in literature, including voice-as-strategy, voice-as-right, voice-as-difference, and voice-as-participation. Within these common usages literature has discussed how integrating student voice into higher education can improve diversity, equity, powerimbalances, and support student active participation. Therefore, similar to co-creation, student voice research has been applied to a wide variety of university activities, including curriculum, governance and quality assurance (Varnham, Olliffe, Waite \& Cahil, 2016). Seale (2010) additionally notes that much of student voice research has been for institutional purposes, including using student voice to improve quality assurance (e.g. Shah \& Nair, 2006) and staff professional development (e.g. Campbell et al., 2007). Within this stream of research, student voice is often defined as eliciting student voices and perspectives to improve university services or offerings and ultimately encourage students to take a more active role in their university experiences (Seale, 2010; Walker \& Logan, 2008). Seale (2010) further found in a review of literature on student voices and subsequent roles in higher education that students have been conceptualised in the following ways: students as stakeholders or representatives, students as consumers or customers, students as teacher or facilitators, students as evaluators or informants, and students as story-tellers. 
Scholars have previously found the faculty who hold the perspective that their role is to facilitate the development of knowledge for students, rather than pass on knowledge through transfer, were more likely to be engaged with the student voice (Lueddeke, 2003). This research emphasises that in order for student voice to have meaningful impact in higher education, it is not enough the student voice be collected (i.e. through questionnaire or feedback mechanisms) but also that student voice be accepted (Blair \& Valdez Noel, 2014). This highlighted a need for student voice to progress from not only collecting data and perspectives from students but treating students more equally in their educational experiences. One could therefore argue that a progression of literature relating to the importance of hearing the student voice has helped support another stream of literature, related to student co-creation, students-as-partners.

\section{$\underline{\text { Students-as-Partners }}$}

The concept of students-as-partners $(\mathrm{SaP})$ is increasingly being discussed in literature and applied in higher education settings (e.g. Bovill, 2017; Mercer-Mapstone et al., 2017). Defined as "a metaphor for university education that challenges traditional assumptions about the identities of, and relationships between, learners and teachers", SaP has become an ethos by which a growing number of people identify with (Matthews, 2017, p. 1). Values espoused by SaP include respect, reciprocity and shared responsibilities, all of which help support a reframing of the value and roles of students and elevates students from constricted observers of higher education to legitimate partners (Cook-Sather, Bovill \& Felten, 2014). As SaP continues to grow in prominence, it has also become a catalyst for many in higher education to reflect and also change their current practices. Though not an entirely new idea, as there are numerous examples of students acting as partners historically (see Healey, Flint \& Harrington, 2014), the language and discourse developing as the term $\mathrm{SaP}$ becomes more well-known allows for a community to form around the topic and invigorates future research. Examples of SaP being adopted include both inside and outside classroom settings, including engaging with students as pedagogical consultants (Cook-Sather, 2011), university representatives (Varnham, Olliffe, Waite \& Cahill, 2016) and in quality assurance mechanisms (Gotel et al., 2008). In a systematic review, beneficial outcomes reported for students through $\mathrm{SaP}$ included increased student engagement/motivation/ownership for learning, increased student confidence and selfefficacy, and increased understanding of the "other's" experience (Mercer-Mapstone et al., 
2017). Benefits for staff further included enhanced relationships or trust between students and staff and development of new or better teaching or curriculum materials (MercerMapstone et al., 2017).

Bovill (2017) notes that students-as-partners can be conceptualised as a scale, similar to the stages of co-creation, with listening to student voices on one end of the spectrum and student control or partnership on the other. Matthews (2017) further notes that student partnership literature in the future could be extended to various groups, including students working not just with educators, but students working in partnership with administrators or industry experts. However, students-as-partners research focus on achieving ethical and inclusive partnership with students is also what may set it apart from co-creation as discussed in the research presented here. Matthews (2017) notes that there are five guiding propositions underpinning $\mathrm{SaP}$ approaches including fostering inclusive partnerships, nurturing power-sharing relationships, accepting partnership as a process with uncertain outcomes, engaging in ethical partnerships and enacting partnership for transformation. While these propositions also align with co-creation, co-creation does not necessarily require partnership, through that can be one form of co-creation and in fact Prahalad and Ramaswamy to advocate for balanced roles (2004). As discussed earlier in this chapter, cocreation often occurs in stages, however, and many of which do not meet the criteria of partnership as defined by SaP literature. Further, while much of $\mathrm{SaP}$ literature focuses on the benefits of partnerships for individual students or staff, for example improved leadership skills for students or better understanding of student perspectives for staff, cocreation literature also seeks to explore the institutional benefits, such as marketing and improved offerings (Prahalad \& Ramaswamy, 2008). This differs significantly from SaP literature, which is often presented as a counter-narrative to neoliberalism and consumerism in higher education, as it challenges traditional views on students passively consuming education and strived to create mutually beneficial learning partnerships (Matthews, Dwyer, Hine \& Turner, 2018).

\section{Co-creation in higher education}

Emerging studies in higher education are beginning to use co-creation as a lens to understand student and staff interactions. For example, Navarro-García, Peris-Ortiz and Rueda Armengot (2015) apply a co-creation lens to the university context for an online 
course environment. Students within the course come from diverse backgrounds through the European exchange process with the goal of building competencies for communication and problem solving. Using an adapted framework, the course and its platform were designed with four principles of co-creation: transparency, accessibility, commitment and flexibility. The authors note that outcomes of using co-creation integration was linked in improved student teamwork, more efficient use of time, and students' ability to handle new online resources to find ideas and solutions. Gros and López (2016) also use co-creation as a process for selecting digital resources for the design of a course. Four courses across two universities were selected to understand how student participation and co-creation could influence the course design. Similar to Navarro-García, Peris-Ortiz and Rueda Armengot (2015) the researchers' findings found that students felt the co-creation process positively impacted their communication and collaboration between each other and with teachers.

Fleischman, Raciti and Lawley (2015) also used a co-creation perspective in a study of higher education international students' engagement with their university and their community. Their findings put forth that there are degrees of co-creation among students, with some emerging as consumers, collaborators or co-designers. They also find that students' motivations and culture, as well as a clear purpose or link to why they should participate in co-creation are important mediators of the process (Fleischman, Raciti \& Lawley, 2015). Emerging research using the concept of co-creation has also explored cocreation of rubrics (Fraile, Panadero \& Pardo, 2017) and co-creating learning analytics in higher education (Dollinger \& Lodge, 2018). Also, important to note, is the increasing amount of literature on co-creation in higher education that does mention the terms organisational literature roots as conceptualised from Prahalad and Ramaswamy (e.g. Boyle, Buckley \& Whelan, 2018; Taylor \& Bovill, 2018). This is interesting as it may mean that term 'co-creation' begins to take on several variations with scholars referring to the same term and yet not deeply describing how their perspective on the term aligns with competing research. However, this is likely unavoidable, as the phrase 'to co-create' is vague to begin with. Yet for the purposes of this study, the delineation of the usages of the term is important to frame the current research. 


\section{Challenges to co-creation in higher education}

While co-creation literature and practices, and related concepts, has expanded in recent years, challenges still remain, some which are likely to make application of co-creation in higher education difficult. For example, one of the most critical challenges is the extra workload, time, and professional development needed to assist co-creation approaches and also the equity and range of voices and perspectives within co-creation approaches. For example, Healey (2005), when discussing co-creation in relation to student partnership, writes that co-creation approaches can often clash with the current staff and faculty roles, especially as above-standard workloads and casualisation of many positions are on the rise. As co-creation often takes a considerable amount of time, project planning, objective setting, as well as implementation, it is difficult for staff and faculty to find the time needed to adopt a co-creation approach. However, it is not only the challenges of time that may need to be considered. White (2007) writes that it is overly simplistic to assume that all students have the same expectations or goals in their higher education experiences. Research underpinning this include Newton, Grayson, and Thompson (2010) that found that medical students alone had a wide variety of reasons and goals for their higher education experience, from wanting to graduate from a prestigious school, to doing research related to their interests, to future income expectations. If co-creation is going to continue grow in the context of higher education, addressing both the needs of staff and faculty who do not have available time, as well as recognising the diversity of the student cohort, are two challenges that will need to be explored. However, other challenges such as wavering motivation, power imbalances and lack of clarity will also be discussed in later chapters (Chapter 8 and 9) as part of the key findings of this research.

\section{Locating the gap}

This chapter summarised a wide variety of literature on what is co-creation, what are key considerations and stages, adopting in other industries and contexts, how co-creation links to similar terms such as participatory design, how co-creation relates to similar terms in higher education, and the challenges may arise from co-creation being used as a lens in the higher education context. From this review, there are three key areas that the study aimed to explore as it investigated the nature of co-creation in higher education. 
The first area the study paid special attention to is how co-creation is adopted in higher education. As can be seen from the various stages of co-creation in industry and the ways co-creation has been applied to a wide variety of fields, co-creation can take numerous forms. It is of note therefore that the ways in which the study finds co-creation to be occurring in the higher education is already a useful finding. To date, much of the similar terms to co-creation in higher education, such as SaP has been explored predominately in teaching and learning contexts (Peseta et al., 2016). However, as this study later explains in Chapter 6, only two of ten cases of co-creation included in the study took place in a traditional classroom setting and two cases were distinct from teaching and learning contexts altogether (enrolment and social media).

The second key area this study aimed to explore is how co-creation may or may not enhance value in the student experience. There are concerns that by allowing students to co-produce their experiences, higher education may take on a 'consumer' approach to the way in which we treat our students. In relation to the similar concept of student voice, Rudduck (2006) points out that the zeitgeist commitment to student voice is actually reinforcing the fears in the higher education sector that students are becoming consumers and thus, will always be right. This is a possibility and thus the study analysed the results in Chapter 8 to discuss if co-creation could, in fact, lead to elevated levels of consumerism in higher education.

Finally, the last area the study aimed to explore in relation to the nature of co-creation was the barriers and challenges to co-creation. The study presented here took a critical lens to evaluate how student co-creation could benefit, but also potentially hinder the student experience. Research to date has been very positive about the benefits of student cocreation without enough concern for the challenges that partnership may bring and the need to understand the pitfalls of student partnership as well (Seale, 2010; Shah \& Nair, 2006). Thus, the research relating to student co-creation needs to be less descriptive and more evaluative (Seale, 2010). All three of these gaps were explored within this research in the hopes to contribute to the current field of literature and help further understand how co-creation can be adopted in higher education.

As students and higher education institutions both want to improve the student experience more approaches to support improvement, such as co-creation, need to be explored. 
Institutions are motivated by their desire to find additional revenue, as government subsidies are reduced, and global competition grows (Altbach, 2015; Frasquet, Calderón \& Cervera, 2012). To attract and satisfy students, universities are applying concepts formerly confined to business, such as relationship marketing theories, that help facilitate organisations to build strong relationships with their consumers (Schlesinger, Cervera \& Iniesta, 2015). Students, meanwhile, have shown interest in playing a more active role in their higher education experience as partners (e.g. Bovill \& Felten, 2016; Healey, Flint \& Harrington, 2014). Motivated by growing tuition fees and graduate employment concerns, students are looking to find value in their degrees that will satisfy their current and future needs (Tomlinson, 2017; Vickers \& Bekhradnia, 2007). Yet while both institutions and students are motivated to improve the student experience, there are few pathways to help them do so collaboratively. In this literature, therefore, co-creation was put forth as a mechanism to improve the student experience for both students and institutions. In the following chapter, a model for co-creation in higher education is discussed as the basis for investigating co-creation through ten case studies. 


\section{Chapter 4. Conceptual Framework of Co-Creation for Higher Education}

\section{$\underline{\text { Introduction }}$}

The literature in the previous chapter discussed the foundations of co-creation, both theoretical and conceptual. From the consideration of these factors, this chapter builds a conceptual model for co-creation specifically in regard to the higher education context ${ }^{3}$. Included within the chapter is a review of how co-creation has been conceptually framed in previous studies outside of higher education. The chapter also aimed to discuss in-depth what indicators and predicted benefits were included in the conceptual model of cocreation and why. The review of each of the indicators and predicted benefits individually and discussion of their relevance to the higher education sector is also included. Ultimately, the model for assessing co-creation in higher education that was used in the research design is presented (Chapter 5).

As will be discussed in the discussion and conclusion chapters of the dissertation (Chapters 8 and 9), the model for co-creation in higher education was modified after empirical data was collected. The modification of the model presented here, and the model presented post-data analysis further stresses the need for this particular study and also the importance of context when exploring the nature of co-creation.

\section{Previous relevant models on co-creation}

Previous studies seeking to quantify, describe and/or better understand co-creation have been limited to date because of the abstract and rapidly changing parameters of cocreation. For example, the most widely used conceptual model, DART (Dialogue, Access, Risk Assessment, Transparency) (mentioned earlier in Chapter 3 by Prahalad \& Ramaswamy, 2004) is only a simple environmental indicator for co-creation and lacks not only key considerations that have more recently emerged, such as culture, which is in increasingly identified as important factor (Cova, Dalli, \& Zwick, 2011). Further much of the research on co-creation does not assess co-creation as both a process involving co-

\footnotetext{
${ }^{3}$ The major components of this chapter including the model for co-creation in higher education have been published. Citation: Dollinger, M., Lodge, J., \& Coates, H. (2018). Co-creation in higher education: towards a conceptual model. Journal of Marketing for Higher Education, 1-22.
} 
production and value extended beyond the value chain (Ranjan \& Read, 2016). Previous studies seeking to create taxonomies for co-creation are also limited in their applicability. For example, Zwass (2010) attempted a complex taxonomy. First co-creators are categorised by type of performer (e.g. prequalified individuals or community members) and then by motivation (e.g. passion, career advancement, or financial rewards). Next the process is informed by governance type, including incentives and IT support. The task characteristics are also integrated such as structural complexity and time frame. Finally, the co-creation value is divided by autonomous co-creation or sponsored co-creation by the organisation. However, taxonomies in co-creation may be limiting to ongoing research as forms of co-creation may continue to emerge (Ramswamy \& Ozcan, 2014). Further, the types of co-creation in the future will undoubtedly rest on the technology available and attempts such as Zwass (2010) do not include technology as a consideration.

Malone, Laubacher and Dellarocas (2009) have also put forth co-creation as a collective intelligence genome, developed at the Centre for Collective Intelligence at Massachusetts Institute of Technology. Focusing solely on co-creation through the use of technology platforms such as Netflix (a movie watching platform) and Facebook (a social media platform), Malone and colleagues have identified 'genes' or factors of co-creation that play off one another as dominant or recessive, much like human genes (Malone, Laubacher \& Dellarocas, 2009). For example, if the question is 'who creates', the genes are 'crowd vs. hierarchy'. Or if the question is 'how to create' the genes are 'collection vs. contest vs. collaboration' and so forth. This research relies too heavily on technology, however, and as discussed earlier co-creation in the higher education context does not always occur through the use of digital platforms (e.g. Healey, Flint, Harrington, 2015).

Yet the contribution of the previous studies within this research highlights the variety of research that exists, much of it focused on the types or classifications of the co-creation process. For example, Yi and Gong (2013) found various types of customer-led cocreation including feedback, advocacy and helping. Other research has sought to classify staff-led co-creation, with Merrilees, Miller and Yakimova (2017) suggesting several types including proactively helping clients, providing new ideas, and initiating in their spare time (as a form of advocacy). Research has also explored contingency frameworks for supporting co-creation, for example, explaining a firm's ability to absorb capacity that leads to knowledge creation resulting from co-creation (Kazadi, Lievens, Mahr, 2016). Finally, 
research has also questioned the motivations and ethical implications of co-creation, exploring how users feel in the process of co-creation and if they feel they should have ownership in the anticipated outcomes (Arnold, 2017). These emerging studies suggest that co-creation is a complex and multifaceted concept. Due to this, this study strove to explore co-creation in higher education openly. As Maul (2017) argues in a recent methodological piece, research projects that too quickly initiate measurement processes without suitable conceptual frameworks are scientifically unsound. Therefore, as cocreation is complex, and rarely applied to higher education, this study used an iterative process of literature review, open-ended questionnaires, and interviews to capture the full phenomenon of co-creation (more on research design in Chapter 5).

\section{$\underline{\text { Co-creation conceptual components }}$}

Missing from previous research on co-creation is a way to benchmark co-creation through indicators that do not impose categories or binary factors. Co-creation is still a developing concept and should be approached with a wider net, especially within novel contexts such as higher education. As such, an aim of this research utilised recent literature that found co-creation is comprised of two distinct constructs, co-production and value-in-use (ViU) (Ranjan \& Read, 2016). Therefore, in this chapter, co-creation was conceptualised as a third-order construct, with co-production and value-in-use as second-order constructs. Both second-order constructs additionally have first-order constructs (see Table 1). 
Table 1. Summary of Indicators for Co-Creation

\begin{tabular}{|c|c|c|}
\hline Second-order construct & First-order construct & Purpose of indicator \\
\hline \multirow{3}{*}{ Co-Production } & Knowledge Sharing & $\begin{array}{l}\text { Extent to which students- } \\
\text { stakeholders could } \\
\text { combine resources }\end{array}$ \\
\hline & Equity & $\begin{array}{c}\text { Extent to which students } \\
\text { were allowed access and } \\
\text { relevant information }\end{array}$ \\
\hline & Interaction & $\begin{array}{c}\text { Extent to which students } \\
\text { could interact with } \\
\text { stakeholders }\end{array}$ \\
\hline \multirow{3}{*}{ Value-in-Use } & Experience & $\begin{array}{c}\text { Extent to which students } \\
\text { and stakeholders valued } \\
\text { the experience }\end{array}$ \\
\hline & Personalisation & $\begin{array}{l}\text { Extent to which students } \\
\text { and stakeholders could } \\
\text { personalise the experience }\end{array}$ \\
\hline & Relationship & $\begin{array}{l}\text { Extent to which } \\
\text { relationships formed or } \\
\text { grew from the experience }\end{array}$ \\
\hline
\end{tabular}

\section{Co-production}

Co-production is one component of co-creation. Defined by Lusch and Vargo (2006) coproduction is a process that allows for consumer resource integration very early in the value chain of production, where consumers knowledge, experiences and opinions can influence the creation of the service or product. Thus, co-production rests on many of the same principles as co-creation, such as active participation with the consumer (Auh, Bell, McLeod \& Shih, 2007) and continuous dialogue that facilitates collaboration (Grönroos, 2012; Lusch, Vargo \& O’Brien, 2007; Prahalad \& Ramaswamy, 2004). Within coproduction, consumers can be thought of as partial employees or part of the production team (Lengnick-Hall, 1996; Nuttavuthisit, 2010). 
However, co-production does not fully encapsulate the co-creation process, as it does not discuss value post-production. Co-production is just one part of the co-creation process (Ranjan \& Read, 2016). Researchers have also further posited that co-production can break down into three additionally constructs: knowledge sharing, equity, and interaction (Ranjan $\&$ Read, 2016). Yet these constructs have not been modified to a higher education context. To understand this more, the next section presents the underlying constructs of coproduction and their modification for the higher education context.

\section{Knowledge sharing}

Sharing knowledge between users and organisations is a critical mechanism in the coproduction process as it helps identify current and future needs (Gibbert, Leibold \& Probst, 2002). Knowledge sharing is how organisations and consumers combine their knowledge and skill sets to achieve greater innovation (Ramirez, 1999). Gibbert, Leibold and Probst (2002) found that organisations that participate in knowledge sharing practices were more likely to predict future market opportunities, improve established processes and create more value for the organisation, shareholders and consumers. Numerous authors also note that, in order to gain a competitive edge more companies are including consumer knowledge in the developing of services, products and marketing (Cova \& Dalli, 2009; Prahalad \& Ramaswamy, 2000). Fisher and Smith (2011) give the example of Google, a company that now encourages consumers to 'hack' or develop their current offerings. Research further shows that the knowledge organisations extract from consumers often results in more desirable outcomes than if the organisation had worked independently (Enz \& Lambert, 2012; Ramirez, 1999).

However, while knowledge sharing is growing in industry, it is not as commonly found in higher education. Instead, higher education institutions often adopt a traditional manufacturing mindset, where consumers are given little information or power to change the production (i.e. teaching) process (Spohrer \& Maglio, 2008). Higher education as a traditional organisation, therefore, may be less flexible and slower to change than other kinds of organisations (Bowden, 2011). Yet as the higher education market grows more competitive, user resource integration through knowledge sharing may help innovate institutions. Von Hippel (2005) has written that consumers who experience specific problems within their daily lives are the same people who are most suitable to solve those problems. For example, the student who struggled within the higher education system is 
the same student who might offer the most insightful guidance on how to improve upon it. Cook-Sather, Bovill and Felten (2014) adds while students are not disciplinary experts, they are experts at being students ${ }^{4}$, and therefore, have the ability and knowledge necessary to contribute meaningfully to advancement of practice. If institutions allow students to share knowledge more freely this may help them to innovate their service while avoiding future risks (Spohrer \& Maglio, 2008).

Equity

Yet while knowledge sharing is key to facilitating co-production, the process cannot take place without also user access, otherwise known as equity, which allows users of the organisation to offer knowledge and resources (Gummesson, 2002; Vargo \& Lusch, 2008). However, research examining the role of equity in co-creation has found that equity is difficult to achieve and, in most organisation-consumer relationships, is unlikely to meet a mutual level of reciprocity (Fisher \& Smith, 2011). In fact, the ability for the organisation to provide equal access to consumers may be contingent upon two factors. First, Prahalad and Ramaswamy (2002) write that an organisation's ability to provide equity to their consumers is often deeply rooted in the organisation's self-interest and willingness to relinquish control. Secondly, Payne, Storbacka and Frow (2008) further found that equity is closely linked to the organisation's ability to provide a supportive environment for consumers.

The difficulty of creating equity in co-creation is not a problem limited to just industry, either. Literature on student engagement for example has shown that institutions often do not address to distribution of power between students and institutions (Healey, Flint \& Harrington, 2014). Higher education has also struggled to include all students, not just limited lead users, within student participation and engagement activities (Healey, 2014; Kahu \& Nelson, 2018; Kuh, 2007). Felten et al. (2013) additionally found that without balanced access and roles in higher education contexts, co-creation with students may actually progress inequity among students.

\footnotetext{
${ }^{4}$ This claim is highly contested, as there is also much evidence that highlights students are not experts are students, such as attrition rates. Perhaps a middle ground would be to argue that students are experts in their own perspectives and prior experiences. As such, regardless of how well trained a teacher is in pedagogy or learning design, it may still be beneficial for them to consistently co-create with students to inform their knowledge base and stay grounded in what students think.
} 


\section{Interaction}

Interactions between stakeholders in the co-creation process are also an important indicator of the level of co-production as well, as interactions facilitate knowledge sharing and equity (Grönroos, 2006; Payne, Storbacka \& Frow, 2008). Without interactions organisations and consumers cannot maintain continuous dialogue or establish trust (Pluijm, 2010; Prahalad \& Ramaswamy, 2004). Interactions help team building and some scholars have compared interactions between stakeholders as a process similar to alliance building (Kale, Dyer \& Singh, 2001; Vargo, Maglio \& Akaka, 2008).

Moore and Bowden-Everson (2012) note that interactions between institutions and students will become increasingly important in the future as interactions can improve institutions knowledge about their students and also help improve student retention. Further, as higher education marketisation grows, interactions with current students could help institutions understand prospective student needs and goals as well (Helgesen, 2008). Institutions that foster interactions between multiple stakeholders will help align asymmetrical knowledge that otherwise might lead to underappreciated services, courses, or policies (Von Hoppel, 2009). Therefore, through co-creation students' differing knowledge and resources can jointly interact with university faculty and staff to further create more integrated and superior outcomes than if only one group tried to satisfy the needs of the other alone (Frow et al., 2015; Von Hippel, 2009; Zwass, 2010).

By evaluating knowledge sharing, equity and interactions in selected higher education activities, this research will, therefore, be able to assess the level of co-production in the activity. However, as Vargo and Lusch $(2004 ; 2008)$ note, co-production while allowing consumers to integrate their resources in the value chain, is predominantly controlled by the organisation. It is the organisation that can decide how, when and to what extent consumers can co-produce with them. Therefore, co-production is not sufficient to describe the process of co-creation (Ranjan \& Read, 2016). Co-creation research also needs to include what happens to products and services once they have been produced, into how they are used. 


\section{$\underline{\text { Value-In-Use }}$}

If co-production is the process that occurs between users and organisations during service design and delivery, value-in-use can be thought of as what happens to the value for both users and organisations once they start using the service or product. Value-in-use (ViU) is a term that originates from service-dominant logic (SD-Logic) (also mentioned in Chapter 3). First espoused by Vargo and Lusch (2004), ViU explains that all products or services are value-free until the consumer imposes value upon them. SD-logic emphasises the intangibles and relationships as key factors in the value creation process. Therefore, true value of the exchange is the application of the resource by the consumer (Vargo et al., 2008).

$\mathrm{ViU}$ is related to how consumers consume or use the products or service provided for them through their time, location, experiences, and stories (Vargo \& Lusch, 2004; Fisher \& Smith, 2011). Thus, because ViU relies heavily on the consumers' usage to derive value, it is especially interesting to apply to the higher education context. As higher education is a 'credence' good, whereby the students are unable to know the value of their educational experiences or their degree qualifications until they have graduated and left the higher education environment (van Vught \& Westerheijden, 2010). Ranjan and Read (2016) have uncovered three constructs as indicators for $\mathrm{ViU}$ : experience, personalisation, and relationship. These constructs are discussed below both in general terms and also with application to the higher education context.

\section{Experience}

The first indicator of ViU is the consumer's experience and how experience relates to the consumer's perceived value with the service or product (Lusch \& Vargo, 2006). User experiences with their services or products are important to not only the organisation but also the consumer. If the experience is positive, the consumer is more likely to form a positive relationship with the service, product, or even the organisation (Füller, Hutter \& Faullant, 2011; Prahalad \& Ramaswamy, 2003). This will later impact consumer's future behaviour with the product or service (Payne et al., 2008). However, consumer experiences not only impact the likelihood of the consumer returning but also impacts if they choose to promote the organisation to other users and make future contributions to the development of service or product (Von Hippel \& Katz, 2002). Research also shows that 
consumers themselves benefit from positive experiences, as it can further increase the value of the service or the product for the consumer (Mathwick \& Ridgon, 2004).

In higher education literature, numerous scholars discuss the student experience. Shah and Richardson (2016) define the student experience as students' learning experiences, regardless of the mode of delivery. However, increasingly the term "the student experience" is focused on the ways students can actively participate in higher education and even take on consumer-type roles (Furedi, 2010). This has spawned a research stream of its own, some in favor of students taking on more consumer-type roles (Bowden, 2011), and others not (Furedi, 2010; Molesworth, Nixon, Scullion, 2009). Yet as the higher education market grows more competitive, student experiences may continue to be an important indicator to understand the quality of the service and students' perception of the value of their education (Shah \& Richardson, 2016).

\section{Personalisation}

ViU includes not only user experiences with the service or product but also how they can further personalise the service or product to their own usage (Ranjan \& Read, 2016). Unlike co-production where the personalisation or consumer preferences are integrated at the start of the production process (Grönroos \& Voima, 2013; Ramaswamy \& Ozcan, 2014), personalisation in ViU occurs later in the value chain (Vargo \& Lusch, 2008). The product or service has been created (or perhaps co-produced) and now allows for consumers to additionally alter or impact the usage, meaning, or value (Cova et al., 2011).

Users, whether they be traditional consumers in an industry (Fisher \& Smith, 2011) or students within higher education (Healey, Flint \& Harrington, 2014) have increasingly shown interest in being able to personalise their experiences. Thus, more organisations are acknowledging that many consumers want to be change their products or services after their purchase (Prahalad \& Ramaswamy, 2000; Ramaswamy \& Ozcan, 2014). Muniz and Schau (2005) explain that consumers in some circumstances can actually piece together their own products or services, given the raw parts, not in a superficially or predetermined fashion, but to their own individual and unique needs. In higher education, personalisation through ViU would also allow for students to piece together services, such as degrees or courses, within their higher education experience to suit their own needs or desires. Research on personalisation in higher education so far has been defined as more similar to 
customisation, such as a student usage of e-learning platforms (Ozkan \& Koseler, 2009). However, the term used in co-creation is more suited to describing how students can modify the service and experiences of higher education to their own needs, such as flexible education trends like mixed mode delivery courses (Kim \& Bonk, 2006) or alternate timetabling options (Burton \& Nesbit, 2008).

\section{Relationship}

The third indicator of $\mathrm{ViU}$ is the relational construct. While interactions and relationships may imply similar terms, they are distinct (Carù \& Cova, 2003). Interactions in coproduction are a mechanism for communication that later impacts relationships. Relationship as an indicator also differs from experience and personalisation as it can more strongly impact a user's overall perceived value with the product and/or service (Bonsu \& Darmody, 2008).

In higher education, the student's relationship to their institution can impact their feelings towards their entire institution and their higher education experiences (Carini, Kuh \& Klein, 2006). Student's positive relationships with their institutions can also create a community (Zhao \& Kuh, 2004) that may later predict future collaborative behaviours. As co-creation builds underlying aspects of relationship formation, such as continuous dialogue and balanced roles (Prahalad \& Ramaswamy, 2004), it may have the unique capability to improve students' relationships with their institutions. Just as in the private industry, research shows that students believe they are in a communal relationship with their institution (Yang, Alessandri \& Kinsey, 2008). Yet while research to date has mostly focused specifically on student-faculty interactions and peer interactions, only a few studies have looked at the nature and quality of interactions, which are more likely to predict students' relationship with their institution (Pascarella \& Terenzini, 2005). Moreover, research has shown that students' value of the higher education experience and overall relationship to their institution is significantly affected by the quality and frequency of their student-faculty interactions (Hu \& Kuh, 2003; Tierney, Corwin, \& Coylar, 2005).

Student relationships in higher education are often built on trust, commitment and loyalty to the faculty or the institution (Bowden, 2011). Additionally, relationships may be impacted by not only classroom experiences but also out-of-classroom contexts of social interactions (Padgett, Keup \& Pascarella, 2013; Terenzini, Pascarella, \& Blimling, 1996). 
Therefore, through a co-creation process where students have quality interactions with stakeholders both in and out of the classroom, students' relationships may be impacted.

\section{Mapping the predicted benefits of co-creation}

The aim of this chapter was to understand how higher education co-creates and also the benefits of co-creation. This is key in the higher education context as services are often catered towards the student experience without mind towards a larger institutional purpose or goal, or for institutional purpose without enough attention placed on the student experience (Judson \& Taylor, 2014; Ng \& Forbes, 2009). Yet co-creation moves beyond the notion that services must be only for one or another group, and instead posits through the process of co-creation, experiences and activities can benefit multiple stakeholders.

Benefits to student-staff collaboration in the higher education have begun to be explored (e.g. Cook-Sather, 2014; Bell, 2016; Matthews, 2017). However, much of this work is conceptualised through 'students-as-partners' which is a variation of the topic ${ }^{5}$ and does not include the underpinning constructs of co-production and ViU. Therefore, as the conceptual lenses vary from student partnership or student voice to co-creation the study instead used previous literature on co-creation to map the benefits within this study. However, benefits from other studies outside of co-creation (e.g. Cook-Sather, 2014) were still integrated to regard to specific benefits and discussed in the findings of the study. The three explored benefits included: innovation, knowledge, and relational (see Reypens, Lievens, Blazevic, 2016). These broad categories were useful to apply to higher education because benefits of co-creation in higher education have not been widely studied and therefore too specific of parameters might have missed important outcomes. It is important to note that these three benefits often overlap and intertwine with one another.

\section{Innovation}

The first expected benefit of co-creation that was explored in this research was innovation, or how the offerings and services of higher education can be improved and developed through a co-creation process. In industry literature on co-creation, innovation is frequently discussed a benefit from the process, as valuable information often resides

\footnotetext{
${ }^{5}$ As previously discussed in Chapter 3.
} 
within the consumer/user, hidden from the producer or organisational members (Thomke \& Von Hippel, 2002). Similarly, producer knowledge on how systems or productions operates is hidden from the user, limiting the users' ability to make meaningful choices or contributions. Thus, through an interaction such as co-creation, sharing knowledge, can result in improved services.

In higher education, innovation may relate to both technological and non-technological advancements. As learning technologies and e-learning continue to be developed in higher education, technological innovation through co-creation may be especially beneficial (Yuan \& Powell, 2013). Students may not be able to give feedback on technical aspects, but by sharing their experiences, technical aspects of e-learning can be modified and fitfor-purpose (Dollinger \& Lodge, 2018). Moreover, through co-creation students' personal ability to innovate may be impacted as student participation in innovative activities often impacts their autonomy and cognitive development (Martín, Potočnik, Fras, 2015). Innovation that may occur through co-creation in higher education includes improved learning and teaching practices for both students and faculty (Healey et al., 2014) as well as improved course design and learning resources (Gros \& López, 2016).

\section{Knowledge}

A second benefit that was explored in this research was how co-creation impacts knowledge. Knowledge, in this study, was not explored in content-specific ways, for instance, whether the student has a greater understanding a particular learning goal after co-creation. Instead, this study explored how general knowledge was impacted for both staff and students, for example, students' graduate capabilities such as self-efficacy and perception of employability. Graduate capabilities are skills that students can transfer or use in lifelong learning and their professional lives, including communication and leadership (Sumison \& Goodfellow, 2004). Previous studies have shown that those involved in co-creation can often report higher levels of confidence and even link their participation to future career paths (Navarro-García, Peris-Ortiz \& Rueda Armengot, 2015; Yi \& Gong, 2013).

In recent years higher education has become more focused on providing their students with graduate capabilities (Sin \& McGuigan, 2012). These skills can vastly range (Sin \& McGuigan, 2012). Examples of graduate capabilities include writing clearly and effectively, 
thinking clear and effectively, solving complex problems, and understanding different social contexts (Coates \& Edwards, 2009). A student with the ability to participate actively in institutional projects has also been shown to have more agency (Barnes, Slate \& RojasLeBouef, 2010) and enthusiasm for learning (SooHoo, 1993) that may impact their graduate capabilities. Through the process of co-creation, where students are jointly producing services or products with their institution, and therefore actively participating as well as taking on leadership roles, graduate capability may be impacted.

\section{Relational}

The third anticipated benefit that was explored in this research was relational. Higher education research has long focused on the importance of student-faculty interactions as key for creating student belongingness, engagement, or facilitating learning outcomes $\mathrm{Hu}$ \& Kuh, 2001; Kahu, 2013; Pascarella \& Terenzini, 2005; Tierney, Corwin \& Coylar, 2005; Yang, Alessandri \& Kinsey, 2008). Amongst this research, studies have shown that it is not only the frequency of interactions as an important indicator to the strength of studentfaculty relationships, but also the quality of the interactions in an authentic or meaningful context (Cox \& Andriot, 2009).

Student relationships with the faculty have also been shown to impact how they perceive their entire higher education experience (Komarraju, Musulkin \& Bhattacharya, 2010; Rosenthal et al., 2000). Further, quality interactions, like the ones potentially occurring through the process of co-creation, could help students understand their faculty and vice versa, building mutual respect (Schlesinger, Cervera \& Iniesta, 2015). Bowden (2011) additionally found that, while satisfaction and trust were critical to student loyalty, research often overlooks the important role of affective commitment, which may a stronger predictor than satisfaction. Moreover, Lundberg and Schreiner (2004) have actually found that faculty-student relationships are the only predictor of student learning across different cultural backgrounds.

Co-creation has the potential to positively impact student relationships because it has been shown to build trust and understanding through diverse stakeholders (Kale, Dyer \& Singh, 2001; Sheth \& Uslay, 2007). Co-creation also drives collaboration and relational exchanges between formerly separated producer and consumer categories (Yi \& Gong, 2013). 
$\underline{\text { Indicative Model Illustration }}$

This section introduces the exploratory model that was used to investigate co-creation in higher education. The model was constructed to address an important overarching question of this research, how can co-creation be assessed in the context of higher education? Model construction, therefore, helped to illustrate and evaluate the indicators and benefits of co-creation. The model subsequently breaks down the underlying indicators and benefits of co-creation to explain how the model was used in fieldwork. The model was also used to assess case studies selected through the research design. As elaborated further in the research design chapter, selected case studies were higher education activities that had varying types and levels of co-creation.

\section{Introduction to Model}

As discussed through literature presented in previous chapters, co-creation has rarely been applied in higher education (e.g. Elsharnouby, 2016; Flesichman, Raciti \& Lawley, 2015; Gros \& López, 2016) and thus there was need for a comprehensive model to better understand how co-creation occurs and adapts to the higher education context. Empirical analysis of co-creation in higher education using the model presented here helped to create a foundation for the complex process of co-creation in higher education. It further helped to highlight what indicators were present in specific activities included in the research and how these indicators relate to benefits. In the context of growing concerns about the quality of higher education and how students can be active participants in their higher education experience (Coates, 2016), this model also helps to better understand how cocreation can be utilised in higher education in order to assure better outcomes for institutions, faculty/staff and students.

The first part of the model addresses the indicators of co-creation in higher education to evaluate which activities, as selected through case studies, have elements of co-creation. Indicators are important elements when studying how a phenomenon occurs (Nardo et al., 2005). Indicators additionally provide benchmarks to understand the differences between types of co-creation (Nardo et al., 2005). Indicators in this model were explored through two underlying constructs of co-creation, co-production and ViU. These constructs as identified by literature (Ranjan \& Read, 2016) have three first-order 
constructs as well. Co-production indicators included knowledge sharing, equity and interaction. ViU indicators included experience, personalisation, and relationship.

Co-production indicators were designed to assess the type and extent to which students, faculty, and other stakeholders co-produced the activity. For example, knowledge sharing assesses how students and other stakeholders combined their resources, including physical resources, skills, and experiences to improve outcomes of the activity (Ramirez, 1999). Equity further indicates the extent to which students and other stakeholders were allowed to access the activity and/or information relevant to the activity (Gummesson, 2002). Finally, interaction indicates how interactions between students and other stakeholders not only facilitated knowledge sharing and equity but also how interactions established dialogue and built trust (Payne, Storbacka \& Frow, 2008).

ViU indicators additionally assessed how the activity was later used and valued by students and other stakeholders. The three underlying indicators of $\mathrm{ViU}$ are used to evaluate the process. For example, the first indicator, experience, assesses how the students and stakeholder experiences formed in relation to their participation in the activity (Lusch \& Vargo, 2006). Personalisation further assesses how the student and stakeholders could personalise the activity to their own preferences and/or needs (Vargo \& Lusch, 2008). The relationship indicator lastly assesses how the activity impacted the relationship between students or between students and stakeholders (Bonsu \& Darmody, 2008). The second part of the model explores the benefits of co-creation also as identified by literature (Reypens, Lievens, Blazevic, 2016). These benefits were explored through co-created higher education activities to further understand the impacts of co-creation on multiple stakeholders. Benefits identified by Reypens, Lievens and Blazevic (2016) and adapted here for the model include innovation, knowledge, and relational. Innovation benefits included how the co-creation activity resulted in solutions, new ideas or processes within the activity, or new products or activities stemming from the original activity (Reypens, Lievens \& Blazevic, 2016). Knowledge benefits sought to understand how the co-creation activity impacted graduate capabilities, such as critical thinking and perspective taking (Coates \& Edwards, 2009). Knowledge benefits were also applicable to other stakeholders in the co-creation activity including teachers and/or staff who may have deeper knowledge about their students or about their roles through taking part in the activity. The research 
also evaluated relational benefits, or how the co-creation process impacts students and other stakeholder relationships to each other and to their institution more generally.

To note, the study explored the benefits discussed above, but also through empirical research, the study presented here was also able to identify the benefits of co-creation in more detail. For example, student ownership was found to be a benefit but was not included in the conceptual model presented here. More on this will be discussed in Chapter 8 , but it was important that the model which was used in the data collection of this study was presented here, to help demonstrate where the study began and how it developed over time. 


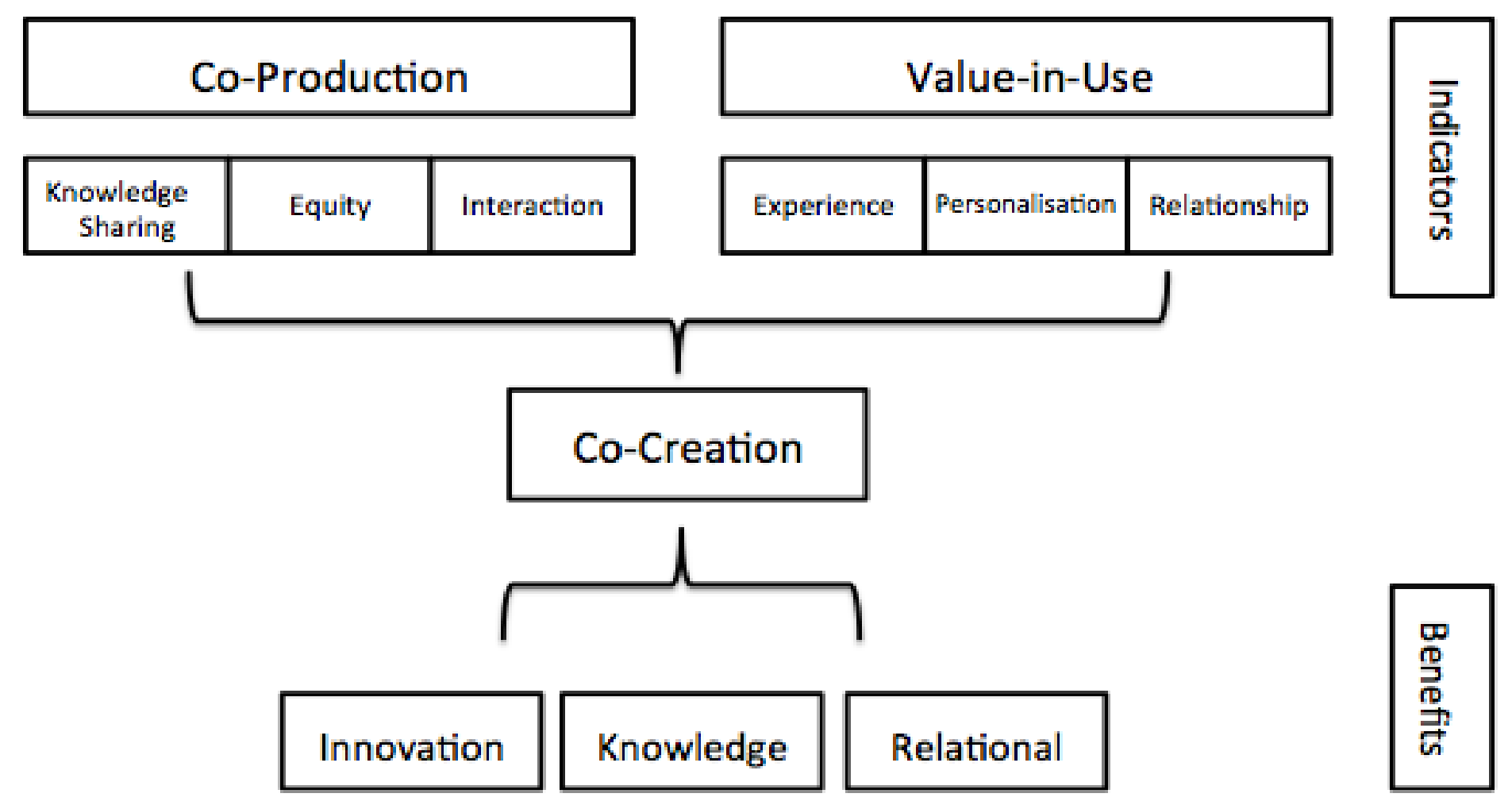




\section{Assumptions and Limitations}

The model presented here, similar to many models and frameworks, is subject to several assumptions and limitations. This study took measures to ensure assumptions and limitations were minimised when possible. For example, to reduce the likelihood that previous experience or background factors influenced students or stakeholders' participation in a co-creation activity, all participants were asked demographic questions and were questioned about their previous cocreation related experiences ${ }^{6}$. Another important assumption to note is that the model was constructed using literature that is largely outside of the higher education context. Therefore, it is implicit in the research, that the model assumes the indicators and benefits of co-creation in other industries are similar to the indicators and benefits of co-creation in higher education. However, as this model was tested empirically, eventually the findings of the study showcase how the model above relates to the higher education context, and if the benefits in the model above are similar to the ones found in higher education (see Chapter 9).

Limitations in the model relate closely to the research design, which is discussed further in the coming chapter. The research was only able to select a fixed number of activities in higher education to evaluate for co-creation, therefore, limiting the generalisability of the findings. Further, due to the constriction of time allotted to the research data collection, it is unknown if the benefits of co-creation change over a longer period of time ${ }^{7}$.

\section{$\underline{\text { Summary of Conceptualisation of Co-Creation }}$}

Growing numbers of studies on co-creation in higher education (e.g. Elsharnouby, 2016; Flesichman, Raciti \& Lawley, 2015; Gros \& López, 2016) allude to the potential co-creation might have in the field. Moreover, Pinar, Trapp, Girad, Boyt (2011) write that many of the challenges facing higher education stem from a misunderstanding between students and other stakeholders and an inability to understand one another's perspectives, that could be positively impacted through facilitating co-creation processes. Therefore, more research is needed on how co-creation occurs and impacts in the higher education context.

\footnotetext{
${ }^{6}$ This actually became a major finding in the study, that previous experiences of co-creation or other collaborative experiences were prominent in many staff and students' participants.

${ }^{7}$ Evaluating the benefits of co-creation over five or ten years, however, would be a useful contribution to the field in the future.
} 
Yet research on co-creation thus far has not adequately acknowledged its complex underpinnings (Grönroos, 2011; Ranjan \& Read, 2016). Co-creation is a multi-dimensional concept. It includes both co-production of value, where the service and/or product are created alongside the consumer, and also value beyond production into the consumption of such value; a concept from service-dominant logic known as ViU (Kristensson, Matthing \& Johansson, 2008; Lusch \& Vargo, 2006). This study attempts to address this through thoroughly conceptualising co-creation before collecting empirical data and creating a lens to understand the benefits of co-creation that may be uncovered through case studies. As noted, the study investigated the benefits of co-creation through three established benefits of co-creation in other fields including, innovation, knowledge, and relational outcomes (Reypens, Lievens, Blazevic, 2016). Ultimately, by better understanding how co-creation exists in higher education and the benefits it may bring, the study attempts to understand the potential value of co-creation and its applicability in the field. 


\section{Chapter 5. Research Approach and Design}

\section{Introduction}

This chapter aimed to introduce the research approach and design that was used in the study. Included in the chapter are research questions and researchers' worldview that guided the study. Following which, the research methodology of case study as the appropriate method for this study is justified. Research steps are also discussed, which help to explain the steps that were undertaken in order to design the study, validate the instruments, collect data, and code and analyse the data towards model development. The chapter ends with a discussion on the implications and limitations of the design, including the rationale and limitations of qualitative methods, how trustworthiness was established, and the ethical procedures undertaken in the study. Finally, a discussion which links the research questions to the research methods is presented as a summary to the research approach and design.

\section{$\underline{\text { Research Questions }}$}

The aim of the study was to explore how student contributions (also defined in this research as 'student resources') could be integrated into a higher education context through the conceptual lens of co-creation. Important to note in this is that there are several terms relating to student contributions that are used within literature, including students' resources (e.g. Ryan \& Ryan, 2013; Walker \& Zhu, 2008) and students' capabilities (e.g. O’Neill \& Palmer, 2004). Bovill et al. (2016) has written that within this discussion, it is most critical to remember that student contributions, or resources, are different than those of a staff member. For example, a student may contribute their personal experience to enhance a co-created curriculum, while a teacher may contribute their expertise in pedagogy.

The focus of the research was to explore the co-creation phenomenon in an effort to uncover more about the nature of co-creation between students and university faculty/staff. To explore this, two research questions were developed and investigated, which helped to investigate the overarching research question of this study, see below:

I. What is the nature of co-creation in higher education?

A. How is co-creation occurring in higher education within the Australasian context? 
B. What are the outcomes (i.e. benefits) and barriers of co-creation in higher education within the Australasian context?

To investigate the first research question, the study would need to explore the contexts and spaces in which co-creation in higher education occurs, and also the antecedents and environmental factors that may facilitate co-creation. The study also aimed to analyse the types and levels of cocreation. Meanwhile, to explore the second research question, the study aimed to evaluate the benefits of co-creation, for both institutions and students as well as the barriers. These research questions can be thought of as looking at the 'inputs', 'process' and 'outcomes' of co-creation to develop an understanding of the nature of co-creation in higher education.

\section{Researchers' Worldview}

A rigorous research design must be situated within a philosophical worldview (also known as research paradigms, see Lincoln, Lynham \& Guba, 2011) that helps provide a framework for describing and justifying the research design choices. Although in many research design chapters the philosophical worldview remains hidden (Mackenzie \& Knipe, 2006; Slife \& Williams, 1995) worldviews have a large influence on the design in practice. Creswell (2014) writes there are four main worldviews utilised by researchers, including: postpositivist, constructivist, transformative and pragmatic. The postpositivist worldview is also known as the scientific method (although not exclusively the only method that is 'scientific') and its major elements include: determination, reductionism, empirical observation and measurement, and theory verification, for this reason, it is often the selected worldview for quantitative research. Transformative worldviews, on the other hand, are often political, power and justice oriented, and change oriented, and therefore, lend themselves to research perspectives such as racialized discourses and queer theory (e.g. Dilley, 1999).

Considering the best approach to frame this research, I have consulted literature and found the most appropriate frame to be a social constructivist approach. The constructivist approach, situated in an interpretive paradigm (sometimes considered the constructivist/interpretive paradigm, for example, see Mackenzie \& Knipe, 2006), has the central goal of seeking to understand the social world (Higgs \& Titchen, 2001). As this research is seeking to understand the nature of co-creation, an approach that is based on the notion that there are multiple constructed realities or several versions of reality, the constructivist approach is most suitable (Crotty, 1996). 
Social constructivism (there are multiple forms of constructivism see Bodner \& Klobuchar, 2001) is further relevant in this study as it focuses on how social interactions influence the process by which knowledge is constructed (as opposed solely within an individual's mind). By selecting a constructivist worldview this research attempts to build an understanding, through multiple participant meanings (e.g. student vs. faculty/staff perspectives) and use the data collected for theory generation, as co-creation is a relatively new phenomenon.

\section{Research Methodology: case study}

Case studies are a suitable method for exploring multiple perspectives within an interpretive paradigm. As defined by Gerring (2004) a case study is "an intensive study of a single unit for the purpose of understanding a larger class of (similar) units" (p. 341). Yet, common to the case study approach is a multiple case study (sometimes also known as a collective case study), where several cases are studied. This approach is useful when studying a phenomenon that occurs in several different- yet related- contexts (Baxter \& Jack, 2008; Creswell, 2002). For example, in the research design presented here, co-creation occurs in several different activities (e.g. cases) across several universities but all within higher education. One downside to a multiple case study approach is the time often imposed on the researcher(s) as it requires an in-depth understanding of varying cases, yet the data collected is considered by most to be 'robust and reliable' (Baxter \& Jack, 2008). However, the multiple case study method is the best approach when looking for replication of the same phenomenon across several cases (Yin, 2009) and for this reason it was selected.

Each case within a multiple case study approach is understood as the research design's sample (Gerring, 2004). Stake (1995) writes that for case study research design, "nothing is more important than making a proper selection of cases" (p. 243). Case studies, unlike other forms of research, benefit from instrumental or manually selected case studies that highlight the alternatives of the research theme and allow for greatest amount of variation (Stake, 1995; Yin, 1994). Case study design is often improved by the purposeful sampling methods that allow for atypical cases, and thus, deeper understanding of the phenomenon (Yin, 1994). As this study used purposeful sampling methods, informed by expert consultation, the cases selected were optimally chosen to ensure a range of activities to compare. Purposeful selection also ensured that a full range of types of cases, including emerging contexts for co-creation to occur, would be included. Additionally, the case studies selected in this research are referred to what Gerring (2004) noted as crosssectional or without an explicit temporal component. This is common in case studies designs 
where it is often impractical to be both across units (multiple cases) and also across extended periods of time (Gerring, 2004). Therefore, in this design each case was studied in one-time frame to provide a 'snapshot' of the case (see Jensen \& Rodgers, 2001).

A case study approach was also chosen for the research design as it is appropriate when the research question is seeking to understand the 'how' and 'why' questions of the phenomenon (Perry, 1998; Yin, 2003). This relates to the research topic of co-creation, because while the phenomenon has been investigated in industry or public governance contexts (see Chapter 3), there remains much to be explored in the higher education context. Yin (2004) elaborates by noting that case studies are useful when the phenomenon is in the early stages and not much literature to date has mapped the landscape, as is the case for co-creation in the higher education context.

While a limitation of case studies is the inherent difficulty of generalising the findings broadly across contexts, the approach also has many merits (Baxter \& Jack, 2008; Flyvbjerg, 2006; Gerring, 2004; Perry, 1998). For example, Flyvbjerg (2006) and Perry (1998) argue that case studies are especially appropriate for young researchers as they help scholars go from beginners to experts on a specific topic. Moreover, case studies allow for the generalisability of data through falsification, a precise form of data analysis, whereby if only one observation does not fit it may not be considered valid (Flyvbjerg, 2006). Thus, the atypical data often uncovered through case studies is critical when studying new phenomenon and generating hypotheses for further testing (Flyvbjerg, 2006). Case studies are also an interesting way to study a phenomenon such as co-creation because they allow for close interaction with the participants (Gibbert, Ruigrok \& Wicki, 2008). The researcher can more deeply understand that case and its participants, which can add depth to data analysis and also to help create practical and relevant suggestions after.

Therefore, the research design can be summarised as social constructivist approach or worldview, suitable for a case study method to purposefully select multiple cases of interest. All of this is suitable for a research topic that is seeking to explore the nature of co-creation in the higher education context.

\section{$\underline{\text { Research Steps }}$}

This section will explain the research steps unique to this study for clarity of the research design. The following steps were originally based on Dooley (2002) however have been lightly modified 
for the specific study. The steps include: literature review, expert consultation, case study selection, instrument creation and validation, data collection, data organisation, coding and analysis approach and model development.

\section{Literature review and research question formation}

The literature review is a key component of research and theory building (Creswell, 2014). Literature reviews are important not only because they help the researcher gain an understanding of the concepts used in the research, but also because they set a foundation to begin forming research questions. However, literature reviews should not too strongly dictate the path of the research in a case study design, which is often exploratory (Perry, 1998). Instead, literature reviews main contribution can be to help the researcher form research questions, which can guide research approaches, design and steps (Baxter \& Jack, 2008; Perry, 1998). Key areas of literature review that were undertaken included: student experience, student engagement, student-staff partnership, and co-creation. The evidence of the literature review includes the previous chapters which highlighted how the research was framed and situated in the current literature.

\section{Expert consultation and review}

This study used purposeful sampling for case study selection meaning the cases were specifically chosen because they exhibited elements of co-creation, as informed by experts. Therefore, in order to make sure the purposeful sampling had justification, the study also integrated an expert consultation and review prior to select co-creation cases (results of which presented in Chapter 6). In October 2016, an online questionnaire went out to experts $(n=19)$ in co-creation in organisations or within higher education fields across Australia, Europe, the United Kingdom and the United States. Experts were asked first to define co-creation from their perspective and subsequently asked to rate typical student activities as having low, medium, or high potential of co-creation based on the experts' perceptions. Experts indicated several activities as high potential areas for co-creation including co-research with faculty $(\mathrm{n}=15)$, work-integrated courses $(\mathrm{n}=11)$ and student-centered tutorials $(n=10)$. These areas were highlighted to find cases to explore from. However, not all cases that experts highlighted as best cases for examining to low, medium or high potential of co-creation were able to be incorporated within this study due to availability of participants (see step 'case study selection' below). 
Case study selection was informed by both literature and also the expert consultation on the potential of co-creation to occur in certain higher education activities. The literature review and key articles such as Healey, Flint and Harrington's (2014) scan of students acting as partners in their higher education experiences were helpful in forming an initial understanding of what types of cases might be of interest in this study. The case study selection was also tempered by what was available to select from. While the expert consultation and literature review help inform what types of cases could be approached for the study, finding participants often did not align to this structure. Staff from cases that had low potential for co-creation (as informed by expert review such as lecture-style classroom setting) chose not to participate in the study, most likely because they did not believe they would yield positive results. The researcher, thus, had to select cases in which the lead faculty/staff member was willing to participate and allow for their students to participate. However, in the future, it would be useful to find cases of anticipated low levels of co-creation (e.g. a one-off short focus group with students on their perspective on an assessment item) to evaluate how the benefits of these cases align or divert from more developed co-creation cases.

Descriptions of all case studies were also collected. The initial description of the cases was formed through discussion(s) with the faculty/staff members who received the invitation to participate. The case study descriptions were further informed from the data results from the online instrument and interviews. Dependent on the types of cases sometimes document analysis was also available (e.g. co-authored publications, websites, grant applications) and sometimes even informal observation was available to the researcher. All available types of methods to ascertain a deep understanding of the activity or the case selected. Once the data collection was complete, aligning with qualitative member-checking procedures (Carlson, 2010), a copy of the description was given back to the initial faculty/staff member(s) to check that it was an accurate portrayal of the activity (i.e. member-checks). All case study descriptions and overview of the selected cases are included within Chapter 6 (the following chapter).

\section{Instrument(s) creation and validation}

For the first step of data collection, an online questionnaire was developed for eliciting qualitative data and descriptive characteristics. Following which, an interview protocol was then also developed. The instrument(s) underwent several steps before they were finalised including: 
- Literature review,

- Focus groups, and

- Cognitive interviews (i.e. interviews where participants read aloud questions to help researchers' gauge their understanding of the question).

Literature informed what qualitative questions were selected to be included. To keep the instrument organised, an excel file was created with several ways to organise the data including: item number, original item (from literature), source of original item, adapted item (if needed), and how it corresponded to a research question. Once the excel file was compiled, an indicative paperbased and corresponding online instrument was created and tested through focus groups and cognitive interviews. The five focus groups, each with four students $(n=20)$ helped pilot the development of questions/items, as well as test the style and format. The data from the focus groups further helped to identify ambiguities or missing elements. The participants involved in the focus groups were master's students studying design, who became available to the researcher through networks as the students were studying elements methodology at the time. They were recruited through a newsletter from their tutors where a call for participants was put out and then delivered via the tutors with a plain language statement and the consent form, if students wished to participate. All related activities were covered under the ethics application.

Following the focus groups, the latest version of the online instrument was piloted with cognitive interviews. Cognitive interviews are where the participants take the survey aloud, so the researcher can check for misunderstanding and pauses. Cognitive interviews have been shown in research to be a widely adopted tool that helps the researcher ensure each item on the instrument is working properly (Ouimet, Bunnage, Carini, Kuh \& Kennedy, 2004). In this step, five separate cognitive interviews took place, with students varying from bachelors, masters, to doctoral level and across several disciplines. Cognitive interviews also included international students, to test for the readability of the language. They were asked to take an online version of the instrument in a private setting, where they could read the questions aloud to the researcher and discuss their impression of the construct (consistent with cognitive interview approaches in Ouimet et al., 2004). During the cognitive interviews, questions were further identified as particularly interesting or debatable to participants, thus informing the later interview protocol.

Data collection I: qualitative (online) survey 
The data collection for this research utilised qualitative methods. In a case study design the researcher can collect varying types of data including open ended survey responses and interviews, which can then be processed analytically to converge on a deep understanding of the phenomenon at hand (Baxter \& Jack, 2008). These multiple sources can serve to improve the data credibility or validity of the data (Yin, 2003). This section will explain the two phases of the data collection including the online instrument and interviews.

The first instrument used in data collection was an online questionnaire that included both openended responses and descriptive Likert-style scale items (see Likert, 1932). The online instrument helped to form an initial understanding of the variability in perspectives across student and faculty perspectives (see Leech \& Onwuegbuzie, 2009). An online instrument was also more appealing and accessible to most participants within the case studies (Creswell, Plano Clark, Gutmann \& Hanson, 2003). As the study was aimed to ensure the maximise the number of participants for the widest range possible of perspectives, an online instrument that could be taken in under 20 minutes was feasible and suitable for both busy students and busy faculty/staff members. Yet if the instrument has been only descriptive Likert-scale items the research might run the risk of making too many assumptions (as questions were derived from literature outside of the higher education context) about the student or faculty/staff's perspectives and feelings towards the nature of co-creation, the study used mostly open-ended responses. Additionally, the sample, while including 10 case studies, still had relatively few participants per specific case. In fact, one case study of a single student co-researching with a staff member had only two participants. For this reason, collecting quantitative data would have been inappropriate (Jansen, 2010). Therefore, while some descriptive data was collected, it was not analysed in a typical quantitative method, such as frequencies. Jansen (2010) notes that when samples are small and spread out across variations (i.e. multiple case study approach) Likert-scale style questions should be used only for the researcher to understand the context more deeply, rather than establish frequencies or means. Bazeley (2004) further notes that when the number of participants is fewer than 20, frequencies are not appropriate.

The online instrument had four sections: 1) antecedents, 2) co-production, 3) value-in-use and 4) outcomes of co-creation. These sections were informed through a literature review and previously conducted data from expert consultation. As previously discussed in chapter 4, the study conceptualised co-creation as two parts, co-production and value-in-use. Any questions that were adapted from an existing source adequately pre-tested through focus groups and cognitive 
interviews to ensure transferability. The main parts of the online instrument are summarised in table below as they relate to the research questions.

Table 2. Summary of online questionnaire instrument ${ }^{8}$

\begin{tabular}{|l|l|l|}
\hline Section & Question Style & Informing \\
\hline $\begin{array}{l}\text { Previous exposure/existing } \\
\text { co-creation }\end{array}$ & Open-ended response & $\begin{array}{l}\text { How is co-creation occurring } \\
\text { in higher education? }\end{array}$ \\
\hline $\begin{array}{l}\text { Co-production }{ }^{10} \\
\text { Value-In-Use }\end{array}$ & Likert-scale & $\begin{array}{l}\text { How is co-creation occurring } \\
\text { in higher education? }\end{array}$ \\
\hline $\begin{array}{l}\text { Benefits/barriers to co- } \\
\text { creation (for students, } \\
\text { faculty/staff and institutions) }\end{array}$ & Likert-scale & $\begin{array}{l}\text { How is co-creation occurring } \\
\text { in higher education? }\end{array}$ \\
\hline
\end{tabular}

\section{Data collection II: interviews}

Following a social constructivist research approach (see Yin, 2003), this research was inductive to understand the occurrence of co-creation in higher education from several different perspectives that would later inform a model that is typical in an interpretive paradigm. While the online instrument was useful in order to maximise the number of participants and perspectives, semistructured interviews were also important to ensure the depth of data that is often found through qualitative methods, such as interviews. The interviews also allowed willing participants (all

\footnotetext{
${ }^{8}$ For a full copy of the online instrument, please see the appendix.

${ }^{9}$ Questions pertaining to participants' previous exposure, existing experiences and beliefs on student co-creation and benefits to co-creation were informed by previous literature, focus groups and cognitive interviews.

${ }^{10}$ Questions pertaining to participant's attitudes on the co-production or value-in-use of their experience (e.g. case study) were informed through a meta-study conducted by Ranjan and Read (2016) that analysed the elements of cocreation through two variables: co-production and value-in-use.
} 
participants who took the online instrument were invited to participate in an interview) to provide meaningful commentary about the topic and allow for them to further convey their perspectives and experiences (Yin, 2003). The interviews further allowed a different type of data to verify the findings of the online instrument and help triangulate the concepts and themes that would emerge (Corbin \& Strauss, 2008).

Through the focus groups, cognitive interviews, online instrument responses, and discussion with experts on student contributions in higher education an interview protocol came to form that aligned with the research aims of this study. As the research is broadly interested in the nature of co-creation across inputs, processes, and outcomes, the interview protocol was designed to stimulate participants to reflect on these aspects and offer additional insight that could not be provided in the online instrument. It was frequently found that participants noted that before taking the online instrument they had not deeply reflected on the activities co-creation elements, so the online instruments also served as a suitable precursor to the interview stage, helping participants reflect before the interview.

The four main questions in the semi-structured interviews included:

1. Please tell me about your participation in the experience. (E.g. your role; why join/why participate, etc.)

2. To what extent did students and faculty/staff contribute within this activity? (E.g. who had what responsibilities, protocol, processes of co-creation)

3. What do you believe the benefits of this activity were, both for students and for faculty/staff? In your opinion, how are they similar or different?

4. How (if any) recommendations would you make for this activity in the future? (E.g. identify barriers and suggest improvements)

All the interviews in the study were fully transcribed by the researcher herself. The task of transcription was aided by the fact the interview protocol was semi-structured and kept to just four main questions, with some smaller follow-up or clarifying questions added depending on the participant response. The interview protocol (see appendix), therefore, aligned to the broad research question, as well the sub-questions, and further aligned very closely to the questions asked through the online instrument. All of this helped ensure the data collected was more easily aligned to the other forms of data and could help build a strong, but focused, perspective. Semi-structured 
interviews were suitable in this research design as it allowed for probing questions that then could allow the participant to answer in their own words or comment on specific aspects that were meaningful to them (Harrell \& Bradley, 2009).

Before starting the interviews, participants were given a plain language statement and consent form to read and sign. They were also given a verbal explanation from the researcher on what the research was about and given some sample questions to help prepare them for the questions to be asked later. To help set the interview stage, it was important that the participants felt at ease and be allowed to ask any questions about the research or have a bit of small talk/ introduction to the researcher to feel comfortable (Harrel \& Bradley, 2009). When conducting interviews, the researcher was careful to let the participant speak at their own pace and to let them construct their knowledge about their experiences as they discussed their participation in the case study. The researcher further took on the role of 'active listener' (Van Manen, 1990) and tried to listen to what the participant was saying and direct any follow-up or clarifying questions to their own experiences.

\section{Summary of data organisation}

The data that was collected in two methods, through an online survey supported with a survey software called Qualtrics, and through interviews that were recorded and transcribed. Both of these forms of data collection results in text that would be input through a data coding software called Nvivo. Within Nvivo all text was organised first by case, then by role of the participant (staff or student). Copies of the results from the online survey (exported from Qualtrics) and transcribed interviews were further kept on a hard drive and accessible throughout the coding and analysis processes. Caulley (1994) writes that data collection, data organisation, and data analysis processes can often be entangled in one another. For example, while case studies were collected from April 2017 to October 2017 the researcher often made notes and descriptions of the cases, which were then used to conduct member-checks after the data was collected.

\section{Coding and analysis approach}

The data that were collected in this study was qualitative. Patton (2002) notes that in qualitative data analysis the researcher is the primary analytical instrument and as such the paradigm of qualitative research is interpretivist. Qualitative analysis in this study also used an inductive approach, rather than deductive, as the research was exploratory, and the aim of the study was to 
read the raw data to derive concepts and a model (see Thomas, 2006). Thomas (2006) writes that in an inductive approach the first step of analysis is to condense the extensive and various types of raw data into a brief summary format. This was done for all ten cases as can be seen in the case summaries in chapter 6 . The second step was to establish clear links between the research questions and the summary findings (Thomas, 2006). As is common with qualitative data, large amount of data is collected and not all of this data corresponds to a research question. Therefore, in order to keep the results organised, the researcher needs to constantly link the raw data back to the original research aims. The final step in the analysis process is to develop a model based on the data (Thomas 2006). These steps also closely align to Miles and Huberman (1994) three step process of data reduction, data display, and conclusion drawing and verification.

Data were originally coded through Nvivo. Chunks of data that illustrated similar concepts were grouped into codes (Liamputtong, 2009). Following the steps put forth by Bryman (2008) a read through of initial transcripts, field notes, and documents was conducted first before attempting to code any data. An index of coding was eventually generated through the coding process which further helped explore links between codes and eventually help form a thematic map (also known as axial coding) (Thomas, 2006). As Miles and Huberman (1994) note data display or thematic mapping is critical for later model development as it helps give a visual display of the data for the researcher to reflect upon. To this end, the Gioia method was used. The Gioia method (Gioia, Corley, Hamilton, 2012) was developed to support rigorous qualitative data analysis. It includes a three-step process of data display, with the researcher first using $1^{\text {st }}$ order concepts (e.g. key quotes) to then group them together to form $2^{\text {nd }}$ order themes. These themes and then grouped together as appropriate to inform aggregate dimensions. This method further aligns with previous research that finds it is through qualitative coding processes that patterns often emerge (e.g. Bazeley, 2004). Further, $20 \%$ of all my codes was checked by a supervisor separately, to offset risks of individual bias. See table below for an example.

Table 3. Example of Gioia Method

\begin{tabular}{|l|c|c|}
\hline \hline \multicolumn{1}{|c|}{$1^{\text {st }}$ Order Concepts } & $2^{\text {nd }}$ Order Themes & Aggregate Dimensions \\
\hline $\begin{array}{l}\text { "I liked that the staff member } \\
\text { and I both were able to give } \\
\text { ideas" }\end{array}$ & $\begin{array}{c}\text { Equity (share control/ } \\
\text { transparency/access) }\end{array}$ & Co-Production \\
\hline
\end{tabular}




\begin{tabular}{|l|l|l|}
\hline "The experience helped me & & \\
understand staff roles a lot & & \\
more, like their expectations." & & \\
"Learning from students is & \\
most valuable source of & & \\
knowledge" & Knowledge Sharing & \\
"I am always learning about & & \\
students more each semester" & & \\
\hline
\end{tabular}

Model development

Through the analysis process, concepts, themes and aggregate dimensions came to light which would later inform a model. The Gioia method was also useful in the model development stage as Thomas (2006) that having quotes and themes linked to dimensions helps the researcher illustrate the meanings of the dimensions and provide consistency.

\section{Implications and Limitation of Research Design}

There are several implications and limitations of the above research design. For example, while it was decided to collect qualitative rather than quantitative data because of the exploratory nature of the study, there are limitations to qualitative data. Additionally, the study sought to have rigorous data collection methods and as such validity and trustworthiness were critical. Lastly, as with all scholarly research, there were ethical procedures that needed to be followed. This section will discuss these considerations.

\section{Rationale for Qualitative Methods}

Anderson (2010) writes that qualitative research is "often criticised as biased, small scale, and/or lacking rigor, however, when it is carried out properly it is unbiased, in depth, valid and reliable" (p.1). While qualitative research cannot be reduced to numbers or statistics, it often provides more rich descriptions and is suitable for research that focuses on a relatively unknown phenomenon, such as the study here on co-creation (Anderson, 2010). Further, within qualitative research studies, researchers do not see the world as "observable, measurable facts" (Glesne \& Peshkin, 1992 , p.6) but rather multiple realities that are contingent upon contextual factors. While this is a less black and white perspective on research, the acceptance of multiple realities is also an issue for reliability in a study. Far from being able to replicate the study, qualitative research methods 
are rarely replicable because they are by definition hinged upon contextual factors, which are likely to change over time (Golafshani, 2003). This is an important limitation to note, however, as the benefits of qualitative research support deep understanding of complex and relatively new phenomenon, the lack of generalisability of the study was accepted as an unavoidable consequence.

Research questions in the study therefore were explored using qualitative data methods. However, to provide for triangulation of the data (i.e. comparison of data sets across various types of data) both were explored using the online survey instrument and interviews.

\section{Establishing Rigor of Data}

Quantitative studies often seek to establish reliability and validity (Yin, 2003). However, these terms are not appropriate when discussing qualitative research (Bowden, 2005). For example, reliability, or the extent to which the results of research can be replicated (Yin, 2003) is impossible in an exploratory qualitative study, where the study is situated in a specific time and location. Further, validity is often not suitable for this study. While, internal validity, or the clarity of the research to support research to check and confirm the results, is achievable through data storage and organisation (Nunan, 1992), external validity is harder to achieve. As it refers to the generalisability of the study, case study approaches typically struggle to establish generalizable findings. Instead, the benefit of a case study approach is how it can refine theory and gather data for future directions of research on the topic (Stake, 2000).

Triangulation, another common function in quantitative research, was further not attempted in the traditional method in this study. Denzin's original definition of triangulation (1970) assumed a single reality, which could be confirmed through varying types of data (Bazeley, 1994). However, more recent methodology studies, including Mathison (2008) instead argue that there are variations within reality and different perspectives on knowing. Denzin (1989) has further distanced himself from the idea there is a single reality. Instead of confirming a single perspective therefore triangulation is now used as a mechanism for understanding the different types of knowing, and variations found in the data (e.g. through surveys or interviews) is welcomed and adds to the researchers' understanding (Bazeley, 1994).

In 1994 Denzin and Lincoln wrote for a qualitative study within an interpretive paradigm, such as this one, there are four steps to achieve trustworthiness, including credibility, transferability, dependability, and confirmability. To establish creditability, or confidence in the findings, 
triangulation and member checking are critical. Therefore, this study included both survey and interview data (and observation data when possible) and conducted member checks of the data. To establish transferability the study needs deep descriptions and clear presentation of the data, to not only help connect it to existing literature but also help the findings be used by other researchers (Bazeley, 1994). Dependability refers to how the findings over time remained stable and coherent, which can be achieved in a $\mathrm{PhD}$ dissertation through the involvement of supervisors. Supervisors read and understand the data and together with the student researcher create an audit trail, that helps ensure the study findings were sound. Lastly, to achieve confirmability, all data needs to be kept safe and organised, and interview data transcribed, so all findings can be confirmed at a later date. Through these four steps, trustworthiness of the study was achieved.

\section{Etbical Procedures}

Punch (2009) notes ethical considerations for research design must consider not only the university's professional conduct rules and guidelines for research, but also the relevant literature. This involves understanding the risk of harm in the research, gaining consent from participants, making sure there is no deception within the research, and addressing privacy and confidentiality in the data collection and storage.

The ethical procedures within this research first began with a reading on the literature of how to ethically conduct research. This informed me about the importance of being clear to all participants about the aims and purpose of the research and being careful of my relationships to participants. I applied and obtained consent through the University of Melbourne to conduct my research after writing an application that included copies of invitation letters, plain language statements, and consent forms for the different stages the research. Within these documents the research was explained in simple terms and participants were also informed about the privacy and anonymity that could be provided for them. Participants were given a plain language statement to keep, while returning a signed consent form to me. Further, all data collection through the online instrument and the interviews was voluntary, and participants in the interviews were reminded of that they could stop at any time if they wished. Full copies of the invitation letters, plain language statements, and consents forms are included with the final appendix of this thesis.

\section{$\underline{\text { Summary of Research Design }}$}


To summarise the research design of this study, a socio-constructivist approach was used and of which it was situated within the interpretivist paradigm to explore the nature of co-creation in the higher education context. Qualitative data were further collected, through an online survey instrument and supplemented with semi-structured interviews. Data analysis and coding underwent several steps and resulted in data display using the Gioia method, which helped inform the subsequent model for co-creation in the higher education context, based on the iterative model described in Chapter 4. 


\section{Chapter 6. Overview of Case Studies and Results of Descriptor Data}

\section{$\underline{\text { Introduction to Cases }}$}

A selection of ten case studies were included in the sample to explore the nature of student-staff co-creation for this study. Case studies were found through targeted emails to university departments, conference newsletters, or other networks where it was perceived the population may know of co-creation case studies that could be included within the study. Case studies were sought to include a range of activities with different purposes underpinning the co-creation design (see Table 5 and 6 for complete overview). Through a range of activities, the aim of the study was to adopt a wide lens perspective on what constituted student-staff co-creation and also sought to compare and contrast the case studies to deeper explore the question of what the nature of cocreation is. This chapter offers an overview of cases as well as present the results of the descriptor data for each of the cases. Descriptor data includes the type and aim of the case, as well as the number and type of participants, and also what resources (e.g. ideas, physical resources) the participants believed they contributed within the project or activity.

Data collection for all case studies took place between April and November of 2017. Case studies included nine cases originating from Australia and one case from a university in New Zealand. Additionally, case studies included a range of institutions including Australian universities in the Group of Eight (Go8), the Australian University Technology Network (ATN), Innovative Research Universities (IRU) and institutions that do not belong to a specified network. These specific institutions are not identified to protect the identity of cases, and thus the participants. Yet the different groupings of universities highlight the range of contexts the activities took place in, some within research-intensive universities where academics are traditionally quite pressured to pursue research outcomes rather than teaching or student engagement outcomes versus some universities that comparatively are less concerned with research outputs and more concerned with student satisfaction within teaching or campus experiences (See Table 5). 
Table 5. Location and Type of Institution of Case Studies

\begin{tabular}{|c|c|c|c|c|}
\hline $\begin{array}{l}\text { Case } \\
\#\end{array}$ & Case Study Activity & Abbreviation & $\begin{array}{l}\text { Country of } \\
\text { Origin }\end{array}$ & $\begin{array}{l}\text { Type of } \\
\text { Institution }\end{array}$ \\
\hline 1 & $\begin{array}{l}\text { Student/staff produced } \\
\text { magazine }\end{array}$ & PUB & Australia & ATN \\
\hline 2 & $\begin{array}{l}\text { Student participation in } \\
\text { a work-integrated } \\
\text { learning course }\end{array}$ & WIL & Australia & Go8 \\
\hline 3 & $\begin{array}{l}\text { Student co-design of } \\
\text { curriculum }\end{array}$ & $\mathrm{CD}$ & Australia & Go8 \\
\hline 4 & $\begin{array}{l}\text { Student/staff customer } \\
\text { experience project }\end{array}$ & EXP & New Zealand & $\mathrm{N} / \mathrm{A}^{11}$ \\
\hline 5 & $\begin{array}{l}\text { Student/staff creation of } \\
\text { learning resources }\end{array}$ & RES & Australia & IRU \\
\hline 6 & $\begin{array}{l}\text { Student/staff program } \\
\text { implementation }\end{array}$ & PROG & Australia & Go8 \\
\hline 7 & $\begin{array}{l}\text { Student peer mentor } \\
\text { program }(A)^{*}\end{array}$ & PEERA & Australia & IRU \\
\hline 8 & $\begin{array}{l}\text { Student created social } \\
\text { media }\end{array}$ & MEDIA & Australia & Go8 \\
\hline 9 & Student governance & GOV & Australia & Regional \\
\hline 10 & $\begin{array}{l}\text { Student peer mentor } \\
\text { program }(\mathrm{B})^{*}\end{array}$ & PEERB & Australia & ATN \\
\hline
\end{tabular}

* Two cases were known as student peer mentoring programs; therefore, one program will be noted as A and another as B.

The purpose and aims towards supporting the co-creation activities were similarly unique. Three case studies were aimed towards creating a resource such as a publication (case 1), learning resource (case 5), or social media (case 8). Three case studies were aimed towards co-creating a program, with two case studies designed for peer mentoring (case 7, case 10) and one program co-created between a single staff member and a single student to co-create a program for fostering studentsas-partners initiatives within the university (case 6). Two cases were aimed towards co-creating curriculum, one within a traditional project-based course (case 3) and another within a workintegrated learning (WIL) course that included project-based learning with industry (case 2).

${ }^{11}$ New Zealand does not have university groupings. 
Another case study was taken from student governance (case 9) and another from a student-staff co-created customer experience project that sought to improve the service design of a university (case 4). Case studies often had supplementary aims as well including helping students add to their resume or apply their skills towards a project that may help them bolster their employability in the future (for example, case 1 and case 5). Cases often also the purpose of improving university functions or reputation such as through service design (e.g. improving admissions process for students as seen in case 4), building networks with local professionals through industry placements (case 2), improving social media to appeal more to current and prospective students (case 8), or innovating governance to include more student voice (case 9). Moreover, common throughout all case studies was the additional aim of community building, student engagement, student belongingness, and/or student identification to the university community and/or network. This aspect will be analysed later within the data analysis and discussion sections but is likely fostered through the relationships that students and staff build through working together towards a shared purpose or goal.

The participants from each of these case studies varied, with some cases including more participants and thus having larger samples to draw on for questionnaires and interviews. Cases also varied on how many staff were involved, with the majority of cases led by a single staff member with a group of students. The study sought to include as many participants as possible, often eliciting several reminder emails to participants. However, since the study also sought to include participants that had finished the activity (to see their whole perspective on the activity) it could be difficult to get willing participants at times. For all cases, more participants elected to participate in the online questionnaire than also participate in the follow-up interview.

In the end, the contextual environment of the activity (i.e. the type of institution), the purpose supporting the co-creation activity, and the number and types of participants led to ten very different case studies. However, these ten case studies still do not represent all the types of cocreation between students and staff that may exist. Further, comparison between case studies should be done carefully, and honestly about the issues comparing different cases. A table with a summary of case studies can be seen in Table 6 . 
Table 6. Case Study Selections $(\mathrm{n}=10)$

\begin{tabular}{|c|c|c|c|c|c|}
\hline $\begin{array}{l}\text { Cas } \\
\text { e \# }\end{array}$ & $\begin{array}{l}\text { Type of } \\
\text { Activity }\end{array}$ & $\begin{array}{c}\text { Purpose of Co- } \\
\text { Creation }\end{array}$ & $\begin{array}{c}\text { Data } \\
\text { Conduct } \\
\text { ed }\end{array}$ & $\begin{array}{c}\text { Total of } \\
\text { Qualitative } \\
\text { Survey } \\
\text { Responden } \\
\text { ts }\end{array}$ & $\begin{array}{c}\text { Total of } \\
\text { Interview } \\
\text { Participan } \\
\text { ts }\end{array}$ \\
\hline 1 & $\begin{array}{l}\text { Student/staff } \\
\text { produced } \\
\text { magazine }\end{array}$ & $\begin{array}{l}\text { Community } \\
\text { building, graduate } \\
\text { employability and } \\
\text { marketing to } \\
\text { prospective } \\
\text { students }\end{array}$ & $\begin{array}{l}\text { April } \\
2017\end{array}$ & $\mathrm{~N}=9$ & $\mathrm{~N}=4$ \\
\hline 2 & $\begin{array}{l}\text { Student } \\
\text { participation } \\
\text { in a work- } \\
\text { integrated } \\
\text { learning } \\
\text { course }\end{array}$ & $\begin{array}{l}\text { Job preparation and } \\
\text { industry-linkages }\end{array}$ & May 2017 & $\mathrm{~N}=11$ & $\mathrm{~N}=2$ \\
\hline 3 & $\begin{array}{l}\text { Student co- } \\
\text { design of } \\
\text { curriculum }\end{array}$ & $\begin{array}{l}\text { Improving graduate } \\
\text { employability (e.g. } \\
\text { solving real world } \\
\text { problems) }\end{array}$ & May 2017 & $\mathrm{~N}=7$ & $\mathrm{~N}=4$ \\
\hline 4 & $\begin{array}{l}\text { Student/staff } \\
\text { customer } \\
\text { experience } \\
\text { project }\end{array}$ & $\begin{array}{l}\text { Eliciting student } \\
\text { feedback and } \\
\text { perceptions on } \\
\text { improving service } \\
\text { design }\end{array}$ & June 2017 & $\mathrm{~N}=17$ & $\mathrm{~N}=5$ \\
\hline 5 & $\begin{array}{l}\text { Student/staff } \\
\text { creation of } \\
\text { learning } \\
\text { resources }\end{array}$ & $\begin{array}{l}\text { Improving graduate } \\
\text { employability (e.g. } \\
\text { communication } \\
\text { skills) }\end{array}$ & July 2017 & $\mathrm{~N}=7$ & $\mathrm{~N}=4$ \\
\hline 6 & $\begin{array}{l}\text { Student/staff } \\
\text { program }\end{array}$ & $\begin{array}{l}\text { Foster student } \\
\text { partnerships, } \\
\text { student partnership }\end{array}$ & $\begin{array}{l}\text { August } \\
2017\end{array}$ & $\mathrm{~N}=2$ & $\mathrm{~N}=2$ \\
\hline
\end{tabular}




\begin{tabular}{|c|c|c|c|c|c|}
\hline & $\begin{array}{l}\text { implementati } \\
\text { on }\end{array}$ & $\begin{array}{l}\text { approach to } \\
\text { program } \\
\text { design/implementat } \\
\text { ion }\end{array}$ & & & \\
\hline 7 & $\begin{array}{l}\text { Student peer } \\
\text { mentor } \\
\text { program }(A)^{*}\end{array}$ & $\begin{array}{l}\text { Improving } \\
\text { retention, student- } \\
\text { led help, student } \\
\text { self-help }\end{array}$ & $\begin{array}{l}\text { August } \\
2017\end{array}$ & $\mathrm{~N}=4$ & $\mathrm{~N}=3$ \\
\hline 8 & $\begin{array}{l}\text { Student } \\
\text { created social } \\
\text { media }\end{array}$ & $\begin{array}{l}\text { Community } \\
\text { building and } \\
\text { improving student } \\
\text { engagement }\end{array}$ & $\begin{array}{l}\text { August } \\
2017\end{array}$ & $\mathrm{~N}=4$ & $\mathrm{~N}=3$ \\
\hline 9 & $\begin{array}{l}\text { Student } \\
\text { governance }\end{array}$ & $\begin{array}{l}\text { Quality assurance, } \\
\text { community } \\
\text { building, and } \\
\text { improving student } \\
\text { engagement }\end{array}$ & $\begin{array}{l}\text { Septembe } \\
\text { r } 2017\end{array}$ & $\mathrm{~N}=9$ & $\mathrm{~N}=5$ \\
\hline 10 & $\begin{array}{l}\text { Student peer } \\
\text { mentor } \\
\text { program }(B)^{*}\end{array}$ & $\begin{array}{l}\text { Improving } \\
\text { retention, student- } \\
\text { led help }\end{array}$ & $\begin{array}{l}\text { Novembe } \\
\text { r } 2017\end{array}$ & $\mathrm{~N}=27$ & $\mathrm{~N}=3$ \\
\hline
\end{tabular}

* Two cases were known as student peer mentoring programs; therefore, one program will be noted as A and another as B.

\section{Descriptions of Cases}

To help give background and understanding to the analysis section, this section will briefly summarise the ten selected case studies. As mapping the ways in which co-creation was currently occurring in higher education was also one of the aims of this study, this chapter in some ways is also an output of the study. Cases will be summarised in three parts, the background to the case which will offer a description of why the co-created activity began and what the motivations were behind it. Participant descriptors will also be noted, the number of participants, and their roles (i.e. student or staff) and lastly, the types of contributions the students believed they made within the activity (e.g. personal experiences, ideas, expertise and/or knowledge, opinions and suggestions, or physical objects or tools). 
Case 1. Student-Staff Co-Designed Magazine

Abbreviation: PUB

Background: This case was situated in a large public research university in a metropolitan area in Australia. The activity was a student-staff co-designed magazine in which a single academic staff member had decided to initiate to help build a stronger community within the department (extending relationships into alumni) and allow students to apply their learning in a real-world context. The aim of the publication was also to serve as a physical resource or marketing tool for prospective students. The publication was part of the Global Studies department and included contributions from staff, alumni and students across Bachelor of Arts, Master of Development and the $\mathrm{PhD}$ program. The publication includes a range of contributions from poems, pictures, to editorial stories on travel and global issues. Students were also invited as editors of the publication and helping with layout designs and editing articles.

Participant Descriptors: There were a total of 9 participants included within the sample for this case. Participants included one academic staff member, six undergraduate students, one Honours student and one postgraduate student. Of the four of the participants who chose to also participate in an interview, one participant was staff, one participant was an Honours student, and two participants were undergraduate students.

Types of Contributions: Students and staff both indicated student contributions in the form of opinions or suggestions $(n=9)$, expertise or knowledge $(n=8)$, and ideas $(n=8)$. Most participants also indicated they contributed personal experiences $(n=7)$. Additionally, two participants chose to write-in two types of contributions not included in the question choices, with one writing 'editorial work', and the other writing in 'time'.

Case 2. Work-Integrated Learning (WIL) Course

Abbreviation: WIL

Background: This case was situated in a large public research university in a metropolitan area in Australia. The activity was a third-year undergraduate subject in the department of management and marketing where students had to apply to be selected into the course, with an acceptance rate around $60 \%$. Students were selected based on previous grades and also an interview. The course was run by a subject coordinator who also served as a tutor, and two additional tutors. Each tutor was responsible for 4-5 teams of students (4-5 students in a team) and were additionally matched 
with an industry partner. The industry partner and student team helped negotiate a project and its scope that would be conducted over the course of the semester. The subject coordinator and tutor roles were to help the students along the semester offering feedback and ideas when teams needed guidance. The course was developed before the current subject coordinator was in his role, however, was said to be developed to give students a real-world based problem and also strengthen ties with professionals in the Melbourne region to highlight the qualities of the universities graduates.

Participant Descriptors: There were a total of 11 participants included within the sample for this case. Participants included two academic staff members (one subject coordinator and one tutor) and 9 undergraduate students. Only two participants elected to participate in a follow-up interview, one academic staff member and one undergraduate student. Further, one student participant identified themselves as a mature age student.

Types of Contributions: Students and staff both indicated students' contributions in the form of ideas $(\mathrm{n}=11)$ with all participants noting that students had contributed ideas. The majority of participants additionally noted students' contributions in the form of opinions or suggestions (n $=10)$, expertise or knowledge $(n=8)$, and personal experiences $(n=8)$. Two participants also noted physical resource contribution in the form of slideware (e.g. PowerPoint) templates and design software.

Case 3. Co-Design of Curriculum

Abbreviation: CD

Background: This case was situated in a large public research university in a metropolitan area in Australia. The activity was a third-year project-based subject in the department of engineering (however, open to non-engineering students). The subject was designed to a process called 'cocreating learning intent' (CCLI) and encouraging students to help design the class content, methods and outcomes. Students therefore had a large degree of control over their groups, the topics or type of project they would work on, and how they wanted to lead the project towards a goal or outcome with the subject coordinator supporting them through the process. The course was developed by the university to help offer more subjects were students could be equipped with graduate attributes for future employment such as solving complex problems and leadership. 
Participant Descriptors: There were a total of 7 participants included within the sample for this case. Participants included one academic staff member (subject coordinator) and 6 undergraduate students. Three of the participants chose to also participate in an interview, one academic staff member and two students.

Types of Contributions: All participants (staff and students) all felt that students contributed in the form of opinions or suggestions, ideas, and personal experiences (all $n=7$ ). Six participants also indicated that students contributed expertise or knowledge. Given the case was an example of project-based learning, another participant noted that students had contributed as models for the final presentation.

\section{Case 4. Student-Staff Customer Experience Project}

Abbreviation: EXP

Background: This case was situated in a large teaching intensive university in New Zealand. The activity was a series of co-created workshops towards different specific issues or challenges that the university was facing. For this case study, the activities that were related to improving the admissions process were chosen. These activities included interviews between students and staff and a student/staff workshop where students and staff were put in diverse groups to help generate ideas and pinpoint specific issues within admissions. The project was initiated by staff after attending a conference where customer experience projects were discussed and presented as a mechanism for understanding student-centered problems and innovating effectively for future students.

Participant Descriptors: There were a total of 17 participants included within the sample for this case. Participants included eight undergraduate students and nine staff members (non-academic). This was the first case study where participants were also asked to indicate if they were an international student or staff member (an addition to the online questionnaire after receiving feedback) and one staff member and four students identified as international, or non-New Zealand citizens. For the follow-up interview, 5 participants chose to participants with 3 staff participants and 2 students.

Types of Contributions: All participants felt that students had contribute personal experiences, ideas and opinions or suggestions $(n=17)$. The majority $(n=14)$ also indicated that students contributed expertise or knowledge. 
Case 5. Student-Staff Creation of Learning Resources

Abbreviation: RES

Background: This case was situated within a large public university in a metropolitan area in Australia. The activity had been running previously in future years in different forms but was now a volunteer-based group made up of communication/journalism students and health sciences students. While the health science students in the group would be assessed on the project for part of a subject (note not all students chose to participate in this activity and did solo-based projects instead) the communication/journalism students were not formally evaluated. The task of the group was to create a project that could help communicate disease. The group of students, with staff help, elected to create a series of videos on the warning signs and impact of hypertension. The project was aimed improving the communication skills of health science students, which was a previously identified issue.

Participant Descriptors: This case included a total of 7 participants, five participants identified as undergraduate students (one of whom identified as mature age), one professional staff member and one academic staff member. Four participants additionally selected to participate in a followup interview, one academic staff member and three undergraduate students.

Types of Contributions: All student and staff participants indicated that students had contributed ideas $(n=7)$ and the majority felt students also contributed expertise or knowledge $(n=6)$, opinions or suggestions $(n=6)$, and personal experiences $(n=5)$. Within this case study five participants also noted that students had contributed physical resources in the form of educational video equipment, software, or providing props for the production of videos.

\section{Case 6. Student-Staff Program Implementation}

Abbreviation: PROG

Background: This case was situated in a large public research university in a metropolitan area in Australia. The project was a spin-off from a previous working group devoted to exploring how students are acting as partners within the university (students-as-partners). A recommendation from the working group was to help fund a team to help support and develop more activities for students acting as partners, and a postgraduate student and professional staff member were chosen for the roles, as the working group stressed the importance of student partnership in design. 
Participant Descriptors: This case study included a single postgraduate student (studying towards a PhD) and a single non-academic staff member. The postgraduate student was studying studentsas-partners (a concept similar to co-creation, see earlier chapter) for her dissertation and was asked to help co-lead a program for fostering more examples across campus. She was paired with a nonacademic staff member, who while new to the concept, had years of experience in university services and administration.

Types of Contributions: Both participants felt that the postgraduate student had contributed personal experiences, ideas, expertise or knowledge, and opinions or suggestions. The student also noted she contributed resources in the form of literature.

\section{Case 7. Student-Staff Peer Mentor Program (A)}

Abbreviation: PEERA

Background: This case was situated in a large public university in a metropolitan area in Australia. The program was situated within the library on campus and employed academically advanced students to help answer student questions about their subjects through a help-desk physically located at the library and also run study skill sessions generally for students as well. The aim of the program was to improve retention of at-risk students or low-performing students and also to create another non-staff led resources for students seeking help. The future aims of the program are further to move some study skills help resources online, so students can begin to engage in selfhelp.

Participant Descriptors: This case included four participants, three students and one non-academic staff member. All but one student also chose to participate in a follow-up interview. The students within this case also identified themselves as staff as they were paid employees of the university and worked as peer mentors within the library of the university.

Types of Contributions: All four participants (three students and one staff) felt that the students had contributed personal experiences, ideas, expertise or knowledge, opinions and suggestions. Students and staff also noted the students contributed PowerPoints, handouts and activities (such as training for other mentors or for other students). 
Background: This case was situated in a large public research university in a metropolitan area in Australia. The activity was started by the communications office with the idea of including students in the production of media, including social media platforms such as Instagram and Snapchat. Students were invited to control, for example, the university account of Snapchat for the day and take videos and pictures of their day to share with all the universities followers of their account. The aim of the project was to generate student produced content that would help bring together the student community and also perhaps improve student engagement.

Participant Descriptors: A total of four participants were included within this study, two nonacademic staff members, one undergraduate student and one graduate student. One student was an international student. A total of three interviews were also conducted in this case, with two participants as students and one as a non-academic staff member.

Types of Contributions: All four participants felt the students had contributed personal experiences, and one student participant felt students contributed expertise or knowledge. This is unique from other case studies where participants additionally felt students had contributed ideas, opinions or suggestions.

Case 9. Student-Staff Governance

Abbreviation: GOV

Background: The case was situated in a large university that has several regional locations and city study centres. The university is both an online and in-person university and has a mixture of traditional-aged students (18-25) and mature age students. Due to this, and a strong mission to include students in decision-making the university recently has chosen to expand their student representative committees (SRC) to include both in-person and online student representatives. The university is also expanding the roles of students in academic boards, working groups and committees, inviting students to increasingly be present at meetings and report back to the student senate. Additionally, the university is in the process of developing an online module for students involved in student governance, so they may receive recognition and additional support in their roles. All of these initiatives are aimed at improving student engagement and integrating student voice more deeply into the development of the university. 
Participant Descriptors: A total of eight participants were included within this case, four nonacademic staff members, four undergraduate students, and one graduate student. Of these participants one third $(n=3)$ identified as international students or staff. Further, of the five students included within the sample, two students identified themselves as online or distance students.

Types of Contributions: The majority of participants indicated that students contributed opinions or suggestions $(n=7)$, personal experiences $(n=6)$ and ideas $(n=6)$ into the student senate at the university. Four participants also indicated that students contributed expertise or knowledge. Two participants also wrote in that students contributed 'networks outside of the university' and 'enthusiasm and innovation'.

Case 10. Student-Staff Peer Mentor Program (B)

Abbreviation: PEERB

Background: This case was situated at a large research university located in a metropolitan area in Australia. The program is a peer advisory program with three tailored programs within it, one for computer science and information technology, one for engineering and one for general study skills facilitated by peer advisors. All advisors are either undergraduate or graduate students and are paid to participate in training and run subsequent workshops for students. The application process is competitive, with more students applying than the program has positions for. The programs were developed in part to help retention of students, especially first-year students or students in large subjects (where they may not receive enough support or attention). The programs also aimed to offer a safe environment where students could ask their peers, rather than staff or tutors, to help them or support them in solving questions.

Participant Descriptors: A total of 27 participants were included, including two non-academic staff members, 18 undergraduate students, four graduate students, and three alumni (who were previously undergraduate students). Four students included within sample were non-Australian. Of this sample, three participants elected to participate in a follow-up interview, two undergraduate students and one non-academic staff member.

Types of Contributions: The majority of participants indicated that students had contributed personal experiences $(n=23)$, ideas $(n=21)$, opinions or suggestions $(n=21)$ and expertise or 
knowledge $(\mathrm{n}=19)$. Ten participants also noted that students contributed physical resources in the form of work sheets, practice tests, games, PowerPoints, flashcards and other studying materials intended for their peers.

\section{Discussion on the Cases}

As can be gleaned from the descriptions above, the cases varied significantly from one another. However, as the aim of the study was to explore the nature of co-creation, analysis from the cases was critical. Mapping the cases included within the study, there appear to be four main categories of university functions in which students can co-create within. They include, teaching and learning, research and development, governance, and student life. Therefore, cases vary in their context from Healey, Flint and Harrington (2016) whom previously created a model for where student partnership takes place that included: learning, teaching and assessment, curriculum design and pedagogic consultancy, subject based research and inquiry and the scholarship of teaching and learning.

\section{Teaching and Learning}

One way students can co-create with staff is through teaching and learning activities. For example, in this study we found two examples, including a WIL subject and a co-designed curriculum subject, that relate to in-classroom experiences. In the WIL case, students co-created the project with an external industry partner and their assigned tutor (or coach). As the project direction shifted over the semester, so did the subject's curriculum as students learned new skills and knowledge. Similar to this, the co-design curriculum in the other subject also allowed students to form teams and lead their own projects, which would drive a co-created curriculum. In literature, there are also examples of students working as teaching consultants and co-designing assessment items (Healey, Flint \& Harrington, 2016).

Additionally, the study included two cases where students were acting as peer learning advisors. While these activities do not occur in the traditional classroom, they do relate to the students' overall teaching and learning experiences. Students in these examples worked alongside staff to help their peers who were struggling, thus co-creating the learning experiences for students, with students. 


\section{Research and Development}

Research and development within universities takes place in many ways, both internally and externally. From the cases included in the study here, three examples relate to university research and development. The first case, creating learning resources, was not only led by students to explore a specific area within health research (hypertension), but also created a learning resource that could be used either internally in the classroom but also throughout campus. To illustrate, the staff member involved mentioned they would like the video resource to be shown on library screens and distributed through social media. Another case that falls into this category, though is very different, was the research and development of a student partnership program. The student in this case was instrumental in creating a literature review of the area and best practice guide to help guide the implementation of the program, as well as offer their own specific feedback on how students could be attracted to participate in the program. The third case, a co-design workshop on how to improve university enrolment is another example of how a university can integrate the student perspective into their own internal research and development. As Healey, Flint and Harrington (2016) also note in their model, co-research could be another way that universities. Other ways universities can co-create in this space with students including co-designing university websites and apps, as well as incubators and entrepreneurial programs.

\section{Governance}

Only one case included in this study related to governance in this study, where students (online and in-person) participated in various academic governance structures at the university. The area of governance in higher education has a long history of student representation (Austin \& Jones, 2015). However, exploring co-creation practices and stages (as presented in Chapter 4) this area could further develop more co-creation activities in the future. Ways universities could co-create with students could also include, for example, crowdsourcing policy ideas and frameworks and allowing for students to customise their own data analytics agreements and policies.

\section{Student Life}

The fourth area that students can co-create within is relating to student life (e.g. co-curricular, university marketing). There were two examples within this study relating to student life, including co-created social media, and a co-created magazine publication. Through co-creation processes, both of these cases were able to harness student perspectives and energy into enhancing activities for students, while also creating a unique experience for themselves. Other possible examples of co-creation in this area relate to students co-designing student spaces, students co-creating 
orientation and transition activities for other students, and students co-designing events and university seminars.

To supplement the above findings from the study, an expert review on the places co-creation could take place in higher education (described in Chapter 5) also took place. Experts on cocreation were asked to rate a series of typical student activities as having low, medium or high potential for co-creation $(\mathrm{n}=19)$. While this could be displayed in the discussion chapter of this dissertation, it is more relevant to place the table within this chapter, as it will help the reader understand the importance of the cases contextual factors before analysing for other factors of cocreation.

Interesting from the table below is the activities in higher education that were perceived as having the highest co-creation potential were co-research with faculty $(15,77 \%)$, work-integrated learning course $(11,58 \%)$ and student-centered tutorial $(10,53 \%)$. This study sought to include examples of all of these and achieved this through a case study on work-integrated learning, a case study on co-publication with students-staff (though not scholarly in nature), and a case study on co-creation of curriculum in a subject that was taught similar to a student-centred tutorial format. However, the case also included some examples that had less assumed benefits, according to the expert consultation. For example, university social media was given a medium co-creation potential level $(14,77 \%)$ as was student representation on policy panels $(13,69 \%)$. In this study, all our cases studies though were found to be examples of co-creation, in some way or shape. 
Table 7. Expert Consultation on Co-Creation Potential ( $\mathrm{n}=19)$

\begin{tabular}{|l|l|l|l|}
\hline \hline Activity & $\begin{array}{l}\text { Low Co-Creation } \\
\text { Potential }\end{array}$ & $\begin{array}{l}\text { Medium Co-Creation } \\
\text { Potential }\end{array}$ & $\begin{array}{l}\text { High Co-Creation } \\
\text { Potential }\end{array}$ \\
\hline $\begin{array}{l}\text { Student-Centered } \\
\text { Tutorial }\end{array}$ & $2(10 \%)$ & $7(37 \%)$ & $10(53 \%)$ \\
\hline $\begin{array}{l}\text { Teacher-Centered } \\
\text { Lecture }\end{array}$ & $13(68 \%)$ & $5(26 \%)$ & $1(5 \%)$ \\
\hline Online Course & $9(47 \%)$ & $8(42 \%)$ & $2(11 \%)$ \\
\hline $\begin{array}{l}\text { Campus } \\
\text { Forum/Seminar }\end{array}$ & $14(74 \%)$ & $4(21 \%)$ & $1(5 \%)$ \\
\hline $\begin{array}{l}\text { Study Abroad } \\
\text { Program }\end{array}$ & $5(26 \%)$ & $7(37 \%)$ & $7(37 \%)$ \\
\hline $\begin{array}{l}\text { University Social } \\
\text { Media }\end{array}$ & $1(5 \%)$ & $14(77 \%)$ & $4(21 \%)$ \\
\hline $\begin{array}{l}\text { Questionnaire } \\
\text { Participation }\end{array}$ & $14(77 \%)$ & $4(21 \%)$ & $1(5 \%)$ \\
\hline $\begin{array}{l}\text { Work-Integrated } \\
\text { Course }\end{array}$ & $1(5 \%)$ & $7(37 \%)$ & $11(58 \%)$ \\
\hline Postgraduate Thesis & $6(32 \%)$ & $7(37 \%)$ & $6(32 \%)$ \\
\hline $\begin{array}{l}\text { Co-Research with } \\
\text { Faculty }\end{array}$ & $0(0 \%)$ & $4(21 \%)$ & $15(77 \%)$ \\
\hline $\begin{array}{l}\text { Use of Campus Space } \\
\text { for Individual/Group } \\
\text { Study }\end{array}$ & $12(63 \%)$ & $4(21 \%)$ & $3(16 \%)$ \\
\hline Student Council & $2(11 \%)$ & $13(68 \%)$ & $5(26 \%)$ \\
\hline Sporting Event & $10(53 \%)$ & $8(42 \%)$ & $13(69 \%)$ \\
\hline $\begin{array}{l}\text { Student } \\
\text { Representation on } \\
\text { Policy Panels }\end{array}$ & $2(11 \%)$ & & $50)$ \\
\hline $\begin{array}{l}\text { Teaching Assistance } \\
\text { and Tutoring }\end{array}$ & $1(5 \%)$ & $12 \%)$ & \\
\hline
\end{tabular}

While the implications of this will be discussed in more depth in the findings and discussion chapters of this dissertation, from the summary of the cases, already some interesting questions arise. The first is that while some activities may have more potential than others to be co-created, for example, co-design elements are more easily included, many activities, even those with low potential, may still be able to integrate aspects of co-creation. While teacher-centered lecture was rated as low potential, there has actually been a great deal of literature on students acting as pedagogical consultants with lecturers, which some consider to be a form of co-creation (Bovill et al., 2016, Cook-Sather \& Felten, 2014). The second, is that if we consider all student experiences to be co-produced (as students cannot passively consume, they must attend, listen, study, etc.) and we know all student experiences include ViU (see Chapter 3) then perhaps one could understand all activities in higher education to be co-created. And thus, co-creation could be a lens not only 
to evaluate more obvious student-staff partnerships, but actually, all experiences. If this is the case, then how educators and students perceive the student experience could shift significantly.

\section{$\underline{\text { Summary of Cases }}$}

The ten selected case studies included within this study thus are different from one another across contexts, backgrounds, purposes and aims, types of activities, and types and numbers of participants. For example, the cases include a range of aims, including resource creation, program development, and curriculum design. They also included a range of supplementary aims, including student engagement and innovation towards student-centered or student informed designs. Across case studies the contributions of students also differed, with some participants in case indicating that students had contributed in many different forms, including through opinions, suggestions, ideas, and personal experiences, while other cases being more specific and indicating that students contributed in more narrow ways, such as just through personal experiences (e.g. case 8, social media). In the next section a more thorough analysis of the cases is discussed with cases analysed through the model presented in the previous chapter to specific constructs such as co-production and ViU. The benefits and barriers of activities were additionally explored. 


\section{Chapter 7. Exploring the nature of co-creation through empirical data}

\section{Introduction to empirical data}

This chapter presents the key findings from the analysis of interviews and qualitative questionnaire responses. The results were derived using methods documented in Chapter 5. Comparisons and insights resulting from the findings are later discussed in Chapter 8, as well as how the findings link to literature.

The chapter was structured around aggregate dimensions of the co-creation model, including: antecedents, environmental factors, barriers, co-production, ViU, and benefits. Each dimension is explained in terms of the underlying concepts and themes within them. These are summarised in Table 7. Where helpful, direct quotes are used to illustrate and clarify the findings. Please note, the chapter uses the case study abbreviations presented in Chapter 6 and distinguishes between student and faculty/staff participants in quotes.

This chapter bridges the gap between the iterative co-creation in higher education model that was created through literature review (see Chapters 3 and 4) and the redesigned model based on the empirical findings of this study. This chapter therefore aimed to discuss how second order themes emerged through the data and how the model's aggregate dimensions were modified with the input of empirical data. Further findings are summarised in the appendix, presented using the Gioia method (Corley \& Gioia, 2004) where a selection of the participants' quotes are presented to highlight how they informed the second order theme, and subsequently, how the second order themes led to the aggregate dimensions.

In Table 7 an overview of the aggregate themes that arose in the study as well as corresponding sub themes is presented. As described previously in the research design chapter, the study sought to explore the nature of co-creation in higher education through inputs, processes and outputs. Due to this comprehensive aim, numerous themes emerged through the results. In regard to inputs results indicated that both antecedents to co-creation on an individual level (e.g. participants' personal outlook) and environment factors (e.g. online platforms) influenced the co-creation activity. While processes in co-creation include Ranjan and Read (2016) dual conceptualisation of co-creation through co-production and $\mathrm{ViU}$, barriers also emerged as a critical theme in this area. 
Lastly, outcomes were explored through the theme of benefits to co-creation, exploring both benefits to student participants and for the university.

Table 7. Overview of Themes

\begin{tabular}{|c|c|}
\hline Aggregate Theme & Sub Theme \\
\hline \multirow{4}{*}{ I. Antecedents to Co-Creation } & Participants' Personal Outlook \\
\hline & Participants' Previous History and Experiences \\
\hline & Students' Initial Perceptions and Motivations \\
\hline & Staff Aims and Motivations \\
\hline \multirow{3}{*}{ II. Environment Factors } & Online vs. In-Person Platforms and Structures \\
\hline & Authenticity of Activity \\
\hline & Novel or Confusing Elements \\
\hline \multirow{8}{*}{ III. Barriers to Co-Creation } & Need for Staff Guidance and Direction \\
\hline & Time \\
\hline & Lack of Clarity \\
\hline & Wavering Motivation of Staff and Students \\
\hline & Assessment Design \\
\hline & Inexperience of Participants \\
\hline & Power Imbalance between Staff and Students \\
\hline & $\begin{array}{l}\text { Disengagement or Lack of Motivation from } \\
\text { Participants }\end{array}$ \\
\hline \multirow{3}{*}{ IV. Co-Production } & Equity \\
\hline & Interaction \\
\hline & Knowledge Sharing \\
\hline \multirow{3}{*}{ V. Value-in-Use } & Experience \\
\hline & Personalisation \\
\hline & Relational \\
\hline \multirow{4}{*}{ VI. Benefits to Co-Creation } & Student Employability \\
\hline & Student Self-Efficacy \\
\hline & Student Ownership \\
\hline & Innovation \\
\hline
\end{tabular}




\section{Antecedents to co-creation}

The Oxford dictionary defines antecedents as "a thing that existed before or logically precedes another." Yet while antecedents are often thought of as what happened before the activity, in the case of co-creation, they were shown to be important within this study to make sense of the activity itself. The primary reason antecedents were shown to have a large impact on the co-creation cases was because most of the projects were voluntary (i.e. the participant did not have to participate, with the exception of subjects were the participant initially signed up, but then the process became mandatory for marks such as WIL and CD). Due to this, the type of participant and their perception and motivations to engage in co-creation related activities was already a finding within itself. For example, across case studies it was found that many of the staff and students identified student participants as 'high-achievers' or students who participated in a range of co-curricular activities and often received high marks in their course. Similarly, staff often noted that they were already interested in student engagement and believed integrating student perspectives into higher education was important, which motivated them to initiate or manage the co-creation activity. From the data, therefore, several second order themes under the aggregate dimension of antecedents were uncovered including: personal outlook, previous history, students' initial perceptions and motivations, and staff aims and motivations.

\section{Participants' Personal Outlook}

Within both the qualitative questionnaire and interviews, participants were asked whether they believed students' resources (e.g. perspectives and ideas) should be integrated within higher education activities. As all participants were already involved in co-creation activities (as per selective sampling) it was not a surprising finding of this study to learn that many staff and student participants felt strongly about supporting student co-creation. Various sentiments emerged within the theme of personal outlook, including how students have much more recent experiences of higher education than staff and that student perspective integration is of growing importance within the context of a competitive market for higher education. However, not all examples of personal outlook were positive towards co-creation. For example, one student (CD) also noted 
that integrating the student perspective for them was a hindrance to their student experience unless marks would be also part of the co-creation experience. They note,

I don't want to waste time coming up with assessment strategies or co-teaching my class, especially not if it muddies that rubric of marks we're all chasing, or meaning I'm having to put up with material taught that's irrelevant to the exam I will be sitting in 12 weeks' time. I don't have time for that. For a co-creative approach to appeal to me, there'd have to be marks in it for me (Student, CD)

Yet most participants included in sample has a positive personal outlook towards co-creation, with many also noting that student co-creation could benefit not just individual students but the entire university system. For example, one student felt that universities should include student resources in activities because it the students who are most affected by the higher education student experience. They note,

Students provide a front-line perspective that cannot be given by anyone else. Their lived experiences, ideas and knowledge are therefore invaluable when it comes to contributing to the improvement of higher education activities. Students are therefore the best people to consult when it comes to changing or implementing new strategies in higher education because it is them who are directly affected by such changes (Student, GOV)

Participating staff within the study also tended to have strong positive outlooks on the involvement of students in co-creation activities. Several participants noted that students were under-utilised resources, while another staff member (PEERB) mentioning that “...students are absolute powerhouses we miss...". This finding relates to contextual factors of the participating staff as many of them either volunteered to initiate the co-creation project, such as the publication or social media campaign, or their job is directly related to running an activity with students such as a peer advisory program.

\section{Participants' Previous History and Experiences}

Similar to participants' personal outlooks on co-creation, which found to be largely positive, participants' previous history also helped explain why many participants had chosen to become involved in co-creation type activities. One staff member had a strong activist background, 
empowering locals to become involved in politics, while another was trained previously in psychodrama, a practice that advocates building group interactions. Students also had a wide range of previous experiences that led them to participate in their respective activities. Some students had previously held positions of student representation, or had family or friends who had, while others were disenchanted with the student experience which led them to consider co-creation activities. One student, for example notes,

Prior to coming to the educational field, I was really disengaged in my studies and frustrated at the sense of injustice about dismissal of students' role in education but that was more because of my beliefs on egalitarianism more than anything else (Student, PROG)

In particular, students involved in the case of governance (GOV) had either previously noted in student council and other type of activities in high school or had friends and family that were involved. Another student involved in governance noted they had been involved in several roles working with staff and faculty before and was no longer intimated by working alongside staff. They note: “Me, personally, I don't have an issue talking up at these meetings, I'm very vocal. I think I'm one of the first student leaders to be so vocal, or so I was told" (Student, GOV). Yet this raises questions of equity and how co-creation activities can appeal to and include students who have no previous history in student leadership roles (to be discussed further in Chapter 8).

\section{Students' Initial Perceptions and Motivations}

While students' personal outlook and previous histories were critical for understanding what type of students were involved in co-creation activities, it was equally critical to understand students' initial perceptions and motivations for participating in their specific activity. Student responses to why they decided to participate in activities ranged from personal growth, to developing employable skills, to the appeal of participating in a project where students had the majority of control. For example, “... we had complete control over that project. Actually, that's why I picked this course because I wanted more of that" (Student, CD).

As some of the activities were considered part-time jobs, many students in these specific activities, such as peer mentoring, alluded to the financial benefits as a key reason why they decided to participate. However, these students typically also noted that the type of job, such as helping 
others, was also a motivation, especially when compared to their other employment options. For example,

I was working at a liquor store and doing retail work and I wanted to try and get some other kind of job, but I didn't know where to start. I liked the idea also of helping other people because I do like teaching and one of my plans is maybe to get into academia... so I thought this kind of thing would look really good for future jobs. (Student, PEERA)

A similar sentiment was also conveyed in the work-integrated learning (WIL) course where several students were motivated by the opportunity to test out the business skills and theories they had learned in other classes in a practical way. Other students in alternate cases such as a student experience workshop, were also motivated by making sure they received the most value they could within their degree. One student notes, "It's pretty common for me to voice my opinions anyways because as a low-income student I want to make sure I get the most out of my university experience. Like, I pay 6,000 NZ a year, that's a lot" (Student, EXP).

Yet other students were not only motivated by value or gaining employable skills, but also personal development or representing students in a meaningful way, with one international student involved in the social media activity noting, "I think sometimes as an international student sometimes people see us as lesser, like we are not capable of doing things, and I want to show people that international students are just as good as local students" (Student, MEDIA). Yet another student, also involved in the social media activity, decided to participate in the activity to have an artefact of their university experience, "I thought it would be a really cool experience to look back on from my university says and say oh you know, during my university days I took over the snapchat for a day" (Student, MEDIA). The perceptions of the activities and the motivations for students therefore ranged considerably from case to case. However, not to be overlooked is that all students did see something in for them, be it monetary or personal. This finding will be discussed in the following chapters, but no doubt has implications for future co-creation activities to ensure they are appropriately and earnestly conveying the potential benefits for students as that is likely a driver for widening student participation. 
The study also sought to explore staff aims and motivations for either initiating or managing a student co-creation type activity. Interesting to note, that staff aims and motivations were quite different from students' motivations, as staff were more interested in benefits the university or university services, rather than personal or individual benefits that often-motivated students. For example, one staff member who began a student-staff publication had multiple aims, including to improve the community around the related degree, to strengthen links with alumni, to create a marketing tool for prospective students and also to help students add to their CV. Other staff were motivated by improving a specific service of higher education, for example, the enrolment procedure was addressed through a student-staff co-created workshop, with one staff her motivation as, “...there are so much hock-ups (i.e. issues) in the process now that any way I can get some sense of where the pain points are and where I think the gains are would be good for me to know" (Staff, EXP).

A recurring theme of staff aims was helping students become more employable. Staff, both directly and indirectly, mentioned that they believed the students who participated in the project would gain competencies such as communication skills, leadership, and team work, as mentioned in the PUB, WIL and CD examples. Though important to note these cases were all done within a department or subject and driven by an academic staff member. Cases arising from non-curriculum related activities led by non-academic staff members, such as student governance or peer advising had broader goals, such as retention or democratising the university decision-making process. For example, one staff member involved in a peer mentoring activity notes,

There's really a push towards a digital learning strategy so partly what we do is selfhelp resources and the PLAs often in the workshops also show them how to access materials that are available to them. It's also part of the engagement and retention strategy so making sure that students are aware of the support that's available (Staff, PEERA).

The differences between cases led by an academic or by a non-academic staff member will continue to be explored in the following sections. It is likely, that not only the type of role the staff member, but also their personal outlook and previous history are all significant when analysing the specific barriers and benefits of the co-creation cases. 


\section{Environmental factors}

This study also sought to explore environmental factors within co-creation activities. While this area has been largely overlooked, especially in related co-creation literature such as student leadership and student partnership streams, an understanding of how environmental factors impact co-creation may be necessary for exploring the scalability of co-creation activities. For example, in industry many organisations and companies are moving to online platforms for cocreation to widen the access of both who can involve themselves in co-creation and also to allow for easier involvement (i.e. from the comfort of home).

However, important to exploring this aspect of co-creation is also to question firstly what are environmental factors? This study takes an inclusive view of what can be considered an environmental factor, including not only the type of platform (online vs. in-person) but also the characteristics of the structure, such as whether the environment was authentic (i.e. student cocreation was integrated to improve a service or outcomes rather than just a learning experience) and whether the environment was novel or confusing to students and staff.

\section{Online vs. In-Person Platforms and Structures}

All of the ten cases included some environmental factors that were both online and in-person, however, some were much more majority in-person or online than others. The two cases that exhibited the most online tendencies were the social media activity (MEDIA) and the student governance case (GOV), as participants included online students and students spread out across different regional campuses requiring online platforms. However, these two cases also significantly differed from one another, as the social media activity has students involved in short-term Snapchat or Instagram contributions, while the governance case required ongoing communication between students and staff. Unsurprising perhaps then, that while the online platform received few complaints from the social media participants, with instead students commenting how enjoyable it was to share contributions across the student body, the governance participants struggled in an online platform. Students in this case were members of student representative committees (SRCs) which up until recently had only been open to students studying on-campus at one of the six campuses. Recently, however, the university had established an online SRC, the students of which participated largely through video chats. Perhaps due to their experiences as online students, both for academic purposes and now student representation, these students voiced concerns over their experiences as online students, 
Because the distance and isolation that online students feel is far greater than an oncampus student and the danger is that universities think online students are the BandAid to fix all of our funding issues, but online students are just as expensive and costly to service as in-person students in a lot of ways. I think the university is getting away with it, but if they are serious about capturing that market then they have to be serious about capturing those voices. (Student, GOV).

Yet while online students, who are given limited access to in-person interactions, felt dismissed, in-person students, across a range of cases, often noted more online platforms options would be better suited to them. One student in a peer learning program notes,

I think enabling online students to participate is key. This could involve recording sessions, allowing students to ask questions via video recordings, forums or email and get responses from all facilitators/participants in a similar way. The ability to "time shift" the questions, answers and discussion in an engaging way is absolutely required and has been missing from all peer advising programs I have been involved in. (Student, PEERB).

However, other students still preferred in-person platforms and meetings, with one noting, “...whilst the online aspect of submitting/editing is time efficient, it doesn't do too much for students who would like talk out their ideas before writing them or work through a complexity" (Student, PUB).

As can be seen from this section results were mixed whether activities should facilitate more online environmental factors or not. It seems that overall preference is for students to meet mostly inperson but have supportive online platforms to supplement in-person meetings and communication.

\section{Authenticity of Activity}

Authenticity as a theme within the dimensions of environmental factors relates to whether the students perceived the activity as un-staged, or having tangible benefit to the university, rather 
than just designed for students as an exercise. Students and staff also stressed how their co-creation activities were authentic in the sense that they were similar to scenarios that students would face in the workplace. One staff member notes,

It's not a simulation, it's not a setup in any way, it's a genuine business problem and they have to research it and provide recommendation and report that is of some strategic or operational value to the client... (Staff, WIL).

Meanwhile, students who detected inauthenticity, or simulations, were often disappointed. In one case a student summarises this feeling by noting,

So, I felt like yeah it was great for our skill development but not great for us to actually be leading change in the real world. So, I think it would be great it actually has the implementation aspect as part of the course because it's the actually doing it that's such an important part of leading change, not just suggesting change. (Student, CD).

However, within this same case, the staff member involved did believe the activity was authentic, but in a different way. While the student based their perception of authenticity on implementation of the project, the staff member based their perception on working together in a group without a formal structure, similar to the workplace, noting, "It's modelled on real life, there isn't someone who just gives you structure, you need to go and work it out.” (Staff, CD). This contrast brings up the question of what makes an authentic environment, and should authenticity be based on the definitions and perspectives of staff or of students.

Questions of authenticity also came to the forefront in the case of student governance. The word 'token' was used by both staff and students, who expressed concern over the authenticity of the student input in governance activities. One staff member involved in the activity notes,

Academics may want to plan [student involvement in governance] better, but ultimately, they need to avoid bringing their bias into the conversation from the start. For example, topics that are to be covered are often decided well before students turn up. Agenda's seems to be guided by the desired outcomes of the university. (Staff, GOV). 
Students also felt this disconnect between involving students in governance but in an inauthentic way. Some selection of student quotes from this case to highlight this include,

One of the biggest issues we're facing is the mindset of our faculty members. To them it's kind of student reps, having students on their boards, is just a token. (Student, GOV)

Honestly, it really does feel like I am there to give feedback. And that's why I feel about anxious and not on the same level as everyone. Even though they do try to welcome and involve me I do feel like the student representative position is more of a feedback, or they treat it like a feedback position. (Student, GOV)

And the university probably needed to ask the question themselves, you know here's the token online students, I can't imagine what they are going to be whinging (i.e. complaining) about again, give you a chance to have a rant, not that I do that, but great we've heard from you so then it's ok well let's move on. (Student, GOV).

Yet it is also key to note that the case of student governance is difficult to compare to other cases. Student involvement in governance in Australia, and in many other countries, is in fact mandated by the quality assurance organisation that oversees the higher education sector. And while student involvement in governance has a long history in higher education, it is not a new finding that much of student governance is found to be superficial or an act of tokenism.

\section{Novel or Confusing Elements}

Many co-creation cases were initially confusing to both staff and student participants. For example, in the student-staff publication, the staff member noted "This entity so far as I can tell, has no parallel elsewhere", a sentiment which may explain why both students and staff involved in the case noted that structure and environment was still changing without a set procedure yet. Other cases with a set procedure, however, were still confusing to staff and students at times. For example, in the work-integrated learning case, while the lectures and assessment were set, the type of tutor involvement in projects was not. The staff remarked, 
I think it's one of those scenarios where there is no firm line in the sand, it's a bit of grey area and it's up to each workshop course to make decisions on the spot about how much they contribute to the students' project... (Staff, WIL).

A student echoed this uncertainty noting,

I think biggest challenge was the initial few weeks in the course where we had to develop a team contract and the project scope - so there was a lot going on but there wasn't a lot of information or examples. (Student, WIL).

However, for the project to be transformational, many staff felt that too clear of guidelines or examples would take away from the overall experience or the quality of the outcomes for students. For example, in the curriculum design case, the staff member notes,

And that whole process I find they struggle because it's being with the unknown the whole time, and then suddenly in week 11 or 12 it all comes together, and they go oh wow, look at all that we've done and how it all fits in. But they couldn't see that until that point. (Staff, CD).

Therefore, within this theme arising the debate of how much the unknown can both benefit and hinder the students' benefits. For example, the staff member in CD believed the unknown aspect helped the students understand the unknowingness that often accompanies the workplace, where essays with word limits do not exist. But in other cases, for example the peer mentoring, having too little structure led to issues, such as students believing they could handle more responsibility than they were ready for. One student notes,

One of the new PLAs wanted to get more hours and do more work and needed to sustain themselves but they didn't have the skills for the workshops they were doing... they weren't knowledgeable enough, in my opinion. But they needed the money, not because they felt they could do a good job. So those things cropped up this year because there were big upheavals to the program. (Student, PEERA). 
It seems that the confusing or novel aspects of co-creation are only beneficial if the student eventually can overcome and learn from them. For example, in the governance case, one student struggled to find their voice in the beginning noting,

At first it was a little daunting because I felt like I was in a room of very professional and senior academics and there are also ministerial appointed positions there and a lot of them sit on other boards, so they are quite corporate kind of people- and I hadn't had any experience in that field. (Student, GOV).

But then the same student went on to note, but once they realised that their role was not meant to compete with staff, but add to the expertise of the student perspective, they felt a lot more confident and a lot more enjoyable in the process, indicating that time to adjust may be an important factor to student-staff co-creation.

\section{Barriers to co-creation}

The study sought to explore the nature of co-creation in higher education and to be able to investigate this topic, it was important for barriers and issues to also be explored. While previous literature on students and staff partnerships, and co-creation in organisations, provided a basic foundation to explore barriers in student-staff co-creation, the study wanted to keep this section relatively open to allow for students and staff to mention barriers that had previously not been investigated.

The study included ten case studies and from this the responses of students and staff were coded thematically to uncover barriers. The barriers however listed in this study may not be exhaustive as the cases do not represent all the types and forms of co-creation that exist or may exist in the future. The barriers arising from the data in the study include: need for staff, time, lack of clarity, wavering motivation, assessment, inexperience, power imbalances and disengaged students and staff.

\section{Need for Staff Guidance and Direction}

In the previous section the theme of the 'staff driven' environment was discussed, otherwise known as how the staff had a key role in decisions of the where, when, and how the case's 
environment and structure were designed. However, the need for staff also arose as a barrier to co-creation, with students unable to take on some of the roles and responsibilities of staff. Students frequently mentioned that they did not receive the level of staff support they had hoped for in the activity and craved more staff attention. These are indications that co-creation may need staff to play a larger, rather than equal, role.

For example, one student notes, "I thought there would be someone over our shoulder a bit more... at times I felt like there was a lack of support." (Student, WIL). This comment was made despite the students' two-hour weekly lecture, and two-hour tutorial session with staff, highlighting students desire for even more staff attention when participating in unfamiliar projects. This finding was similarly found in a case where students were creating a video learning resource with staff. One staff member notes that a similar project, with less staff support had been piloted before and the project had failed to complete because of the lack of staff scaffolding. They note,

We thought things were fine, but we found towards the end of the semester that students had decided not to go ahead [with the project], and they were just doing the assessment with everyone else in the module (Staff, RESO).

Another case, where a single staff member worked with a single PhD student, the PhD student noted that the responsibility could not have gone to any student, but rather required a student with experience managing projects and a working knowledge of students as partners conceptual framing. Students involved in peer mentoring also mentioned a need for a staff member noting,

It is necessary to have one full time staff member because she knows the system better than we do and she also has a bit more clout when dealing with the other academics and so when it comes to dealing with the politics, and dealing with a lot of the trickier situations (Student, PEERA).

The need for staff in co-creation is categorised in this study as a barrier because co-creation as a concept in literature previously stresses the importance of equality between users and organisational members. However, in the cases presented in this study, staff and students were not equal, with staff in the majority of cases handling the most critical aspects of the activity. However, this does mean that it is impossible for students and staff to be equal in co-creation, but rather 
points to likely a need for students to first develop experience and confidence before taking on more complex responsibilities and leadership roles.

\section{Time}

As most of the co-creation projects were voluntary and/or supplementary to students or staff required roles, the limitation of time was frequently discussed. Staff and students also acknowledged that most of the co-creation activities required more time than other activities, with one subject coordination from the work integrated learning (WIL) course noting: "[The subject] is an awful lot of work! The subject has a far greater work load than a normal subject." Students often reported feeling the pressure of the increase in responsibilities in co-created activities with one student noting,

If by doing a 10\% assignment I used to it being maybe 10 hours, but now I'm doing a $10 \%$ assignment and its taking four days. There are things like that are harder to get used to, as there isn't a normal expectation of time for a mark (Student, CD).

Other comments related to time that came up were participants desiring more time to get to know each other and connect, either before or after the activity. Other participants noted that while the current compensation or incentives (e.g. wages, marks) was sufficient to participate in the project, they would not want to participate in the activity if it were take up any more time without additional compensation or incentives. Other participants, however, said regardless of compensation they would continue to use their spare time to finish the activity. For example, students co-creating learning resources were particularly motivated with students noting,

I personally worked on it in my spare time. Adding pictures, or visual cues, and whatnot. Also, once a week near the end we met for about 2-3 hours before a meeting with the head of the department and catch up where we up to (Student, RESO)

The only downside though is it's become bigger than Ben Hur. No one had idea just how big this was going to get. It's still going, semester is long gone (Student, RESO).

It is not surprisingly to uncover that many co-creation cases were large undertakings for both staff and students. As many cases were new, it is realistic that expectations and project goals were not always realistically matched to resources and time available. In one peer mentoring program is was 
found that many students seeking peer mentors would only begin to attend sessions at the end of the semester, putting pressure on the student-staff at the same time they needed to be preparing for their own exams. The staff member notes,

And then at the end of the semester we run big three-hour work course study parties, for each course. Where we've had reasonable attendance all the way through, all of the sudden 300 people will come to the study. But just murders the facilitators, and so we need to correct that. (Staff, PEERB).

Moreover, the strain of time does not only impact the participants involved but can also stop future participants from volunteering. For example, in the program development case (PROG) the student wrote it was difficult to recruit new staff participants, as they note, "[they are] not able to justify their involvement to their bosses as it is outside the scope of their job description." If co-creation activities are going to expand and grow in scale, the issues of time most likely need to be addresses with more clear and realistic goals, and more streamlined processes.

\section{Lack of Clarity}

Some cases lacked clarity of the roles and responsibilities that students and staff were expected to perform. In both classroom cases (WIL, CD) students did not understand what would be expected of them until far into the course of the semester. Further, in one of the cases, a student group who was working to propose a community project believed they were actually implementing the project, not realising that their assignment was only to design a potential project.

Some students also reported a lack of clarity in their roles. Students involved in many of the cases straddle the student and staff roles and often reported feeling confused about which role they identified with. One student, who was employed as a staff member, notes,

It's tricky... I think because I get a lot of internal conflict with my roles of student and staff and that I find challenging. And I think specifically at the moment I face difficulty with that because I strongly identify as a student, particularly in the context [of the project]. I've always identified as a student in the student-staff relationship. Whereas technically, now, as I'm employed in the role some people see me as a staff member, whereas I would argue I'm a paid student partner. And while some staff may think of me as a staff member - and I get some conflict with that because it conflicts with my 
strong identity as a student. Not that they are incorrect, just that there is that kind of internal cognitive dissonance (Student, PROG).

Co-creation literature in the organisational context have previously identified the need to set clear roles and responsibilities before activities begin to avoid issues with lack of clarity. However, while adoption of organisational practices to assign responsibilities are likely to help processes, they are unlikely to address the lack of clarity of role identification for students involved in these projects. As seen above, the new situational contexts and unorthodox roles of many cases may lead to uncertainty over who is their peer and what their goals within their role are, to help students, or to help the university? This issue, for example, was often brought up in the student governance case, where students struggled to know where their alliances fell.

\section{Wavering Motivation of Staff and Students}

As previously discussed time put a strain on students and staff, which sometimes meant for some participants wavering motivation to participate in the co-creation activity. Participants, as the time and pressure of the project continued, would often feel less motivated than they had when they originally got involved, with one student noting, "I'm still mostly motivated, but the last few weeks we've been struggling. After the [summer] break it was hard... we're just starting to get going again." (Student, RESO).

However, wavering motivation does not always need to be conceptualised as a barrier, as depending on students and staff available time and interests, it can also be a benefit that they choose to involve themselves in project with varying degrees of commitment. For example, it may mean that students can engage when it suits them, as one student notes:

We are getting less student contributions now then we were at the start. think particularly the first edition had more students involved and more contributions. I think that happens with any project though... some people are just very fired up and keen. We also get more contributions in first semester than second (Student, PUB).

Students involved in some case studies also had their motivation waver if there were not enough new challenges within their role. For example, with the peer mentoring programs, students often wanted to gain an increasing amount of responsibility as they were employed as peer mentors. One staff member who observed this note, 
And some of them that have been in the program a few years and we're getting bored with desk work will ask just to do workshops and I just think it's been exceptional from a professional development view as well (Staff, PEERA).

Strategies to address wavering motivated that were reported therefore included a growing amount of responsibilities, finding new and continuously beneficial incentives, and building a strong community around the activity where participants would not want to abandon the project. However, in particular finding incentives other than money could be challenging, as highlighted by one staff member,

I think there are challenges in making it work in a university, one of the challenges is the incentives to participate both for staff and for students, so finding a way to do that that doesn't involve giving a lot of money to people and to find the other motivations that connect people. (Staff, PROG).

Instead, challenging participants and building strong community around the activity may help relieve the pressure of universities to always incentive students and staff to participate in cocreation projects with funds.

\section{Assessment Design}

Cases that reported less issues with wavering motivation were cases where the students were being assessed with marks within a subject. However, the pressure of assessment led to other issues, especially when coupled with other barriers, such as lack of clarity or time. The staff member in the work integrated learning (WIL) subject noted that while they wanted the students to feel empowered to make decisions and have an equal role in working towards the outcome of the project report for clients, this needed to be tempered but the assessment criteria of the subject. They note,

There is never a situation where the 5,000-word report can be reduced to a 1,000-word report because the client doesn't want to read 5,000 words, it still has to conform to the assessment guidelines... Also, one of the challenges for us as a course is we too have to fulfil the expectations of the industry partners. Some partners expect a higherlevel quality student, and so we give those ace teams to them. That's just the way it 
works, even though the ace team isn't always the most successful, it's a safer choice (Staff, WIL).

In the other case with assessment, the course design case, there were also tensions between students and staff over the issue of assessment. One student notes that while co-creation was fun, it is “...hard to work around when you're a normal university student and you're trying to good mark at the end" (Student, CD). Meanwhile, the subject coordinator for this subject purposefully designed the course without clear examples or assessment criteria, instead preferring students to imagine for themselves what their 'bar' should be towards achievement. For example, they note: "They want me to give them examples and structure... and by structure they mean what is it exactly that you want me to do? But the subject actually has a lot of structure, but they don't see it as structure."

The barrier of the impact of assessment with co-creation cases may need to be explored further in the future. The results from this study suggest that while motivation towards projects remains high when assessment is present, students feel that traditional measure of assessment do not capture the effort and learning undertaken to participate in the projects. There are also questions of fairness when co-creation projects lack clarity to students when they grade may be affected.

\section{Inexperience of Participants}

Many staff and students noted a barrier to them in their respective co-creation cases was inexperience. Students were not familiar with having increased responsibilities, going from passive learners to active ones. One student notes, "I had never participated in anything like this before, it was the first subject where I had responsibility like this..." (Student, WIL). With the staff echoing this sentiment, noting,

In the beginning they feel very much like they are completely out of their depth but by the time they get to week 8 or 9 , like the team presentation they are starting to get that sense, 'hey we might actually be able to do a decent job with this' but it probably isn't until they finish the final report that they truly get that sense of wow, we actually accomplished this (Staff, WIL).

In respect to inexperience, many participants noted they would have felt less uncomfortable if they knew the other participants more. For example, one staff notes, 
I think it could be better if people arrived a bit more prepared or comfortable with the process, and some more of the connector stuff like a shared webpage or group - or something where people could process beforehand, so you can jump right in .... (Staff, EXP)

Another student from co-creating learning resources remarked,

Initially it was a bit awkward because no one knew each other but as we worked on the project and got to know each other it became a lot easier (Student, RESO).

Inexperience was also a barrier to the recruitment of participants in some cases. In both the program development case (PROG) and the social media case (MEDIA) staff noted that they could not just select any student, but rather needed a student who had specific skills that would complement the staff member's resources and skills. One staff member notes,

I guess just someone familiar with social media and snapchat and knows how the features work and we do ask to see a sample of something they've created before on snapchat cause the more engaging they are the more success we will have and the more we can put into doing more in the future. So, we don't look for a certain type of student, or a course, or an age, it's just more about how experienced they are on social media. (Staff, MEDIA)

The barrier of inexperience further relates to how the inclusivity of co-creation. While noted previously many of the students were high achievers it is unknown whether this is solely explainable because these students sought out co-creation opportunities or also if students who were less experienced or academically gifted did not feel welcomed or able to participate.

\section{Power Imbalance between Staff and Students}

A critical theme that arose in the dimensions of co-creation barriers was power imbalance. This barrier is actually echoed in many of the other barriers and themes generally, for example, lack of clarity was often due to the staff not allowing for enough transparency of the project, and thus using their position of power to obstruct the students' understanding of the project and how to contribute. The theme also arose in many other instances, including decision making, structure, 
what feedback is considered, as well as students feeling intimidating by staff, staff feeling they forced to participate (e.g. someone above their position encouraged it), staff being reluctant to share information with students, students being disrespected or overlooked by staff members, students feeling like were not adequately compensated, staff concerns of students not following through with their commitments, staff concerns over giving students too much power, students feeling pressured to align themselves with the wishes of staff, and students feeling their relationships were constricted, to name a few.

One case that highlighted several power imbalances was with the case of student governance. The activity was to include online students in the student representative committees (SRC) and other student governance structure, however, the authenticity of that representation frequently came into question. One student notes,

I think are a few [staff members] who make an effort to help me join in, whereas sometimes there are others who just kind of shut it down and keep it to the couple of people who do most of the talking (Student, GOV)

But students also voiced concerned over power imbalances between students themselves, noting,

I think it quite a different thing student senate to bring in online students. I think that revealed a few interesting issues. One, the perceptions of online students, other students didn't take us seriously in terms of our concerns. And we didn't feel like we had a strong enough voice. It took us a long time to actually get the message through to them that we have an equal voice in student rights (Student, GOV).

The students' perception that staff and students may not fully welcome online students' perspectives also aligned to comments by made staff members, with, one staff member noting,

I think we'll probably see it change but we have to be careful what we wish for, we don't want the entire decision body of the university to be decided by a bunch of online students. And they're absolutely valid but it's about trying to get it right, so proportion representative is maybe not our best option at the moment... But it's funny, they've already started rocking the boat in the amount of finances that they have in their pool based on the number of student they have and what not, so those things are starting 
to bubble and it's really quite good because they've only just started saying look, we want genuine representation and we're excited about that. I don't think it's a personal issue class, but it's right to question that it is quite static across the groups in terms of representation and quotas (Staff, GOV).

These comments are interesting for several reasons. First, they highlight that while staff alluded to desiring to move past 'tokenism', fully embracing students in roles of power and decision-making can be a concern. This concern is only amplified further when those students lack tangible relationships with staff, as is the case with online students. Issues of trust and assumptions about wanting different outcomes, means that staff in power and wary of transferring power to students. However, these issues arise not only between staff and students, but also students to students. Where in-person or traditional students felt that online students were not equal to them, and also were reluctant to share power. Yet while one might assume the solution is to build stronger relationships between students and staff, in the case of student governance a student warns about this, noting,

I've had a staff member recently say that there's a situation around one of the strategies being implemented and I guess the staff aren't really happy with it and I said to the staff you have ever right to email me your concerns. But in my reply, I said, I understand your concerns and fears, but as the student representative, my position will always be for students. And they turned around and said this doesn't affect students, so you shouldn't vote for students you should vote for staff, what's the point of having you if you don't have our backs. And I replied with strong words... [laughs] (Student, GOV).

It is not unique to the governance case that there were power imbalances uncovered in many staffstudent co-creation activities. In a particularly interesting case, where the student and staff worked alongside one another to create a student-partnership program, the student reported that despite having a staff role, she did not perceive that other staff respected her equally to others. She tells an anecdote,

In a meeting the other day where the head of the student strategy office was meeting with myself, my staff partner, and the co-chair of the steering group to find out about the progress of the project for the program design and he addressed all of his questions 
by name to my co-chair who was the dean. Now the dean has nothing to do with project because of the divorce between the steering group and the project. But regardless of the fact he was not involved, the officer continued to address all of his questions to the person with the most senior authority in the room, and regardless of his expertise on the questions he was asking. To me that was an illustrative example of the way the power hierarchy within higher education continues to permeate every aspect of my interactions, regardless, and almost ironic of the context. I found that meeting really challenging and really disenfranchising, and I felt devalued and marginalised in a way that I guess I notice more because of the strength of my beliefs as a result of my partnership work.

From these examples it can be seen that not all faculty or staff are as enthusiastic about involving students in decision-making processes as others. This is an important aspect to note, as while all the staff participants in this study were involved in co-creation, and thus fairly positive about cocreation, faculty that were mentioned in the case studies but not involved, were not always portrayed as to be positive about the opportunity to co-create with students. Even in cases where the staff involvement with students was very limited, for example a short workshop to brainstorm ideas about enrolment processes with students, some staff were not interested to co-create with students, one staff member notes,

There might have been some people there because they were told to be there. And they might have felt it was bit touchy feely and nothing come out of it. I think they are more linear people. But only a couple seemed to be like that. Always standing at the back.... They already came with the solutions and didn't want to be a part of the process (Staff, EXP).

Staff members involved in the workshop experience case were additionally concerned about airing their "dirty laundry" or problems in front of students, unsure if it was appropriate to disclose some less positive aspects of the university experience to students. In other cases, it was also found that despite staff telling students they could give feedback and ideas, many students felt uncomfortable to do so, for example, one student notes,

I think if [the staff member] put forth ideas that we weren't happy with, we don't feel like we can't say no... for example when my friend and I were coming up with a theme 
[the staff member] said he had a suggestion and we said let us come with a list first and then we can narrow it down to our top three, and then we can add your one in and float them around.

However, the issues related to power imbalance are difficult to address. While students reported feeling that they had little decision-making control and that their feedback was not always considered, they also reported in other ways that they needed staff to help guide the activities and lead the processes. Power imbalances, thus, are unlikely to be resolved unless structural aspects and processes are first made more equitable. Yet for this to occur there would need to be not only a shift in staff perspectives of students, but also students' perspectives of themselves.

\section{Disengagement or Lack of Motivation from Participants}

One rare, but determinately negative barrier that found in cases was if student(s) or staff member(s) were either disengaged or not motivated to be a part of the co-creation activity. While most the cases were voluntary, there were cases where once the student or staff volunteered it may be more difficult to quit later on, for example, enrolling in a subject. For example, in the case of course design, one student enrolled in subject caused issues within the student group, with a student noting that he conflicted with many of the other students' ideas and was not willing to do his share of the work. The staff member similarly picked up on this occurring and notes,

Like I had one student, this semester, who I knew was going to be a problem. He arrived in week 3 and he had been off traveling, which already says something about his values. And for him it was, tell me exactly what I need to do. He would come late to class or not come. And then he wanted a 9/10 of his marks. But you know, actually, you're an arrogant shit (Staff, CD).

Indeed, with co-creation activities, motivation also hinged on everyone participating equally and when some participants did not view the activity positively, the activity itself often was thrown into disarray. Staff in some cases were also found to be disengaged, for example, in the student governance case one staff, remarking upon their peers, notes,

I also feel that academics have included the student voice as a 'box ticking' exercise. Essentially universities need to demonstrate they are listening to the students. However, the spaces they have created are not reflective enough to accept the 
(stronger) views of students. There is certainly a view that the students' voice is important, but it is only one data-point that academics and professional staff will use to make decisions on pedagogical change (Staff, GOV).

In the peer mentoring cases, students also reported disengagement from staff who often perceived student mentors (a different role than tutors) to be interfering with their subjects and thus did not help them with materials or information that would enable them to peer mentor the students more efficiently. The barrier of disengagement, like power imbalance, may be a difficult one to resolve. Co-creation activities often strive to be inclusive, however, inclusivity may also be a weakness when some participants are not carrying equal responsibility. Further, co-creation should most likely remain voluntary, as when students or staff are forced to participate, they often can cause havoc on the experience for everyone.

\section{Co-Production}

As previously described in earlier chapters, this study on student co-creation aimed not only to understand the antecedents and benefits of co-creation, but to also explore the nature of cocreation through the processes and various types of activities. To achieve this, the study has used the constructs of co-production and $\mathrm{ViU}$ as the lens to understand the types of co-creation that occurs in the cases. The first construct, co-production, has been explored more deeply in literature to date. Co-production defined within this study refers to how the student and staff members share the responsibilities within the activity to produce a specific outcome(s) (e.g. publication, curriculum). The second order themes of this construct include equity (e.g. willingness of staff to share control with students, transparency), interaction (e.g. engagement and ongoing communication) and knowledge sharing (i.e. how student and staff resources, such as their perspectives, are able to be translated across stakeholder groups).

Unlike the previous constructs, the second order themes for co-production and ViU did not emerge organically from findings, rather they were based on a previous meta-analysis by Ranjan and Read (2016) of co-creation activities within organisations. Part of the aim of this study therefore was to explore how these constructs fit within the new context of higher education and if they were still useful frames to understand how co-creation occurred. The results highlighted how these constructs were suitable for being able to decipher between different types of cocreation (as will be discussed more in detail in Chapter 8). 
Equity

Equity as an element of co-production refers to several aspects including the degree of access that was given to participants, whether all participants were supported and encouraged to adopt responsibilities within the activity and level of transparency that was shared across participants. Within this study the element of equity varied greatly between cases, with some cases having a relatively high degree of equity between participants and others have a relatively small degree. For example, in the case of student and staff co-created learning resources, students shared a considerable amount (if not the bulk) of the responsibility, including decision making processes, as well as a high level of transparency afford to them. One student from the case notes, "It's no longer a student-teacher relationship, but an equal playing ground" (Student, RESO). However, other cases were predominantly still staff-driven, for example, while students had access to participate, and were given some information, much of the control was still in the hands of staff.

In fact, staff members throughout the cases often reported decisions they had made with little or no mention of if students had informed their perspective and preferences before the decision was made. This despite the fact that the activities did include student perspective in other ways. Overall, this alludes to a common tendency of student-staff co-creation activities in higher education, as observed in this study, where students were invited to contribute their resources, but in specific and mandated ways. A selection of quotes that highlight staff decision-making include:

I have thought before about letting the students pick their groups or pick their company, but I don't actually think that fosters the right attitude. In real life you don't get to pick your teammates, so why should you in a course? (Staff, WIL)

The principle I am working off, if there is a student that has been involved before and wants to take it on as the editor, then I think they have earned the merit to be entrusted with that. I don't want someone parachuting in. (Staff, PUB)

I do not encourage PowerPoints at all. At all. We don't. I never use one, the only way we use one in training is to demonstrate how destructive they are. (Staff, PEERB)

Staff final say in many activities did not go unnoticed by students. One student involved in the student governance case noted, "I often get the feeling that student senate has to be run by a 
'responsible adult' who is employed by the university with the students there as representatives, rather than change makers." (Student, GOV). Yet ultimately while most staff retained the majority of control in decision-making processes of activities it is unclear whether this practice is a hindrance or a help to co-creation activities. For example, in some cases it was found that students may get sometimes argue with other students when the decision-making rested solely in student hands (e.g. CD, GOV).

Equity can further be explored as how much access was available to student participants. As many co-creation activities are voluntary, either for students or staff or both, there are concerns that those who choose to participate in co-creation activities are a unique subset of the population and not representative samples of students or staff. In this study, it was found that many of the students in particular who chose to participate in studies were academically top preforming students who had often been involved in other co-creation type activities (see antecedents). For example, a staff member involved in the learning resources case notes,

It is only the high achieving, really engaged students that would put their hand up for this, because a lot of other students just want to tick the boxes and get their marks, without really thinking about the learning or the experience (Staff, RESO).

Additionally, requiring future research, is whether domestic students are more likely to volunteer in co-creation activities, as it was found that in some cases (e.g. PUB, PEERA, GOV) that very few international students were involved, with a staff member from student governance noting, “Our senate representatives are very much Australian, I don't think international students knew the channels" (Staff, GOV).

However, students not being aware of the opportunities to co-create may not only be an issue to international students. In the social media case, students also note that they were unsure how many other students had heard about the activity. In this case, however, the student notes that this may be a benefit to the activity, as it rewards students who are passionate and more likely to seek such opportunity out, they note,

I think it's there for those who are looking out for it. And I think that's a good thing because you don't want to open the door to people to those who aren't as passionate 
and then your product isn't as great but yeah for those that are eager I think there's enough publicity for you to know about such things (Student, MEDIA).

Cases included within the study, while voluntary, also frequently required a type of application process, hindering the overall access of the activity to students. While the application processes were intended to select the students most suited for the roles and activities, they could also be exclusionary. For example, both the work-integrated learning case and the peer mentoring programs had both a formal application hurdle of students' previous grade history and also an interview. One staff member in a peer program explains what she is looking for in potential student participants,

I'm really looking for inclusive personalities. They gotta understand a little bit of our power rank and how to notice people who are of lesser rank to be adding and stand by them and engage them and really value them and their input. I think we have a very strong equality kind of focus in that. But they also got to be relatively confident in the material. I find it doesn't matter too-too much around the material. If they got a credit and above, and they have been given the job, they jump in and upskill themselves pretty quickly, you know? (Staff, PEERB)

As many activities were new, there was relatively little discussion or interest from staff about how to expand the activities or improve the access of the activities to more students. One exception to this was found in the student governance case, where online students were for the first time invited to form their own student representative communities. Further, voting for all representatives, not just online students, was beginning to take place online. Staff noted that this had unexpectedly raised the rates of both nominations and voting, noting,

This year we had a change with SRC with all the voting now happening online and we saw that the voting became more popular and more people nominated themselves and a different mix of students came forward, and not just the students who were friends with the students who are already on. (Staff, GOV)

Finally, the element of equity could also be investigated as to how much transparency was provided in the activity. For example, were students aware of not only what their direct objectives were but also how the activity was situated in the larger context and what the aims, if unique, were of the 
involved staff members? In some cases, staff tried to be open with their students, not only about the project, but about their roles and how a university operates. One staff member involved in the learning resources case notes,

I think it was a chance for students to see that as academics, we don't know the answers to everything and there often is no right or wrong answer. I think they also got an insight into the way we also work in teams and of the competing interests there are in our day to day jobs (Staff, RESO)

However, there was still a detectable lack of transparency with students for most cases. Yet in some cases, staff explained this was intentional, to help students feel comfortable. For example, in the student experience workshop, staff were instructed not to share their titles, so students would not feel intimidated if they were speaking to a senior faculty member. Additionally, staff were instructed not to use academic terms, and instead encouraged students and staff to share ideas through pictures, eliminating terminologies. They explain their decisions,

The staff aren't allowed to say their position or who they are. They are only allowed to put their name. Because we want everyone to feel equal (Staff, EXP).

People in teaching roles sometimes use words that are confusing and there might be a bit of a power thing, but with pictures everyone is on equal footing (Staff, EXP).

As highlighted in above discussion equity was a particularly interesting element within the construct of co-production to investigate. This is partially because elements of equity, such as sharing control, access, and transparency are also very linked to power. In future chapters (e.g. Chapter 8) this will be further discussed.

\section{Interaction}

Interaction has been defined as the primary interface of co-production and essential for cocreation between students and staff to occur (Ranjan \& Read, 2016). Interaction within this study was analysed by exploring whether students and staff had ongoing communication, if students and staff were engaged in the activity, and if there were honest conversations between participants. Interaction further supported other aspects of co-production, such as equity and knowledge 
sharing. For example, one staff member notes that the interaction with staff was the primary opportunity to understand student perspectives and notes,

Often this close proximity gives students the opportunity to provide suggestions for improvement, discuss their experiences and voice their ideas. (Staff, PEERA)

Students involved in co-creation activities also mentioned that the experience gave them an opportunity to get to know staff members and other students more. For example, students involved in the student-staff publication found it enjoyable to get to interact with each other outside of a classroom setting, while students involved in the learning resources case found it was more meaningful to meet faculty through a joint activity, rather than typical office hours. They note,

I think the project gave us a chance to see each other outside of class in terms of our intellectual and creative capacity, I also think it was really nice seeing what people from our degree can turn out and create in a sense (Student, PUB)

From my experience from this project, I did realise that the follow up meetings with the faculty was a much better interaction as compared to a much more formal interaction as individual student. I able to communicate and share my ideas with much more ease (Student, RESO)

Staff additionally mentioned the benefits of the increased interactions with students. Comments included helping to inform them about students' perspectives and gaining motivation in their roles. One staff member notes,

I think it's been beneficial for me to work in a different way to work with a student and to learn from them and a different working relationship for a better outcome and it's made me think how I can improve students in other aspects and projects. And thinking that actually there's a lot of benefit in doing that ... (Staff, PROG)

However, while interaction between students and staff did occur, it was often not as frequent or open as it could have been. For example, when students were asked if they had meaningful interactions with staff members, they often felt the interactions were unauthentic or superficial, as a selection of quotes highlights, 
I try to give feedback at every meeting but probably not as much as I should. Like one meeting I didn't say anything and afterwards I thought oh, I should have said something. But I think sometimes that comes down to there are so many people on council, it goes around, and everyone has a say (Student, GOV)

No, our interaction with academics was very limited, the peer assisted study session program ran in parallel with the academic coursework, but we never worked together personally with lecturers. We worked with a full-time staff member coordinating the program who we interacted with frequently and team leaders who were also students. (Student, PEERB)

Not really to be honest... I got some interesting insights from the lecturers and tutors I spoke to like that, but in terms of like working for the university, I wouldn't say [we interacted] because I still think I was a student in my role. (Student, MEDIA)

Staff were also aware of the nature of some interactions as inauthentic or too infrequent. For example, in the student governance case, staff members noted they were actively trying to improve the degree of interaction between staff and students, yet the structure of the activity made interaction difficult, they note,

The online time they engage with other representatives is at student senate and that's where they engage on a regular basis. That's the big thing we try to do. We also have an academic senate where the undergraduate is an internal student and our postgraduate is an online student. So there's opportunity there but the dialogue is probably quite siloed (Staff, GOV)

Staff also mentioned that students may need more time to adjust to their new roles, and that interaction could be improved with more opportunities for students and staff to get to know each other, for example, one staff member notes,

Initially, the students were a little reserved, because it could potentially be a little intimidating, and of course if you are student you don't necessarily want to say bad things an area that someone might be responsible for. But if you have the right mix of 
staff, and you do a first ice breakers and laugh, then the students start to realise it's a comfortable space I think (Staff, EXP)

\section{Knowledge Sharing}

The third and last aspect within the construct of co-production is knowledge sharing. Knowledge sharing can be defined as the degree to which students and staff could express their current and future needs, as well as sharing information, as well as other resources, such as their perspectives and ideas. The cases of co-creation included in this study highlighted how both students and staff learned from one another. Staff noted frequently that they had learned from students and enjoyed participating in an activity where they were not viewed as the sole 'expert'. For example, staff note,

The premise that as a lecturer I am the expert takes away the reality that we're all learning in this together. And I have learned enormously from my students both in my interaction with them and also the way the projects are, I've learned a lot about various elements such as homelessness in Melbourne (Staff, CD)

We acknowledge we have some incredibly creative students and when we open up competitions we had some student design our open day filter, and they are amazing artists and could probably do better graphic design than me! I mean we're not going to be experts at everything... (Staff, MEDIA)

In particular the exchange of knowledge was exemplified in a case where a student and staff member worked together to develop a program. The staff member, who was not familiar with program initiatives to foster student-staff partnerships, notes that she learned a lot from the student partner which allowed the partnership to feel more balanced, noting,

The particular student I'm working with is more familiar with the students as partners concept than I am, it's something they've worked on before and they have a thorough academic understanding of it. And they bring a lot of knowledge and experience on that side whereas my experience is more understanding how the university works and how-to coordinator a program and design a new program and arrange some of the more administrative aspects. So, both of us have quite unique skills and we've found a way for both of us to contribute equally (Staff, PROG) 
The student involved echoes this as well, noting,

I think that the clear division of expertise and labour kind of makes it a moot point because she doesn't know anything about the partnership literature and I don't know anything about how to do all of the administrative processes that she's an expert in so there's a clear delineation between our areas of expertise and neither of us is vying for power or competing. (Student, PROG)

Knowledge sharing, moreover, not only relates to how students and staff can equally contribute to a project but also how they can understand each other's roles more. For example, in a peer mentoring program a student who hosted a workshop related to how staff felt when students did not show up, after teachers prepared a workshop or lesson for them, noting,

It just seems like if we organise a workshop and it's something that students want, but we might organise it and we wait for 30 minutes and no one turns up and just realising that--- I guess you kind of think about your own student experience, what if it was like the lecturer turned up and no one was there. And I think you realise what the processes you have to go through what it's like. (Student, PEERA)

Students also mentioned learning more instrumental and useful aspects of the university, such as specific programs or courses that were offered, how reporting takes place, and even administrative processes. For example, one student involved in the publication case notes, "I also discovered departments I didn't know existed. The printing department is huge!” (Student, PUB).

Yet one of the most salient themes that came through knowledge sharing was that many students felt co-creation opportunities gave them the chance to share personal aspects of their experience to staff. For instance, students felt like through the range of activities they could share their perspectives of what it was like to be a student. Quotes that highlight this theme include,

I think we showed them our perspective as university students and what we thought of the corporate environment and sort of our expectations on what to do and how to do it (Student, WIL) 
Staff get to know the student and realise that students aren't just our ID numbers with papers to grade in a certain amount of time. But rather that we are people, young ones, with flaws, who won't get everything right for an essay, who still need guidance and someone to properly teach us thoroughly about skills we need to contribute to society (Student, CD)

By sharing their own experiences and insights it is likely that the student-staff relationships were also affected. As relationships are also a theme within the construct ViU this highlight some of the overlap between co-production and ViU and why the two constructs can be found in conjunction with one another in co-creation activities.

\section{$\underline{\text { V. Value-in-Use }}$}

Value-in-Use (ViU) extends past elements of co-production and begins to conceptualise how the users, in this case students, use the value proposition available to them within the university experience. ViU contains three key elements, including the value of the experience itself to students, for example, if they find it memorable or transformational, as well as how they can personalise the experience to their own needs and desires. Finally, ViU refers to the value the students and staff gain from the relationships they have formed during the co-creation process. Thus, ViU can be thought of the value to the individual or group of individuals, while coproduction is more closely aligned to the value that is created for the institution (e.g. more studentcentered curriculum, a student peer mentoring program that improves retention).

\section{Experience}

Experience can be an ambiguous term. In this study, however, it refers to how participants perceived their co-created activities to support memorable, and even transformational, experiences. In previous literature, experience within co-creation has been also been conceptualised as if the intrinsic value for the participants (e.g. Ballantyne \& Varey, 2008; Lusch \& Vargo, 2006), meaning the value participants saw not from the experiences outcomes (i.e. improving confidence, helping find a job) but just enjoyment within the activity itself.

Interesting within the study was that while many participants frequently noted the barriers to cocreation, such as issues with time, lack of resources, and power imbalances, the majority of participants, especially students, still saw their experiences as extremely valuable. In particular, 
students frequently mentioned the joy they received from helping other students through their activities, as highlighted below, including,

I've never had a job or area of study where I've been this passionate about doing it, driving institutional change is just... the joy I get from working in students as partnership is enough to sustain my work, but the prospect of facilitating a hundred other students a year to have partnership experience it just puts me over the moon. (Student, PROG)

Anybody who asks me about jobs around campus I'm always like try peer mentoring, if you can get in, it's a really worthwhile thing to do because it's a great feeling when you help other students and see the light of realisation when you see students get it, it's a really satisfying feeling (Student, PEERA)

Students also mentioned how they believed their participant in co-creation activities to be one of their most memorable experiences as a student. While some of these students alluded to have a physical artefact such as a magazine or a social media video to look back on, the experience itself was also highlighted. For example, one student who made a social media notes, "It's a good thing to look back on... or just watch from time to time. I must say, I did save it and I do watch it... you know... randomly" (Student, SOCIAL). Within the same case another student also noted she enjoyed the co-creation of social media and notes, "It's been one of the highlights of being a university student" (Student, SOCIAL).

Staff also remarked upon their experiences within co-created activities and the enjoyment and intrinsic value it afforded them. One staff member involved in student-staff co-created publication notes, "I find more meaning in engaging with students and helping them realise their awesomeness. This space helps give my work a greater sense of meaning" (Staff, PUB). Another staff member who manages a peer mentoring program also noted, "We have a really great time, we dress up, we make videos, it's really fun. It's a whole person of kind of process" (Staff, PEERB).

However, while the experience was positive for most, not all students who participated in cocreation enjoyed their experiences. For example, in the case of student governance a few students mentioned that they were not satisfied with the overall experience and did not feel that they were authentically integrated into the activity. This is interesting, as students noted it was not staff 
members, but rather other students that left them feeling excluded. One student summarises this tension between students,

Particular the president of the student senate [was not welcoming], and maybe that's just being precious, but if I were to assume that role, knowing basic aspects of leadership, I would probably go out of my way to make sure I'm connected with the people I am responsible to. I don't think that effort was made and that just reflected the mindset that was already ingrained towards online students (Student, GOV)

The student goes on to they did not intend to continue their role and were unlikely to get involved in student governance in the future. As with all experiences, negative experiences in co-creation are likely to discourage participate in similar activities in the future.

\section{Personalisation}

Personalisation within this study was investigated as how the participants saw the activity's value as malleable to their own desires, needs and interests. As some cases were quite structured and others less so, levels of personalisation across cases varied. Additionally, personalisation could vary on how the student chose to immerse themselves in the activity, as the more actively engaged within the activity they became, the more likely they could shape the value of the activity to their own desires. For example, some students involved in the student-staff co-created publication only submitted pictures or articles to the magazine, while others eventually sought to be editors of the magazine, which both highlights the ability of the participants to participate how they wanted to, and how the personalisation levels developed with the increasingly engaged roles.

However, staff, especially those involved in co-created activities within the classroom such as curriculum design and work-integrated learning, were also wary of too much personalisation. This issue was likely tied to additional element of assessment. For example, in both cases the subject coordinator noted concerns over allowing students too much freedom with the structure of their projects or involvement when there was still an assessment required. Additionally, the staff members mentioned how while some students enjoyed the co-creation opportunities, other students who enrolled in the subjects did not, and subsequently struggled. One staff member notes, 
There was a real split between students who thought this is fantastic- I can go out and explore my own interests and do self-directed learning and research and the others who said there's no structure in the subject (Staff, CD)

Other staff involved in cases with assessment, such as the learning resources case, thought the opportunity allowed them more flexibility in the assessment of students. Noting,

Rather than adhering specifically to a tight assignment that may not allow for too much freedom (although this assignment did allow for freedom regardless of this voluntary experience), students are able to be creative on a wider scale if that is what they think they are able to manage (Staff, RESO)

However, important to note, is that the learning resources case had relatively fewer students, only a group of less than 10, compared to the other cases such as curriculum design and work-integrated learning which had between 30-60 students.

Despite staff challenges on how to support both personalisation and assessment, students were relatively positive about how they could engage in the cases to suit their own needs. A student involved in the peer mentoring program remarks how unique it was to, along with the students who attended, be able to structure the mentoring as they saw fit. He notes,

I think that's one of the key advantages of the program is that I and I guess also the students that attend get to make the sessions their own in their own way and finds what works for them and for the students that come along regularly. And you get to make it your own and do things that work for everybody (Student, PEERB)

Other students involved in project work also enjoyed the opportunity to study their own chosen topics or areas of interest, as highlighted by the quote below,

This is way better than any of the other projects I have participated in. It was better because of the freedom that we had to actually choose what we work on and how to deliver the information, also because it was across the university staff I think were easier to get a hold of (Student, RESO) 
Overall, the element of personalisation is increasingly interesting element for those involved in cocreation to consider. As could be seen through the student and staff aims and motivations, many participants chose to participate because the activity rewarded them with something they valued (whether it be relationship to others, a feeling of value, or work experience). By allowing students and staff to personalise their co-creation activities thus activities may have more appeal to a wider range of students and staff and improve inclusivity as well as scalability.

\section{Relational}

The last element within the construct of ViU is relationships. The study sought to understand how co-created activities effected student-staff relationships and possibly led to closer relationships between students and staff. The results from the study found that students involved in co-creation activities often felt closer with staff, while staff remarked how the activities gave them the opportunity to connect more deeply with students. Some quotes even highlight that co-creation may improve students' long-term engagement with the university. However, issues within relational aspects also were found, including students involved in co-creation activities feeling as though the boundary between students and staff was blurred and subsequently more confusing. Finally, some students noted that the closeness they felt with staff in co-creation activities actually amplified their lack of relationships with other members of staff.

Students involved in the cases often remarked upon how the corresponding staff seemed to care about them more than other staff they had interacted with previously, as highlighted in the quotes in below,

There is a genuine interest from staff in the students they teach. Are not just there to get through the content, actually want to help students (Student, WIL)

Like she realises that you just a human trying to get a degree. I think she has respect for us as people, and it's not like other tutors don't but you don't feel it as much (Student, CD)

Yes, as these staff members have developed a therapeutic relationship with students as they have shown us that our opinions have value and merit. Other facility staff do not always give us this impression (Student, EXP) 
Staff additionally felt the activities changed their perceptions and relationships with students. Staff noted that they got to know and understand students more, and the experiences were rewarding to be able to know students on a more personal level. For example, a staff member involved in the student-staff co-created workshop notes,

I think it also is quite a visible way to show that you care about their input - and that the organisation is trying to improve things that might be pain points for them and putting in the time and energy into the investment - that we're all here with the same goal. I think that is quite strong messaging for the students, actually (Staff, EXP)

While the staff member involved in a student-staff co-created publication similarly notes,

And the vicarious reward of seeing something come into print and see students reference it in their CVs I find that this is an idea that create a community and that's rewarding in itself. (Staff, PUB)

Moreover, investigation of the effect on relationships also highlighted that co-creation activities may enhance relationships long-term. Students often noted that the activities had led them to form not only closer relationships with staff but also fellow students. They also mentioned how the activity had built a community for them, noting,

I think I was already going to stay involved in the university community. But I'd like to see where the magazine goes and how it continues to evolve. I think it's a good point of contact with the university (Student, PUB)

Because from my personal experience I had a strong feeling after the co-creation that I'm (finally) part of the University of Melbourne society (Student, MEDIA)

However, investigation into how co-creation activities impacted relationships was not entirely positive. Students and staff also sometimes noted that the new responsibilities given to students also caused some role confusion. For example, in the student governance case, one student noted that students who feel too close to staff sometimes begin to take on staff perspectives too strongly, or want to please staff members too much, and thus, may compromise their student perspective. One student notes, 
Yes, students do feel closer with the staff involved with senate as they are working together and often form a good relationship from this. Sometimes I view this as a negative as student representatives can get caught up in pleasing staff they are close with or listening to their ideas and viewing them as more valuable due to their position within the university. This can sometimes result in students not speaking up about certain issues or giving reports that sugar coat the details (Student, GOV)

The tensions caused by new responsibilities also may negatively impact student to student relationships as well. A staff member involved in a peer mentoring program notes that the student peer mentors have to mindful of how they interact with non-mentor peers as they should not be seen to show favouritism, noting,

I don't want people to be seeing to be mates with the facilitators because I think that sets up the bonded, a bit too bonded I think bridging with a little bit of bonding and that happens in a safe space, but we have to be continuing bridging people... (Staff, PEERB)

Finally, while co-creation activities often enhanced student-staff relationships, this enhancement also highlighted less positive relationships students may have had previously or following. One student for example, felt that his closeness with a non-academic staff member actually made him feel more disconnected to the academic staff, noting,

I guess it kind of highlighted my disconnect with the faculty. Because that was a key missing thing from [my experience]. But it really highlighted how amazing the student community as well as the rest of the support staff were, I mean, you know, it really, really touched me into that sort of side of the university, which was really fantastic. But it ripped me away more from the [academic] faculty... (Student, PEERB)

Therefore, in the later discussion of co-creation (see Chapter 8) it will be critical to understand the impact that co-creation may have on student-staff and student-student relationships, analysing both the positive and negative results from the new roles and responsibilities that arise. 


\section{Benefits to co-creation}

To investigate the nature of co-creation across of cases the study lastly sought to investigate the additional benefits that participants felt the activities awarded them. While some benefits to cocreation have already been discussed, such as knowledge sharing as an element of co-production and relationships as an element of $\mathrm{ViU}$ the study also uncovered benefits that have not been previously conceptualised by co-creation literature. The additional benefits uncovered in the study included: employability, self-efficacy, ownership, innovation and university marketing.

Important to mention again here is that this research used an iterative model (Chapter 4) to help guide research into the nature of co-creation in higher education. Through a literature review, cocreation benefits, as showcased in the model, included knowledge, relational, and innovation. However, as the research explored these ideas through empirical data, it was found that knowledge and relational, while benefits, are mostly aptly discussed through the concepts of co-production and $\mathrm{ViU}$. Therefore, only innovation (improvement to services) is considered a benefit outside of the co-creation process. Moreover, as will be discussed now, innovation was not the only benefit found within the study. Student employability, student self-efficacy, student ownership and university marketing were also found to be benefits of co-creation outside of the co-production and ViU constructs.

\section{Student Employability}

While many of the staff involved in the co-creation cases noted that improving student employability was one of their aims, this particular benefit has not yet previously been investigated closely as a result of co-creation activities. The study highlighted, however, that for many students and staff, they perceived student employability to positively affected. Part of this was seen instrumentally, as students who worked to co-create an artifact could now showcase a particular outcome to future employers, for example,

For resume building this is a point that I highlight, I applied to a magazine and showed this, and I hope it will be seen as a point of difference... (Student, PUB)

This has been a great experience for me and something I will speak highly of- and tie back to the university. It's actually something I will mention in job interviews as well. 
It's a chance to show teamwork, throw myself out of comfort zone and so on. I'll definitely be talking about it (Student, RESO)

But students also noted that the activities allowed them to work closely with others in a professional atmosphere, which in turn, helped them feel prepared for future employment.

Students have first-hand experience in their course and can provide insight on worked best for them in achieving their goals or what they have learned from other successful individuals around them (Student, WIL)

Students also remarked upon how the experiences had impacted their future career paths. This may point to a finding that students who are involved in their own educational processes become more interested in educational work and thus, want to continue their studies or become teachers. For example, students note,

My future career path is going to be in education. I plan on transiting to academic professional positions around student engagement. Students as partners involvement has completely transformed [it] my trajectory (Student, PROG)

I have been involved with PLA since my 2nd year but I've also volunteered other things for lecturers and stuff because it's something I'm passionate about. So sometimes I come in and talk about student involvement to other students and considering going forward and I am thinking about getting a $\mathrm{PhD}$ and lecturing further on (Student, PEERA)

The link between employability and co-creation will be further discussed in the following chapters.

\section{Student Self-Efficacy}

Self-efficacy has been defined previously as the perspective or confidence one sees in himself or herself to succeed in accomplishing tasks or succeeding generally (see Bandura, 1997). As highlighted by several cases, many students felt their participation in co-creation activities improved their beliefs about themselves and improved their own confidence. Highlights of student quotes include, 
Feeling empowering that you know that what you've done, you've really done, and you can see yourself in what you created more so than in other subjects (Student, CD)

For me the benefits have been a huge boost in self-efficacy and belief in my capacity in my role as a student regardless of it rather than in spite of it (Student, PROG)

I am really proud to be a part of the social media team. And I think it has given me confidence and if there were more opportunities I would do more (Student, MEDIA)

Staff also mentioned noticeably watching students develop self-efficacy through the activities. For example, staff felt that students realised that their perspectives were meaningful, with one staff member noting,

I think they feel that their ideas are valued, and they are taken seriously. Also, they come to understand that they have something worthwhile to contribute (Staff, PEERA)

Another staff member involved in a work-integrated learning subject felt that by encouraging students in a group project with industry students could see applicable use of the knowledge they had learned as students, and notes,

The big one I see in the students is their self-efficacy, they come in and start as university students with for the most part a self-perception that were just students and despite the fact we are high achieving student and we're at the end of our degree we really don't know much about much and we're not ready for the workforce... but their involvement in project work helps address that (Staff, WIL)

\section{Student Ownership}

Related to students' self-efficacy but distinct, was also the benefit of developing student ownership in co-created activities. While not all activities created a sense of ownership for students, some of the cases did, including the student-staff co-created publication, student co-created social media, and student co-created curriculum. What these cases have in common is a lack of previous examples for them for students to base their own contributions off of, therefore, it may be that 
the newness of co-created activities leads students to feel like they shaped the activity more deeply, and thus, are more likely to develop ownership.

Ownership was particularly strong in the case of the student and staff co-created publication, with numerous students alluding that they had first come up with the idea or helped developed the initial ideas. For example, to highlight, two different students note,

I actually was one of the people who had the genesis of the idea... (Student, PUB)

When I brought the idea up with the staff member it was conversational, rather than a formal proposal, because I can't pinpoint exactly when it came about (Student, PUB)

The benefit of ownership is also linked to pride. For example, a student involved in the social media case notes, "I feel proud. And when my friends notice it and say something to me I will feel happy about it. Like it's an achievement...” (Student, MEDIA).

\section{Innovation}

Student and staff co-creation also resulted in benefits through the innovations of services and/or products. For example, the social media of the university was improved by having students contribute student-centered material. In fact, in all of the cases, participants, both student and staff, noted that the outcomes of the activity were improved by incorporate student voices and preferences into the activity itself. For example, the subject coordinator for the curriculum design case notes that the activity improves each semester, as she learns something on how to improve each semester from the students, she notes,

Yes, it has evolved! Each cohort shapes it. It gives it depth and breadth each time. Every year there's something I think wow that's fantastic and I do something a little different the following year. While some of the improvements are minor, there have been some significant changes due to a "co-created learning moment" (Staff, CD)

Staff members from the social media case also mentioned how improve their offerings were from having students involved as contributors. They note, 
Sometimes we're a bit detached from the student experience (our building is off campus) so these student takeovers bring us back in and act as a reminder (Staff, MEDIA)

Additionally, students felt strongly about how their perspectives could future enhance services and productions (i.e. offerings) within higher education. For instance, many students noted that as current students, their perspectives on how to improve higher education were more valuable than staff, who may have been students quite some time ago when expectations were different. They note,

Students can bring a fresh perspective to how things can be taught. Every person regardless of age has had unique experiences throughout their lifetime and has their own ideas and knowledge base. Collaboration with students allows institutions to tap into this knowledge pool (Student, RESO)

As a current student, I have a much stronger understanding of what students may be struggling with, especially in my field of study. As a result, I can provide valuable insight into the student mindset (Student, PEERA)

While both students and staff mentioned that co-creation led to elements of innovation, future study of co-creation cases could take a longitudinal research design to further understand how the perspectives and ideas that students integrate into co-creation impact later activities, teaching designs, and related practices and policies.

\section{University Marketing}

The last benefit that arose from the study was how the co-created activities were linked to future university marketing and/or the university image. For several staff involved, improving university branding or image, or appealing to future students, was an intended aim, which seemed achieved in most cases. For example, the staff member involved in the work-integrated learning subject noted that the subject is often used in promotional materials and that the university has designed the subject in part to show local companies how skilled the graduates from the program are, he notes, 
The subject is also used in promotional materials feedback from clients that will say things like, 'the student work in the WIL course was exceptional and on par with contract work that we've sent out to professional consulting organisations' and obviously the faculty loves that kind of feedback and uses that strategically (Staff, WIL)

Meanwhile, one of the aims of the staff member involved in the student-staff co-created publication was to have an example to show to prospective students about the uniqueness of the program and the opportunity to contribute to a magazine and notes,

I also keep a pile [of the magazine] at my desk and so students who come to be and say they are interested in the degree I can say, well here is what we do (Staff, PUB)

However, the finding of the benefit of co-creation to university marketing was especially interesting as it was not only staff, but also frequently students who remarked that they believed one of the benefits of their activities was for future university marketing. Highlights of students quotes include,

I hate to use the word 'market' but it's a way to market the output of the degree as well... because I know the idea came from Brown University in the USA with a really good student publication, and at the end of the day I think it does create a good image for the degree (Student, PUB)

Can I be a bit blunt? With the university I think they are looking for something to pull in students and trying to show students that if you are a student here you can do this, this and this... and it's good to show things where the students and staff are working together because it shows there's collaboration with the final product. So, it's a marketing tool to get more students (Student, RESO)

Happier and more successful students and a more successful program and pass rate. Increased status of the university for having programs in place to look after students (Student, PEERB)

Thus, while university marketing is not an explicit aim of most of the co-creation case studies included, it does arise from the findings as a benefit across many cases. As co-creation cases continue to develop in the context of higher education, it will be interesting to see if co-creation 
activities beget more co-creation activities, spurred by students and staff seeing the activities as a selling point for universities and towards prospective students.

\section{$\underline{\text { Summary of Data Results }}$}

The results presented within this chapter originated from ten cases on various activities between staff-student partnerships in which both interviews and qualitative surveys were undertaken. The results showcase the intricacy surrounding student-staff co-creation, within dimensions including antecedents, environmental factors, barriers, co-production, ViU and benefits. From these dimensions, numerous themes arose, as supported through student and staff responses (summarised previously in Table 7). Yet while the major findings from the study have been presented and briefly analysed within this chapter, further analysis and discussion in the following chapter are still critical to make sense of the findings, as they are numerous and complex. 


\section{Chapter 8. Discussion of Findings}

\section{Overview of Main Findings}

The previous chapter (Chapter 7) presented the empirical data resulting from the study. It highlighted the themes that emerged from the study and discussed the evidence that linked to those themes. This chapter will add to the discussion presented previously by connecting the empirical data arising from this study to the current literature on topics such as co-creation, student engagement, students-as-partners and trends in higher education. This aim will be achieved by presenting the seven major findings of this study in relating to the nature of co-creation in higher education ${ }^{12}$. A discussion of the unanticipated findings from the study will also supplement this discussion.

This chapter will further link all the parts of the dissertation together by discussing the where, what and how of co-creation in higher education. This will be achieved by summarising the areas where co-creation can take place (as discussed in Chapter 6), the stages of co-creation that may take place in higher education and comparing the findings of the study to the previously highlighted key considerations of co-creation found in literature (as discussed in Chapter 3).

Therefore, the structure of this chapter will include:

- Six major findings on the nature of co-creation in higher education,

- Discussion on unanticipated findings from the study, and

- Overview of the places, stages, and key considerations of co-creation in higher education.

\section{Discussion of Six Major Findings}

The six major findings in this study include, antecedents have a significant impact, environment dictate behaviour, barriers come in all shapes and sizes, the first step to co-creation is coproduction, co-production may amplify value-in-use, and benefits of co-creation can outweigh costs.

\footnotetext{
${ }^{12}$ Each finding will be connected to what has already been found and discussed on the topic in previous literature, however, please note, some topics have been discussed more widely than others.
} 


\section{Finding 1. Antecedents have a significant impact}

The first major set of findings resulting from the research relates to the antecedents of co-creation. Within the study several antecedent factors were explored including participants' personal outlook, participants previous history and experiences, students' initial perceptions and motivations and staff aims and motivations. Previous studies outside the higher education context have looked at how antecedents have shaped the co-creation and specifically how perceived support can positively influence social exchanges (Bettencourt, 1997; Ind \& Coates, 2013). Additionally, Yi and Gong (2013) explored three antecedents of customer participation behaviour as role clarity, ability and motivation. However, in their study there was no link between antecedents as a predictor for customer value.

Yet in this study, antecedents were found to be critical component of co-creation. For example, one question that arose from this area was, "Who participates in co-creation?" All of the cases included within this study were voluntary ${ }^{13}$, so this question was especially interesting given that students involved were not forced to co-create but rather elected to enrol in a co-creation type subject or choose to participate in a co-curricular activity. Staff similarly often initiated the cocreation activity themselves, outside of their major responsibilities, or were hired to facilitate student-staff co-creation (e.g. facilitating a peer learning program). Therefore, both students and staff personal outlooks and previous history often aligned to the values shared by co-creation, such as collaboration. As one staff member with an activist background notes, "I think that disposition towards the empowerment of individuals and enabling them, is sort of a fundamental value behind what I'm doing." Students further often had collaborative and innovative perspectives on encouraging change in universities, with one student noting that even before his participation in student governance he believed, “...the student perspective brings about the best kind of change as it is targeting the key stakeholders of the university; the students. An improved university experience can result from this as students give ideas and suggestions based on their time at university, therefore improving the experience for future students." In fact, to the researcher's knowledge, no student or staff member involved in the study came into their specific co-creation activity with a negative perspective on student-staff collaboration or student voice ${ }^{14}$. Further, while students were not asked to report their academic performance, students often alluded to being ambitious about their career goals, involved in various projects throughout the university, and being motivated by high grades and/or learning. This was expected, as other similar studies have

13 Note: Prahalad \& Ramaswamy, 2004 argue that all co-creation must be voluntary

${ }^{14}$ However, it is possible they were involved in the activities and did not choose to participate in the interviews. 
also noted the difficultly in recruiting minority or low academic achieving students in co-creation type activities (Rakrouki, Gatenby, Cantore, Rowledge \& Davidson, 2017).

The finding that students and staff who are already highly engaged in university choose to participate in co-creation is important for two reasons. Firstly, it appears that co-creation is especially appealing to highly engaged students and staff members. This has previously been detected in studies both inside and outside of higher education (e.g. Rakrouski, Gatenby, Cantore, Rowledge \& Davidson, 2017; Sanders \& Strappers, 2008). To further illustrate, in industry, cocreation is often limited to 'lead users' who like their higher education context counterparts are already highly engaged users (Von Hippel, 2005). In the context of questions over the value of higher education (see for example Haynes, Wynard, Madal, 2017; Hazelkorn, 2015) co-creation may be able to serve as a supplementary activity for students and staff who want to go beyond their current roles and responsibilities (Judson \& Taylor, 2014). However, this finding is also important as it calls into question whether co-creation has the ability to be scalable and perhaps even equitable. There remain questions relating to how co-creation could be expanded and whether co-creation could be extended for traditionally less engaged students (e.g. poor academic performance, low SES, part-time, etc.) (Dollinger \& Lodge, 2018). ${ }^{15}$ Additionally, outside of higher education, co-creation has been found to be more successful if users are intrinsically motivated rather than persuaded to participate (Kristensson, Matthing, Johansson, 2008). As this study's findings align with similar findings that high achieving students are often those involved in cocreation (Mercer-Mapstone, Matthews, Rueckert, Thomas \& Varnham, 2016; Varnham, Olliffe, Waite \& Cahill, 2016) a similar doubt is raised in this study as well. This is especially troubling in examples of student-staff co-creation of governance, where one student representative is often expected to speak for an entire student population. Therefore, if that one student representative is highly engaged and academically exceptional are they really appropriate for the position of speaking for the disengaged and academically underperforming groups? These questions were previously raised by Varnham et al. (2016) as a collection of case studies in student governance in Australia also found that underrepresented groups are difficult to recruit into student leadership roles.

\footnotetext{
${ }^{15}$ It should be noted that while students did allude at times to coming from low income families or backgrounds, they also often mentioned they were highly engaged students, with strong motivations for enrolling in higher education and high expectations of what they expected to achieve. As such, they were still considered 'high achievers' and 'highly engaged' students.
} 
To tackle the question of how co-creation could be more scalable, the study also collected data on the motivations of staff and students to participate in co-creation. Perhaps by better understanding the highly engaged staff and students' motivations for participation, an understanding of why cocreation appeals strongly to this sub-set of the population could be gathered. Analysing the data, what was found that was students' motivations to participate usually centered around control, money and/or future employment, and helping others. The differences in motivations to participate in co-creation aligns with previous literature that has found that motivations to participate often vary across individuals and types of activities (Roberts, Hughes \& Kertbo, 2014). For example, students involved in the social media case were motivated by the idea that they would help decide what goes into the video and/or pictures that all the student population could later see. Meanwhile, students involved in co-creation of curriculum were motivated to enrol in the subject, so they could tailor the curriculum and project to their own interests. Other students, those less motivated by control, were motivated as their participation was paid, for example, the peer learning assistants. These students, and others, often remarked that they believed their participation in the project would help them find future employment. Further, in many of these cases students explicitly noted that they knew their participation in the activity would take time, often more time than other subjects or other part-time work opportunities, but that the time commitments were mitigated by helping others. Yet while students noted this, previous research on co-creation outside of the higher education context has found that personal benefit is often the primary motivation to participate (Roberts, Hughes \& Kertbo, 2014). Further, students' priorities often ranked time as an overall less important factor than other factors such as control, money or helping others. Therefore, in order for co-creation activities to be both scalable and equitable to students in the future, time commitments may need to be considered as perhaps disengaged students are cautious to participate in activities that appear to require too much of their time (Dollinger \& Lodge, 2018; Shockley-Zalabak, Barge, Lewis, Simpson, 2017). Yet time commitments may further be able to be offset if activities amplified the amount of student control, student financial benefit, links to future employment, and conveyed the authenticity of helping others in their calls for participation.

However, important to note, is also it is unclear if widening the participation of co-creation will produce the same benefits. For example, if co-creation was to become expected, rather than voluntary, within the student population other issues, as discussed through barriers in Chapter 7 (e.g. wavering motivation, inexperience of participants) could diminish the benefits of co-creation. While this area is research in relation to co-creation is currently unexplored, it is likely that by 
extended co-creation to students who do not wish to volunteer nor do not have the motivation to go beyond their current student responsibilities could hinder the process.

In regard to staff motivations, it was found that staff were often motivated to initiate or participate in co-creation to improve their current responsibilities or roles. One staff member noted that there were so many current issues in the current process that they wanted to participate in co-creation with students to get a better sense of the pain points. Another staff member noted their motivation for co-creating with online students was that online students constituted the majority of the growing student population and they wanted to ensure that online students received the support they needed. Thus, co-creation for staff members often served an explicit need or issue. This finding was not unexpected given the growing importance of managerialism in higher education (Hazelkorn, 2015; Lynch, 2015). In fact, most of the staff members who participated did not previous to the study refer to their work as 'co-creation' or even 'student partnership' and instead often spoke of their work as simply 'talking to students'. Therefore, in order for co-creation to grow within the staff community, it is plausible that co-creation needs to be encouraged as a means for solving ongoing issues and challenges. For instance, despite the initial time commitments and extra work, co-creation could lead to better outcomes for staff and teams within the university. However, this method of encouraging co-creation is not always discussed positively in the current literature. Authors such as Healey and Healey (2018) and Matthews (2016) note that student partnership (closely related to co-creation) is an ethos rather than practice and thus should not be proposed as an ad-hoc approach to solving an issue or improving overall managerialism. However, in this study, given the limitations of the cases that were studied, cases where the student/staff members sought a holistic ethos to co-creation or student partnership were not available. Future studies, therefore, should compare and contrast the processes and outcomes of co-creation and student partnership activities that are ad-hoc and holistic to better understand the differences that may occur.

Future research relating to the antecedents of co-creation should further address whether cocreation has the ability to change student and staff perceptions of student voice and collaboration. As noted previously, all the students and staff who participated in the cases were positive about the inclusion and promotion of student voice and perspectives. Yet the value of co-creation activities is limited if the activities can only appeal to already pro-student activism and participation students and staff. In short, future research could extend research questions to evaluate if cocreation has the ability to change perspectives and dispositions of those who do not believe student 
voice or collaboration are important. Previous work on transdisciplinary research and student-staff partnership have found that students who participate in these activities may have a greater ability to change perspectives and practices (Jensen \& Bennett, 2016; Vilsmaier \& Lang, 2015). Currently, analysis of the collection of ten cases on co-creation highlights that co-creation requires deep commitment from students and staff. Therefore, building a team or collaboration between motivated students and staff (with varying motivations, albeit, uniformly motivated) is critical for co-creation activities to occur.

\section{Finding 2. Environments can dictate behaviour}

The study also sought to understand the environmental factors that shape co-creation activities. Distinct from individual factors, such as personal motivations and previous experiences, environmental and contextual factors also have an impact on the later processes and outcomes of co-creation activities (Chathoth, Ungson, Harrington \& Chan, 2016; Zhang, Schmidt, Xie \& Li, 2016). As the cases were very unique to one another, participants were asked generally to discuss what environmental factors they believed impacted the activity with three themes emerging including: online vs. in-person platforms and structures, authenticity of the activity, and novel or confusing elements.

Ultimately, as the cases differed sustainably from one another, findings related to environmental factors should be considered with caution. For example, two case studies included were predominately online, the social media case study, and the student governance case study (as it was extending to include online students). These two cases differed as the social media case involved students only for a short period of time, while they were designed a short video for the universities' SnapChat (an online video sharing application), while the governance case included students through an online platform for an entire year. Therefore, while comparing these two cases it was found that within the short-term social media case students and staff were very positive about online co-creation, as opposed to the longer-term governance case where participants were less optimistic, these results would need to be researched further before concrete conclusions could be made. However, previous research on online student engagement has also found that engagement may be challenged in ongoing activities as opposed to short-term projects (Henrie, Halverson \& Graham, 2015). 
Co-creation from its inception as a construct has often been explored through online communities due to the adoption of web applications. Companies such as Starbucks, BMW, Samsung, Dell and Heineken have all launched web applications geared towards co-creating with online communities (Lee \& van Dolen, 2015). Much the reasoning for exploring co-creation through online communities has been to allow for large segments of the user population to help identify future needs and wants (Vargo \& Lusch, 2004). However, this was not the focus in most of the case studies included here. One case was hoping to improve their enrollment processes, but this is still much more specific than many of the co-creation initiatives that were started by industry. Perhaps this is why all the cases included here were primarily in-person and staff and students did not express a desire to move to a wholly online setting.

Interestingly, authenticity was frequently mentioned when students and staff were asked about the environmental or contextual factors that related to their co-creation activities. Previous research on co-creation and student partnership have highlighted the importance of authenticity as a means for encouraging meaningful relationships as opposed to a superficial exercise (Bryson, 2016; Miles \& Power, 2017; Ranjan \& Read, 2016). Dijk, Antonides, Schillewaert (2014) further found that authenticity was also a potential outcome of co-creation, as users considered the organisations that sought their perspective as more authentic and sincerer in wanting to improve services and products. Similar importance to authenticity was found here, both from students and staff members. For example, several staff members noted that the co-creation activity, for example cocreated curriculum or WIL, was a real opportunity for students to see what employment would be like after their studies. They strove to create an experience where students were equals, could contribute ideas, and had industry or community partners expecting results. Students engaged in these activities often noted they deeply enjoyed the responsibility relating to these projects and the ability to make decisions. In the instance where one student learned they were creating only a proposal for a community project, and that the project would not actually be funded by the community, the student noted the team was disappointed their ideas would not be implemented.

One future question therefore for co-creation and student partnership experts is how to ensure that all activities are authentic. Contrary to many of the traditional tasks of student life, such as writing an essay that only a marker will read, it appears from the data analysis in this study that students involved in co-creation activities (perhaps because they are voluntary and require significant amounts of time) expect the outcomes of the activity to have a relatively more tangible impact. Cook-Sather (2014a) writes that the inclusion of student voice can, in fact, be undermined 
through tokenism and/or other manipulations that only integrate student perspectives and ideas superficially. Therefore, when the students in the co-created curriculum class and WIL subject did not see their ideas implemented in the real world they may have perceived the task to be tokenistic in nature.

The last theme to emerge from environmental factors was the novel or confusing elements that often-accompanied co-creation activities. In fact, results indicated there seems to be a fine line between too much structure and guidelines that would limit student co-creation (i.e. mimic traditional student tasks such as in-class group assignments) and would overwhelm students. Staff members often noted they wanted to give students as much free reign as possible to support their creativity as well as the authenticity of the task. However, not all students flourished under these circumstances. For example, as one peer learning assistant noted, while they enjoyed the freedom, newer students they saw participating were given too much responsibility too soon and often underperformed in their leadership roles as a result. Yet in ideal circumstances, students reported that while they first feel intimated by the new responsibilities of co-creation, as they became experienced in their roles, they enjoyed them and considered the activity transformational. This outcome is what many co-creation activities hoped to achieve, instilling confidence in students, which has been shown to have be a strong predictor of academic performance (Richardson, Abraham \& Bond, 2012). Previous research on how to support and facilitate student self-efficacy and self-regulated learning has stressed both motivational and cognitive aspects (Garcia \& Printrich, 1994; Pintrich, 1999). Therefore, students in co-creation activities may not only need to be supported through their cognitive learning tasks but supported motivationally within their environment. Printrich (1999) writes motivational type that support self-regulated learning include self-efficacy beliefs about oneself, belief that the task is valuable and goal orientations. The second of these, believing that the task is valuable, further links back to the student feeling as though their involvement in the co-creation would have real-life outcomes. Tinto (2006) also notes that for student success (in regard to retention) clarifying expectations is an important predecessor to ensuring students understand the tasks expected of them. In co-creation activities, setting clear expectations may be equally important.

Ultimately, therefore, the findings around environmental factors relate to how co-creation can best be designed and supported. Results indicate that authenticity is critical (aligning with previous research such as Bryson (2016) and Cook-Sather (2014a) but also that co-creation activities may need to be designed in steps where students are given clear expectations. To assure that students 
are not overwhelmed by the activities, baseline structures or guidelines that support motivational component, are critical to ensure that projects can build, rather than diminish, student confidence.

\section{Finding 3. Barriers to co-creation come in many shapes and sizes}

There were numerous observed barriers to co-creation that emerged from the study, some of which were expected and discussed in previous literature. For example, students and staff struggled with the time commitments often imposed by participation in co-creation activities. Time commitments are especially difficult for students who work part-time or have other family-related commitments (Vander Schee, 2010) and other research has found that time commitments of those involved in co-creation can exceed expectations and may need to be considered in the design of the task (Kay, Dunne \& Hutchinson, 2010; Pennington, 2011).

Another barrier that was reported and also expected was the inexperience of participants (Chathoth et al., 2014; Coe \& Smyth, 2010; Pongsakornrungsilp \& Schroeder, 2011). These findings, while common, can still be addressed through design principles such as ensuring time commitments are minimalised, allowing for structure and guidelines, and giving examples of contributions to inexperienced participants. Previous research further aligned to the findings here that found that it was not only students but academic and professional staff that were inexperienced in co-creation. Cook-Sather (2014b) found that student-staff partnership was often new and uncomfortable for staff and yet had the potential to be transformative. Interesting to note, is that limited expertise on subject-content was not found to be a barrier in this study. Similar studies have also found that a lack of user expertise does not negatively impact creative thinking, even if the issues or challenge is technical in nature (Kristensson, Matthing \& Johansson, 2008). Some studies have been posited that too much expertise can instead have a negative impact on creativity, as it limits the ability of the participant to think outside of what they know (Wiley, 1998).

To an extent, wavering motivation was also expected to be a barrier, especially in the context of ongoing commitments on time. However, the was the results also indicated that wavering motivation of participants in co-creation does not always need to be thought of as a barrier. For example, this finding came out clearly in the case study on a student-staff co-creation publication where students mentioned that they may get heavily involved for one semester (e.g. with both editorial and writing contributions), take a semester off, and then get re-involved down the line. For other ongoing cases, such as peer assisted learners or social media contributions, wavering 
motivation similarly does not need to be a barrier. It further may allow for new students to come in and participate, as well as allow students to take a break and have flexibility with their schedules. McBrien, Cheng and Jones (2009) came to a similar conclusion when designing online learning structures that support student engagement, whereby allowing for flexible forms of engagement may further improve student autonomy, emotional independence and self-direction. However, not all cases are awarded the ability to allow for wavering motivations. For the example of WIL, curriculum design, student designed learning resources, students needed to make a commitment for the entire length of the semester. Further, in the case of student governance, students take on the extra responsibility for a year. In these instances, therefore, wavering motivation, from both students and staff, could be more detrimental to the projects.

Why did motivation waver? Other than time commitments, some reasons for wavering motivation included students expecting more responsibility than they were given and questioning the authenticity of the project. This highlights the interdependency between many of the findings discussed here. For example, if projects are not authentically designed and implemented, students may lose motivation halfway through the project. These findings are not particularly novel as previous research as uncovered the importance of designing authentic activities to promote student engagement but critical nonetheless (Herrington, Oliver \& Reeves, 2003; Meyers \& Nulty, 2009). Therefore, in order to guard against wavering motivation that could hinder the activity, other factors, such as the authenticity of the project, and allowing for gradual progression of responsibilities may be important to consider.

Related to wavering motivation was the barrier of disengagement or lack of motivation from participants. This was a rare finding in the results, as mentioned previously, cases were voluntary. However, in the case of co-created curriculum a student who had enrolled yet was disengaged caused serious issues within his group and for the teacher. This finding relates the earlier discussion in the antecedents' section about the widening participation and scalability of co-creation. As educators and researchers cannot expect all students to be highly engaged in their studies, does this mean co-creation should be limited to cases where it is voluntary and open to only a select group of engaged students? However, if this is the case, how is equitability of co-creation to low performing students or students with family or work responsibility impacted as previous research has found these groups to be less willing to volunteer for time-intensive student tasks (Bridges, Cambridge, Kuh \& Leegwater, 2005; Pike \& Kuh, 2005). These are critical questions for the area of co-creation and student partnership to address. 
Another complex barrier to address is assessment design. Most the cases included in the study were co-curricular in nature and therefore did not include any assessment, however, three cases did include assessment. These cases were the WIL subject, a co-created curriculum subject, and a subject where student co-created learning resources. While emerging research on assessment increasingly discussed co-created assessment (Deeley \& Bovill, 2017; Doyle, Buckley \& Whelan, 2017; Fraile, Panadero, Parda, 2017), none of the activities included within the study had co-created assessment. Instead all three cases had more typical forms of assessment, including lecturer/tutor marked essays or reports or an in-class presentation. In the WIL case, the staff member believed the structured assessment was part of the learning process for students, as when they are workers they will be asked to write reports as they see fit, but they will still be received by a manager. In the co-created curriculum design case the staff member held an opposing perspective and found that assessment often led students to participate in the subject as a 'box ticking' exercise. Therefore, she was abstract about how the assessment would be designed ${ }^{16}$. However, this approach, while perhaps allowing for more student creativity, also was difficult for some students to handle. As one student noted they often thought to themselves, "what is it you want me to do?". In the learning resources case, another issue emerged when students who had elected to participate in the activity (they could have taken the standard subject if they had wished) received satisfactory marks but at a much higher cost to their time and effort. All of these instances raise questions about how assessment can and should be implemented alongside co-creation activities. There is likely an element of structure that needs to be addressed, allowing for student creativity but still giving them enough guidance about how they will be evaluated. Additionally, equitability may need to be considered as well if some students are contributing more time and effort than others ${ }^{17}$.

Power imbalances between students and staff were further found to be a barrier to co-creation. Much has been written previously about power imbalanced between students and staff in student partnership (Cook-Sather, 2018; Bryson, 2016; Mercer-Mapstone \& Mercer, 2018) yet there is still debate over how to lessen power imbalanced. Boud and Molloy (2013) found in a study that investigated mutually constructed assessment and feedback between students and staff that power relations continued to exist. However, literature on student partnership has found that while not always achieved, student and staff partnerships have to ability to help transform power dynamics (Dwyer, 2018; Matthews, Dwyer, Hine \& Turner, 2018; Seale, Gibson, Haynes \& Potter, 2015).

\footnotetext{
${ }^{16}$ This may also allude to the need for future research to investigate how co-creation can be assessed.

${ }^{17}$ However, asking students who have other work or family commitments to match times of students without work or family commitments is equally unequitable (Pike \& Kuh, 2005.
} 
Matthews et al. (2018) writes that by creating more equal relationships with staff, and fostering communication and collaboration, students as staff are able to form new types of relationships that extend from traditional power dynamics.

In fact, just the single barrier of power balances could warrant a stand-alone topic for investigation. Examples of power imbalances that could be analysed included decision-making processes, structure of feedback and assessment, students or staff treating one another differently, a lack of transparency between students and staff, students feeling like they are not being adequately compensated and so on. However, in this particular study on student-staff co-creation power imbalances, while frequently mentioned, were not as discussed as other barriers, such as time and lack of clarity. Why? One reason may be that within the case studies evaluated participants were often unfamiliar with the term 'co-creation' and further did not refer to their activities as 'partnership'. Perhaps then, to them, students and staff were simply collaborating and expectations of equality, or equal power distribution, were not expected and thus, not challenged. In fact, in much of the students as partners literature, students who work with staff on research projects or as teacher consultants are often familiar before the activity begins with phrases such as partnership and have been prompted or trained to reflect upon power structures (Cook-Sather, Bovill \& Felten, 2014; Mercer-Mapstone \& Clarke, 2018). As such, their concerns for power may be stimulated.

This study actually found that most students seemed to want staff to take the lead and drive the activity. In fact, another barrier uncovered in the study was categorised as "need for staff". For example, students in the creation of learning resources enjoyed their ability to create what they wanted, but also mentioned how they enjoyed periodic meetings with staff that helped them structure their ideas and provide motivation. WIL students and curriculum students similarly often noted they wished they had more attention from the teachers to give them feedback. While striving for feedback and creating equal power distribution does not have to be mutual exclusive and can actually be complementary it may indicate that students still feel like, if not are, the less knowledgeable other in many instances. A future study would benefit from researching and evaluating if all students seek equal power with staff and what they imagine an ideal power structure to look like.

This is not to say there were not some issues of reported power imbalance. One student, who helped co-create a student partnership program, told the story of having a person in the university 
administration thank a staff member who was not involved in the project for her work at a meeting. Other students had issues in student groups, where some students were vying for more control. In the governance case, a staff member further alludes to power imbalance when mentioning that while he wanted to involve online students, they want to be careful not shift power too quickly. These results align with previous literature that caution that much of student governance and student policy making can be tokenistic (Carey, 2013; Obondoh, 2003). Again, showing the interdependency of findings, in order to progress past tokenism, that is fuelled by power imbalances, transparency and authenticity may be important components (Carey, 2013; Varnham, Olliffe, Waite \& Cahill, 2016). Future research, therefore, should address questions such as can co-creation or student be equal? Can students lead, and if so, what type of students? And further, what do mean when we refer to equality? If students prefer staff-driven projects then is it equitable to ask them to take on equal parts of the responsibility when there are perhaps instances when they are not being financial compensated, feel uncomfortable in their role, and are paying for a service where they expect to be guided?

\section{Finding 4. The first step to co-creation is co-production}

The work of Mike Neary and others has been foundational in exploring student-staff coproduction in higher education as an institutional priority (Neary \& Winn, 2009; Neary, 2010). The work relating to 'Student as Producer' is positioned as a lens to redesign learning in higher education and encourage students to develop a critical mindset on their teaching and learning experiences (Neary, 2010). It is based on the argument that universities are increasingly focused on research and yet there is a lack of collaboration between researchers and students (Neary \& Winn, 2009). This argument is echoed within co-creation, that also seeks to connect users (or students) with all the functions of an organisation. However, while the distinction between phrases such as co-production and co-creation are not evident in higher education literature, in business literature, the two terms are distinct (Chathoth et al., 2013). Co-production refers to the interactive nature of services and is conceptualised as a type of exchange mechanism (Yen, Gwinner \& Su, 2004). Therefore, in this view, co-production as a distinct concept without a consideration for how value is co-constructed as well and is still an organisationally-dominant perspective and would not fit the definition of co-creation as discussed in this study (Chathoth et al., 2013).

As mentioned previously, co-creation comprises both co-production and ViU constructs. In this delineation, co-production is the act of collaborating towards a specific outcome (e.g. curriculum). 
Therefore, the elements underpinning co-production are tangible for optimising collaboration, such as knowledge sharing between people, equity (i.e. making sure all parties are heard) and interaction (see Ranjan \& Read, 2016). As these aspects are less abstract than many of the elements underpinning $\mathrm{ViU}$ (the second half of co-creation) detecting them in the findings of this research were relatively straightforward.

Equity, as the first element underpinning co-production, has a unique application in the included case studies. While many staff members espoused the importance of equity and made it clear that one the aims of the activity was to integrate the student voice, equity was usually applied haphazardly. For instance, in the case of student-staff workshops students were invited to be equal members in proposing ideas to improve student services. Yet in the workshops staff were advised not to disclose their roles to ensure that all participants felt equal and intimidation was kept to a minimum. These decisions on how to introduce staff to students and the transparency of their roles was not discussed with students. Further, once the workshops had concluded, students who participated were no longer considered part of the team. Instead, changes or modifications were made without any follow-up to the students who had contributed. Thus, the application of equity in the project was debatable as transparency and commitment across stakeholders was not supported.

Equity being applied unequally in regard to project decision making and transparency was common in cases that included student assessment as well. After all, students may have been co-creators of curriculum, but they were not co-creators or co-decision-makers of assessment practices. Therefore, in this study, while equity was defined as the degree of access given to participants, distribution of responsibilities and level of transparency shared across stakeholders, a case that expressed all these elements was not found. And yet, previous co-creation studies have highlighted the importance of transparency of information when co-creating with users as it not only can improve the quality of ideas and suggestions but also help users become aware of their own needs and stimulate reflection (Kristensson, Matthing \& Johansson, 2008).

In the study presented here, however, we found that as equity was not commonly applied to all aspects relating to the cases (decision-making, access, transparency) that collaboration or cocreation with students was in specific and mandated ways. This does not align to a fully developed model of the co-creation process (see Chapter 3), however, may align with less developed steps towards co-creation such as crowdsourcing. 
Although, while participants within cases may have struggled to achieve equity, many case studies did highlight improved student-staff interaction and knowledge sharing, the other two critical elements to co-production. In fact, all projects included within the study provided evidence of improved interactions between staff and students, and often between students themselves as well. Student and staff in the projects often referred to a shared goal that brought them together. Shared goals between staff and students are relatively rarer in higher education, where usually student interaction with staff is through a subject where a test or essay is mandated or asking for help from a staff member in an administration context. Yet shared goals are critical to foster interaction and knowledge sharing within co-creation as well as build trust among stakeholders (Chow \& Chan, 2008). Therefore, in the case studies including within the project, where students were working with staff to produce a publication, social media content, or curriculum, students and staff were awarded the opportunity to share a common goal.

As previous literature has highlighted, sharing a common goal and sharing a vision can support knowledge transfer and knowledge sharing (Chow \& Chan, 2008; Chua, 2002; Inkpen \& Tsang, 2005). Therefore, a shared goal, coupled with the increased interaction that often accompanies cocreation, often results in various stakeholders sharing their perspectives and ideas (Prahalad \& Ramamswamy, 2002). One of the most profound findings from case studies was the extent to which staff and students mentioned how they were able to understand the others perspective more from their experience in co-creation related activities. In cases both in and outside the classroom, participants noted how useful it was to understand one another's perspective and previous knowledge. For example, in the co-creation of a students-as-partners program the staff member had years of experience in program coordination and development but was unaware of the specific literature and theories surrounded students-as-partners. By partnering with a $\mathrm{PhD}$ student who understood the research well, she mentioned that the two could work well together, with her leading the program coordinator and the student leading the research base. Similarly, in the social media case, the staff member mentioned how useful it was to see students co-create media as it helped inform the team about what types of media posts students are interested in and what they could do better to improve their own posting.

While knowledge sharing is not the only critical aspect of co-creation, what emerged from the study is that it is one of most frequently mentioned and one that becomes a foundation for many other aspects (such as relationship building). This was an interesting insight, as the findings from 
this study suggest that co-production may be a crucial first step before ViU (and comprehensive co-creation) can take place.

\section{Finding 5. Co-production may amplify ViU}

Co-production in this study is considered one facet of co-creation, while the other facet is a concept known as value-in-use (ViU) (Ranjan \& Read, 2016). ViU is how stakeholders (e.g. students, staff) begin to harness the value, which in this study, was often created through coproduction. While there are numerous ways to define value (e.g. Bowman \& Ambrosini, 2000; Normann \& Ramirez, 1993), this study used ViU as a lens to view value. For example, in a construct such as a $\mathrm{ViU}$, stand along products (e.g. a car) does not have value until someone then places value on the product or service (e.g. uses it to commute to work, feels prestige when looking at it) (see Chapter 3 for a more detailed discussion). In fact, ViU is becoming the standard perception on how many in industry see value, as increasingly it is discussed that users are always involved in the creation of value as value cannot be a stand-alone entity (Ballantyne \& Varey, 2006; Macdonald, Wilson, Martinez \& Toossi, 2011; Sandström, Edvardsson, Kristensson, \& Magnusson, 2008). However, due to its abstract nature, ViU can be difficult to measure as the underlying constructs (experience, personalisation and relationships) are more abstract that those in co-production (interaction, equity and knowledge sharing).

From the data, it was found that students and staff reported high levels of ViU. For example, despite the many barriers to co-creation, such as time or lack of resources, students and staff reported their participation in a co-created activity as being a positive experience. Experience, as defined in this study as an "empathetic, emotional, and memorable interaction that has intrinsic value" (Ballantyne \& Varney; Lusch \& Vargo, 2006 in Ranjan \& Read, 2016, p. 293) was detected across many instances. Students spoke of how their participation in the experience of co-creation was a formative memory of their higher education experiences and how it was a rare instance in their educational histories where staff interacted with them and treated them as colleagues. This is critical because how students experience activities often influences their perception of the specific and overall value (Bitner, 1992). Interestingly, it was not only students that reported the experiences as memorable, many staff members also reported their participation was unique to their other roles and responsibilities. Participants also frequently alluded to a feeling of transformation that occurred through the co-creation process, either through seeing others' perspectives or feeling like that were more connected to the community. 
Analysing the responses from participants who were negative about their experiences revealed, however, that deriving value from the experience was more challenging for some. In particular, students who struggled in cases often had issues with other students, rather than staff. In fact, part of challenges in regard to the scalability of co-creation, may be how to allow for all student voices, as opposed to just one. For example, in the governance case and in the co-created curriculum case, students mentioned how when they disagreed among peers, it was difficult for everyone involved to feel like they were a part of the process. This challenge is not confined to the higher education context alone, with industry literature also questioning how heterogeneous needs can be met (e.g. Franke \& von Hippel, 2003). To overcome these challenges in industry, co-creation is often implemented broadly, including as many voices as possible to safeguard against solutions only be valuable to a small segment of users (Kristensson, Matthing \& Johansson, 2008).

Conflicts between peer groups was not the only challenge for participants to receive value from their participation. Personalisation, another underlying construct of ViU was also more prominent in some cases than others. Personalization is an important aspect of ViU because the theoretical perspective underpinning the construct is that the more one can personalise the product/service to their own preferences, from the value they can create (Bendapudi \& Leone, 2003). Yet, many of the co-creation cases that were included in the study did not allow for the full range of personalisation that could have been available to students. Instructors, such as those in the WIL and curriculum case, were wary of allowing too much personalisation, as the activity was still linked to assessment. In other cases, such as social media or publication, the staff were also concerned that the product match the institution's culture and views, and thus, felt there may need to be times where they need to limit personalisation. In fact, the findings around personalisation are unique, as many of the studies on co-creation between students and staff discuss power imbalances yet do not specifically discuss personalisation (Bovill, Cook-Sather \& Felten, 2011; Bryson, 2016; Kay, Dunne \& Hutchinson, 2010). Yet it is an important topic for future research as it could be that the students' desire to personalise the experience can have negative consequences for other students, or for the institution. This aligns with co-creation literature that has found users often co-create based on what they see as having apparent benefit for them (Roberts, Hughes, Kertbo, 2014; Kristensson, Matthing \& Johansson, 2008). Roberts, Hughes and Kertbo (2014) for example found that participants' motivations are primarily based on a hedonic desire to develop their own competencies and skills. Therefore, it is possible that a certain degree of personalisation may be optimal. For instance, students in many of the cases such as the learning resources were able to pick the topic (hypertension) and present the disease in a way that they thought was best (short 
videos). This level of personalisation resonated with the students, who often reported that they enjoyed being able to have control over the topic and mode. However, having some boundaries (i.e. must be a disease, must be a form of media) allowed for the staff to not worry that the students would 'over' personalise it past it producing value for the subject or for other students. Future studies, comparing cases that had more or less degrees of personalisation could further explore this balance to investigate whether some boundaries produce better outcomes. In other fields, such as creativity, it has been found that creativity is in fact heightened when some boundaries are in place (Sternberg \& Kaufman, 2010).

Important to note is the difference between personalisation or customisation and co-creation if the degree of involvement of the user or student (Kristensson, Matthing \& Johansson, 2008). To personalise or customise a service or product without the other components of co-creation such as interaction and relationships, is simply to modify the service or product in the final stages for personal usage (Kristensson, Matting \& Johansson, 2008). Therefore, one of the future discussions within co-creation in higher education may be to decipher whether some of the activities that are discussed as co-created are, in fact, only customised.

The third underpinning construct of $\mathrm{ViU}$ is relationships. As discussed in Chapter 7, relationships between staff and students often were enhanced through co-creation. This finding was not unexpected, as the cases required students and staff spend more time with each other, therefore, the two parties becoming closer was a likely outcome. A benefit to students and staff spending more time with one another through co-creation was often that students perceived the staff to care more about them than previous staff had. As connections with staff, as well as perception of care and feelings of belongingness all relate to student engagement and retention (Krause \& Coates, 2008; Zepke \& Leach, 2010) in this way, co-creation was an asset to complement the overall student experience. Staff also felt the increased value in forming closer relationships with students. Through the activities, and a deeper understanding of the students' perspectives, staff felt closer to whole student cohort and often relayed a feeling that they felt more dedicated to their roles.

Issues that arose in regard to relationships included role confusion. In the co-created program, where there was just one staff and one $\mathrm{PhD}$ student, the student mentioned they felt conflicted over whether they felt their identity lied more with students or with staff. This sentiment was also mentioned in the student governance case, where student representatives felt almost disconnected 
from the student population because of their new roles. While role confusion is a relatively unexplored area in relation to the co-creation process, other literature has found that when staff take on multiple roles, such as assessor and mentors, that relationships can become more blurred (Bray \& Nettleton, 2007). Therefore, it may be interesting to explore this topic more in the future.

However, role confusion is not the only negative consequence from a change in relationships during co-creation. In a peer learning advisor case, one student mentioned that his new close relationship with a professional staff member made him feel more negative towards his academic faculty members. Struggling to get materials from them for his workshops, he mentioned that he and the professional staff member both felt that the academics were not putting forth equal amounts of effort. This is interesting for many reasons. First, it highlights the fact that when students begin to work with staff and become colleagues, the result is not always positive. Humanizing students and staff to one another also can mean a loss of curated images. The second point arising from this instance is that similar to no singular 'student voice' there is no singular 'staff voice'. Students and staff have varying perspectives on aggregate, and they also have varying perspectives individually. A partnership that works or fails between a student and staff member does not necessarily speak to generalisable conclusion, it may simply be dependent upon the individual perspectives, value and behaviours. This is important to recognise as growing literature reflects on the importance not to conflate staff and student perspectives (Rakrouki, Gatenby, Cantore, Rowledge \& Davidson, 2017) literature has not fully reflected upon the need to recognise individual differences in perspectives and voices as well.

Future research on co-creation may also need to explore the lasting impact of close relationships between students and staff. A few participants in cases collected here, such as co-created publication and social media, alluded to feeling that they were more positive about the whole university community and even the university brand after their experiences. As higher education continues to explore long-term upskill ventures and continuing education (Sandeen, 2008) and building stronger alumni networks (Hall, 2011) the quality of relationships that form through cocreation may be one mechanism to encourage student and staff meaningful relationships.

\section{Finding 6. When benefits outweigh costs}

One of the questions that arose from the research was, given the challenges of co-creation, do the benefits outweigh the costs? To answer this question, benefits of co-creation were first analysed. As seen in Chapter 7, the benefits of co-creation as detected from this study included student 
employability, student self-efficacy, and student and staff ownership (to the process and outcomes). Additionally, neoliberal benefits to the university were found, including innovation (improved services) and potential for university marketing. The discovery of the benefits within the study were not particularly novel. Previous literature has found that student engagement (either through student partnership or student collaboration) has led to employability, self-efficacy and ownership (Healey, Flint \& Harrington, 2016; Mercer-Mapstone et al., 2017). While other studies have found that deepening relationships with students can positively impact university service innovation and university marketing (Brown \& Mazzarol, 2009; Hemsley-Brown \& Oplatka, 2006). Literature had also previously linked co-creation to these benefits. For example, studies have found that co-creation is a useful mechanism for predicting users current and future needs (Chathoth et al., 2013; Gustafsson, Kristensson \& Witell, 2012). Additionally, previous research on co-creation has found that by allowing users to co-create in new products or services, ideas are more creative, highly valued by the users, and can be more easily implemented (Kristensson, Gustafsson \& Archer, 2004). In a study that investigated students partnering with staff to co-create videos, the staff member estimates that approximately $20 \%$ of videos were higher quality than they could have achieved alone (Browne et al., 2017).

Yet while the benefits of co-creation seem appealing, there were also costs and challenges. As discussed in Chapter 7 and within this chapter, challenges to co-creation include finding motivated and diverse participants, providing the necessary support, addressing ongoing issues over control (e.g. assessment) and power. Scalability and moving past the idea that there is 'one' student voice is further challenging.

It is of the researcher's perspective, that given that the co-creation cases included in this study were voluntary, and this naturally arose given the conditions and the personalities of those involved, that moving past this and forcing co-creation would negatively impact the process and likely decrease benefits while increasing costs. Therefore, while the findings are unable to answer definitively if co-creation is worth the costs, the author would suggest that this study only highlighted that voluntary co-creation has benefits. Another study, exploring mandated cocreation, would have to be conducted before one could assume a top-down approach would result in similar positive benefits for staff and students. 


\section{Discussion of Less Anticipated Findings}

Findings included both those that were expected (e.g. closer relationships between students and staff, barriers of time and clarity) and those that were less anticipated. There were three findings in particular that were expected and will be discussed in more detail within this section.

\section{Importance of Antecedents}

This study did not seek out to quantify which factors have a greater influence on the overall outcomes of the activity, however, from the researcher's point of view, antecedents played a much larger role than previous literature has perhaps highlighted. As noted earlier, the findings of this study suggested that it is often high-achieving students that are drawn to co-creation. However, what this study also uncovered was that many of the staff who choose to participate in co-creation are also unique. They often spoke about being more committed to the student perspective and the facilitation of the student voice than their peers and some had previous experiences helping marginal groups or student advocacy before. Staff members also often noted the extra time and energy they had volunteered towards ensuring the quality of the activity as well. Further, both students and staff reported they had felt before the activity had begun that their personal outlook was that students and staff should work together to co-create higher education experiences. As this study was not longitudinal it is unclear if this finding would be accurate if studied over several time intervals. However, it may again speak to the unique types of participants that are drawn to co-create.

\section{Mediation of Control and Constraints}

One theme this study sought to explore was how students and staff perceived the control and constraints pertaining to the co-creation activity. An unexpected finding within this area was that students often requested staff have a larger role to play and even remain in control of the activity. Regardless of whether the activity included assessment or not, students enjoyed working with staff and staff continuing to play the leading role within the activity. As evidence of this, in the learning resources case the staff reported that the first time they had piloted the activity they allowed students to take the lead and were disappointed to find the activity had failed. Yet in the second trial, where they insisted on regular meetings to check progress, the students had produced quality learning resources. In other cases, similar stories were told, where staff may have wanted to allow for equal responsibility but had found that the students needed more oversight and scaffolding 
than they had anticipated. This aligns with previous research exploring student and staff collaboration and partnership, that often finds that scaffolding for students is a critical aspect of collaboration (Browne et al., 2017).

It is perhaps important to discuss that for some students' part of the joy of co-creating was also linked to receiving positive feedback from staff. If staff did not play a large role in the activity, students perhaps would receive less positive feedback and therefore derive less joy from their involvement. While this topic has not been explored in the higher education context, other studies on co-creation in online communities similarly found that organisational members interactions with users mediated user sentiment and perception of the experience (Lee \& van Dolen, 2015). Perhaps highlighting the importance of staff communication and interaction within co-creation.

\section{Large Variation Across Cases}

The research design of multiple case studies was selected to explore different variations of cocreation currently occurring in higher education. A previous survey of experts before case studies were selected already began to highlight the numerous possibilities of activities in higher education that could be co-created. Services and products from curriculum, learning resources, workshops and pedagogy, co-curricular activities, governance and policy making, peer advising, publications and social media, the design of buildings and programs could have all been included. In all of these cases other variations also occurred, including how the activity started, who was involved, the design or structure around the activity, the intended benefits and outcomes, and how students perceived and experienced the activity. This study, faced with such variations, sought to explore the nature of co-creation generally. Thus, a major finding of this study, and one that expected but not to the degree that manifested, was the large variations that occur under the banner of 'cocreation ${ }^{18}$. From this finding two questions emerge. The first is, should there a more refined definition of co-creation? For example, one case included in this study was students participating with staff in a workshop about finding solutions for common issues in the enrolment process of the university. Students were invited to attend, give feedback and offer their ideas on how to improve the functions of the service. In organisational and industry literature, this would constitute as co-creation as the organisation is tapping into student resources (i.e. their perspective) to increase value. However, by taking this broad definition of co-creation the research relating to co-

${ }_{18}$ Note, a similar challenge has occurred in students-as-partners literature with large variations of definitions within literature occurring (see Matthews, 2017) 
creation may run the risk of becoming too wide-ranging and lacking focus. In similar large areas within higher education literature, including student engagement and learning analytics, scholars have mentioned these terms have lost value over a lack of focus on the literature emerging from the areas.

The second question relating to the large variations across cases is how generalisable can the outcomes of a co-creation case be? As previously discussed in Chapter 5 relating to the research design, case study methods inherently lack the ability to apply findings to a wide range of literature, as there are numerous contextual factors. However, given the broad definition of what is cocreation, even a large-scale survey designed to include thousands of participants from co-creation activities would still be hindered by the variations within each case. The participants, their attitudes and values, the location and length of the activity, the constraints and controlling factors around the activity, to name a few, are all factors that would have a significant impact on the activity. Future studies, hoping to generalise findings, should be wary of this and seek to control contextual factors as much as possible. For example, collecting data from cases that similar to one another.

\section{Overview of the places, stages and key considerations of co-creation in higher education.}

As the findings from this research have been various, this section will review the discussion on the places, stages, and key considerations that occurred before the presentation of the findings (Chapter 7) and link this discussion to literature, as well as findings.

\section{Places of Co-Creation in Higher Education}

As discussed in Chapter 6 (Overview of Cases) this study uncovered four main areas where cocreation has, and can continue, to take place in the higher education context. These places include: teaching and learning, research and development, governance and student life. To date, most discussion within literature on student-staff collaboration in higher education has focused on teaching and learning spaces, such as students acting as pedagogical consultants (Cook-Sather, 2014), co-creating assessment (Fraile, Panadero, \& Pardo, 2017), or co-designing curriculum (Bovill, Cook-Sather \& Felten, 2011). The benefits of these activities have been well-documented as well, including teachers' greater understanding of the student perspective and students' building their self-efficacy (Bovill, Cook-Sather, Felten, 2011; Bryson, 2016; Healey, Flint \& Harrington, 2016). However, what this study aimed to showcase was that the value students can add by cocreating their teaching and learning experiences can extend to places outside of the classroom as 
well. In the area of governance, for example, higher education has a long history of including students as representatives (e.g. Lizzio \& Wilson, 2009; Varnham, Olliffe, Waite \& Cahill, 2016), however, these practices could be extended to include more forms of co-creation. For example, co-creation developing past student representation (e.g. three students on an academic board) to policy and strategy documents being publicly available to all students prior to finalisation. This may be especially relevant as higher education is increasingly focused on quality assurance (Bryson, 2016; Jarvis, 2014; Knight, 2015).

The two areas where co-creation takes place that this study uncovered that are less discussed in the current literature are research and development and student life. While there has been research on students acting as co-researchers on scholarly publications ${ }^{19}$ (Bovill et al., 2016), there is less published $^{20}$ research on how students can help with university's internal research and development. However, in industry, co-creation was actually primarily aimed for this purpose. Companies that adopted co-creation practices, such as LEGO and Starbucks did not include users in the cocreation of their main service offering (which in higher education would be teaching and learning), nor in governance structures (Prahalad \& Ramaswamy, 2004). Rather, these companies aimed to include users in internal research and development functions to learn more about what users' desired and what their preferences were. Interesting, therefore, that this has not translated to the same practice in the higher education context. Yet, as higher education is increasingly market orientation, and processes such as NPM continue to permeate operations (Olssen \& Peters, 2005; Parker, 2012), it is likely that this area for student-staff co-creation could grow considerably.

The second area of co-creation that this study uncovered but is less discussed in literature is how students could potentially co-create aspects of student life. To an extent, this is already occurring commonly throughout the university sector, as students run student clubs, student unions and other student organisations. Students have also been increasingly included in on-campus volunteering (Holdsworth \& Quinn, 2010), which could potentially continue to grow in the future as universities are eager to offer 'work placements' to students. As discussed in this study, current students can also become valuable assets for universities hoping to attract more students. As students are able to understand their peers' preferences and desires more deeply than university

\footnotetext{
${ }^{19}$ In fact, several journals, such as the International Journal of Students-as-Partners encourages authors to co-author with students.

${ }^{20}$ The author here acknowledges that many universities may include students on internal audits and other working groups, however, if this does occur, it rarely is discussed in scholarly literature which stunts its ability to develop best practice.
} 
staff. Students may further be positioned, in the future, to act almost as brand ambassadors for their university. This could include helping the university attract students, helping set up links with the local community or industry partners both during and after their degree, and acting as valuable alumni in the future that could one day mentor the next generation. In universities, all these programs are currently evolving and are likely to continue to develop as competition grows.

From the analysis of the places where co-creation takes place it is clear that there are numerous opportunities for universities to co-create with students. Similar as in industry, these opportunities allow universities to leverage a relatively untapped resource, students. Students included in these opportunities can offer their perspectives, experiences, and ideas to help make the services more student-centered. Students can develop skills, build their confidence, and be more workforce-ready through these initiatives. As such, these activities could be perceived by some as 'win-win' situations for the universities and students alike. However, as these activities continue to expand, it will be interesting to continue analysing how these opportunities play out, and whether the barriers of co-creation, as previously discussed, hinder development.

\section{Stages of Co-Creation}

In industry, higher education, or other contexts where co-creation takes place, there has not been much discussion on the stages of co-creation. A literature review, presented in Chapter 3, discussed how co-creation could potentially develop over time, though many of these examples, including crowdsourcing and prosumer behaviour, were not found in this study. Bovill (2017), in an opinion piece for the International Journal of Students-as-Partners (IJSaP) gave an example of a participation matrix that could outline how student partnership may develop in higher education. The level of involvement spanned from inform, consult, participate, partnership and control. While actions that students could contribute to included course design, evaluation design, conduct evaluation, analysis of results, and dissemination. The matrix thus was situated in the context of a collaborative evaluation project, however, is a useful basis for mapping how co-creation could occur in stages in higher education. For example, in regard to places where co-creation takes place (teaching and learning, research and development, governance, student life) and actions associated with cocreation, a participation matrix could be developed. In the table below, an example is shown, where actions include, idea formation, design, implementation and evaluation. Meanwhile on the other axis, the level of involvement includes, elicit feedback, consult with lead students, open 
consultation (e.g. open and transparent consultation with all students, lead student co-creators (e.g. one or two students involved deeply) and finally, inclusive and scalable co-creation (see Table 8).

Table 8. Example of Co-Creation Participation Matrix

\begin{tabular}{|l|l|l|l|l|}
\hline $\begin{array}{l}\text { Activity and } \\
\text { Participation }\end{array}$ & Idea Formation & Design & Implementation & Evaluation \\
\hline Feedback & & & & \\
\hline $\begin{array}{l}\text { Lead Student } \\
\text { Consultation }\end{array}$ & & & & \\
\hline $\begin{array}{l}\text { Open } \\
\text { Consultation }\end{array}$ & & & & \\
\hline $\begin{array}{l}\text { Lead Student } \\
\text { Partnership }\end{array}$ & & & & \\
\hline $\begin{array}{l}\text { Inclusive and } \\
\text { Scalable Co- } \\
\text { Creation }\end{array}$ & & & & \\
\hline
\end{tabular}

Mapping the cases included within this study to the matrix, however, finds that in all cases the level of participation never surpassed 'lead student consultation'. Even in subjects where all students participated, this cannot be considered open consultation, as it was still limited to the students involved in those subjects. Further in cases such as peer mentoring or governance, students were either hired, chosen or elected to those positions. While within the cases students did participate across all activities, idea formation, design, implementation and evaluation. This is one of the most critical findings of this study and points to perhaps major challenges to co-creating with students at scale. Without question, this is an area for future research to investigate.

\section{Key Considerations of Co-Creation in Higher Education}

Chapter 3 outlined the key considerations for co-creation found in literature to date, including, resources, environment, roles, time and experience, and culture. Using the empirical data collected in this study, these key considerations are discussed here as well as their unique nuances in the higher education context.

Student resources, or how students contributed, was found to be very similar to previous literature. In the case studies, we could witness students contributing ideas, past experiences, opinions, and preferences. Similar to industry, students also contributed a great deal of time and energy, which was often unpaid. The environment where co-creation takes places, however, was found to be very different in the higher education context. While in industry most co-creation takes places with 
technology support platforms, in higher education it appears most co-creation takes place face-toface. Also, to echo the discussion earlier in this chapter, while co-creation often occurs in higher education for teaching and learning and governance, industry typically co-creates with users for research and development.

In regard to roles for co-creation in higher education it was observed that even though students are still taking on newer roles and responsibilities, they still prefer the control to be in the hands of staff (Chapter 7). This is similar in industry as well, where users have pathways to co-create but still do not take on leadership roles within the company. In the study here as well, time and experience were found to be important considerations for co-creation. Students and staff sometimes even needed several iterations of the activity before it could be successful implemented. As discussed previous, prior experiences and personal outlook of participants, further played a large role in shaping who participated.

One key consideration, however, not aptly picked up in this study was culture. In a study by Peñaloza and Mish (2011) it was found that co-creation culture could be analysed on three levels: cosmological principles, norms and standards, and individual judgements and interpretations. While this study did not pick up findings on co-creation culture aggregated to that of cosmological principles, a select few findings did relate to how co-creation is shaping higher education's norms and standards and individual judgements and interpretations. For example, a few staff noted the importance of co-creating with students, given the increasingly student-centric perspectives of their universities. A few students additionally alluded to this, stating that it is universities obligation in include students in design and delivery of services. Additionally, many participants mentioned their own individual judgements and interpretations of co-creation. As noted previously, most participants already felt students and staff should co-create together before their participation in the activity. Yet future research could further begin to unpack how university culture is both impacting, and being impacted by, co-creation.

\section{Summary of Major Findings}

This chapter has presented numerous findings and discussion points arising from the empirical data of the ten case studies on co-creation in higher education. The six major findings include:

- Antecedents have a significant impact,

- Environment dictate behaviour,

- Barriers come in all shapes and sizes, 
- The first step to co-creation is co-production,

- Co-production may amplify value-in-use, and

- Benefits can outweigh costs.

While these findings are themes that are likely to be useful for future research exploring co-creation in higher education there were also less anticipated findings that arose from the research. Mainly, it was not anticipated that antecedents would play such a large role in shaping the motivations to participate in co-creation and thus how the co-creation process was structured and who was involved in it. The mediation between control and how constraints impacted co-creation was also an unexpected findings as previous literature has not highlighted this. In fact, despite research arguing that many consumers and students want more participatory roles in today's current climate, this finding may point to alternative argument, that users may seek some additional participatory roles, but still prefer for the bulk of control to lie within the organisation. Finally, the study uncovered that across the ten case studies there were large variations across cases, finding that the nature of co-creation in higher education is extremely varied and multidimensional.

The major findings presented in this chapter further link back to the previous discussion on the places, stages and key considerations of co-creation in the higher education context. Together, with the six major findings on how co-creation occurs in higher education, create a thorough picture of the nature of co-creation in higher education. 


\section{Chapter 9. Conclusion of the Study}

\section{Overview of Study}

The investigation into the nature of student-staff co-creation in higher education began in June 2015. To lay a foundation for the study, literature reviews on the context of higher education (both in Australia and globally) and on previous research on co-creation were conducted. Additionally, a literature review on similar concepts in higher education including 'student voice' and 'studentsas-partners' were conducted to ensure that the concept discussed in this study, co-creation, would be presented as a distinct concept. An expert review on co-creation was further conducted, with experts on higher education and/or co-creation sampled for their perspective on definitions and possible activities that would be considered co-creation in higher education (e.g. peer-learning, copublication, work-integrated learning). Through these literature reviews and expert reviews, the study began to take shape, and in particular, the literature on previous research into co-creation helped form a conceptual model (Chapter 4) from which would ground the subsequent data collection. Of specific interest, was the defining of co-creation based on two underlying constructs, co-production and ViU, previously conceptualised by Ranjan and Read (2016).

As the constructs and foundations of the study took shape, a multiple case study research design was selected, given that the topic was a new phenomenon occurring in higher education and that the aim of the study was to gather varying forms of co-creation. Through networks and promotion, the researcher was able to gather 10 unique examples of co-creation as their sample population. From this sample, a qualitative survey and interview protocol data collection method (both piloted with focus groups and through cognitive interviews) was utilised, as the study sought to explore broadly the nature of co-creation, yet structure these results loosely around the conceptual model for clarity and organisation. Rigorous data analysis methods accompanied data collection including fully transcribed interviews, member checks, and peer-reviewed coding (conducted by a supervisor).

From the analysis and the findings of the study it was found that co-creation in higher education is not only occurring in many various forms between students and staff, but there exist varying levels of types of co-creation. To illustrate, from an analysis of cases, the study highlighted examples of co-creation that included just two individuals (one student and one staff member) and also found examples with entire classes (20-30 students). Also, co-creation examples included 
those that occurred in mostly in-person settings and also ones that included online or technologysupport elements. Through analysis, the findings also point to differences in duration, organisation, structure, and approaches in co-creation activities. To add to this, it was revealed that depending on the antecedents and environmental factors, co-creation can further take on many varying processes and forms. While some barriers to co-creation were present in almost all of the cases (e.g. need for staff guidance, time) some barriers were very specific, depending on the activity, such as assessment design and lack of clarity.

The presence or absence of barriers further influenced the two main processes of co-creation, coproduction and ViU. Co-production, or the co-creation elements between students and staff that take place during the production were found to align to the previous literature by Ranjan and Read (2016) and consisted of equity, interaction and knowledge sharing. However, in the higher education context, unique from industry contexts, these sub-constructs shifted slightly, with equity including aspects such as sharing control, transparency and access, and interaction including honest communication (see Figure 2). Knowledge sharing, in particular, was of interest in this area, as it was found that not only did students learn more about the way in which a university operates because of their involvement in co-creation, but staff also learned more about how students think.

The second processual element of co-creation, $\mathrm{ViU}$, was further explored in the study, and aligned to Ranjan and Read's (2016) previous conceptualisation of experience, personalisation and relation. $\mathrm{ViU}$, far from independent of co-production, was found to rely quite strongly on co-production, and therefore, could be thought of as a higher-level construct on which involvement in coproduction is mediated on. To put it simply, everything has $\mathrm{ViU}$, as all products become services (through their use) and all services require use by the user (i.e. co-creation) for value to occur (Vargo \& Lusch, 2002). However, as this study uncovered, the potential ViU of services (i.e. higher education) is likely amplified with the inclusion of co-production elements. To summarise, experiences, personalisation and relationships (e.g. ViU) are best nurtured through equity, interaction and knowledge sharing (e.g. co-production). This is the major contribution of this study and the foundation that will guide future research exploring the value of the student experience in higher education.

The study also uncovered, apart from the value created in $\mathrm{ViU}$, there are other benefits to cocreation as well, for both students and staff. These benefits include benefits for students such as employability, self-efficacy and ownership, and benefits for universities, such as university 
marketing and innovation. These benefits can also help guide future research on co-creation in higher education.

The model below (Figure 2) showcases the culmination of three years of literature reviews, expert reviews, qualitative surveys, interviews, and analysis. The model includes inputs, such as antecedents and environmental dimensions of co-creation, processes, such as barriers, coproduction, and $\mathrm{ViU}$ and also outputs or the benefits of co-creation. While the model was initially grounded by the work of Ranjan and Read (2016) in the co-production and ViU constructs, the rest of the model is formed through various reviews of literature and analysis of the data. This is further highlighted, as the model is markedly different from the conceptual model was that presented in Chapter 4. For example, the conceptual model presented previously did not recognise any inputs, and yet when the data on co-creation in higher education was analysed, it was found that antecedents (e.g. individual aims) and environmental factors were critical to forming the foundation of the co-creation activity. In fact, almost all staff and students who participated in such activities frequently mentioned previous experiences, personal outlook, and personal motivations throughout the discussion of the co-creation activity. Environmental factors also played a large role, including the authenticity of the activity, the presence of confusing and/or novel elements, and the activity's context being in-person or with online components. 
Inputs

\section{Antecedents}

- Personal Outlook

- Previous History and

Experiences

- Students' Initial

Perceptions and

Motivations

- Staff Aims and

Motivations

\section{Environmental}

- Online vs. In-Person Platforms and Structures

- Authenticity of Activity

- Confusing or Novel

Elements
Processes

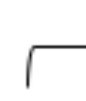

\section{Barriers}

- Need for Staff Guidance

- Time

- Lack of Clarity

- Wavering Motivation

- Assessment Design

- Inexperience of

Participants

- Power Imbalance

- Disengagement or Lack of Motivation

\section{Outputs}

\section{Co-Production}

- Equity (share control/ transparency/ access)

- Interaction (honest

communication)

- Knowledge Sharing

Value-in-Use

- Experience (memorable/

transformational)

- Personalization (individual

preferences)

- Relational

\section{Benefits}

Employability

- Self-Efficacy

- Student Ownership

- Innovation

- University Marketing 
The model was further modified and improved through the analysis and conceptualisation of the many barriers that may influence the co-creation activity. These barriers ranged depending on the activity, but included, the need for staff guidance, time, lack of clarity, wavering motivation, assessment design, inexperience of participants, power imbalance and disengagement or lack of motivation from participants.

The final way in the model was modified with the inclusion of empirical data was how some of the 'benefits' to co-creation, such as knowledge sharing and relational, were re-positioned back in their corresponding processes (co-production and $\mathrm{ViU}$ ) as opposed to putting them under the outputs with other benefits (as was done in the conceptual model presented in Chapter 4). This was because, as the research uncovered, co-production and ViU are both processes and, in some ways, outputs. To illustrate, knowledge sharing is essential for co-production between students and staff to occur, but it also becomes a long-term benefit for the student or staff member as they take that experience (an element of $\mathrm{ViU}$ ) and use it to inform later actions either in, or outside, the university experience. Further, that same experience of co-creation may be transformational for the student, for example, through peer-learning they learn that they love teaching. That creates value for them, as they use that experience to guide their future. But the value creation does not necessarily stop there. The memory of that experience may continue to create value for that individual over the course of a lifetime as they reflect on it periodically and use it as a cornerstone of their identity. In this way, the actions or elements of co-production and ViU are not only processes during the actual activity but continue to process for the individuals involved long after the activity has ended.

Moreover, co-creation results not only in value-adds conceptualised in co-production and ViU, but also through more tangible benefits to students and staff. These benefits can help create more engaged, confident and employable graduates, improve the services of higher education, and lend value to university marketing and promotion.

\section{New Insights for Higher Education Research}

Following the conclusion of this study, this study has developed several new insights for higher education research generally and to explore co-creation. The first insight of this study relates to the importance of input factors in the student experience. While this is not a new finding, as socio- 
economic factors and culture have often been discussed as factors for student success (i.e. completion or satisfaction) it was interesting in this study that these factors also play an important role in stand-alone activities within higher education, too. While the study did not explore background factors such as family's economic status or individual's race or religion, the study did find that, for both students and staff, personal outlook and previous experiences played a large role in motivating that individual to get actively involved in university experiences. This has many implications for higher education research, regardless of whether the study is exploring cocreation. For example, how can future studies conceptualise students and staff personal outlooks and how do these outlooks shape their daily experiences at the university? And how can universities interact with students and staff pre-existing outlooks and find ways to harness this understanding to improve relationships and engagement of both students and staff? Further, if we know that previous experiences play a large role in motivating students and staff to participate in extra-role behaviour, what more can universities do to promote that first initial experience to motivate a student or staff to go outside their mandatory role and responsibilities?

The findings of the study also contribute to the understanding of the different types of forms of co-creation, in particular, in relation to environmental factors. As the cases in this study and much of the literature on student partnership reveal, the majority of the current environments for facilitating student-staff co-creation is face to face. However, student preferences are changing, with more online students and part-time students. This, coupled with the need to find ways to include more students in co-creation to support equity and access, means that there needs to be more research that explores how co-creation can be scalable. As the literature review in Chapter 3 revealed, industry is already far ahead of higher education in this respect. Crowdsourcing, customisation and prosumer behaviour are all close to becoming well-established mechanisms in industry, and yet have barely begun to sprout in the higher education context. This research, therefore, helps make the case that more work needs to be done in this area, and case studies that involve scalable options, need to be explored and discussed more prominently in literature.

One of the major contributions of this study is also the findings that relate to the barriers of cocreation. Co-creation is neither easy to design nor to implement, and it is not a panacea that can be used to solve all the ails within the student experience. The barriers to co-creation vary, and if not considered, can cause the activity to be detrimental rather than beneficial. Specific barriers that need to be considered prior to the activity include time (and effort), how to support an assessment requirement if necessary, and how to lessen power imbalances not only between staff and students, 
but students and students. Barriers that will often appear and yet still must also be considered during the process include a lack of clarity, inexperience of participants, wavering motivation, and disengagement or lack of motivation. As the findings of this study show, co-creation is typically voluntary, making motivation and engagement not just desired elements, but critical ones. Both students and staff are likely to lose motivation and engagement throughout the activity (depending on the duration) and support mechanisms to re-invigorate motivation and engagement should be considered. In many cases, this was achieved through periodic group meetings, to refine or redirect efforts, and varying participants getting involved in leadership, to take the pressure off having only one leader. The inexperience of participants further often aggregated participants' understanding of the clarity of the activity and could make them dependent on other students or staff for guidance. Therefore, a recommendation resulting from this study is that co-creation should most likely start small and grow gradually. This helps ease new participants into the process and make them more capable to do deeper co-creation activities in the future.

Another insight from this study, yet one that needs more exploration, revolves around the power balance between staff and students during co-creation. Co-creation can insinuate equality, however, there were no cases involved in this study that had equal responsibilities split between students and staff. The case that came the closest to this, was where there was just one student and one staff member involved. However, the student was a PhD student (and now an expert on student partnership) and the staff member was a professional staff member. In this case, the student was charged with leading the academic work of the program, while the staff member was left to administrative tasks, such as promotion and budgeting. Yet, it is difficult in this case to generalise this to cases where more students would be involved, and students are in an undergraduate or masters level course. However, what can be gleaned from this example, is that very clear distinctions of responsibilities are important for co-creation. Role clarity as a concept thus should be explored further in future research to see if this can offset some of the natural power imbalances that occur when varying stakeholders co-create together.

As this study points out, co-production and $\mathrm{ViU}$ are not new activities in higher education (though they are new constructs and are increasingly discussed). In fact, the student experience has always been co-produced, as teachers lecture on content, students' study and learn, and then provide evidence (e.g. exams, essays) that they understand the content. Therefore, elements such as interactions between students and staff and knowledge sharing between students as staff occur frequently. What is unique about this study however is how to amplify the elements of co- 
production. For example, while all students currently co-produce their subject learning experience, most do not currently co-produce their study spaces, or the university social media accounts, or the design process for enrolling new students. It is probably overly ambitious at this point to argue that all students should be co-producing all of aspects of the student experience, but it is realistic to assume that more of these opportunities will, and should, present themselves to students. These activities give students the opportunity to see more of what it is like to work at a university (and work in general), with considerations such as time, budget, infrastructure and so on. They also give students an opportunity to interact with staff not as students, but as colleagues. And finally, they provide benefits to both the students and staff, as students learn about the activity, and staff learn students' perspectives.

What is also not new, yet now conceptualised, is the idea of ViU. Similar to co-production, ViU is present in all student experiences. All students have experiences, all students personalise their experiences in their own unique fashion, and they all form relationships. However, what this study contributes, is first, the idea that co-production opportunities can amplify ViU. And secondly, that ViU reaches far beyond the typical production chain, or in this case, student journey. Anecdotally, those of us who have been to higher education or work in higher education know this. Our student experiences shape our futures in ways we did not anticipate when we were students. Yet, by introducing the concept of $\mathrm{ViU}$, and modifying it for the higher education context, one of the major contributions of this study is laying a foundation to further explore how to measure, amplify, and understand value in the student experience.

\section{New Directions for Research on Co-Creation}

As common with many large studies into relatively unexplored area, one could argue that a major contribution of this study is not what this specific study uncovered, but the path it has uncovered for future research. This section, therefore, will once again, summarise the major findings of this work and then discuss briefly the new direction for research.

The first finding of the study was that importance of antecedents in co-creation. As mentioned above, this is interesting because it means individual aspects such as personal outlooks and students' perceptions may have a strong influence on they choose to engage with their student experience. Subsequent questions arising from this finding therefore include: 
- What are common student/staff personal outlooks? How do they change depending on demographics, generational differences?

- How can personal outlooks be accounted for and supported for student success?

- How do students perceive the student experience activities and opportunities that are available to them? How can we improve their initial perceptions to help support motivations to get engaged?

- Why do some staff engage more frequently in extra-role behaviour? How can we support more staff to engage in extra-role behaviour?

The second finding of this study was how the environmental factors, such as in-person or online platforms and structures often dictate later co-creation processes. This is useful for stakeholders seeking to initiate co-creation as it is not only the aim of the activity that is important to consider when designing, but also the environmental factors. Subsequent questions arising from this finding therefore include:

- How do the differences in environments such as online or in-person influence later co-creation processes and outcomes?

- How can technology help support the equity and scalability of co-creation?

- To what extent does the authenticity of the activity (staff and university genuinely seeking student co-creation) influence later processes and outcomes?

- How can confusing or novel elements in co-creation be integrated to support deep participant and successful outcomes?

The third finding of this study relates to the various barriers that occur in the co-creation process. While co-creation, and related terms such as student partnership, are often discussed in the ways in which they benefit students and staff, more research could explore how they can also negatively influence students and staff perceptions or satisfaction. Subsequent questions arising from this finding therefore include:

- Can students be fully equal peers (i.e. co-creators) with staff? How can this be supported?

- How can co-creation activities accommodate for common barriers such as wavering motivation of participants and inexperience of participants? 
- In what ways can power imbalances be mitigated? How can power imbalances account for student differences?

The fourth finding, the first step to co-creation is co-production, points to a need to for future research to further uncover all the ways in which the student experience can be co-created. Therefore, subsequent questions for research include:

- In what ways can the student experience be co-produced?

- How can universities provide more opportunities for students to have control, access, and transparency within their student experience? And are there specific activities that should not be co-produced?

- How can university staff support ways to interact with students in an honest communication style?

- What are the aspects of the student perspective that is most useful for staff to know and what should students learn from the staff experience?

The fifth finding, co-production may amplify ViU, additionally should be explored in future research. For example, it is unknown is certain type of co-creation influence specific elements of $\mathrm{ViU}$ and how significant the impact may or may not be. Subsequent questions for future research therefore include:

- How significant is the impact of co-production experiences to students' value-inuse?

- Are there other, non-co-creation type activities, that can also impact value-in-use?

- What are some of the ways the student experience continues to add value for students after they have graduated? What aspects of their student experience have the most potential to keep gaining value?

- How does higher levels of ViU relate to other measures of student success such as student completion, student satisfaction and student employability?

The final finding of this study was that benefits of co-creation can outweigh costs. To elaborate on this, all of the cases were found to result in more reported benefits to students and staff than drawbacks. Therefore, while it possible that students and staff exaggerated benefits, or that the study happened to select ten cases that all had positive results, it is more likely that any type or 
form of co-creation results in at least some added value for students and staff. This makes sense, as co-creation type activities require time and energy from participants, and when stakeholders work in extra-role behaviour there is often extra benefit, regardless of the specific activity. Subsequent questions from this finding also include:

- Are there examples of co-creation activities where costs do not outweigh benefits?

- Is co-creation the optimal mechanism for improving value in the student experience? What other mechanisms could help improve value?

- To what extent do specific processes of the co-creation activity lead to specific benefits, such as employability or university marketing?

- Do other benefits not uncovered in this study exist?

To summarise, what can be seen from the above discussion, is that there are numerous ways for future research to continue to explore co-creation and value in the student experience. This study, however, forms a foundation for this important work to take place. The study has further successfully evidenced that a concept from organisational business literature does have a place in the current university climate, even if these two contexts have more differences than similarities. The study has additionally uncovered a model for which future work on co-creation in higher education can be based while accurately discussing the limitations and the need for future research in the area.

As discussed in Chapter 2, the climate of higher education is changing. There are more universities and more university students than ever before. This growth has created a market mentality in context of higher education, where quality assurance, market orientation and even university branding are increasingly important. There are likely downsides to this shift, but there are also benefits. In the midst of choice, student preferences can come to light and student voices can be heard. Thus, from the market orientation of higher education, there emerges opportunities for staff and students to co-create together and work together to improve the student experience. 


\section{References}

Abras, C., Maloney-Krichmar, D., \& Preece, J. (2004). User-centered design. Bainbridge, W. Encyclopedia of Human-Computer Interaction. Thousand Oaks: Sage Publications, 37(4), 445-456.

Akaka, M. A., Schau, H. J., \& Vargo, S. L. (2013). The co-creation of value-in-cultural-context. In Consumer culture theory (pp. 265-284). Emerald Group Publishing Limited.

Albinsson, P. A., Perera, B. Y., \& Sautter, P. T. (2016). DART scale development: Diagnosing a firm's readiness for strategic value co-creation. Journal of Marketing Theory and Practice, 24(1), $42-58$.

Allen, M., Bourhis, J., Burrell, N., \& Mabry, E. (2002). Comparing student satisfaction with distance education to traditional classrooms in higher education: A meta-analysis. The American Journal of Distance Education, 16(2), 83-97.

Altbach, P. (2015). Higher education and the WTO: Globalization run amok. International Higher Education, (23).

Altbach, P. G., \& Knight, J. (2007). The internationalization of higher education: Motivations and realities. Journal of Studies in International Education, 11(3-4), 290-305.

Altbach, P. G., Reisberg, L., \& Rumbley, L. E. (2009). Trends in global higher education: Tracking an academic revolution. Report prepared for the UNESCO 2009 World Conference on Higher Education. Accessed at: https://s3.amazonaws.com/academia.edu.documents/30910755/Altbach Reisberg Rumbley Tracking an Academic Revolution UNESCO 2009.pdf?AWSAccessKeyId=AKIAIWOWY $\underline{\text { YGZ2Y53UL3A\&Expires }=1542157624 \& \text { Signature }=\mathrm{a} 3 \mathrm{jMdu} \text { M0MPUd0\%2Bv7YRyq5Ib3UTw } \%}$ 3D\&response-contentdisposition $=$ inline $\% 3 \mathrm{~B} \% 20$ filename $\% 3$ DTrends in global higher education Tracki.pdf

Alves, H., Fernandes, C., \& Raposo, M. (2016). Value co-creation: Concept and contexts of application and study. Journal of Business Research, 69(5), 1626-1633.

Anderson, C. (2010). Presenting and evaluating qualitative research. American Journal of Pharmaceutical Education, 74(8), 141.

Anderson, M. (2011). Crowdsourcing higher education: A design proposal for distributed learning. MERLOT Journal of Online Learning and Teaching, 7(4), 576-590.

Andreu, L., Sánchez, I., \& Mele, C. (2010). Value co-creation among retailers and consumers: New insights into the furniture market. Journal of Retailing and Consumer Services, 17(4), 241-250.

Arnold, M. (2017). Fostering sustainability by linking co-creation and relationship management concepts. Journal of Cleaner Production, 140, 179-188.

Arthars, N., Dollinger, M., Vigentini, L., Liu, D., Kondo, E., \& King, D. (2018). Empowering Teachers to Personalise Learning Support and Feedback. In Ifenthaler, D., Mah, D., Yau, J. (Eds). Utilising Learning Analytics to Support Student Success. Springer.

Astin, A. W. (1984). Student involvement: A developmental theory for higher education. Journal of College Student Personnel, 25(4), 297-308. 
Auh, S., Bell, S. J., McLeod, C. S., \& Shih, E. (2007). Co-production and customer loyalty in financial services. Journal of Retailing, 83(3), 359-370.

Austin, I., \& Jones, G. A. (2015). Governance of higher education: Global perspectives, theories, and practices. Routledge.

Baldwin, G., \& James, R. (2000). The market in Australian higher education and the concept of student as informed consumer. Journal of Higher Education Policy and Management, 22(2), 139-148.

Ballantyne, D., \& Varey, R. J. (2006). Creating value-in-use through marketing interaction: the exchange logic of relating, communicating and knowing. Marketing Theory, 6(3), 335-348.

Bandura, A. (1997). Self-efficacy: The exercise of control. Macmillan.

Barnes, W., Slate, J. R., \& Rojas-LeBouef, A. (2010). College-readiness and academic preparedness: The same concepts?. Current Issues in Education, 13(4).

Baxter, P., \& Jack, S. (2008). Qualitative case study methodology: Study design and implementation for novice researchers. The Qualitative Report, 13(4), 544-559.

Bazeley, P. (2004). Issues in mixing qualitative and quantitative approaches to research. Applying Qualitative Methods to Marketing Management Research, 141, 156.

Bendapudi, N., \& Leone, R. P. (2003). Psychological implications of customer participation in coproduction. Journal of Marketing, 67(1), 14-28.

Bennett, R., \& Ali-Choudhury, R. (2009). Prospective students' perceptions of university brands: An empirical study. Journal of Marketing for Higher Education, 19(1), 85-107.

Berthon, P., Pitt, L., \& Campbell, C. (2008). Ad lib: When customers create the ad. California Management Review, 50(4), 6-30.

Bettencourt, L. A. (1997). Customer voluntary performance: Customers as partners in service delivery. Journal of Retailing, 73(3), 383-406.

Bice, S., \& Sullivan, H. (2014). Public policy studies and the "Asian Century": New orientations, challenges, and opportunities. Governance, 27(4), 539-544.

Binkhorst, E., \& Den Dekker, T. (2009). Agenda for co-creation tourism experience research. Journal of Hospitality Marketing \& Management, 18(2-3), 311-327.

Bitner, M. J. (1992). Servicescapes: The impact of physical surroundings on customers and employees. the Journal of Marketing, 57-71.

Bizzi, L., \& Langley, A. (2012). Studying processes in and around networks. Industrial marketing management, 41(2), 224-234. 
Blair, E., \& Valdez Noel, K. (2014). Improving higher education practice through student evaluation systems: is the student voice being heard?. Assessment \& Evaluation in Higher Education, 39(7), 879894.

Bodner, G., Klobuchar, M., \& Geelan, D. (2001). The many forms of constructivism. Journal of Chemical Education. ACS Publications.

Bok, D. (2009). Universities in the Marketplace: The commercialization of higher education (Vol. 39). Princeton University Press.

Bonnema, J., \& Van der Waldt, D. L. R. (2008). Information and source preferences of a student market in higher education. International Journal of Educational Management, 22(4), 314-327.

Bonsu, S. K., \& Darmody, A. (2008). Co-creating second life: Market-consumer cooperation in contemporary economy. Journal of Macromarketing, 28(4), 355-368.

Boud, D., \& Molloy, E. (2013). Rethinking models of feedback for learning: the challenge of design. Assessment \& Evaluation in Higher Education, 38(6), 698-712.

Bovill, C. (2017). A framework to explore roles within student-staff partnerships in higher education: Which students are parners, when, and in what ways?. International Journal for Students as Partners, 1(1).

Bovill, C., Cook-Sather, A., \& Felten, P. (2011). Students as co-creators of teaching approaches, course design, and curricula: implications for academic developers. International Journal for Academic Development, 16(2), 133-145.

Bovill, C., Cook-Sather, A., Felten, P., Millard, L., \& Moore-Cherry, N. (2016). Addressing potential challenges in co-creating learning and teaching: overcoming resistance, navigating institutional norms and ensuring inclusivity in student-staff partnerships. Higher Education, 71(2), 195-208.

Bovill, C., \& Felten, P. (2016). Cultivating student-staff partnerships through research and practice. International Journal for Academic Development, 21(1), p.1-3.

Bovill, C., Morss, K., \& Bulley, C. (2009). Should students participate in curriculum design? Discussion arising from a first year curriculum design project and a literature review. Pedagogical Research in Maximising Education, 3(2), 17-25.

Bowden, J. L. H. (2011). Engaging the student as a customer: A relationship marketing approach. Marketing Education Review, 21(3), 211-228.

Bowden, J. L. H., \& D’Alessandro, S. (2011). Co-creating value in higher education: The role of interactive classroom response technologies. Asian Social Science, 7(11).

Bowen, H. (2018). Investment in learning: The individual and social value of American higher education. Routledge.

Bowman, C., \& Ambrosini, V. (2000). Value creation versus value capture: towards a coherent definition of value in strategy. British Journal of Management, 11(1), 1-15. 
Brabham, D. C. (2008). Crowdsourcing as a model for problem solving: An introduction and cases. Convergence, 14(1), 75-90.

Brandenburg, U., \& De Wit, H. (2015). The end of internationalization. International Higher Education, (62).

Bray, L., \& Nettleton, P. (2007). Assessor or mentor? Role confusion in professional education. Nurse Education Today, 27(8), 848-855.

Breidbach, C. F., \& Maglio, P. P. (2016). Technology-enabled value co-creation: An empirical analysis of actors, resources, and practices. Industrial Marketing Management, 56, 73-85.

Brew, A. (2006). Research and Teaching: Beyond the divide. Macmillan International Higher Education.

Bridges, B. K., Cambridge, B., Kuh, G. D., \& Leegwater, L. H. (2005). Student engagement at minorityserving institutions: Emerging lessons from the BEAMS project. New Directions for Institutional Research, 2005(125), 25-43.

Brodie, R. J., Hollebeek, L. D., Jurić, B., \& Ilić, A. (2011). Customer engagement: Conceptual domain, fundamental propositions, and implications for research. Journal of Service Research, 14(3), 252-271.

Brown, R. M., \& Mazzarol, T. W. (2009). The importance of institutional image to student satisfaction and loyalty within higher education. Higher Education, 58(1), 81-95.

Browne, C., Vyas, Y., Mendoza, A., Sindermann, A., Holland, B., \& Lynch, E. (2017). Students as Cocreators of an Online Learning Resource. Teaching and Learning Together in Higher Education, 1(21), 3.

Bryman, A. (2008). Why do researchers integrate/combine/mesh/blend $/ \mathrm{mix} / \mathrm{merge} /$ fuse quantitative and qualitative research? Advances in mixed methods research, 87-100.

Bryson, C. (2016). Engagement through partnership: Students as partners in learning and teaching in higher education. International Journal for Academic Development, 21(1), p. 84-88.

Bunce, L., Baird, A., \& Jones, S. E. (2017). The student-as-consumer approach in higher education and its effects on academic performance. Studies in Higher Education, 42(11), 1958-1978.

Burton, S., \& Nesbit, P. L. (2008). Block or traditional? An analysis of student choice of teaching format. Journal of Management \& Organization, 14(1), 4-19.

Campbell, F., Beasley, L., Eland, J., \& Rumpus, A. (2007). Hearing the student voice: Promoting and encouraging the effective use of the student voice to enhance professional development in learning, teaching and assessment within higher education. The Higher Education Academy.

Carey, P. (2013). Student as co-producer in a marketised higher education system: a case study of students' experience of participation in curriculum design. Innovations in Education and Teaching International, 50(3), 250-260.

Carini, R. M., Kuh, G. D., \& Klein, S. P. (2006). Student engagement and student learning: Testing the linkages. Research in Higher Education, 47(1), 1-32.

Carlson, J. A. (2010). Avoiding traps in member checking. The Qualitative Report, 15(5), 1102-1113. 
Carù, A., \& Cova, B. (2003). Revisiting consumption experience: A more humble but complete view of the concept. Marketing Theory, 3(2), 267-286.

Caruso, R., \& De Wit, H. (2015). Determinants of mobility of students in Europe: Empirical evidence for the period 1998-2009. Journal of Studies in International Education, 19(3), 265-282.

Caulley, D. (1994). Notes on the basic characteristics of postpositivist interpretive inquiry. In Qualitative Research in Adult Education: a colloquium on theory, practice, supervision and assessment, Centre for Research in Education \& Work, Adelaide: University of South Australia.

Carrington, R., O'Donnell, C., \& Prasada Rao, D. S. (2018). Australian university productivity growth and public funding revisited. Studies in Higher Education, 43(8), 1417-1438.

Carvalho, S. W., \& de Oliveira Mota, M. (2010). The role of trust in creating value and student loyalty in relational exchanges between higher education institutions and their students. Journal of Marketing for Higher Education, 20(1), 145-165.

Chathoth, P., Altinay, L., Harrington, R. J., Okumus, F., \& Chan, E. S. (2013). Co-production versus cocreation: A process based continuum in the hotel service context. International Journal of Hospitality Management, 32, 11-20.

Chathoth, P. K., Ungson, G. R., Harrington, R. J., \& Chan, E. S. (2016). Co-creation and higher order customer engagement in hospitality and tourism services: A critical review. International Journal of Contemporary Hospitality Management, 28(2), 222-245.

Chemi, T., \& Krogh, L. (2017): Co-Creation in Higher Education. Students and Educators Preparing Creatively and Collaboratively to the Challenge of the Future. Sense Publishers

Chow, W. S., \& Chan, L. S. (2008). Social network, social trust and shared goals in organizational knowledge sharing. Information \& Management, 45(7), 458-465.

Chua, A. (2002). The influence of social interaction on knowledge creation. Journal of Intellectual capital, 3(4), 375-392.

Coates, H. (2005). The value of student engagement for higher education quality assurance. Quality in Higher Education, 11(1), 25-36.

Coates, H. (2016). The Market for Learning: Leading transparent higher education. Springer.

Coe, N. M., \& Smyth, F. M. (2010). Students as tour guides: Innovation in fieldwork assessment. Journal of Geography in Higher Education, 34(1), 125-139.

Coffield, F., \& Williamson, B. (2011). From Exam Factories to Communities of Discovery: The Democratic Route. Institute of Education-London. 20 Bedford Way, London, WC1H 0AL, UK.

Cook-Sather, A. (2014a). Multiplying perspectives and improving practice: what can happen when undergraduate students collaborate with college faculty to explore teaching and learning. Instructional Science, 42(1), 31-46.

Cook-Sather, A. (2014b). Student-faculty partnership in explorations of pedagogical practice: a threshold concept in academic development. International Journal for Academic Development, 19(3), 186-198. 
Cook-Sather, A. (2018). The Transformative Potential of Pedagogical Partnership: A Sampling of Student Partners' Stories. Teaching and Learning Together in Higher Education, 1(23), 1.

Cook-Sather, A., Bovill, C., \& Felten, P. (2014). Engaging students as partners in learning and teaching: A guide for faculty. John Wiley \& Sons.

Corbin, J., \& Strauss, A. (2008). Basics of qualitative research: Techniques and procedures for developing grounded theory. Audio e-book.

Cova, B., \& Dalli, D. (2009). Working consumers: the next step in marketing theory?. Marketing Theory, 9(3), 315-339.

Cova, B., Dalli, D., \& Zwick, D. (2011). Critical perspectives on consumers' role as 'producers': Broadening the debate on value co-creation in marketing processes. Marketing Theory, 11(3), 231241.

Cranton, P. (2011). A transformative perspective on the scholarship of teaching and learning. Higher Education Research \& Development, 30(1), 75-86.

Creswell, J. W. (2002). Educational research: Planning, conducting, and evaluating quantitative (pp. 146-166). Upper Saddle River, NJ: Prentice Hall.

Creswell, J. W., Plano Clark, V. L., Gutmann, M. L., \& Hanson, W. E. (2003). Advanced mixed methods research designs. Handbook of Mixed Methods in Social and Behavioral Research, 209, 240.

Creswell, J. W. (2014). A concise introduction to mixed methods research. Sage Publications.

Crotty, M., Willis, P., \& Neville, B. (1996). Doing phenomenology. NOTE 363p.; Produced by the University of South Australia, Centre for Research in Education, Equity and Work. Grant towards production provided by Texts in Humanities, School of Education, University of South Australia. Papers from, 274.

Cuthbert, R. (2010). Students as customers. Higher Education Review, 42(3), 3-25.

Davis, G. (May 2016). "Facing the zeitgeist: Dissolving the university." Grifith Review, 52: Imagining the Future.

De Wit, H. (2002). Internationalization of higher education in the United States of America and Europe: A historical, comparative, and conceptual analysis. Greenwood Publishing Group.

Deeley, S. J., \& Bovill, C. (2017). Staff student partnership in assessment: Enhancing assessment literacy through democratic practices. Assessment \& Evaluation in Higher Education, 42(3), 463-477.

Deem, R., Hillyard, S., Reed, M., \& Reed, M. (2007). Knowledge, Higher education, and the New Managerialism: The changing management of UK universities. Oxford University Press.

Deloitte Access Economics. (2015). The importance of universities to Australia's prosperity. Prepared for Universities Australia.

Denzin, N. (1970). Strategies of multiple triangulation. The Research Act in Sociology: A theoretical introduction to sociological method, 297, 313. 
Denzin, N. (1989). The Research Act. A Theoretical Intro to Sociological methodology. Publisher: Englewood and Cliffs.

Denzin, N. K., \& Lincoln, Y. S. (1994). Handbook of Qualitative Research. Sage publications.

Di Gangi, P. M., \& Wasko, M. (2009). Steal my idea! Organizational adoption of user innovations from a user innovation community: A case study of Dell IdeaStorm. Decision Support Systems, 48(1), 303312.

Díaz-Méndez, M., \& Gummesson, E. (2012). Value co-creation and university teaching quality: Consequences for the European Higher Education Area (EHEA). Journal of Service Management, 23(4), 571-592.

Dijk, J., Antonides, G., \& Schillewaert, N. (2014). Effects of co-creation claim on consumer brand perceptions and behavioural intentions. International Journal of Consumer Studies, 38(1), 110-118.

Dilley, R. (Ed.). (1999). The problem of context (Vol. 4). Berghahn Books.

Dollinger, M. (accepted at Australasian Society for Computers in Learning in Tertiary Education). Technologies for the scalability of co-creation.

Dollinger, M., Lodge, J., \& Coates, H. (2018). Co-creation in higher education: towards a conceptual model. Journal of Marketing for Higher Education, 1-22.

Dollinger, M., \& Lodge, J. M. (2018, March). Co-creation strategies for learning analytics. In Proceedings of the 8th International Conference on Learning Analytics and Knowledge (pp. 97-101). ACM.

Dooley, L. M. (2002). Case study research and theory building. Advances in Developing Human Resources, 4(3), $335-354$.

Dossick, C. S., \& Neff, G. (2011). Messy talk and clean technology: communication, problem-solving and collaboration using Building Information Modelling. The Engineering Project Organization Journal, 1(2), 83-93.

Doyle, E., Buckley, P., \& Whelan, J. (2017). Evolving Towards Co-Creation in Assessment. In 24th International EDINEB Conference (p. 64).

Doyle, W. R., \& Delaney, J. A. (2009). Higher education funding: The new normal. Change: The Magazine of Higher Learning, 41(4), 60-62.

Dwyer, A. (2018). Toward the formation of genuine partnership spaces. International Journal for Students as Partners, 2(1), 11-15.

Edwards, S., Rowe, J., Barnes, M., Anderson, P., \& Johnson-Cash, J. (2015). Learning for life and work in a complex world. In Annual Conference (p. 141).

Elg, M., Engström, J., Witell, L., \& Poksinska, B. (2012). Co-creation and learning in health-care service development. Journal of Service Management, 23(3), 328-343. 
Ellis, R. A., Goodyear, P., O’Hara, A., \& Prosser, M. (2007). The university student experience of face-toface and online discussions: coherence, reflection and meaning. ALT-J, 15(1), 83-97.

Elsharnouby, T. H. (2015). Student co-creation behavior in higher education: the role of satisfaction with the university experience. Journal of Marketing for Higher Education, 25(2), 238-262.

English, L., Guthrie, J., \& Parker, L. D. (2005). Recent public sector financial management change in Australia. International Public Financial Management Reform, 23-54.

Enz, M. G., \& Lambert, D. M. (2012). Using cross-functional, cross-firm teams to co-create value: The role of financial measures. Industrial Marketing Management, 41(3), 495-507.

Fagerstrøm, A., \& Ghinea, G. (2013). Co-creation of value in higher education: using social network marketing in the recruitment of students. Journal of Higher Education Policy and Management, 35(1), 4553.

Favaloro, C. (2015). Marketing in the Australian higher education sector. Journal of Higher Education Policy and Management, 37(5), 490-506.

Felten, P., Bagg, J., Bumbry, M., Hill, J., Hornsby, K., Pratt, M., \& Weller, S. (2013). A call for expanding inclusive student engagement in SoTL. Teaching and Learning Inquiry, 1(2), 63-74.

Felten, P., \& Clayton, P. H. (2011). Service-learning. New Directions for Teaching and Learning, 2011(128), 7584.

Fisher, D., \& Smith, S. (2011). Cocreation is chaotic: What it means for marketing when no one has control. Marketing Theory, 11(3), 325-350.

Fisk, R. P., Brown, S. W., \& Bitner, M. J. (1993). Tracking the evolution of the services marketing literature. Journal of Retailing, 69(1), 61-103.

Fleischman, D., Raciti, M., \& Lawley, M. (2015). Degrees of co-creation: an exploratory study of perceptions of international students' role in community engagement experiences. Journal of Marketing for Higher Education, 25(1), 85-103.

Flyvbjerg, B. (2006). Five misunderstandings about case-study research. Qualitative Inquiry, 12(2), 219-245.

Forsyth, H. (2014). A bistory of the modern Australian university. NewSouth.

Fraile, J., Panadero, E., \& Pardo, R. (2017). Co-creating rubrics: The effects on self-regulated learning, self-efficacy and performance of establishing assessment criteria with students. Studies in Educational Evaluation, 53, 69-76.

Franke, N., \& Von Hippel, E. (2003). Satisfying heterogeneous user needs via innovation toolkits: the case of Apache security software. Research policy, 32(7), 1199-1215.

Frasquet, M., Calderón, H., \&Cervera, A. (2012). University-industry collaboration from a relationship marketing perspective: An empirical analysis in a Spanish University. Higher Education, 64(1), 8598.

Freeman, R. E. (2010). Strategic Management: A stakeholder approach. Cambridge university press. 
Freeman, R. E., Harrison, J. S., \& Wicks, A. C. (2007). Managing for Stakeholders: Survival, reputation, and success. Yale University Press.

Freire, K., \& Sangiorgi, D. (2010, December). Service design and healthcare innovation: From consumption to coproduction and co-creation. In 2nd Nordic Conference on Service Design and Service Innovation, Linköping, Sweden. Retrieved July (Vol. 5, p. 2011).

Frow, P., McColl-Kennedy, J. R., \& Payne, A. (2016). Co-creation practices: Their role in shaping a health care ecosystem. Industrial Marketing Management, 56, 24-39.

Frow, P., Nenonen, S., Payne, A., \& Storbacka, K. (2015). Managing co-creation design: A strategic approach to innovation. British Journal of Management, 26(3), 463-483.

Füller, J., Hutter, K., \& Faullant, R. (2011). Why co-creation experience matters? Creative experience and its impact on the quantity and quality of creative contributions. R\&D Management, 41(3), 259-273.

Furedi, F. (2009). Now is the age of the discontented. Times Higher Education, 4, 30-35.

Furedi, F. (2010). Introduction to the marketisation of higher education and the student as consumer. In The marketisation of higher education and the student as consumer (pp. 15-22). Routledge.

Gambetti, R. C., \& Graffigna, G. (2010). The concept of engagement. International Journal of Market Research, 52(6), 801-826.

Garcia, T., \& Pintrich, P. R. (1994). Regulating motivation and cognition in the classroom: The role of self-schemas and self-regulatory strategies. Self-regulation of learning and performance: Issues and educational applications, $127153,433-452$.

Geertz, C. (1973). Thick description: Toward an interpretive theory of culture. The interpretation of cultures: Selected essays (pp. 3-30). New York, NY: Basic.

Gerring, J. (2004). What is a case study and what is it good for?. American Political Science Review, 98(2), 341354.

Gibb, A., \& Hannon, P. (2006). Towards the entrepreneurial university. International Journal of Entrepreneurship Education, 4(1), 73-110.

Gibbert, M., Leibold, M., \& Probst, G. (2002). Five styles of customer knowledge management, and how smart companies use them to create value. European Management Journal, 20(5), 459-469.

Gibbert, M., Ruigrok, W., \& Wicki, B. (2008). What passes as a rigorous case study?. Strategic Management Journal, 29(13), 1465-1474.

Gioia, D. A., Corley, K. G., \& Hamilton, A. L. (2013). Seeking qualitative rigor in inductive research: Notes on the Gioia methodology. Organizational Research Methods, 16(1), 15-31.

Glesne, C., \& Peshkin, A. (1992). Being there: Developing understanding through participant observation. Becoming Qualitative Researchers: An Introduction. White Plains, NY: Longman, 39-61. 
Golafshani, N. (2003). Understanding reliability and validity in qualitative research. The Qualitative Report, $8(4), 597-606$.

Gotel, O., Kulkarni, V., Scharff, C., \& Neak, L. (2008, July). Students as partners and students as mentors: an educational model for quality assurance in global software development. In International Conference on Software Engineering Approaches for Offshore and Outsourced Development (pp. 90-106). Springer, Berlin, Heidelberg.

Grönroos, C. (2012). Conceptualising value co-creation: A journey to the 1970s and back to the future. Journal of Marketing Management, 28(13-14), 1520-1534.

Grönroos, C., \& Voima, P. (2013). Critical service logic: making sense of value creation and co-creation. Journal of the Academy of Marketing Science, 41(2), 133-150.

Gros, B., \& López, M. (2016). Students as co-creators of technology-rich learning activities in higher education. International Journal of Educational Technology in Higher Education, 13(1), 28.

Gummesson, E. (2002). Relationship marketing and a new economy: it's time for de-programming. Journal of Services Marketing, 16(7), 585-589.

Gustafsson, A., Kristensson, P., \& Witell, L. (2012). Customer co-creation in service innovation: a matter of communication?. Journal of Service Management, 23(3), 311-327.

Guthrie, J., \& Neumann, R. (2007). Economic and non-financial performance indicators in universities: the establishment of a performance-driven system for Australian higher education. Public Management Review, 9(2), 231-252.

Hall, S. (2011). Educational ties, social capital and the translocal (re) production of MBA alumni networks. Global Networks, 11(1), 118-138.

Hamel, G., \& Prahalad, C. K. (1990). Strategic intent. Harvard Business Review, 68(3), 18-38.

Hao, Z. (2018). What It Is Like and What Needs to Be Done: A Status Report on Higher Education in Macau and Its Research. In Researching Higher Education in Asia (pp. 181-194). Springer, Singapore.

Harrell, M. C., \& Bradley, M. A. (2009). Data collection methods. Semi-structured interviews and focus groups. Rand National Defense Research.

Hayes, D., Wynyard, R., \& Mandal, L. (2017). The McDonaldization of higher education.

Hazelkorn, E. (2015). Rankings and the Reshaping of Higher Education: The battle for world-class excellence. Springer.

Healey, M. (2005). Linking research and teaching exploring disciplinary spaces and the role of inquirybased learning. Reshaping the university: New relationships between research, scholarship and teaching, 67-78.

Healey, M., Flint, A., \& Harrington, K. (2014). Developing students as partners in learning and teaching in higher education. York: Higher Education Academy.

Healey, M., Flint, A., \& Harrington, K. (2016). Students as partners: Reflections on a conceptual model. Teaching \& Learning Inquiry, 4(2), 1-13. 
Healey, M., \& Healey, R. (2018). 'It depends': Exploring the context-dependent nature of students as partners practices and policies. International Journal for Students As Partners, 2(1), 1-10.

Helgesen, Ø. (2008). Marketing for higher education: A relationship marketing approach. Journal of Marketing for Higher Education, 18(1), 50-78.

Hellstén, M., \& Prescott, A. (2004). Learning at University: The international student experience. International Education Journal, 5(3), 344-351.

Hemsley-Brown, J. (2011). Market heal thyself: the challenges of a free market in higher education. Journal of Marketing in Higher Education, 21 (2), 115-132.

Hemsley-Brown, J., \& Oplatka, I. (2006). Universities in a competitive global marketplace: A systematic review of the literature on higher education marketing. International Journal of Public Sector Management, 19(4), 316-338.

Henrie, C. R., Halverson, L. R., \& Graham, C. R. (2015). Measuring student engagement in technologymediated learning: A review. Computers \& Education, 90, 36-53.

Herrington, J., Oliver, R., \& Reeves, T. C. (2003). Patterns of engagement in authentic online learning environments. Australasian Journal of Educational Technology, 19(1).

Higgs, J., \& Titchen, A. (2001). Rethinking the practice-knowledge interface in an uncertain world: A model for practice development. British Journal of Occupational Therapy, 64(11), 526-533.

Holdsworth, C., \& Quinn, J. (2010). Student volunteering in English higher education. Studies in Higher Education, 35(1), 113-127.

Hu, S., \& Kuh, G. D. (2003). Diversity experiences and college student learning and personal development. Journal of College Student Development, 44(3), 320-334.

Huisman, J., \& Currie, J. (2004). Accountability in higher education: Bridge over troubled water?. Higher Education, 48(4), 529-551.

Humphreys, A., \& Grayson, K. (2008). The intersecting roles of consumer and producer: A critical perspective on co-production, co-creation and prosumption. Sociology Compass, 2(3), 963-980.

Ind, N., \& Coates, N. (2013). The meanings of co-creation. European Business Review, 25(1), 86-95.

Inkpen, A. C., \& Tsang, E. W. (2005). Social capital, networks, and knowledge transfer. Academy of Management Review, 30(1), 146-165.

Jaakkola, E., \& Alexander, M. (2014). The role of customer engagement behavior in value co-creation: a service system perspective. Journal of Service Research, 17(3), 247-261.

James, R., Krause, K. L., \& Jennings, C. (2010). The first year experience in Australian universities. Canberra: Department of Education, Employment and Workplace Relations [DEEWR].

Jansen, H. (2010). The logic of qualitative survey research and its position in the field of social research methods. In Forum Qualitative Sozialforschung/Forum: Qualitative Social Research (Vol. 11, No. 2). 
Jarvis, D. S. (2014). Regulating higher education: Quality assurance and neo-liberal managerialism in higher education-A critical introduction. Policy and Society, 33(3), 155-166.

Jaworski, B., \& Kohli, A. K. (2006). Co-creating the voice of the customer. The Service Dominant Logic of Marketing: Dialog, debate and directions, 109-117.

Jensen, M. C. (2010). Value maximization, stakeholder theory, and the corporate objective function. Journal of Applied Corporate Finance, 22(1), 32-42.

Jensen, K., \& Bennett, L. (2016). Enhancing teaching and learning through dialogue: a student and staff partnership model. International Journal for Academic Development, 21 (1), 41-53.

Jensen, J. L., \& Rodgers, R. (2001). Cumulating the intellectual gold of case study research. Public Administration Review, 61(2), 235-246.

Johnson, A. T., \& Hirt, J. B. (2011). Reshaping academic capitalism to meet development priorities: The case of public universities in Kenya. Higher Education, 61(4), 483-499.

Jones, C., Ramanau, R., Cross, S., \& Healing, G. (2010). Net generation or Digital Natives: Is there a distinct new generation entering university?. Computers \& Education, 54(3), 722-732.

Jongbloed, B. (2003). Marketisation in higher education, Clark's triangle and the essential ingredients of markets. Higher Education Quarterly, 57(2), 110-135.

Jongbloed, B., \& Vossensteyn, H. (2001). Keeping up performances: An international survey of performance-based funding in higher education. Journal of Higher Education Policy and Management, 23(2), 127-145.

Joseph, M., Mullen, E. W., \& Spake, D. (2012). University branding: Understanding students' choice of an educational institution. Journal of Brand Management, 20(1), 1-12.

Judson, K. M., \& Taylor, S. A. (2014). Moving from marketization to marketing of higher education: The co-creation of value in higher education. Higher Education Studies, 4(1), 51-67.

Jungblut, J., Vukasovic, M., \& Stensaker, B. (2015). Student perspectives on quality in higher education. European Journal of Higher Education, 5(2), 157-180.

Kahu, E. R. (2013). Framing student engagement in higher education. Studies in higher education, 38(5), $758-$ 773.

Kahu, E. R., \& Nelson, K. (2018). Student engagement in the educational interface: understanding the mechanisms of student success. Higher Education Research \& Development, 37(1), 58-71.

Kale, P., Dyer, J., \& Singh, H. (2001). Value creation and success in strategic alliances: alliancing skills and the role of alliance structure and systems. European Management Journal, 19(5), 463-471.

Karahasanović, A., Brandtzæg, P. B., Heim, J., Lüders, M., Vermeir, L., Pierson, J., ... \& Jans, G. (2009). Co-creation and user-generated content-elderly people's user requirements. Computers in Human Behavior, 25(3), 655-678. 
Kay, J., Dunne, E., \& Hutchinson, J. (2010). Rethinking the values of higher education-students as change agents? Accessed at: http://dera.ioe.ac.uk/1193/1/StudentsChangeAgents.pdf

Kazadi, K., Lievens, A., \& Mahr, D. (2016). Stakeholder co-creation during the innovation process: Identifying capabilities for knowledge creation among multiple stakeholders. Journal of Business Research, 69(2), 525-540.

Kift, S. (2004, July). Organising first year engagement around learning: Formal and informal curriculum intervention. In 8th Pacific Rim First Year in Higher Education Conference, Dealing with Diversity, Queensland University of Technology in conjunction with Monash University, Melbourne, Australia (pp. 14-16).

Kift, S. M., Nelson, K. J., \& Clarke, J. A. (2010). Transition pedagogy: a third generation approach to FYE: a case study of policy and practice for the higher education sector. The International Journal of the First Year in Higher Education, 1(1), 1-20.

Kim, K. J., \& Bonk, C. J. (2006). The future of online teaching and learning in higher education. Educause Quarterly, 29(4), 22-30.

Klem, A. M., \& Connell, J. P. (2004). Relationships matter: Linking teacher support to student engagement and achievement. Journal of School Health, 74(7), 262-273.

Knight, J. (1999). Issues and trends in internationalization: A comparative perspective. In New world of knowledge: Canadian Universities and Globalization. IDRC, Ottawa, ON, CA.

Knight, J. (2015). The international race for accreditation. International Higher Education, (40).

Komarraju, M., Musulkin, S., \& Bhattacharya, G. (2010). Role of student-faculty interactions in developing college students' academic self-concept, motivation, and achievement. Journal of College Student Development, 51(3), 332-342.

Konovsky, M. A., \& Pugh, S. D. (1994). Citizenship behavior and social exchange. Academy of Management Journal, 37(3), 656-669.

Kotler, P. (2011). Reinventing marketing to manage the environmental imperative. Journal of Marketing, 75(4), 132-135.

Kotler, P., \& Armstrong, G. (2010). Principles of Marketing. Pearson education.

Krause, K. L. (2007). Social involvement and commuter students: The first-year student voice. Journal of the First-Year Experience \& Students in Transition, 19(1), 27-45.

Krause, K. L. (2017). The Australian higher education student experience [Book Review]. HERDSA News, 39(3), 24.

Krause, K. L., \& Coates, H. (2008). Students' engagement in first-year university. Assessment \& Evaluation in Higher Education, 33(5), 493-505.

Kristensson, P., Gustafsson, A., \& Archer, T. (2004). Harnessing the creative potential among users. Journal of Product Innovation Management, 21(1), 4-14. 
Kristensson, P., Matthing, J., \& Johansson, N. (2008). Key strategies for the successful involvement of customers in the co-creation of new technology-based services. International Journal of Service Industry Management, 19(4), 474-491.

Kuh, G. D. (2007). How to help students achieve. Chronicle of Higher Education, 53(41), B12-B13.

Kwong, J. (2000). Introduction: Marketization and privatization in education. International Journal of Educational Development, 20(2), 87-92.

Larbi, G. A. (1999). The new public management approach and crisis states. United Nations Research Institute for Social Development. Discussion Paper. 112.

Leavy, B. (2012). Collaborative innovation as the new imperative-design thinking, value co-creation and the power of "pull". Strategy \& Leadership, 40(2), 25-34.

Lee, H. H. M., \& van Dolen, W. (2015). Creative participation: Collective sentiment in online co-creation communities. Information \& Management, 52(8), 951-964.

Leech, N. L., \& Onwuegbuzie, A. J. (2009). A typology of mixed methods research designs. Quality \& Quantity, 43(2), 265-275.

Lengnick-Hall, C. A. (1996). Customer contributions to quality: A different view of the customer-oriented firm. Academy of Management Review, 21(3), 791-824.

Levin, J. S. (2005). The business culture of the community college: Students as consumers; students as commodities. New Directions for Higher Education, 2005(129), 11-26.

Levy, S. J., \& Luedicke, M. K. (2013). From marketing ideology to branding ideology. Journal of Macromarketing, 33(1), 58-66.

Liamputtong, P. (2009). Qualitative data analysis: conceptual and practical considerations. Health Promotion Journal of Australia, 20(2), 133-139.

Liefner, I. (2003). Funding, resource allocation, and performance in higher education systems. Higher Education, 46(4), 469-489.

Likert, R. (1932). A technique for the measurement of attitudes. Archives of Psychology.

Lincoln, Y. S., Lynham, S. A., \& Guba, E. G. (2011). Paradigmatic controversies, contradictions, and emerging confluences, revisited. The Sage Handbook of Qualitative Research, 4, 97-128.

Lizzio, A., \& Wilson, K. (2009). Student participation in university governance: the role conceptions and sense of efficacy of student representatives on departmental committees. Studies in Higher Education, 34(1), 69-84.

Lowry, J. R., \& Owens, B. D. (2001). Developing a positioning strategy for a university. Services Marketing Quarterly, 22(4), 27-42.

Lueddeke, G. R. (2003). Professionalising teaching practice in higher education: A study of disciplinary variation and'teaching-scholarship'. Studies in Higher Education, 28(2), 213-228. 
Luijten-Lub, A., Van der Wende, M., \& Huisman, J. (2005). On cooperation and competition: A comparative analysis of national policies for internationalisation of higher education in seven Western European countries. Journal of Studies in International Education, 9(2), 147-163.

Lundberg, C. A., \& Schreiner, L. A. (2004). Quality and frequency of faculty-student interaction as predictors of learning: An analysis by student race/ethnicity. Journal of College Student Development, 45(5), 549-565.

Lusch, R. F., \& Vargo, S. L. (2006). Service-dominant logic: reactions, reflections and refinements. Marketing Theory, 6(3), 281-288.

Lusch, R. F., Vargo, S. L., \& O'Brien, M. (2007). Competing through service: Insights from servicedominant logic. Journal of Retailing, 83(1), 5-18.

Lusch, R. F., Vargo, S. L., \& Wessels, G. (2008). Toward a conceptual foundation for service science: Contributions from service-dominant logic. IBM systems journal, 47(1), 5-14.

Lyytinen, K., \& Damsgaard, J. (2001, April). What's wrong with the diffusion of innovation theory?. In Working Conference on Diffusing Software Product and Process Innovations (pp. 173-190). Springer, Boston, MA.

Macdonald, E. K., Wilson, H., Martinez, V., \& Toossi, A. (2011). Assessing value-in-use: A conceptual framework and exploratory study. Industrial Marketing Management, 40(5), 671-682.

Mackenzie, N., \& Knipe, S. (2006). Research dilemmas: Paradigms, methods and methodology. Issues in Educational Research, 16(2), 193-205.

Malone, T. W., Laubacher, R., \& Dellarocas, C. (2009). Harnessing crowds: Mapping the genome of collective intelligence.

Marginson, S. (1997). Steering from a distance: Power relations in Australian higher education. Higher Education, 34(1), 63-80.

Marginson, S. (2003). Markets in Higher Education: National and global competition. Monash University.

Marginson, S. (2006). Dynamics of national and global competition in higher education. Higher Education, 52(1), 1-39.

Marginson, S. (2013). The impossibility of capitalist markets in higher education. Journal of Education Policy, 28(3), 353-370.

Marginson, S. (2015). Is Australia overdependent on international students?. International Higher Education, (54).

Marginson, S., \& Considine, M. (2000). The enterprise university: Power, governance and reinvention in Australia. Cambridge University Press.

Marginson, S., \& Rhoades, G. (2002). Beyond national states, markets, and systems of higher education: A glonacal agency heuristic. Higher Education, 43(3), 281-309. 
Marquis, E., Puri, V., Wan, S., Ahmad, A., Goff, L., Knorr, K., ... \& Woo, J. (2016). Navigating the threshold of student-staff partnerships: A case study from an Ontario teaching and learning institute. International Journal for Academic Development, 21(1), 4-15.

Martín, P., Potočnik, K., \& Fras, A. B. (2017). Determinants of students' innovation in Higher Education. Studies in Higher Education, 42(7), 1229-1243.

Mathis, E. F., Kim, H. L., Uysal, M., Sirgy, J. M., \& Prebensen, N. K. (2016). The effect of co-creation experience on outcome variable. Annals of Tourism Research, 57, 62-75.

Mathison, S. (2008). What is the difference between evaluation and research-and why do we care. Fundamental Issues in Evaluation, 183-196.

Mathwick, C., \& Rigdon, E. (2004). Play, flow, and the online search experience. Journal of Consumer Research, 31(2), 324-332.

Matthews, K. (2016). Students as partners as the future of student engagement. Student Engagement in Higher Education Journal, 1(1).

Matthews, K. (2017). Students and staff as partners in Australian higher education: Introducing our stories of partnership. Teaching and Learning Together in Higher Education, 1(21), 1-4.

Matthews, K. E., Dwyer, A., Hine, L., \& Turner, J. (2018). Conceptions of students as partners. Higher Education, 1-15.

Maul, A. (2017). Rethinking traditional methods of survey validation. Measurement: Interdisciplinary Research and Perspectives, 15(2), 51-69.

McBrien, J. L., Cheng, R., \& Jones, P. (2009). Virtual spaces: Employing a synchronous online classroom to facilitate student engagement in online learning. The International Review of Research in Open and Distributed Learning, 10(3).

McCamish, T. (2016). 'Thinking caps on: where has demand driven our universities? The Monthly. Accessed at: $\quad$ https://www.themonthly.com.au/issue/2016/september/1472652000/thorntonmccamish/thinking-caps

McColl-Kennedy, J. R., Vargo, S. L., Dagger, T. S., Sweeney, J. C., \& Kasteren, Y. V. (2012). Health care customer value cocreation practice styles. Journal of Service Research, 15(4), 370-389.

McCulloch, A. (2009). The student as co-producer: learning from public administration about the studentuniversity relationship. Studies in Higher Education, 34(2), 171-183.

McInnis, C. (2003, August). New realities of the student experience: How should universities respond. In 25th Annual Conference European Association for Institutional Research (pp. 24-27).

McLeod, J. (2011). Student voice and the politics of listening in higher education. Critical Studies in Education, 52(2), 179-189.

McMaster University (2018). "Student Partners Program.” Accessed at: https://mi.mcmaster.ca/studentpartners-program/ 
McMillan, J. J., \& Cheney, G. (1996). The student as consumer: The implications and limitations of a metaphor. Communication Education, 45(1), 1-15.

Mele, C., Russo Spena, T., \& Colurcio, M. (2010). Co-creating value innovation through resource integration. International Journal of Quality and Service Sciences, 2(1), 60-78.

Mercer-Mapstone, L., \& Clarke, A. (2018). A Partnership Approach to Scaling Up Student-Staff Partnership at a Large Research-Intensive University. The Journal of Educational Innovation, Partnership and Change, 4(1).

Mercer-Mapstone, L., Dvorakova, S. L., Matthews, K., Abbot, S., Cheng, B., Felten, P., ... \& Swaim, K. (2017). A systematic literature review of students as partners in higher education. International Journal for Students as Partners, 1(1).

Mercer-Mapstone, L., Matthews, K., Rueckert, C., Thomas, L., \& Varnham, S. (2016). 'Students as Partners' in Higher Education: An insurmountable challenge or an opportunity for transformation?. In Higher Education Research and Development Society of Australasia (HERDSA) Conference.

Mercer-Mapstone, L., \& Mercer, G. (2018). A dialogue between partnership and feminism: deconstructing power and exclusion in higher education. Teaching in Higher Education, 23(1), 137-143.

Merrilees, B., Miller, D., \& Yakimova, R. (2017). The role of staff engagement in facilitating staff-led value co-creation. Journal of Service Management, 28(2), 250-264.

Meyers, N. M., \& Nulty, D. D. (2009). How to use (five) curriculum design principles to align authentic learning environments, assessment, students' approaches to thinking and learning outcomes. Assessment \& Evaluation in Higher Education, 34(5), 565-577.

Miles, M. and Huberman, A. (1994) An Expanded Source Book: Qualitative data analysis (2 ${ }^{\text {nd }}$ edn) Thousand Oaks: Sage.

Miles, B. B., \& Power, R. K. (2017). Learners Without Borders: Tales from the Trails of Navigating Transitions from Student Partners to Staff Partners-While Retaining Students as Partners. Teaching and Learning Together in Higher Education, 1(21), 9.

Mittelmeier, J., Rienties, B., Tempelaar, D., \& Whitelock, D. (2018). Overcoming cross-cultural group work tensions: mixed student perspectives on the role of social relationships. Higher Education, 75(1), 149-166.

Mohrman, K., Ma, W., \& Baker, D. (2008). The research university in transition: The emerging global model. Higher Education Policy, 21(1), 5-27.

Molesworth, M., Nixon, E., \& Scullion, R. (2009). Having, being and higher education: The marketisation of the university and the transformation of the student into consumer. Teaching in Higher Education, 14(3), 277-287.

Molesworth, M., Scullion, R., \& Nixon, E. (Eds.). (2010). The Marketisation of Higher Education. Routledge.

Mok, K. H. (2003). Globalisation and higher education restructuring in Hong Kong, Taiwan and Mainland China. Higher Education Research \& Development, 22(2), 117-129. 
Moore, D., \& Bowden-Everson, J. L. H. (2012). An appealing connection-The role of relationship marketing in the attraction and retention of students in an Australian tertiary context. Asian Social Science, $8(14)$.

Morrison, P. D., Roberts, J. H., \& Von Hippel, E. (2000). Determinants of user innovation and innovation sharing in a local market. Management Science, 46(12), 1513-1527.

Mulder, R. A., Pearce, J. M., \& Baik, C. (2014). Peer review in higher education: Student perceptions before and after participation. Active Learning in Higher Education, 15(2), 157-171.

Muñiz Jr, A. M., \& Schau, H. J. (2011). How to inspire value-laden collaborative consumer-generated content. Business Horizons, 54(3), 209-217.

Nambisan, S., \& Baron, R. A. (2009). Virtual customer environments: testing a model of voluntary participation in value co-creation activities. Journal of Product Innovation Management, 26(4), 388-406.

Nardo, M., Saisana, M., Saltelli, A., Tarantola, S., Hoffman, A., \& Giovannini, E. (2005). Handbook on constructing composite indicators.

Navarro-García, A., Peris-Ortiz, M., \& Rueda-Armengot, C. (2015). Value co-creation, collaborative learning and competences in higher education. In Sustainable learning in higher education (pp. 37-45). Springer, Cham.

Neary, M. (2010). Student as producer: a pedagogy for the avant-garde?. Learning Exchange, 1(1).

Neary, M. (2012). Teaching Politically: Policy, Pedagogy and the New European University. Journal for Critical Education Policy Studies (JCEPS), 10(2).

Neary, M., \& Winn, J. (2009). The student as producer: reinventing the student experience in higher education. Accessed at: http://eprints.lincoln.ac.uk/1675/1/Future of HE - Chapter 10.pdf

Neary, M., \& Winn, J. (2015). Beyond public and private: a model for co-operative higher education. Krisis: Journal for Contemporary Philosophy.

Nedbalová, E., Greenacre, L., \& Schulz, J. (2014). UK higher education viewed through the marketization and marketing lenses. Journal of Marketing for Higher Education, 24(2), 178-195.

Neuhofer, B., Buhalis, D., \& Ladkin, A. (2013). Co-creation through technology: Dimensions of social connectedness. In Information and Communication Technologies in Tourism 2014 (pp. 339-352). Springer, Cham.

Newman, J., Barnes, M., Sullivan, H., \& Knops, A. (2004). Public participation and collaborative governance. Journal of Social Policy, 33(2), 203-223.

Newton, D. A., Grayson, M. S., \& Foster Thompson, L. (2010). Money, lifestyle, or values? Why medical students choose subspecialty versus general paediatric careers. Clinical pediatrics, 49(2), 116-122.

Ng, I. C., \& Forbes, J. (2009). Education as service: The understanding of university experience through the service logic. Journal of Marketing for Higher Education, 19(1), 38-64. 
Nicolescu, L. (2009). Applying marketing to higher education: Scope and limits. Management \& Marketing, $4(2)$.

Nonaka, I., \& Takeuchi, H. (1995). The knowledge creation company: how Japanese companies create the dynamics of innovation. Long Range Planning, 4(29), p. 592.

Normann, R., \& Ramirez, R. (1993). From value chain to value constellation: Designing interactive strategy. Harvard Business Review, 71(4), 65-77.

Norton, A. (2013). The online evolution: when technology meets tradition in higher education. Melbourne: Grattan Institute.

Norton, A., Norton, A., \& Cakitaki, B. (2016). Mapping Australian higher education 2016. Melbourne: Grattan Institute.

Nunan, D. (1992). Research Methods in Language Learning. Cambridge University Press.

Nuttavuthisit, K. (2010). If you can't beat them, let them join: The development of strategies to foster consumers' co-creative practices. Business Horizons, 53(3), 315-324.

Obondoh, A. (2003). The Politics of Participatory Decision Making in Campus Governance (No. 14). Association of African Universities.

Ogawa, S., \& Piller, F. T. (2006). Reducing the risks of new product development. MIT Sloan management review, 47(2), 65.

Olssen, M., \& Peters, M. A. (2005). Neoliberalism, higher education and the knowledge economy: From the free market to knowledge capitalism. Journal of Education Policy, 20(3), 313-345.

O’Neill, M. A., \& Palmer, A. (2004). Importance-performance analysis: a useful tool for directing continuous quality improvement in higher education. Quality Assurance in Education, 12(1), 39-52.

Organ, D. W. (1988). A restatement of the satisfaction-performance hypothesis. Journal of Management, 14(4), 547-557.

Ortiz, A., Chang, L., \& Fang, Y. (2015). International student mobility trends 2015: An economic perspective. Accessed

at: https://s3.amazonaws.com/academia.edu.documents/38039591/International_Student_Mobilit y_Trends_2015_Wordpress_version_4_FINAL.pdf?AWSAccessKeyId=AKIAIWOWYYGZ2Y 53UL3A\&Expires $=1542159574 \&$ Signature $=$ s5UaqUEmllKPK4T815DXiSspreM\%3D\&respons e-content-

disposition=inline $\% 3 \mathrm{~B} \% 20$ filename $\% 3$ DInternational_Student_Mobility_Trends_20.pdf

Osborne, S. P., Radnor, Z., \& Strokosch, K. (2016). Co-production and the co-creation of value in public services: a suitable case for treatment?. Public Management Review, 18(5), 639-653.

Ouimet, J. A., Bunnage, J. C., Carini, R. M., Kuh, G. D., \& Kennedy, J. (2004). Using focus groups, expert advice, and cognitive interviews to establish the validity of a college student survey. Research in Higher Education, 45(3), 233-250 
Ozkan, S., \& Koseler, R. (2009). Multi-dimensional students' evaluation of e-learning systems in the higher education context: An empirical investigation. Computers \& Education, 53(4), 1285-1296.

Padgett, R. D., Keup, J. R., \& Pascarella, E. T. (2013). The impact of first-year seminars on college students' life-long learning orientations. Journal of Student Affairs Research and Practice, 50(2), 133-151.

Parker, L. D. (2012). From privatised to hybrid corporatised higher education: A global financial management discourse. Financial Accountability \& Management, 28(3), 247-268.

Parker, L., \& Guthrie, J. (2005). Welcome to "the rough and tumble" Managing accounting research in a corporatised university world. Accounting, Auditing \& Accountability Journal, 18(1), 5-13.

Pascarella, E., \& Terenzini, P. (2005). How college affects students: A third decade of research. San Francisco. Jossey-Bass, 2(848), 11.

Patton, M. Q. (2002). Two decades of developments in qualitative inquiry: A personal, experiential perspective. Qualitative Social Work, 1(3), 261-283.

Payne, A. F., Storbacka, K., \& Frow, P. (2008). Managing the co-creation of value. Journal of the Academy of Marketing Science, 36(1), 83-96.

Pennington, D. D. (2011). Bridging the disciplinary divide: Co-creating research ideas in escience teams. Computer Supported Cooperative Work (CSCW), 20(3), 165-196.

Perks, H., Gruber, T., \& Edvardsson, B. (2012). Co-creation in radical service innovation: a systematic analysis of microlevel processes. Journal of Product Innovation Management, 29(6), 935-951.

Perry, C. (1998). Processes of a case study methodology for postgraduate research in marketing. European Journal of Marketing, 32(9/10), 785-802.

Peseta, T., Bell, A., Clifford, A., English, A., Janarthana, J., Jones, C., ... \& Zhang, J. (2016). Students as ambassadors and researchers of assessment renewal: puzzling over the practices of university and academic life. International Journal for Academic Development, 21(1), 54-66.

Pike, G. R., \& Kuh, G. D. (2005). First-and second-generation college students: A comparison of their engagement and intellectual development. The Journal of Higher Education, 76(3), 276-300.

Pinar, M., Trapp, P., Girard, T., \& Boyt, T. E. (2011). Utilizing the brand ecosystem framework in designing branding strategies for higher education. International Journal of Educational Management, 25(7), 724-739.

Pintrich, P. R. (1999). The role of motivation in promoting and sustaining self-regulated learning. International Journal of Educational Research, 31(6), 459-470.

Pluijm, L. (2010). Realizing co-creation. Master's thesis.

Pongsakornrungsilp, S., \& Schroeder, J. E. (2011). Understanding value co-creation in a co-consuming brand community. Marketing Theory, 11(3), 303-324.

Porter, M. E. (1985). Competitive advantage: creating and sustaining superior performance. 1985. New York: FreePress, 43, 214. 
Porter, M. E., Pabo, E. A., \& Lee, T. H. (2013). Redesigning primary care: a strategic vision to improve value by organizing around patients' needs. Health Affairs, 32(3), 516-525.

Poynter, J. R., \& Rasmussen, C. (1996). A place apart: The University of Melbourne: Decades of challenge. Melbourne University Publish.

Prebensen, N. K., Vittersø, J., \& Dahl, T. I. (2013). Value co-creation significance of tourist resources. Annals of Tourism Research, 42, 240-261.

Prahalad, C. K., \& Krishnan, M. S. (2008). The New Age of Innovation. McGraw-Hill Professional Publishing.

Prahalad, C. K., \& Ramaswamy, V. (2000). Co-opting customer competence. Harvard Business Review, 78(1), 79-90.

Prahalad, C. K., \& Ramaswamy, V. (2002). The co-creation connection. Strategy and Business, 50-61.

Prahalad, C. K., \& Ramaswamy, V. (2003). The new frontier of experience innovation. MIT Sloan Management Review, 44(4), 12.

Prahalad, C. K., \& Ramaswamy, V. (2004). Co-creation experiences: The next practice in value creation. Journal of Interactive Marketing, 18(3), 5-14.

Pucciarelli, F., \& Kaplan, A. (2016). Competition and strategy in higher education: Managing complexity and uncertainty. Business Horizons, 59(3), 311-320.

Punch, K.F. 2009. Introduction to research methods in education. London: Sage.

Raciti, M. (2010). Marketing Australian higher education at the turn of the 21st Century: A précis of reforms, commercialisation and the new university hierarchy. e-Journal of Business Education \& Scholarship of Teaching, 4(1), 32-41.

Ramachandran, N. T. (2010). Marketing framework in higher education: Addressing aspirations of students beyond conventional tenets of selling products. International Journal of Educational Management, 24(6), 544-556.

Ramaswamy, V. (2008). Co-creating value through customers' experiences: the Nike case. Strategy \& Leadership, 36(5), 9-14.

Ramaswamy, V. (2009). Leading the transformation to co-creation of value. Strategy \& Leadership, 37(2), 32-37.

Ramaswamy, V., \& Ozcan, K. (2014). The co-creation paradigm. Stanford University Press.

Ramirez, R. (1999). Stakeholder analysis and conflict management. Cultivating peace: conflict and collaboration in natural resource management, 101-126.

Ranjan, K. R., \& Read, S. (2016). Value co-creation: concept and measurement. Journal of the Academy of Marketing Science, 44(3), 290-315. 
Rakrouki, Z., Gatenby, M., Cantore, S., Rowledge, T., \& Davidson, T. (2017). The Opening Conference: A Case Study in Undergraduate Co-design and Inquiry-based Learning. International Journal for Students as Partners, 1(2).

Restuccia, M., \& Ouellet, J. F. (2009, May). Value co-creation orientation: Conceptualization, measurement and impact on firm performance. In Doctoral Workshop-Naples Forum on Services, Montréal, Canada.

Reypens, C., Lievens, A., \& Blazevic, V. (2016). Leveraging value in multi-stakeholder innovation networks: A process framework for value co-creation and capture. Industrial Marketing Management, $56,40-50$.

Ribes-Giner, G., \& Peralt, A. (2014). Modelling the co-creation between students and universities and its effects to loyalty and satisfaction. Modelling for engineering and human behavior, 121-127.

Richardson, M., Abraham, C., \& Bond, R. (2012). Psychological correlates of university students' academic performance: A systematic review and meta-analysis. Psychological bulletin, 138(2), 353.

Ritzen, J. (2016). European Universities in the Aftermath of the Economic Crisis. International Higher Education, (87), 3-4.

Ritzer, G. (2014). Prosumption: Evolution, revolution, or eternal return of the same?. Journal of Consumer Culture, 14(1), 3-24.

Ritzer, G., \& Jurgenson, N. (2010). Production, consumption, prosumption: The nature of capitalism in the age of the digital 'prosumer'. Journal of Consumer Culture, 10(1), 13-36.

Roberts, D., Hughes, M., \& Kertbo, K. (2014). Exploring consumers' motivations to engage in innovation through co-creation activities. European Journal of Marketing, 48(1/2), 147-169.

Rogers, E. M. (1995). Lessons for guidelines from the diffusion of innovations. Joint Commission Journal on Quality and Patient Safety, 21(7), 324-328.

Rudduck, J. (2006). The past, the papers and the project. Educational Review, 58(2), 131-143.

Ryan, M., \& Ryan, M. (2013). Theorising a model for teaching and assessing reflective learning in higher education. Higher Education Research \& Development, 32(2), 244-257.

Sandeen, C. (2008). Boomers, Xers, and Millennials: Who Are They and What Do They Really Want from Continuing Higher Education?. Continuing Higher Education Review, 72, 11-31.

Sanders, E. B. N., Brandt, E., \& Binder, T. (2010, November). A framework for organizing the tools and techniques of participatory design. In Proceedings of the 11th biennial participatory design conference (pp. 195-198). ACM.

Sanders, E. B. N., \& Stappers, P. J. (2008). Co-creation and the new landscapes of design. Co-design, 4(1), 5-18.

Sandström, S., Edvardsson, B., Kristensson, P., \& Magnusson, P. (2008). Value in use through service experience. Managing Service Quality: An International Journal, 18(2), 112-126. 
Sawhney, M., Verona, G., \& Prandelli, E. (2005). Collaborating to create: The Internet as a platform for customer engagement in product innovation. Journal of Interactive Marketing, 19(4), 4-17.

Schlesinger, W., Cervera, A., \& Iniesta, M. Á. (2015). Key elements in building relationships in the higher education services context. Journal of Promotion Management, 21(4), 475-491.

Schofer, E., \& Meyer, J. W. (2005). The worldwide expansion of higher education in the twentieth century. American Sociological Review, 70(6), 898-920.

Schofield, C., Cotton, D., Gresty, K., Kneale, P., \& Winter, J. (2013). Higher education provision in a crowded marketplace. Journal of Higher Education Policy and Management, 35(2), 193-205.

Schön, D. A. (1983). The reflective practitioner how professionals think in action. Basic Books, ISBN: 0465068782 .

Schuler, D., \& Namioka, A. (Eds.). (1993). Participatory design: Principles and practices. CRC Press.

Seale, J. (2010). Doing Student voice work in higher education: the potential contribution of a participatory framework. British Educational Research Journal, 36(6), 995-1015.

Seale, J., Gibson, S., Haynes, J., \& Potter, A. (2015). Power and resistance: Reflections on the rhetoric and reality of using participatory methods to promote student voice and engagement in higher education. Journal of Further and Higher Education, 39(4), 534-552.

Shah, M., \& Nair, C. (2013). Private for-profit higher education in Australia: widening access, participation and opportunities for public-private collaboration. Higher Education Research \& Development, 32(5), 820-832.

Shah, M., \& Nair, C. S. (2006). Translating student voice into action: a case study at two Australian universities. $A U Q F$ 2006, 139.

Shah, M., \& Richardson, J. T. (2016). Is the enhancement of student experience a strategic priority in Australian universities?. Higher Education Research \& Development, 35(2), 352-364.

Shenkar, O., \& Yuchtman-Yaar, E. (1997). Reputation, image, prestige, and goodwill: An interdisciplinary approach to organizational standing. Human Relations, 50(11), 1361-1381.

Sheth, J. N., \& Uslay, C. (2007). Implications of the revised definition of marketing: from exchange to value creation. Journal of Public Policy \& Marketing, 26(2), 302-307.

Shockley-Zalabak, P., Barge, J. K., Lewis, L., \& Lynn Simpson, J. (2017). Engaged scholarship. The International Encyclopedia of Organizational Communication.

Sin, S., \& McGuigan, N. (2013). Fit for purpose: A framework for developing and assessing complex graduate attributes in a changing higher education environment. Accounting Education, 22(6), 522543.

Singleton-Jackson, J. A., Jackson, D. L., \& Reinhardt, J. (2010). Students as consumers of knowledge: Are they buying what we're selling?. Innovative Higher Education, 35(5), 343-358. 
Slife, B. D., \& Williams, R. N. (1995). What's behind the research. Discovering Hidden. Sage Publications.

Soohoo, S. (1993, December). Students as partners in research and restructuring schools. In The Educational Forum (Vol. 57, No. 4, pp. 386-393). Taylor \& Francis Group.

Spohrer, J., \& Maglio, P. P. (2008). The emergence of service science: Toward systematic service innovations to accelerate co-creation of value. Production and Operations Management, 17(3), 238-246.

Stake, R. E. (1995). The art of case study research. Sage Publications.

Stake, R. (2000). Case study in Handbook of Qualitative Research. Sage Publications.

Sternberg, R. J., \& Kaufman, J. C. (2010). Constraints on creativity. The Cambridge Handbook of Creativity, 467-482.

Sumsion, J., \& Goodfellow, J. (2004). Identifying generic skills through curriculum mapping: a critical evaluation. Higher Education Research \& Development, 23(3), 329-346.

Sung, M., \& Yang, S. U. (2008). Toward the model of university image: The influence of brand personality, external prestige, and reputation. Journal of Public Relations Research, 20(4), 357-376.

Tantalo, C., \& Priem, R. L. (2016). Value creation through stakeholder synergy. Strategic Management Journal, 37(2), 314-329.

Taylor, C. A., \& Bovill, C. (2018). Towards an ecology of participation: Process philosophy and co-creation of higher education curricula. European Educational Research Journal, 17(1), 112-128.

Temple, P. (2011). University branding: what can it do?. Perspectives: Policy and Practice in Higher Education, 15(4), 113-116.

Temple, P., \& Shattock, M. (2007). What does" branding" mean in higher education?. European Association for Institutional Research.

Terenzini, P. T., Pascarella, E. T., \& Blimling, G. S. (1996). Students' out-of-class experiences and their influence on learning and cognitive development: A literature review. Journal of College Student Development.

Tertiary Education Quality and Standards Agency. (2011). Developing a framework for teaching and learning standards in Australian higher education and the role of TEQSA: A discussion paper. Canberra: Author.

Tierney, W. G., Corwin, Z. B., \& Colyar, J. E. (Eds.). (2005). Preparing for college: Nine elements of effective outreach. SUNY Press.

Tilak, J. B. (2008). Higher education: a public good or a commodity for trade?. Prospects, 38(4), 449-466.

Tilak, J. (2015). Global trends in funding higher education. International Higher Education, (42).

Tinto, V. (2006). Research and practice of student retention: What next?. Journal of College Student Retention: Research, Theory \& Practice, 8(1), 1-19. 
Thomas, D. R. (2006). A general inductive approach for analyzing qualitative evaluation data. American Journal of Evaluation, 27(2), 237-246.

Thomas, J. L., \& Cunningham, B. J. (2009). Clients' satisfaction with monopolistic services and commitment to the organization: A university context. Journal of Marketing for Higher Education, 19(2), 179-190.

Thomke, S., \& Von Hippel, E. (2002). Customers as innovators: a new way to create value. Harvard Business Review, 80(4), 74-85.

Tomlinson, M. (2017). Student perceptions of themselves as 'consumers' of higher education. British Journal of Sociology of Education, 38(4), 450-467.

Trowler, V. (2010). Student engagement literature review. York: Higher Education Academy. Trowler, V. and Trowler, P.(2010) Student Engagement Evidence Summary.

Tsigkas, A. C. (2013). The lean enterprise. In The lean enterprise (pp. 1-10). Springer, Berlin, Heidelberg.

Urban, G. L., \& Von Hippel, E. (1988). Lead user analyses for the development of new industrial products. Management Science, 34(5), 569-582.

Van Damme, D. (2001). Quality issues in the internationalisation of higher education. Higher Education, 41(4), 415-441.

Van Manen, M. (1990). Researching lived experiences. State University of New York Press, Albany.

van Vught, F., \& Westerheijden, D. F. (2010). Multidimensional ranking. Higher Education Management and Policy, 22(3), 1-26.

Vander Schee, B. A. (2010). Students as consumers: Programming for brand loyalty. Services Marketing Quarterly, 32(1), 32-43.

Vargo, S. L., \& Lusch, R. F. (2004). Evolving to a new dominant logic for marketing. Journal of Marketing, 68(1), 1-17.

Vargo, S. L., \& Lusch, R. F. (2008). Service-dominant logic: continuing the evolution. Journal of the Academy of Marketing Science, 36(1), 1-10.

Vargo, S. L., \& Lusch, R. F. (2011). It's all B2B... and beyond: Toward a systems perspective of the market. Industrial Marketing Management, 40(2), 181-187.

Vargo, S. L., Maglio, P. P., \& Akaka, M. A. (2008). On value and value co-creation: A service systems and service logic perspective. European Management Journal, 26(3), 145-152.

Varnham, S., Olliffe, B., Waite, K. \& Cahill, A. (2016). Student engagement in university decision-making and governance: Towards a more systemically inclusive student voice. Accessed at: https://www.uts.edu.au/sites/default/files/article/downloads/draft\%20final\%20report.pdf

Verbert, K., Govaerts, S., Duval, E., Santos, J. L., Assche, F., Parra, G., \& Klerkx, J. (2014). Learning dashboards: an overview and future research opportunities. Personal and Ubiquitous Computing, 18(6), 1499-1514. 
Vickers, P., \& Bekhradnia, B. (2007). The economic costs and benefits of international students. Oxford: Higher Education Policy Institute.

Vidovich, L., \& Currie, J. (2011). Governance and trust in higher education. Studies in Higher Education, 36(1), 43-56.

Vilsmaier, U., \& Lang, D. J. (2015). Making a difference by marking the difference: constituting in-between spaces for sustainability learning. Current Opinion in Environmental Sustainability, 16, 51-55.

Vlasceanu, L., \& Barrows, L. C. (2004). Indicators for institutional and programme accreditation in higher/tertiary education. Studies on Higher Education. Bucharest: UNESCO-CEPES.

Von Hippel, E. (1994). "Sticky information" and the locus of problem solving: implications for innovation. Management Science, 40(4), 429-439.

Von Hippel, E. (2005). Democratizing innovation. MIT press.

Von Hippel, E. (2009). Democratizing innovation: the evolving phenomenon of user innovation. International Journal of Innovation Science, 1(1), 29-40.

Von Hippel, E., \& Katz, R. (2002). Shifting innovation to users via toolkits. Management Science, 48(7), 821833.

Walker, L., \& Logan, A. (2008). Learner engagement. A review of learner voice initiatives across the UK's education sectors. Future Lab Report. Accessed at: http://www. futurelab. org. uk/resources/documents/other_research_reports/Learner_Engagement. pdf

Walker, I., \& Zhu, Y. (2008). The college wage premium and the expansion of higher education in the UK. Scandinavian Journal of Economics, 110(4), 695-709.

Wei, C. P., Chen, Y. M., Yang, C. S., \& Yang, C. C. (2010). Understanding what concerns consumers: a semantic approach to product feature extraction from consumer reviews. Information Systems and EBusiness Management, 8(2), 149-167.

Western Sydney University (2018). "Students as Curriculum Partners for the Future of Work". Accessed at:

https://www.westernsydney.edu.au/learning futures/home/21st century curriculum project2 $\angle 21 \mathrm{C}$ curriculum project/future of work/students as partners

White, N. R. (2007). 'The customer is always right?’: Student discourse about higher education in Australia. Higher Education, 54(4), 593-604.

Whitelaw, P. A., \& Wrathall, J. (2015). Developing practice oriented undergraduate courses in a quality framework: A case study: Bachelor of event management. Quality Assurance in Education, 23(4), 395409.

Wilson, K. L., Lizzio, A., \& Ramsden, P. (1997). The development, validation and application of the Course Experience Questionnaire. Studies in Higher Education, 22(1), 33-53. 
Wind, J., \& Rangaswamy, A. (2001). Customerization: The next revolution in mass customization. Journal of Interactive Marketing, 15(1), 13-32.

Wise, S., Paton, R. A., \& Gegenhuber, T. (2012). Value co-creation through collective intelligence in the public sector: A review of US and European initiatives. Vine, 42(2), 251-276.

Wong, A., \& Sohal, A. (2002). An examination of the relationship between trust, commitment and relationship quality. International Journal of Retail \& Distribution Management, 30(1), 34-50.

Woodall, T., Hiller, A., \& Resnick, S. (2014). Making sense of higher education: Students as consumers and the value of the university experience. Studies in Higher Education, 39(1), 48-67.

Yang, S. U., Alessandri, S. W., \& Kinsey, D. F. (2008). An integrative analysis of reputation and relational quality: A study of university-student relationships. Journal of Marketing for Higher Education, 18(2), 145-170.

Yen, H.R., Gwinner, K.P., Su, W., 2004. The impact of customer participation and service expectation on Locus attributions following service failure. International Journal of Service Industry Management 15 (1), $7-26$.

Yi, Y., \& Gong, T. (2013). Customer value co-creation behavior: Scale development and validation. Journal of Business Research, 66(9), 1279-1284.

Yin, R. K. (2003). Case study research design and methods third edition. Applied social research methods series, 5 .

Yin, R. K. (2009). How to do better case studies. The SAGE handbook of applied social research methods, 2, 254282.

Young, S. J. (2002). The Use of Market Mechanisms in Higher Education Finance and State Control: Ontario Considered. Canadian Journal of Higher Education, 32(2), 79-101.

Yuan, L., \& Powell, S. (2013). MOOCs and disruptive innovation: Implications for higher education. eLearning Papers, In-depth, 33(2), 1-7.

Zepke, N., \& Leach, L. (2010). Improving student engagement: Ten proposals for action. Active Learning in Higher Education, 11(3), 167-177.

Zhang, J., Schmidt, K., Xie, H., \& Li, H. (2016). A new mixed approach for modelling and assessing environmental influences to value co-creation in the construction industry. International Journal of Production Research, 54(21), 6548-6562.

Zhao, C. M., \& Kuh, G. D. (2004). Adding value: Learning communities and student engagement. Research in Higher Education, 45(2), 115-138.

Zipkin, P. (2001). Mass customization. MIT Sloan Management Review.

Zwass, V. (2010). Co-creation: Toward a taxonomy and an integrated research perspective. International Journal of Electronic Commerce, 15(1), 11-48. 


\title{
Appendix
}

\section{Expert Review on Co-Creation in Higher Education}

\author{
Expert Review on Co-Creation \\ Expert Consultation - New \\ February 15th 2017, 12:31 pm AEDT
}

Q9 - Co-creation in this research has been preliminarily defined as a balanced interaction between institutions and students where resources are shared and mutual value is created. Do you agree with this definition? If not, how would you define cocreation?

Sorry, this seems like a very poorly thought out questionnaire, but best of luck

Yes, I agree but not sure if it needs to be balanced per se.

I mostly agree. Not sure what you mean by "balanced interaction" but I guess that you define this elsewhere. Also, do you mean educational institutions?

I think definitions of co-creation have to encompass relationships and collaborations between individuals (faculty/staff) and students, not institutions and students. The above definition misses they interaction between people, which is fundamental to co-creation. Institutions (policies, funding, culture) are enablers, catalysts (or barriers).

agreed

its fine.. although I would also emphasise the sharing of genuine power between parties interaction is limiting, and co-creation of value can happen before and after the actual interaction. The word institution is loaded and is not specific. To this extent the definition would need to be expanded as well as made specific.

OK, but be specific about context and not sure about balanced

I agree with the spirit of the statement but not the wording I don't feel that co-creation has to be 'balanced' (uneven power relationships in a co-created curriculum is still co-creation), between 'institutions' (it can be individuals) and I feel 'resources' is too mundane a term to capture the nature of it. Co-creation can and often is messy, and the value doesn't have to be mutual but it should be.

I always refer to co-creation in relation to learning and teaching specifically and therefore I see the collaboration between (mainly academic) staff and students. I am not sure what you mean by balanced...if this implies an equality, then I prefer to use partnership, but as is often the case in $\mathrm{HE}$ it is difficult for it to be equal, I find co-creation a more useful term.

a balanced interaction between institutions, researchers and students where resources are shared and mutual value is created.

Yes, but wondering whether you should also be recognizing the network perspective - that students bring resources from beyond the institution-student dyad. Also, I'm not sure about the use of the word 'balanced' - co-creation doesn't have to be balanced and mostly is not balanced. I'd say most of the time there is an asymmetry occurring in the interaction and this can be good or bad. Thus, I'd think about removing the word interaction 
Well - I see a few of problems right away: 1) Its a definition specific to co-creation in education. And co-creation is significantly broader than that, so any definition should probably recognize that the application of co-creation to the education context can be defined as..." 2) There is little balanced about co-creation. It is an uneven process, both across times and actors. 3) Co-creation can (and in the educational setting probably should) involve many more stakeholders than just students and institutions. 4) Resources are not the only shared element in co-creation. Could be expertise, could be effort, the range is quite broad. So...as a potential reviewer Id say this is the first draft of a definition...

Yes, I'm agree with this definition.

It seems to work, but I wonder why does it have to be balanced? To me this implies that the outcome has to be positive, always.

Co-creation is the development of interaction between institutions and students where both parties play an active role in sharing resources and mutual value is created.

I pause over one important aspect of that definition. Is the interaction between "institutions" and students? Presumably people are acting on behalf of the institution, so it seems to me that the interaction is between representatives of the institution and students -- because partnerships are inherently relational. Put another way, people partner with other people, but people don't partner with organizations or institutions. My employment as a professor, for instance, involves resources being shared between me (my time) and my institution (its money, office space, etc.) and mutual value is created (in theory, at least!). However, I don't think it's particularly helpful to frame my interaction with the university as a partnership. Indeed, under that definition of partnership, a vast number of interactions could be classified as partnership - and that broad of definition rarely is helpful when trying to critically analyze something. may want to use "educational institutions" Where is the teacher? Resources are not only shared but also created in collaboration...at least some of them Not sure if the interaction needs to be balanced Is there any "exchange" process that is needed in defn?

Happy with this definition- I like the use of balance

"The resource sharing and mutual creation aspect of the definition are key elements to any cocreation definition. There are a few areas that I think you have to be careful with. 1). Is the use of the term "balanced". What does this mean? Literally of 50/50 split of interaction and contribution of key resources? If so, this is a big assumption. Coming from the marketing perspective, each individual consumer (students in your context) will have varying degrees of self-agency to want to co-create with the organisation (institution). This will depend on things like: the type of experience (co-creation opportunity) the student is contributing resources to, the context in which the experience (co-creation opportunity) is occurring, and perhaps the cultural background of the student. The use of "balanced" tends to imply each stakeholder as equal in their contribution and this is not always the case; particularly in higher ed where the institution is seen as the gatekeeper of knowledge. 2) Your definition takes a dyadic perspective (i.e. the student and the institution). This can be ok if you make it very clear that this is the only relationship you are concerned about. However, there is a lot of work in the co-creation space that suggests the importance of understanding co-creation beyond dyadic relationships. For example, the community of where the student studies would also be an important stakeholder. I think as you conceptualise your take on value co-creation, you should acknowledge that general definitions of co-creation tend to incorporate a multi-stakeholder perspective (and this is actually a direction that co-creation research is starting to move, as more scholars make the call for this consideration). 3)I think the use of interaction is appropriate as most co-creation work, conceptual and empirical, tends to discuss co-creation as being an active construct, which implies actual interactive behaviour amongst stakeholders. Although, another consideration should be the nature of the interaction. There is co-creation 
work (I believe by Janet McColl-Kennedy) that differentiates between active and passive cocreation, meaning that some co-creation experiences actually require very little direct interaction per se. So, perhaps it would be good to clarify this a bit more in your definition." 
Q3 - The following is a list of activities that often take place in higher education. Please rate the activities based on your perception that the activity allows for co-creation between students and institutions to occur (high, medium or low).

Q3 - The following is a list of activities that often take place in higher educa...

\begin{tabular}{|c|c|c|c|c|c|c|c|}
\hline Question & $\begin{array}{l}\text { Low Co- } \\
\text { Creation }\end{array}$ & & $\begin{array}{l}\text { Medium } \\
\text { Co- } \\
\text { Creation }\end{array}$ & & $\begin{array}{r}\text { High } \\
\text { Co- } \\
\text { Creation }\end{array}$ & & Total \\
\hline $\begin{array}{l}\text { STUDENT-CENTERED } \\
\text { TUTORIAL: Student participation in } \\
\text { a small group (e.g. 5-20 students) } \\
\text { tutorial where students are } \\
\text { encouraged to openly discuss }\end{array}$ & $10.53 \%$ & 2 & $36.84 \%$ & 7 & $52.63 \%$ & 10 & 19 \\
\hline $\begin{array}{l}\text { TEACHER-CENTERED } \\
\text { LECTURE: Student participation in a } \\
\text { large (e.g. } 50-100 \text { students) lecture, } \\
\text { where the instructor lectures in the } \\
\text { front of the room }\end{array}$ & $68.42 \%$ & 13 & $26.32 \%$ & 5 & $5.26 \%$ & 1 & 19 \\
\hline $\begin{array}{l}\text { ONLINE COURSE: Student } \\
\text { participation in a university online } \\
\text { course where students read and watch } \\
\text { content, participate in online forums } \\
\text { and submit assignments }\end{array}$ & $47.37 \%$ & 9 & $42.11 \%$ & 8 & $10.53 \%$ & 2 & 19 \\
\hline $\begin{array}{l}\text { CAMPUS FORUM/SEMINAR: } \\
\text { Student participation in campus fora } \\
\text { or seminars as a participant in the } \\
\text { audience }\end{array}$ & $73.68 \%$ & 14 & $21.05 \%$ & 4 & $5.26 \%$ & 1 & 19 \\
\hline $\begin{array}{l}\text { STUDY ABROAD PROGRAM: } \\
\text { Student participation in a study } \\
\text { abroad program where students travel } \\
\text { internationally to study }\end{array}$ & $26.32 \%$ & 5 & $36.84 \%$ & 7 & $36.84 \%$ & 7 & 19 \\
\hline $\begin{array}{l}\text { UNIVERSITY SOCIAL MEDIA: } \\
\text { Student participation in a university- } \\
\text { sponsored social media platform such } \\
\text { as a university blog, Facebook page, } \\
\text { or podcast }\end{array}$ & $5.26 \%$ & 1 & $73.68 \%$ & 14 & $21.05 \%$ & 4 & 19 \\
\hline $\begin{array}{l}\text { QUESTIONNAIRE } \\
\text { PARTICIPATION: Student } \\
\text { participation in a university } \\
\text { satisfaction questionnaire (e.g. for a } \\
\text { teacher evaluation or course } \\
\text { evaluation) }\end{array}$ & $73.68 \%$ & 14 & $21.05 \%$ & 4 & $5.26 \%$ & 1 & 19 \\
\hline $\begin{array}{l}\text { WORK INTEGRATED COURSE: } \\
\text { With coaching and support from a } \\
\text { university, students are placed in a } \\
\text { company to complete an industry- } \\
\text { related project }\end{array}$ & $5.26 \%$ & 1 & $36.84 \%$ & 7 & $57.89 \%$ & 11 & 19 \\
\hline $\begin{array}{l}\text { POSTGRADUATE THESIS: } \\
\text { Student participation in a dissertation } \\
\text { or thesis as part of a postgraduate }\end{array}$ & $31.58 \%$ & 6 & $36.84 \%$ & 7 & $31.58 \%$ & 6 & 19 \\
\hline
\end{tabular}


degree to make an original contribution to literature

CO-RESEARCH WITH FACULTY:

Student participation in a research project as a partner with faculty and/or staff

USE OF CAMPUS SPACE FOR INDIVIDUAL/GROUP STUDY:

Student use of campus space such as campus green spaces or study rooms for individual or group study STUDENT COUNCIL: Student participation in student council to represent and lead student issues SPORTING EVENT: Student participation in a universitysponsored sporting event as a participant in the audience STUDENT REPRESENTATIVE ON POLICY PANELS: Student participation as a student representative in a university policy formation project

TEACHING ASSISTANCE/TUTORING:

Student employment at a university as $5.26 \%$

\begin{tabular}{|c|c|c|c|c|c|c|}
\hline $0.00 \%$ & 0 & $21.05 \%$ & 4 & $78.95 \%$ & 15 & 19 \\
\hline $63.16 \%$ & 12 & $21.05 \%$ & 4 & $15.79 \%$ & 3 & 19 \\
\hline $10.53 \%$ & 2 & $63.16 \%$ & 12 & $26.32 \%$ & 5 & 19 \\
\hline $52.63 \%$ & 10 & $42.11 \%$ & 8 & $5.26 \%$ & 1 & 19 \\
\hline $10.53 \%$ & 2 & $68.42 \%$ & 13 & $21.05 \%$ & 4 & 19 \\
\hline $5.26 \%$ & 1 & $68.42 \%$ & 13 & $26.32 \%$ & 5 & 19 \\
\hline
\end{tabular}
a teaching assistant or tutor 
Q10 - Do you have any other questions, concerns or feedback on this study?

I think co-creation needs to be contextualised- eg co-creation of the curriculum can be staff and students working together to design the curriculum. Not all activities that involve students would necessarily be thought of as 'co-creation'

Looks good.

A suggestion for refining the descriptions for the likert scale- The examples given are interesting but the current descriptions make it tricky to define whether there is co-creation occurring. If you could modify these to include something on what the student is doing (i.e. can they exercise any control or agency over decision making in the processes) would make it easier to assess if there is co-creation taking place. Good luck with your further studies! I think the most important area is student partnership in creating and implementing curricula.. not sure if your questions capture that?

I felt a tad constricted on the tick boxes because I feel that there are very few areas of the university that don't have the potential for co-creation and can think of many examples of practice in the variety of areas listed. However, that does not mean it is widespread and certainly not the norm so I struggled to accurately answer.

All of the options in question 2 depend hugely on the nature of the relationship between the teacher (or institution....although 'an institution' can't really have a relationship with someone in my view) and the students. So those I have rated lower are because I think they hold low potential for co-creation, but all the rest would depend hugely on whether the teacher or staff involved are willing to co-create and hand over some responsibility to students. So I don't necessarily think a lecture has to be inherently poor for co-creation - there are some good examples out there of people co-creating learning and teaching in lectures, but probably it might be easier to co-create teaching with a smaller group of students in tutorial style teaching....but then I think there's more potential if it's not a one-off tutorial and in fact is a teacher working with a class for the whole of a semester or year. I hope this is helpful in some way.

I think theres a lot of unaccounted variance in your questions. While a lecture may generally not be co-created, there are some lectures which are wholly co-created. Such generalities lead to 'endogeneities' - a lack of understanding about the critical variables in the middle. Its an interesting area. Dont shortchange it.

No.

Good luck

regarding the prior list of activities, I would consider having a few that are more novel...such as perhaps "the teacher and students collaboratively develop the syllabus for the course"

Interesting and good luck

Looking forward to the outcomes! 
1. When I say co-creation between students and faculty/staff, what do you think?

2. Do you think students have resources to offer? What are these resources?

3. Have you ever participated in activity in your higher education experience where you and faculty/staff worked together in a balanced way towards a shared goal?

4. Do you currently feel like your opinions, feedback or ideas are heard by faculty/staff?

5. Would you like to have more opportunities where you worked with faculty/staff to improve outcomes for both students and the institution? 


\section{Example of Focus Group Transcript}

Focus Group 1:

This study is about how student integrate their resources... can you think of any examples where you shared resources in higher education?

S. In what context? Like in drop box?

$\mathrm{S}$. We all find a lot of data and resources and share everything on dropbox so everyone has access

S. I guess if some people have worked before they have office resources, like I have old files from my old office.

But do you consider you having worked there a resource that benefits everyone?

S. Yeah maybe..

S. I also share information via twitter a lot

S. About 5 years ago I had subject, and one of the tasks was to memorize the dates and building, so we went on a flash card website and loaded everything on it. The lecturer found out after and began sharing it with all his students, so five years later we still get notifications of people using it....

Have you ever had a really good idea to improve a class? Can you do that here at Melbourne?

S. Urban design is such a small cohort, we're very opiniated, we don't keep quiet if we're unhappy

S. I guess the SES

S. Before we start the subject we ask about the tutor and decide if we want to take the class, some teachers are traditional

S. I take the SES very seriously, but the thing is we don't see the outcome of it. Too little too late

S. Students don't realize how important the SES scores are, people lose their jobs

S. I find the teachers here really don't want to tell you the answers, they want it to be a process

Have you ever been in a situation when you thought the admin/faculty were working with you, almost balanced?

S. I messed up my timetabling and had to get a core subject omitted, and she really worked with me and she was really understanding- the problem is never know who to speak to

$\mathrm{S}$. Me and tutor designed a bench together, you know the one outside, by standing room? He helped teach me what was possible and I helped him code our idea, so we used his knowledge as well as mine

Would you want more activities where faculty members were more like colleagues?

S. I think you don't want them to be superior to you... 


\section{Example of Instrument Pilot}

Pilot Session v4

S. Can I say this sentence, I don't understand. I understand I have to reflect on a single experience, but I have to read the sentence several times to understand it. [referring to opening part]

S. Ok, this I understand.

S. I don't know if I know what transparency means... maybe an example would be helpful?

S. Would I willingly use my spare time? Oh, you know, I think you mean like, not getting paid yes?

If I used to word volunteer would that help?

S. Yes, yes, that is more clear.

S. I didn't make any suggestions, so this question doesn't make sense to me.

S. You know, some of these questions are so long. I am not a native English speaker and it takes so much time to think.

S. You know, I think the lecturer would have changed things, if I have offered, but I didn't offer, so I don't know how to answer.

S. If you could specify, if the lecturers disposition, or my disposition, because yeah there were times I could have, but you know, I didn't do it.

Would the question be more clear if the question was do you think the lecturers or staff WANTED your opinion?

S. Yes, but the answer would be no!

S. Memorable or enjoyable? These words are a little confusing. I think maybe you put here, compare to other types of similar activities, you know that helps me understand it a bit more like that

S. Here, this question is like the same as the last one, because we didn't experiment anything but if we were prompted then maybe... You should ask, did you try new things.. etc?

Was it possible for students to improve the process by trying something new?

S. Hmmm.... No, we did not try anything new.

S. But I agree, that if we could improve the process if we could try new things!

S. Benefit and value... these are interesting words...

Did you have an equal role, is this question difficult? 
S. Hmm... like generally? No... our roles were not equal

Could you derive benefit from the activity even though you were equal?

S. Yes... ha ha. Maybe split this into two questions or rephrase it?

S. I don't know about close or better to describe the relationships, to me better is very vague, so I would use closer... but I guess it depends on what you are looking at

S. Some people could be closer with faculty, not me, but some could

Ok, now we are switching to open-end responses

S. This is an easy one, just put the resources? Ok, all of them, easy. Oh but you know, also questions...

S. I think the space question you mean the classroom? I don't understand the word platform... platform sounds like an online thing

S. I think the room was very good, it was like a round thing, and everyone could see each other

S. You know I was intimated to co-create I think...

That's great feedback, you think if I asked how confident you were to contribute, 1-10 what would you have said?

S. 9.... Like other people were fine, but not me

Do you think students learned a lot about your perspective?

S. The question doesn't say your, it says students... but I don't think they learned anything about ME... the teacher looked to others, and she was very interested, but not me.

S. Is that it?

Nope, you still have one more section to go

S. I have never worked together...

Not even you master's thesis?

S. Actually no, I get feedback from my supervisors, they monitor the process, and supervise... but do I feel like we are co-creating? No. When I was doing coursework, I also never did anything like this.

S. Yes, absolutely, I think students can improve. I think co-creation is good.

Great, these questions are really important.

S. Then you should put these questions at the beginning. 
Do you think it would be confusing to put them at the front?

S. No I think it is better, it helps frame it, and I think you know oh ok, this is the point of the survey, it helps me understand more about what you are doing

S. I think you could also ask the benefits questions in the beginning, but maybe also at the end... both is ok

S. I think the benefits are also very important to ESL students, it is good to use our English in more ways 
Copy of Qualitative Survey

Case_1_

Q1 Co-Creation in Higher Education

You are invited to participate in the above project, which is being conducted by Ms. Mollie Dollinger supervised by Professor Hamish Coates and Dr. Jason Lodge with the Centre for the Study of Higher Education, Melbourne Graduate School of Education at the University of Melbourne.

This study aims to understand how student resources (for example, experiences, expertise, and ideas) are contributed and integrated within higher education activities. For more information, please see the Plain Language Statement. Your participation in this project is entirely voluntary and you may withdraw from participating at any stage. You will not be required to reveal your identity and all responses will be strictly confidential. Any information provided that may be linked to your identity will be discarded. If you would like more information about the project, please contact Mollie Dollinger. Tel +61 0468601280 or email at mdollinger@student.unimelb.edu.au.

Should you have any concerns or complaints about the conduct of the project, please contact Ms. Kate Murphy, Manager, Human Research Ethics - Office for Research Ethics and Integrity, the University of Melbourne VIC 3010. Tel: +61 383442073 or HumanEthicscomplaints@unimelb.edu.au.

If you would like to participate in this project, please indicate that you have read and understood this information clicking the box below.

Thank you, Mollie Dollinger

Q2 Co-creation is the process where faculty and/or staff members draw on student participation and contributions (such as student ideas, previous experiences, expertise, perspectives, or opinions) to create something together.

Q3 In your entire higher education experience, either inside or outside the classroom have you ever participated in an activity where students and faculty/staff member(s) worked together to co-create something? For example: curriculum/ class activity, research or report, physical object (e.g. bench, poster, art), policy formation, event/seminar, media (e.g. newsletter, blog), etc. If yes, please describe.

Q4 Do you think students can improve higher education activities by contributing their experiences, ideas, or knowledge? Why or why not?

Q5 The following questions will ask you to reflect on your involvement in [insert activity]. Please answer the questions specifically relating to this experience only. 
Q6 Please indicate your role in this activity:

O Academic Faculty (1)

O Staff $(2)$

Undergraduate Student (studying towards bachelors) (3)

O Graduate Student (studying towards masters/ doctorate) (4)

Other (please specify) (5)

Q7 Within [insert activity], please select the following resources or types of contributions students made: (Select all that apply).

- Personal Experiences (1)

$\square$ Ideas (2)

Expertise or Knowledge (3)

$\square$ Opinions or Suggestions (4)

口 Physical Objects/Resources, Tools, or Infrastructure (please specify) (5)

$\square$ Other (please specify) (6)

Q8 Through the [insert activity] experience, did you feel like the space, online platform or physical environment was suitable for students to contribute (e.g. suggestions, experiences, ideas)? Why or why not?

Q9 How do you think the space, online platform or physical environment could be improved to help make it easier for students to contribute? 
Q10 Do you think [insert activity] will be improved in the future as a result of the student contributions (e.g. suggestions, experiences, ideas) to the design or process you witnessed? Why or why not?

Q11 Did students learn more about faculty/staff's jobs and their perspectives on working in higher education through this experience? Why or why not?

Q12 Did faculty/staff learn more about what it is like to be a student through this experience? Why or why not?

Q13 Do you believe students will feel closer to faculty/staff involved in [insert activity] compared to other faculty/staff? Why or why not?

Q14 What do you believe are the benefits TO STUDENTS of integrating student experiences, ideas, and knowledge?

Q15 What do you believe are the benefits TO FACULTY/STAFF of integrating student experiences, ideas, and knowledge?

Q16 What do you believe are the benefits TO UNIVERSITY ADMINISTRATORS of integrating student experiences, ideas, and knowledge?

Q17 Would you be willing to participate in a follow-up phone or Skype interview to tell us more about your higher education experiences? If yes, please leave your contact information.

Email Address (1)

Phone Number (2)

Q18 Thank you! Please select the red button below to submit! 
Interview Protocol

Research Question: To what extent does co-creation occur in the higher education context?

I. What are the elements that may encourage or lead to co-creation?

II. What are the levels or types of co-creation?

III. What are the benefits of co-creation?

1. Can you tell me about your participation in the experience? (E.g. your role, why join/why participate, etc.)

2. Can you explain how students and faculty/staff contributed within this activity? (E.g. who had what responsibilities, protocol, processes of co-creation)

3. Can you explain what you believe the benefits of this activity were, both for students and for faculty/staff? In your opinion, how are they similar or different?

4. How (if any) recommendations would you make for this activity in the future? (E.g. improvements) 
Flyer Used in Study

\section{Co-Creation in Higher Education: \\ Call for Participants}

The aim of this study is to investigate how student resources such as student experiences, expertise, and ideas, and how these resources are integrated within the higher education context. This project will form part of Mollie Dollinger's doctoral thesis and has been approved by the University of Melbourne Human Research Ethics Committee.

For this study we are currently looking for CASE STUDIES of the following activities:

- Lectures of $40+$ students in either undergraduate or masters level

- Seminars or workshops with student participations

- Academic or non-academic groups that have both student and faculty/staff members

- Projects with students involved in co-research with faculty members

- Other projects where students and faculty/staff are working together towards a shared goal (e.g. designing a space, creating curriculum, modifying learning platforms)

If you are involved in one of these activities and would like to participate in the study please contact the research team (details below).

In exchange for participating in the study you will receive a report on students and faculty/staff perceptions of co-creation, whether they believe students have resources to offer, and what those resources would be.

If you agree to participate in the study we will ask students and faculty/staff involved in the activity to complete a short questionnaire about their experiences (approximately 10-15 minutes) and participate in a follow-up interview at a date and time of your convenience either in-person or via Skype.

Please let us know if you have any questions regarding this study of if you require further information, either by email (mdollinger@student.unimelb.edu.au) or over the phone at +61 0468601280 .

Thank you,

Mollie Dollinger 
Plain Language Form for Questionnaire

Centre for the Study of Higher Education

Melbourne Graduate School of Education

Project: Co-Creation in Higher Education

Professor Hamish Coates (Responsible Researcher)

Tel: +61383440756Email: h.coates@unimelb.edu.au

Dr. Jason Lodge (Co-Supervisor)

Tel: 61383442659 Email: jason.lodge@unimelb.edu.au

Mollie Dollinger (PhD student)

Tel: 610468601280 Email: $\underline{\text { mdollinger@student.unimelb.edu.au }}$

You are invited to participate in the above project, which is being conducted by Mollie Dollinger (PhD student) and supervised by Professor Hamish Coates (Supervisor) and Dr. Jason Lodge (Co-supervisor) of the Centre for the Study of Higher Education, Melbourne Graduate School of Education at the University of Melbourne. You have been approached because you are either a student or faculty member involved in a higher education.

The aim of this study is to understand how students can integrate their resources, such as perspectives and experiences into higher education activities to provide benefit to both student and institutional groups. This project will form part of Mollie Dollinger's doctoral thesis and has been approved by the University of Melbourne Human Research Ethics Committee.

Should you agree to participate, you will be asked to participate in an online questionnaire. The questionnaire will ask you to reflect on an activity in higher education. You can stop the survey at any time.

We intend to protect your anonymity and the confidentiality of your responses to the fullest possible extent, subject to any legal requirements. Your name and contact details will be kept in a password-protected computer file, separate from any data that you supply. This will only be able to be linked to your responses by the researchers. Any references to personal information that might allow someone to guess your identity will be removed, however, due to the small sample of participants, it is possible that someone may still be able to identify you. The data will be kept securely in the Melbourne Graduate School of Education for five years from the date of publication, before being destroyed.

Participation is not expected to involve any harm or danger to your physical or mental health and is completely voluntary. Should you wish to withdraw at any stage, or to withdraw any unprocessed data you have supplied, you are free to do so without prejudice.

Once the thesis arising from this research has been completed, a brief summary of the research findings will be made available for the researchers. Any participant who would like to have 
access to this report can contact mdollinger@student.unimelb.edu.au to receive a copy by email. It is possible that the results will be published and presented at academic conferences.

If you would like more information about the project, please either contact the student researcher at mdollinger@student.unimelb.edu.au (+61 0468601280) or the supervisor at h.coates@unimelb.edu.au.

Should you have any concerns or complaints about the conduct of the project, please contact Ms Kate Murphy, Manager, Human Research Ethics - Office for Research Ethics and Integrity, the University of Melbourne VIC 3010. Tel: +61 383442073 or HumanEthicscomplaints@unimelb.edu.au.

If you would like to participate in this project, please indicate that you have read and understood this information by completing the accompanying consent form.

Thank you,

Mollie Dollinger

PhD Student
Professor Hamish Coates

Supervisor
Dr. Jason Lodge

Co-Supervisor 
Example of Data Analysis

Table 5. Location and Type of Institution of Case Studies ${ }^{21}$

\begin{tabular}{|c|c|c|c|c|}
\hline $\begin{array}{l}\text { Case } \\
\#\end{array}$ & Case Study Activity & Abbreviation & $\begin{array}{l}\text { Country of } \\
\text { Origin }\end{array}$ & $\begin{array}{l}\text { Type of } \\
\text { Institution }\end{array}$ \\
\hline 1 & $\begin{array}{l}\text { Student/staff produced } \\
\text { magazine }\end{array}$ & PUB & Australia & ATN \\
\hline 2 & $\begin{array}{l}\text { Student participation in } \\
\text { a work-integrated } \\
\text { learning course }\end{array}$ & WIL & Australia & Go8 \\
\hline 3 & $\begin{array}{l}\text { Student co-design of } \\
\text { curriculum }\end{array}$ & $\mathrm{CD}$ & Australia & Go8 \\
\hline 4 & $\begin{array}{l}\text { Student/staff customer } \\
\text { experience project }\end{array}$ & EXP & New Zealand & $\mathrm{N} / \mathrm{A}^{22}$ \\
\hline 5 & $\begin{array}{l}\text { Student/staff creation of } \\
\text { learning resources }\end{array}$ & RES & Australia & IRU \\
\hline 6 & $\begin{array}{l}\text { Student/staff program } \\
\text { implementation }\end{array}$ & PROG & Australia & Go8 \\
\hline 7 & $\begin{array}{l}\text { Student peer mentor } \\
\text { program }(\mathrm{A})^{*}\end{array}$ & PEERA & Australia & IRU \\
\hline 8 & $\begin{array}{l}\text { Student created social } \\
\text { media }\end{array}$ & MEDIA & Australia & Go8 \\
\hline 9 & Student governance & GOV & Australia & Regional \\
\hline 10 & $\begin{array}{l}\text { Student peer mentor } \\
\text { program }(B)^{*}\end{array}$ & PEERB & Australia & ATN \\
\hline
\end{tabular}

* Two cases were known as student peer mentoring programs; therefore, one program will be noted as A and another as B.

(Exported from Nvivio): Personal Outlook

Individual Antecedents: OUTLOOK

Internals $\backslash \backslash C S U \_G O V \backslash \backslash C S U \_a n o n \_s t a f f-\int 4$ references coded [ 15.95\% Coverage]

${ }^{21}$ Repeated from earlier in the text, to help guide the reader.

22 New Zealand does not have university groupings. 


\section{Reference $1-3.71 \%$ Coverage}

as newcomers to the profession for which the university is preparing them, students have much to contribute in terms of disconnectedness to market, consumers, and citizens with a wide range of experience and skills.

\section{Reference $2-5.69 \%$ Coverage}

Yes, students are more attuned to their deep learning needs. They tend to have strong ideas about how they would like to be consumers of education and know when the quality is not high. Because they know and understand their learning needs they are well placed to contribute to how particular activities will enhance their experience.

\section{Reference 3 - 3.85\% Coverage}

They have first hand experience with their studies and the expectations put upon them. They offer clarity of what they want to develop from events and activities as they develop and create life at Uni for themselves and others.

\section{Reference $4-2.69 \%$ Coverage}

University does not function without students. Need to know the issues affecting each cohort and then the University know where to direct support and funds.

\section{Reference $1-4.40 \%$ Coverage}

Students provide a front line perspective that cannot be given by anyone else. Their lived experiences, ideas and knowledge are therefore invaluable when it comes to contributing to the improvement of higher education activities. This is due to their involvement in the everyday running of the university and the experience they are given as a customer. Students are therefore the best people to consult when it comes to changing or implementing new strategies in higher education because it is them who are directly affected by such changes.

\section{Reference 2 - 3.49\% Coverage}

I do believe students can improve higher education activities through their contribution. In my view the best way to ensure the students are getting the best is to ask them what the best is, have they experienced it, how may this best be delivered etc.

Students do play a key role in contributing to the improvement of higher education activities as their involvement forms part of a universities continuous quality improvement plan.

\section{Reference $3-1.13 \%$ Coverage}

Yes, this can help consolidate learning in subjects as lecturers can run out of ideas or need new input to keep things fresh and interesting.

\section{Reference 4 - 1.51\% Coverage}

There need to be more avenues for students to share their experiences. For instance, more online meetings that engage students both with the student reps, academics and administration.

\section{Reference 5 - $2.68 \%$ Coverage}

I believe the student perspective brings about the best kind of change as it is targeting the key stakeholders of the university; the students. An improved university experience can result from this as students give ideas and suggestions based on their time at university, therefore improving the experience for future students.

Reference $6-4.90 \%$ Coverage 
I believe continuous student input and feedback regarding student experience at university is important for continued improvement. We have spoken about many issues of varying degrees of seriousness and applicability to students on and off campus. Recently, I think student feedback on the release of statistics regarding the prevalence of sexual assault has aided in what prevention strategies will be implemented and how they are introduced.

Yes, student ideas are essential to the progression of university and voices to be heard eg pushing for on campus classes as opposed to moving things online.

\section{Reference 1 - 5.70\% Coverage}

I think the critical issue is that universities don't show they care, a care factor, do they demonstrate that? Online students will continue to be a large constitute and we're going to continue to see growth in that space. And I think there's a risk that universities see online students in a transactional way and the avenues of hearing the students voice is a way to mitigate that feeling and sentiment.

\section{Reference $2-7.72 \%$ Coverage}

Because the distance and isolation that online students feel is far greater than an on-campus student. And so it's very difficult for the university to care for those students. and the danger is that universities think online students are the Band-Aid to fix all of our funding issues, but online students are just as expensive and costly to service as in-person students in a lot of ways. I think the university is getting away with it, but if they are serious about capturing that market then they have to be serious about capturing those voices.

\section{Reference 1 - 6.18\% Coverage}

I went to a conference about higher education and the huge discussion was that a lot of people on council don't think we need the elected position and they think that we should get the students and the staff members, but I don't think that's option, we should have more, cause it's like the voice of the university, it's the people that are receiving everything they are making decisions about.

\section{Reference $1-2.93 \%$ Coverage}

So when people are coming in for a job working with students one of the people on the selection committee is a student. I wouldn't mind students being part of the vice chancellors leadership team too, maybe the role of the student senate president as part of the vice chancellors leadership team.

\section{Reference 2 - 3.31\% Coverage}

We do want to get students in more decision making spaces, but that's a hard thing to indicate. We do want to up the participation rates of our democratic structures, this year we've done a lot of awareness and we've seen a positive uptake on the nominations for that stuff. We want to continue to up the democratization of our students.

\section{Reference 1 - 4.07\% Coverage}

Me personally I don't have an issue talking up at these meetings, I'm very vocal. I think I'm one of the first student leaders to be so vocal, I was told. Having a student who is willing to talk up and might be slightly controversial is something that we need at those levels and its something that the chair and anyone else who sits on the academic senate values.

\section{Reference 2 - 1.98\% Coverage}

What students face these days is completely different from what they faced when they were students do it's about bridging that gap from that they think to what's happening. 
I had one staff who recently saw the handbook with minutes and he said the SRC isn't going to want to change to that. And I said what a second, do they have a choice? If this is the new template this is what everyone is using, if they don't want to use it because they don't want to change, we need to have a conversation about that. That's part of what we're doing. Sometimes the staff do a little bit more hand-holding than they need.

\section{Reference $2-1.43 \%$ Coverage}

The staff give the students excuses when the students have even asked them to do that. They're only in 20 s! Yep.. they are and they can do amazing things.

\section{Reference 1 - 0.34\% Coverage}

I was also willing to give it more time...

\section{Reference $1-1.56 \%$ Coverage}

Inherent to my own value and belief system and my experience- you can't learn without active involvement. You can't learn without an embodied experience, and you can't learn without personally engaging emotionally in the learning.

\section{Reference 2 - 1.99\% Coverage}

The premise that as a lecturer I am the expert takes away the reality that we're all learning in this together. And I have learned enormously from my students both in my interaction with them and also the way the projects are, I've learned a lot about various elements such as homelessness in Melbourne.

\section{Reference 1 - 1.30\% Coverage}

I think being able to engage with people, particularly academics, at university not just there to serve you and teach you but as human beings.

\section{Reference $1-1.58 \%$ Coverage}

[I think I didn't ask for money/salary] because when Julian came to me and said I think I want to create this completely new thing, and I know you are interested in it

\section{Reference 1 - 2.27\% Coverage}

So really trying to work on ways that students might interact and get to know each other better. SO I think that close connection with the students through that forum and also helping the international student association... maybe disposes me well.

\section{Reference 2 - $1.88 \%$ Coverage}

my $\mathrm{PhD}$ thesis was on activists in $\mathrm{KL}$ and how they do their activism. I think that disposition towards the empowerment of individuals and enabling them, is sort of a fundamental value behind what I'm doing.

\section{Reference $1-3.23 \%$ Coverage}

I was working at a liquor store and doing retail work and I wanted to try and get some other kind of job but I didn't know where to start. I liked the idea also of helping other people because I do like teaching and one of my plans is maybe to get into academia... so I thought this kind of thing would look really good for future jobs.

\section{Reference 2 - $1.99 \%$ Coverage}

But I think for those students who are struggling and want someone to be able to kind of understand their perspective then I think peer learning and peer assistance is one of the best 
things for that.

\section{Reference $1-2.68 \%$ Coverage}

And I wasn't sure but I wanted to try something outside of my comfort zone, but it's actually been really good.

\section{Reference $1-1.95 \%$ Coverage}

I guess I've always been student-centric. I guess that's led to the curriculum in line with what we are reading about in the literature about all the skills that students should be developing when they are doing their degree.

\section{Reference $1-2.79 \%$ Coverage}

Definitely yes. Since the educational activities are designed for students, it is a great idea for students to be able to help the academics in designing these activities. I believe it\&apos;s helpful because students are able to provide feedback on what the good aspects of the activities are, and what parts can be improved.

\section{Reference 1 - 1.74\% Coverage}

[When I was asked to join I felt very] keen and really interested. First I was really not sure what they were looking for or what it would involve but I was interested in being part of it.

\section{Reference $1-3.17 \%$ Coverage}

Prior to coming to the educational field, I was really disengaged in my studies and frustrated at the sense of injustice about dismissal of students' role in education but that was more because of my beliefs on egalitarianism more than anything else. So students as partners gave me a frame of reference to think about empowering students where previously it had just been frustration about the lack of empowerment that they had been supported in achieving.

\section{Reference 1 - 3.57\% Coverage}

I participated because the issue to me is quite important. I deal with students a lot in my role as a staff member here, and in unique ways so program coordinator, teaching and also mentoring and guidance.

\section{Reference 2 - 1.33\% Coverage}

I've also been pro co-design with students, none of this is really new to me.

\section{Reference 1 - 23.23\% Coverage}

It's pretty common for me to voice my opinions anyways because as a low income student I want to make sure I get the most out of my university experience. Like, I pay 6,000 NZ a year, that's a lot. I have medical issues too that make it hard for me to work, so this is pretty important.

\section{Reference 1 - 1.46\% Coverage}

At the end of the day who can argue with the voice of the customer? It's their experience, and who's to say its right or wrong, its just their experience full stop. So anyone arguing against that wouldn't get any traction.

\section{Reference $1-6.77 \%$ Coverage}

Yes, as students are most affected by the choices of their facilities. Therfore they know best how 
facility decisions will affect their lives, and weither this is a positive or negative decision. We have knowledge as to how people are really affected and so have relevant insight into what changes need to be made

\section{Reference 2 - 9.13\% Coverage}

yes, I think students can improve higher education activities if they contribute their experiences and ideas because it is students who learn and do the activities, so they know better which activities are better for them and in which way they can improve higher education. By sharing their ideas they may also help staff members and teachers to better understand what is in students\&apos; mind and how they can help students.

\section{$\underline{\text { Summary of Data Analysis }}$}

1. Student/staff co-authored magazine (RMIT)

Type: Resource/Material

Questionnaire $=9$

Interviews $=4$

2. Work-integrated learning subject (Unimelb)

Type: Curriculum

Questionnaire $=11$

Interviews $=2$

3. Co-created curriculum (project based) subject (Unimelb)

Type: Curriculum

Questionnaire $=6$

Interviews $=3 *$ missing faculty

4. Student/staff student experience feedback workshop (WINTEC)

Type: General student experience

Questionnaire $=17$

Interviews $=5$

5. Student/staff created learning resources (La Trobe)

Type: Resource/Material

Questionnaire $=7$

Interviews $=4$

6. Student/staff partnership on program design (UQ)

Type: Program

Questionnaire $=2$

Interviews $=2$

7. Student peer mentors (La Trobe)

Type: Program

Questionnaire $=4$

Interviews $=3$

8. Student contributed social media (Unimelb) 
Type: Resource/Material

Questionnaire $=4$

Interviews $=3$

9. Student peer mentors (RMIT) *** not closed

Type: Program

Questionnaire $=15$

Interviews $=3$

10. Student governance (Charles Sturt)

Type: Governance

Questionnaire $=9$

Interviews $=5$

\section{Type Summary:}

3 Resource/Material cases

3 Program cases

2 Curriculum cases

1 Governance case

1 Experience case

Total participants:

Questionnaire: $\mathrm{n}=84$

Interviews: $n=31$ 
Data Analysis Process

\begin{tabular}{|c|c|c|}
\hline Strategy & Analytical Focus & Product \\
\hline $\begin{array}{l}\text { Analytical immersion in all interviews } \\
\text { and questionnaires }\end{array}$ & Within all cases & $\begin{array}{l}\text { Sense of lived experience } \\
\text { of the phenomenon }\end{array}$ \\
\hline $\begin{array}{l}\text { Immersion in each interview and } \\
\text { questionnaire }\end{array}$ & Within each case & $\begin{array}{l}\text { Identification of significant } \\
\text { statements }\end{array}$ \\
\hline Comparison of significant statements & Across cases & $\begin{array}{l}\text { Identify categories of } \\
\text { statements } \\
\text { common/unique across } \\
\text { participants }\end{array}$ \\
\hline $\begin{array}{l}\text { Reconnection of significant } \\
\text { statements to interviews and } \\
\text { questionnaires }\end{array}$ & $\begin{array}{l}\text { Within and across all } \\
\text { cases }\end{array}$ & $\begin{array}{l}\text { Ascertain fidelity to original } \\
\text { accounts }\end{array}$ \\
\hline Intuiting and critical reflection & $\begin{array}{l}\text { Within and across all } \\
\text { cases }\end{array}$ & Identification of themes \\
\hline Free writing & $\begin{array}{l}\text { Within and across all } \\
\text { cases }\end{array}$ & Realising key findings \\
\hline $\begin{array}{l}\text { Organise } \\
\text { categories/statements/contextual } \\
\text { data by concepts }\end{array}$ & $\begin{array}{l}\text { Summaries within and } \\
\text { across all cases }\end{array}$ & $\begin{array}{l}\text { Essential } \\
\text { structure/evocation and } \\
\text { intensification }\end{array}$ \\
\hline
\end{tabular}

- Adapted from Kavanaugh 1997 cited in Ayers, Kavanaugh, Knafl, 2003

Summary of Conflicts/Issues

1. Who does ownership belong to?

2. Do participants have enough time?

3. How can we sustain projects when students are transient?

4. How can we integrate student voice when there are so many different voices?

5. Is co-creation only for exceptional students?

6. Are the benefits of co-creation diminishing rate of return?

7. Can a project be entirely student led?

8. Does co-creation require in-person interactions?

9. Are students willing to volunteer long-term?

10. Do problem students negatively impact teachers' motivation? How do we deal with this?

11. If students can take on more responsibility do we need as many staff? 
12. Are there some things students can't co-create?

13. Are students motivated by money less effective than students intrinsically motivated? 14. How do we move past tokenism? 
Case 1: PUB

\section{Background:}

Staff member had an activist background, very student-centric. Wanted to design a program/activity that could help strengthen alumni links and bring together students from all levels

\section{Aim:}

Community links, CV lines for students, alumni links, create consciousness; note: both students/staff cited similar aims

\section{Organisation:}

Unclear organisation but led by faculty member who was very well liked and respected, changing throughout the process with varying levels of control, students participated in varying degrees as well, no set protocol

\section{Progress/Change:}

Goal of faculty was to start with more control and lessen over time, also in the beginning to fly under the radar of administration, however, this no longer is the case

\section{Staff reward:}

Meaning to his work, community links, positive student feedback

\section{Student reward:}

Creative outlet, experience, sentimental outcomes, skills building, more university knowledge, ownership, confidence, harnessing their degree

\section{University reward:}

Selling point, open day material, VC satisfied

\section{Issues:}

Students' time, too much on their plate, can't make every student happy, varying levels of interest, some arguing over control

\section{Further analysis:}

Like many cases, this is a very transient example, however, did seem to show substantial benefit to students who were more deeply involved. Student wished they had been given more examples, and some students said their specific needs were not always met. Students also did not feel the control had to be equal for the benefit of this activity to be shared. All student believed 
in the benefits of CC, and everyone felt they had contributed their opinions, but not everyone was sure they had contributed their ideas.

Students varied on preference for online or in-person, as well as if they learned what it's like to be staff, but many shared the belief that the magazine would continue to get better thanks to their contributions.

Interestingly, several students took ownership for the magazine's initial creation

\section{Quotes:}

Faculty:

- I wanted to build a community

- Another kind of space for people to.... Burnish their CV

- I think that disposition towards empowerment of individuals and enabling the is sort of a fundamental value behind what I'm doing

- The first edition for the most part I took the lead in

- We don't have a clear modius of operendi yet

- We wanted to create a consciousness to undergrads about that possible trajectory that we haven't advertised so well

- Seeing what the students are able to do kind of amazes me from time to time

- This space helps give my work greater sense of meaning

- No parallel elsewhere

- It will evolve different as different groups take the helm

- Students are able to give voice to their views

Students:

- When I brought up the idea with Julian it was just conversational

- I hoped my participation would be a point of difference on my CV

- The first edition we didn't have an editor, everyone was equal, Julian was the main point of contact

- This degree is only 3 years, it goes by quickly, and it's nice to say we created a magazine

- I discovered departments I didn't know existed, and I got to meet the VC

- We get less submissions in the $2^{\text {nd }}$ semester, students are more busy

- We don't get many first-year students, they are still learning how to navigate a university

- I was actually one of the people who had the genesis for the idea

- For me it was more about getting my work out there and feeling proud

- I met lots of people I hadn't met before

- Julian has always been one with the kids

- It's a really good selling point for the university

- Julian is the perfect archetype of the person you want to do this

- You can't cater to everyone's wishes

- It did take a lot of work

- At the very start we all had this idea that we were creating something new, but I'm a bit disconnected now... maybe I'm biased 
- I think I was one of those kids in high school that stuck my hand up for everything, and when I got to university, I had such a good experience, why not continue to do that?

- I was involved from the get-go

- We are getting less contributions than we were at the start

- Originally it was going to be entirely student-led but we had some issues, like with the printers

- Some participants are more involved than others, it comes and goes in waves, people get excited when they first hear about it and then they kind of forget

- It was the first time I had enough confidence to write something, not just edit

- We had a few face to face meetings in the beginning, but now it's mostly emails and google doc, I think it is pretty convenient

- I felt like I was harnassing my degree in a really practical way

- There is a real joy in making something I can give to my grandma

- Julian is the most caring academic I've come across

- I do think it might be better to go back to the way it was, have more in-person meetings, I know they are hard to coordinate, but I think they are really good

[Mixed]

- Students are the drivers of higher education activities, they understand how other students may react to/enjoy such activities. Allowing them to contribute makes them feel valued and invested in the success and improvement of these activities, and also generates a sense of belongingness and comfortability at their institutions

- There's nothing like a real world test

- Obviously, we're there to get a degree, but we can contribute ideas that might make the experience better for everyone

- It felt more like a parent supervising the kids baking a mud-pie In the backyard, let us get our hands dirty but didn't let us make offensive mud-cakes, so to speak

- I thin consultation between student/staff must be done from the start

- If [other] students don't contribute, that's on them

- I think better marketing and explanation of the process of writing would help, and more time spent on physically meeting one another

- The magazine will only go onwards and upwards

- The mission as it as is great, if people start to corrupt that balance, we might see a decline

- We were already close with staff, so new info was found

- I felt appreciated

- I think [student interaction] prevents staff from becoming isolated, ensuring they know who they are teaching and have a broader understanding of how their students view their world and their education

Case 2: WIL

\section{Background:}

Existing program, to provide students an authentic experience

\section{Aim:}


Students get matched with a real consulting company and teammates, they work together to solve an issue that the company has suggested and provide a project report at the end of the semester

\section{Organisation:}

Subject is a weekly lecture, very traditional set up, and a weekly workshop/tutorial where they work in groups and the tutor 'coach' walks around and tries to spend equal time helping each group in their specific project

Over 100 students apply, 60 are chosen for the subject based on grades and interview

\section{Progress/Change:}

The subject has not changed much from its original design, however, continuing lecturers/tutors note they get better each teaching period on helping prep students

\section{Staff reward:}

Learning about student perspectives, seeing students satisfied and developing

\section{Student reward:}

Self-efficacy, professional development, shared responsibility, authentic learning

\section{University reward:}

Showcase best students (students must place into the subject), promotional, partnerships, selling point

\section{Issues:}

Student time, students need to be self-directed, outside of their comfort zone, needs to align with the handbook (can't change too much), exclusive and not open to all students, there needs to be more scaffolding with the client, hard for some students to adjust to, sometimes they need more structure

\section{Further analysis:}

This case study is again quite controlled by the staff because it is a subject that requires grading and assessment. The course requires specific room requirements and while the staff felt they learn a lot about students, not sure if students learn much about them.

Students noted they did not feel the design was co-created (only the project), and they wished they had more examples. Students also did not feel like colleagues in this activity, not sure they would volunteer to improve the course, did not feel they had enough ongoing feedback, and did not feel equal.

Many students did not believe this was co-creation, but all students said they believed student contribution in higher education was very important and could help improve the subject. Some 
students felt closer to faculty and learned more about faculty responsibilities and others did not. Students were mixed as well if they noticed any changes made due to student suggestions.

\section{Quotes:}

Staff:

- It is not a simulation, it is not a set up in any way, it's a genuine business problem

- The subject has far greater workload than other subjects

- It is the role of the tutor to work alongside the students, but it needs to be their own work

- This subject pushes student's out of their comfort zone

- The subject, despite its flexibility, still has to conform to the handbook, it has to conform to assessment guidelines like word count

- There's a fair amount of faculty control, whether that's a good thing or bad thing, I'm not sure

- I take all student feedback seriously, but then it's my role to look at that through a pedagogical lens

- They leave the class with a strong belief of I know I still have a lot to learn, but I'm up to the task

- I think I am guilty of making my own judgements about what I think the student perspective is

- The subject helps form strategic partnerships with large multinational corporations, and the subject is blatantly used to achieve that

- The subject is also used in promotional marketing

- I have thought about letting students pick their own groups, but you don't get to do that in real life

Student:

- In the beginning, it was hard to get your head around

- We needed more of an outline of the assessment from the beginning of the course

- I think we taught our workshop coach a younger person's understanding

- For me, working in a team environment where the accountability was put on myself was a real benefit

- I knew about their course before I enrolled at the university, it was a real selling point for me

- There wasn't a lot of examples, it would have been nice to know why each part was important

- I thought the power balance between students and staff was perfect

[Mixed]

- If our ideas are accepted, we'd be more motivated to work

- I don't know what you mean by contribute, how can we make suggestions? Maybe an anonymous box somewhere? It's hard to make suggestions to our workshop leaders as we don't want to annoy them or make them think we are ungrateful 
- This subject was a good opportunity to see whole overview of a consulting project, something I didn't even get from the 3 internships I've done in consulting

- University administrators [who integrate students] can ensure their offerings are up to date

Case 3: Curriculum

\section{Background:}

Staff member designed the course, has a strong background in student-centric policies and design and psychodrama (reflective) practices

\section{Aim:}

To offer students an opportunity for more self-directed learning, authentic learning and links with community

\section{Organisation:}

Based on lots of scaffolding with the lecturer and the tutor as the same person. First couple weeks are devoted to personal values and students are asked to keep journals throughout. Students have a 'hidden assessment' where examples and specific guidelines are purposely avoided so students think more creatively and don't hold themselves to a single level.

Students choose their own groups and their own projects with a community link

\section{Progress/Change:}

Faculty and students alike both note constant learning and readjustment as semester progressing, including changing some syllabus aspects, for example, including a guest speaker on student request and organisation

\section{Staff reward:}

Learning about students, feeling engaged in her work, satisfied seeing students do well and think creatively

\section{Student reward:}

Self-directed learning, real-world application, chance for reflection, team work, independence to study topic of their choosing, deeper relationships with peers, leadership

\section{University reward:}

Most students enjoyed the subject, noted it was a unique opportunity and reflected well on the university (i.e. 'bragging rights')

\section{Issues:}


Unknown factors made students uneasy, some students did not like, faculty noted first year students were more creative than $3^{\text {rd }}$ year, some students didn't want to put forth the extra time/energy, miscommunication between students, some students perceived unfairness if teacher spent extra time with one groups, students wanted to actually implement their project after the course, students were unsure if the teacher would actually change the subject based on their suggestions

\section{Further analysis:}

Students were unsure if this was co-creation, some were disengaged from the course, many students noted they would have liked more teacher-time, and students noted they could tell the teacher really cared about them

Students were slightly, especially at the beginning, less comfortable with the class organisation and confused particularly with the assessment, students did not believe they would keep in touch with the faculty

\section{Quotes:}

Staff:

- The reality is we're all learning together

- The less I do the more students do... but there is a lot of scaffolding support that goes underneath that

- The more connections you can make with other people, the stronger the group is

- The whole process I find they struggle because its being with the unknown the whole time and then suddenly in week 11 or 12 it all comes together

- I think having the unknown factor as part of the subject adds excitement, engagements, fear, challenge...

- There is a real split between students who thought this is fantastic, I can go out and do my own thing

- You're not factory workers!

- By the $3^{\text {rd }}$ year it's almost like they've had their creativity and spontaneity killed by people going no no, just do this

- The assessment is actually structured, but I don't say to them exactly how I am going to do it... it's modelled on real life, where someone isn't going to give you a structure, you need to go and work it out

- Some students before this subject have never done any reflection

- I want them to be able to feel the struggle

- There is still this fantasy in their minds that the teachers know and no else does... it's really hard to break that...

- Each cohort shapes the subject

- I had this student one year, who I knew was going to be problem. He arrived in week 3 and he had been off traveling, which already says something about his values. And for him it was, tell me exactly what I need to do. He would come late to class or not come. And then he wanted 9/10 on his marks. But you know, actually, you're an arrogant shit, but you know, that stuff is unspeakable. I think some teachers don't know how to deal with students like that, don't want conflict, and maybe that makes them want to cocreate with students less 
- As soon as you nail something down, it's dead

Students:

- I wanted control over a project, that's why I picked this course

- We had a bit of difficulty in the beginning

- There was a problem with subject, not everything was super clear all the time

- There was one group who when they did their presentation at the end, we realized they spent the whole semester thinking they would actually have to implement their design proposal at the end, when in reality, that wasn't expected of them

- The teacher doesn't always get up in front of the class to say things, but if we had something written down that would have cleared a bunch up

- She wanted to product of work to emerge rather just have us try to tick boxes

- She wanted us to think, 'what makes a good piece of work?'

- The subject really focused on building relationships and creating a sense of being in something together as a group

- It was a welcoming space where everyone's opinions were valued

- The opportunity to engage in reflecting I found really useful

- This was the only time I could really pick my own topic and I really loved that

- I thought the class was great for our skills development, but I had a problem with not actually implementing the project, I think it would be great if we could actually do it

- We could have done any topic, we could have dogs if we wanted to, we could have done anything

- The verbal structure was a confusing element I think, but I could also see why it's good in a way, but it is hard to work around when you're a normal university student and you're trying to get a good mark in the end

- I had a relationship with the people I was working with and then friendship through that and that is what made you want to turn up to class and keep going

- I think everyone would have struggled if they didn't get an H1

- Some people are more used to being in the university system and having the marking criteria be very explicit and when you don't get a certain mark it makes sense

- If by doing a 10\% assignment I am used to it being maybe 10 hours, but now I am doing a $10 \%$ assignment and it is taking 4 days

- I think I got a sense of pride in my work

- I think she thinks she would be open to suggestions but I don't think she would

- She's really good at listening when she's ready, but if you are the last group [to see her] you might feel like you are getting critiqued on things that you did last week but you've changed now

- It would be good to make sure everyone is getting some type of feedback all of the time

- I'm more satisfied with my university experience now

- I think the university should have more subjects like this because students will be jobready

- Professionally speaking, I learned how to analyse my own progress and make it better

[Mixed] 
- I've only co-created very rarely, faculty and staff are usually closed-minded and result to a dictating like manner, or fake sentimentalism

- Co-creating experiences build other skills sets useful to life, but it's not going to improve our theoretical knowledge- I don't want to waste time coming up with assessment strategies or co-teaching my class, especially not if it muddles that rubric of marks we're all chasing, or meaning I'm having to put up with material taught that's irrelevant to the exam I will be sitting in 12 weeks' time

- Students can't improve higher education because the university, the system, the staff don't listen, they don't take it as constructive feedback, and more importantly don't make the chances that could improve higher education activities, from what I've seen

- We need more tutors so we can discuss more with a mentor figure

- The faculty in this class treated us like humans with flaws and all

- Other subjects mainly facilitate without an end goal and only tell you ALL the things you could ahave done better at the end, so you feel like what you are doing is pointless and you aren't passionate about the subject, actually you come to hate it

- Students aren't just ID numbers

- Staff benefit by realising students are equal to them

- The benefit to universities is that a better university isn't just about business

Case 4: Workshop

\section{Background:}

Went to conference, wanted to implement more co-design/journey mapping/persona work back at home institution to solve problems and issues; had a high level of support

Aim:

Design a series of workshops, each dealing with a different student problem, like enrolment process, and have students and staff interact and come up with solutions together

\section{Organisation:}

Staff do not say their titles to ensure students feel comfortable, high level of support and structure, stepped process designed by staff, ice breakers, and selected students as to participate but with an eye for diversity

Steps include: discovery, literature review, then workshops, then interviews, and maybe observations following

We never have more staff than students

Staff reward:

Understanding students, passionate about student-centric, different perspectives

\section{Student reward:}


Authentic, have a chance to see staff caring about them, helping future students, opportunity to voice their opinions

\section{University reward:}

Solve issues

\section{Issues:}

Need more time, only short-term engagement with students, students who participate may not get to see the reward, limited funds, some staff participants are too linear, don't like the process, initially both students and staff may be uncomfortable, more rewards like money for participating students

\section{Further analysis:}

All participants both students and staff were positive about co-creation and everyone felt the issue was now more likely to be improved

Some participants felt there was not enough time, that students get enough chance to learn about staff roles, that students therefore did not feel closer with staff, that the exchange was just oneoff and activity itself was not changing or being modified due to student input

Students enjoyed having their voices heard, but felt there could have less people, and that could have been more ongoing, some also felt uncomfortable

\section{Quotes:}

Staff:

- At the end of the day who can argue with the voice of the customer?

- The goal is to understand how the users feel, think, what they are saying and doing

- We have participants make I wish statements so for example, if you are given choices A, $\mathrm{B}$, and $\mathrm{C}$, but you might also like $\mathrm{D}$ and $\mathrm{E}$

- We want to make sure the extremes of student diversity are included

- It would be nice if we could invite them back [at later stages of the project]

- There are only limited funds, you can only do so much

- When I went I got a sense of some of the pain points

- I mostly participated because I was passionate about it, I would do it regardless of reward

- I think the students' idea were just as feasible as staff ideas

- I get a lot of student questions about why something isn't working but I can't answer them because I don't have access to what they do and I can't even see what they are seeing

- The 'how might be questions' I've already applied in other ways

- I believe the workshop would have looked differently if it had been staff-led

- For students, it's a chance to be a part of a real life working group

- Initially students were a little reserved

- Some staff felt reserved with students too because they didn't want to air our dirty laundry in front of students 
[Mixed]

- How do we retain students if we do not ask them what a good experience is for them and just keep vomiting out the same approaches, content, processes, and policies?

- An organisation or staff can often get caught up in the bureaucracies of processes and forget the purpose of why?

- The amount of time we had was insufficient for the number of questions

- We needed a better physical environment where students could be more immersed

- The conversations and insights have already triggered conversations of self-reflection and continuous improvement in these areas

- Students may have been surprised that staff have the same gripes

- The student knowledge around how complex institutional processes are being almost non-existent, one student just said, but why? Why does it have to be that way? It was a good question.

- The benefit for me was getting a reality check

- The university can now get an informed basis for decision making, as opposed ti cold and sometimes misused data and stats

Students:

- I would have preferred a voucher to a grocery store as the reward, but I'm a low income student, maybe that's just me

- My brain just doesn't work like that, it was too fast, like speed questions, I needed more time to think

- I want to make sure I get the most out of my university experience, I pay 6,000 a year, and I have medical issues, so this is pretty important

- I thought this is cool, an interaction between staff and students, you get that much

- I think we had pretty valuable feedback for them

- There should be more built-in customization options for us

- I did this half for me, but half for the future students, I'm an international student and I want to help other international students- especially because I'm Asian and I think there's a stereotype that we don't like to voice our feedback

- I didn't do it for a voucher, I did it because I wanted to tell everyone my experience

[Mixed]

- Students can contribute because we are the ones with most direct feelings

- It felt so rushed

- It felt a bit crowded

- I think a 50/50 staff and student ratio is best

- They were very serious about taking what we say and implementing it to create a better experience for us

- A few staff responses surprised me 
- I don't feel any closer to faculty, they were only interested in learning our perspective

- We got to feel like we were being listened to

- The benefit for university is that more students will apply, the standards will improve, student will be more happy

\section{Case 5: RESO}

\section{Background:}

Staff members had attended a conference on the importance of communication in health students, and worked with students-as-partners experts to begin a joint activity between health and media/journalism students. They discuss the progress as quite gradual though they have always identified as student-centric.

\section{Aim:}

To improve the communication (i.e. engagement) skills of health students and allow media students an opportunity to create something tangible

\section{Organisation:}

All students who participated in the group project were volunteers, they could have been assessed individually if they had chosen. Students met up usually once a week and with faculty ocne a week.

\section{Progress/Change:}

This was the second iterative of the activity, the first one had failed because the student group had not delivered the end result, faculty member cites this might have been due to not enough supervision on their part as it needed more scaffolding and too much control was given to students.

\section{Staff reward:}

Staff felt the activity had rewarded them for knowing more people around the university

\section{Student reward:}

Students felt they had the opportunity to do something new, gain new skills as health students learned more about video production and media students learned more about health, they also felt their confidence had improved. Students also mentioned because it was a volunteer project they felt everyone 'wanted' to be there and they go to meet like-minded peers, they also felt good, felt they had more exposure to the real world, had something to put on their CV and felt more confident in teamwork now

\section{University reward:}

Marketing with student videos to use as promotional, aligns with students-as-partners initiative, opportunity for researchers/students to go to conferences and share activity with others 


\section{Issues:}

Issues for students and staff were focused around time, also only some staff/students were interested or willing to take part in the activity; balancing roles and how much control/freedom to allow was also a concern

\section{Further analysis:}

Staff expresses themselves as student-centric already and how they enjoyed the opportunity for the students to learn more about how a university operates and the staff members. They felt they had created a real-world experience for them and that they had learned more about the student perspective. However, they did not provide examples, and did not include students in the design process or modify the activity based on student suggestions yet.

Students felt very engaged and positive about their participation, and felt they had all contributed ideas and opinions to the videos. They felt much closer with staff associated with the project and very comfortable giving their opinions in the future to other staff.

The time table was hard for students though and they were unsure if they understood the staff perspective and vice versa, they did not feel the activity needed to be equal in responsibility and roles with staff, and were unsure if they would keep in touch.

They felt they were much more knowledgeable and confident students know, and that they had helped create a great tool for the marketing of the university. Some commented this had made the university experience worthwhile. They also said they were likely to recommend this activity to their friends.

\section{Quotes:}

Staff:

- It started with an assessment in human physiology where students translated research into an article for popular science and we ran that for a couple of years and then we opened it up to allow students to be more creative and do what they wanted to do

- Student can choose a disease, choose an audience, choose a communication piece... but they had to be able the significance and justify their mode

- Hopefully putting it on YouTube and getting the message across the globe

- Myself a colleague created the student guide for the module, and formed partnerships with the College of Teaching and Learning, and the media communications staff member, so we were the glue that kept the group together

- Also with the students having a more professional type of arrangement rather than I'm the teacher, and you're the student, I'm better than you

- I expect them to know more about hypertension than me and I was just curious and I was asking a few questions and one of the students half-jokingly said, "I think you are trying to put me on the spot" and I said no, not at all, I'm just curious because I think you know more than me

- We couldn't open it up to the whole class, and in fact, it was only those four staff who wanted to do it

- I don't know what the communication students are getting out of it! 
- The university is very resistant to give staff more workload, although $\mathrm{SaP}$ is a term that gets flushed around they want that kind of thing to happen

- Mediocre and struggling students who are not very engaged in their studies will really find this type of activity challenging

- We have screens on campus we can show the videos and we will use the videos to promote the module in the future

- Because it was more of a partnership, we were more open about being swamped with work and just more open in general about our daily work life

Students:

- I wanted to try something outside of my comfort zone

- The only downside through is it's becoming bigger than Ben Hur

- I'm still mostly motivated but the last few weeks we've been struggling

- Everyone opted to do a group thing when they didn't have to

- I said, "Look if you ever get a chance in the last year of your degree to get involved in a project like this, jump at it, it's a fantastic opportunity"

- We never did anything like this 20 years in my first degree!

- The aim isn't to make money. Just to prevent. We are providing information and helping people change their actions.

- I personally worked on it in my spare time.

- They definitely added to ideas and inspired some ideas, but left it entirely in our hands, which was awesome.

- I helped gain experience and exposure in the field

- The fact that it was no longer a student-teacher relationship but an equal playing field was brilliant

- It's been my favourite subject in my entire course. You gain experience you wouldn't get in any other subject

- I was interested in doing something in the sciences but my scores weren't quite up to scratch

- Initially it was just to test my skills but as time went on I thought hang on this is actually a great project and it didn't feel like I was doing much work, it just felt like I was hanging out with people

- Staff meetings were initially helpful but towards the end when it came time to actually produce it, it was hard to get in contact with them because they were busy with meetings

- At time it felt like the staff were taking a backseat.. but I think it was more to let us get our ideas across rather than them just telling us what to do

- This was way better than any of the other projects I have participated in

- Can I be a bit blunt? With La Trobe I think they are looking for something to pul in students and trying to show students that if you are student here you can do this, this, this ... it's a marketing tool to get more students, but it would have tipped the balance in deciding where to go for me

[Mixed]

- Since the educational activities are designed for students, it is a great idea for students to be able to help the academics in designing these activities 
- This opportunity has allowed us to be ready for careers and graduate opportunities as we work with various faculty members

- I couldn't tell you most of the faculty do

- Through the activity I did learn that meetings with faculty as a group was a much better interaction compared to more formal interactions I've had individually

- I got constructive feedback and criticism, real world implications and training

Case 6: Program

\section{Background:}

High level of support, part of the chancellory's strategy to encourage students as partners. The program to oversee the SaP projects was assigned, but the background to the project was a working group that ordered the program and then selected a student on the group to lead, along with a professional staff member.

Aim:

Initiate and support 11 of $\mathrm{SaP}$ programs occurring through the campus

\section{Organisation:}

Just one student and one staff member, did not know each other before, meeting first. They had very different and defined roles, with one having extensive background in $\mathrm{SaP}$ and another one having extension background in university programs and administration. Accountable to someone in teaching and learning unit, but who knows less about the program and topic than student leader.

\section{Progress/Change:}

Changes as they go along

\section{Staff reward:}

Opportunity to learn about $\mathrm{SaP}$ and encourage $\mathrm{SaP}$, now feels strongly about $\mathrm{SaP}$

\section{Student reward:}

Highly engaged, intrinsic motivation in the area, self-efficacy and confidence

\section{University reward:}

Promoting SaP

\section{Issues:}

Time, needed a very capable student to lead up, student vs. staff identity issues, lack of respect for student leader - this was also just one part of staff role 
Also within the program itself recruiting staff members, incentives including not always monetary rewards for students, questions over whether students should get paid but not staff

\section{Quotes:}

Staff:

- At first it was a bit of figuring out what each of us was responsible for, our roles were different but complementary

- It's hard to know how much is about your relationship and how much is about the partnership style

- ...How we wanted to work together, like meetings and who would look after certain things. It was the first discussion of many, but we've rediscussed that clarified that as we've gone along.

- They bring a lot of knowledge on SaP whereas my experience is more understanding how a university works and how to coordinate a program

- We've found a way for both of us to contribute equally

- Most other students don't have as much confidence, so to be paired with one of them I feel would make me leading a lot to make sure we were getting it done

- We did have quite a bit of trouble recruiting staff to our pilot teams

- She's quite involved in the area so she almost does have a certain staff role than a student

- It makes you think where else you should...

Student:

- It's a division of labour between the staff and I where she provides the administrative, and I guess, university processes expertise and I provide the partnership angle

- Prior to studying education, I was really disengaged in my studies and frustrated at the sense of injustice about dismissal of students' role in education

- Students as partners gave me a frame of reference to think about empowering students

- The first role I filled was the co-chair of students as partners steering group

- The group recommended was to have a whole of university SaP program, and I was offered the role as project lead

- I guess the administrative support that we get is primarily driven by the students as partners being put into the students' strategy policy

- I get a lot of internal conflict with my roles of students and staff and that I find challenging

- Some staff may think of me as a staff member... and I get some conflict with that because it conflicts with my strong identity as a student

- In a meeting, the other day where [a leader] was meeting with myself the staff members and others about the progress of the program, he addresses all of his questions by name to the dean of medicine. Now, the dean of medicine has nothing to do with the project because of the divorce between the (former) steering group and our (current) project. So he had no answers. But regardless of the fact he was not involved, the faculty member continued to address all of his questions to the person with most senior authority in the room, regardless of his expertise on the questions. That's a really illustrative example of the way the power hierarchy within higher education continues to permeate every aspect of my interactions, regardless, and almost ironic, of the context. 
- I don't want to sound discriminatory, the roles in our project require a certain level of expertise, for example if an undergraduate had been involved in partnership 3-4 years and had the same level of expertise as me, I don't think it would have made a difference if it was him or me

Case 7: Peer1

\section{Background:}

Unsure how long it was running, but has been running it for over six years, handed to her. Have PLAs on all campuses, except Sydney. Run drop-in sessions in the library from 10-4 five days a week and also workshops.

HEPP funded

Aim:

Help struggling students, inform curriculum re-design, improve retention and help student engage in self-help

\section{Organisation:}

Takes place on regional campuses, when the desks are occupied it is one experience and one less experience student, and higher levels of support if needed. Students air pair, and need at least a $\mathrm{B}+$ average to work there. Based off an increasing responsibility structure

Staff member liaisons with subject coordinators and then PLAs run student workshops around academic skills; staff member helps them train for those sessions

\section{Progress/Change:}

Have made changes to the organisation based on student feedback, including training and offering different workshops as well as informing processes

\section{Staff reward:}

Student perspective and feeling good about helping students; students also provide useful contacts to find staff champions who will participate

\section{Student reward:}

More comfortable with peers, new dynamic, money, academic experience, CV, emotional support, learning about a university, belongingness

\section{University reward:}

Going back to aims, improve retention, self-help engagement

\section{Issues:}


Consistently unsure if it will continue and/or expand, university is not giving full support, not all staff are convinced students can do this, students sometimes encounter students with well-being or mental health issues

\section{Further analysis:}

Students were unsure if they would volunteer, and agreed a mixture of on-line and in-person environments and platforms worked best

PLA training teaches them the whole structure of the university right to VC

Not all students given a chance, and difficult for faculty to serve each students' need differently

\section{Quotes:}

Staff:

- We aren't sure about funding next year and whether it will even exist

- Student's won't necessarily seek out staff help, there are some who don't feel comfortable approaching academic teaching staff, so it's often much less threatening for them to go to their peers

- I hope its altruistic but they do get paid upwards to 30 dollars or more an hour

- I think the program has really helped academic and professional staff get a much greater sense of the capability of some of the students

- Some staff say, "the students aren't skilled teachers, they can't do that..." but I don't buy into that. I think if you set the bar low then that's where it's going to stay.

- I'm not sure the university sees [our benefit]

- There was an element of maybe these student-teachers might take away our jobs a few years when the program started

- Our PLAs are privy to budget discussions and decisions and so their understanding of responsibilities and constraints has become very clear

Student:

- I liked the idea of helping people because I do like teaching and one of my plans is maybe to go into academia

- I think for those students struggling and want someone to be able to kind of understanding their perspective I think peer learning is one of the best things for that

- I had a student once and we talked through her assignment, and she went away feeling a more confident

- Some cases can be particularly challenging if the student is at the same level of writing, or even higher, than myself

- We talk through people's anxieties and issues a lot

- I've now been able to help out my friends and housemates

- The best way to learn is just to do it

- At the beginning, they had all of these kind of plans and all these new staff members and then all of sudden they didn't have the budget

- Some new PLAs weren't knowledgeable enough in my opinion, but they needed the money 
- Some student who come just can't do the work themselves

- People skills... always a challenge

- It's a great feeling when you help another student see the light of realization when you see the student gets it, it's a really satisfying feeling

- We can also just provide support, like emotionally

- I think if I wasn't paid I would still want to be involved but I wouldn't be able to put in the same number of hours that I current do

- I didn't just study here, I worked here, I was advised student, I formed a different and deeper connection with my university- now I'm thinking of doing my masters and here would be my first choice

- They do remind you that because you are student they don't want to put you in jeopardy or anything like that

- To give feedback and actually see it come into practice... now I go through the feedback of others and speak to staff, and say, what can we do it to make sure it is better?

- If we organise a workshop and we wait for 30 minutes and no one turns up, I guess you kind of think about your own student experience, what if it was like the lecturer turned up and no one was there?

[Mixed]

One of the main issues is that the PLAs are paid by the hour so their contributions to forums (LMS) is done in quite times or out of hours. Also as students, finding a time for everyone to meet is almost impossible. *staff

They're not many people that know about us

Case 8: Social Media

\section{Background:}

Social media of growing prominence and importance at the university. Had yet to include students yet, a new team member, formerly an intern, and current graduate student suggested more student involvement

\section{Aim:}

To get students more involved, but also with helps of content creation as student-created content can be quite hard to find, also link with the engagement strategy of the university

\section{Organisation:}

Not funded, all volunteer based, the staff are quite overworked but the new team member helped alleviate some of the pressure, was originally a one-off and has expanded, there are also a few 'hoops' for students to sign beforehand

\section{Progress/Change:}

Lots of momentum, has gone from a one-off to multiple thing, big ideas to expand in the future

\section{Staff reward:}


Student talent (i.e. good at photography), student perspective, student content, students spreading information

\section{Student reward:}

Self-promotional, memories, sharing critical knowledge to others, CV, feeling like an advocate of the university, pride, reputation, and engagement

\section{University reward:}

Helps spread information, student engagement

\section{Issues:}

Not yet, but irresponsible student could pose a risk, not always follow up, students can change their minds, bit exclusive as many students don't know about it, not an ongoing interaction to stay involved for students

\section{Further analysis:}

All students and staff were very positive about co-creation but staff cited concerns over how time consuming it can be, and were unsure if more extreme examples such as having students as colleague, prior consultation and modifications based on student feedback was always possible

Student felt they learned a lot more about the university and felt closer with their university however they wanted more opportunities, they also wanted to give more suggestions, be treated like colleagues, and have more interaction

Staff indicated that students only contributed personal experiences and expertise/knowledge, not ideas/ or opinions/suggestions/ Students indicated they only contributed personal experiences

\section{Quotes:}

Staff:

- Last year I was an intern here and that kind of [student contributions] what was missing

- There wasn't any capacity to go beyond what they were doing, now that I'm here, it's more feasible

- We aren't after a certain kind of student, it's just about how experience they are on social media

- We make them jump through a few hoops... just to sort of mitigate some of the risks

- Content created by students is not easy to come by

- We acknowledge we have some incredibly creative students... they are amazing artists

- We want to link with the university strategy on engagement

- The reason why we went with snapchat for doing takeovers is because that's where most of the students are

- You want to go where the students are, it doesn't make sense to target students on LinkedIn if they are all on snapchat

- It doesn't have to be a one-off thing [we could do more] and then it could be like they are a part of our team 
- When we post something, I'll notice in the week following we have so many other people posting that same picture

- Whether or the university itself a stance [on something political] is irrelevant, if an academic has expressed a view and presented their research then we will show that

- They'll feel like their contributions matter, that we care and that they've given back

- Sometimes were a bit detached from the student experience, so these student takeovers bring us back

Students:

- Even though it's not a paid project I really love to be some kind of inspiration to other students

- I think as an international student sometimes people see us as lesser, like we are not capable of doing things, and I want show people that international students are just as good as local students

- I feel proud when I see my social media contributions on the university's social media

- I now know more about social media, in my local church I hold the social media account and there are no professional guidelines, but I think the Unimelb social team was very professional and now I have a better understanding on how to do the job

- Some of my friends didn't know about it so they can't join... I think they should promote it more

- I had a bit of time on my hands, and I thought I could a couple cool thing I hadn't seen on snapchat before

- It was fun for people who knew me

- I think students have a bit more of a fun fresh view on things

- Sometimes it's a bit daunting to get behind a camera but I think once you do and you get feedback from everyone, it was worthwhile

- I must say I did save it and I do watch it

- It has motivated me to get more involved in the university

- But I think I was a student in my role

- You don't want to open the door to people who aren't as passionate and then your product isn't as great

- As students, we actually have the advantage to relate to other students because we are in the same boat in the term of experiences.

- I was really grateful to work with the staff member and she was very supportive of my ideas

- I had a strong feeling after the co-creation experience that I'm (finally) part of the University of Melbourne society

- Students working with staff helps narrow the gap

- Students who work with staff will feel honoured to share the experience and will get a sense of pride

Case 10: Student Governance

\section{Background:}


For a long time have had student governance, however starting this year is the new addition of including online students in student governance as the online community is continuing to grow and there is interest in including their voices

\section{Aim:}

To integrate online students into existing student governance structures

\section{Organisation:}

Groups on each 7 campuses are known as SRC (student representative committees) and send two reps to sit on the student governance board- online students were given a group as well with two representatives (however they number more much than a single campus)

All representatives are given training and have administrative support as well as a handbook, voting for SRCs now also takes place online, which has helped improve participation rates

Along with SRCs there are also some unique positions to sit on academic governance boards where students are elected

From the student board two reps, one undergraduate and one graduate, also sit on the formal academic board

\section{Progress/Change:}

This is a new change with some issues still to be worked out

\section{Staff reward:}

Aligns to the principles of the university, get to involve students and benefit from student input, for example new introduction of a class-free period when groups/communities can meet and no one will have class

\section{Student reward:}

To have their voice heard, CV, enjoy conferences and meeting with powerful university leaders, belongingness and feeling like they are helping out

Students are motivated

\section{University reward:}

Can say they include online students, help innovate the university

\section{Issues:}

Students in the online community noted they should receive more representation based on their large numbers, but staff/on campus students worry about giving the online students too much power; there seems to alignment issues between the younger on-campus students and the mature age online students as well, some representative also noted they did not want to be token 
Staff also make excuses for students (they are too busy) and some staff are worried about too much student input

Students can also be a little uncomfortable in new roles and feel they have limited voices, also the space can be difficult as they are spread out and some are online, they wish they had more interaction with faculty, and many of the students who represent are extroverts or have previous representative experience, there is also a blurring of lines between student and staff

\section{Further analysis:}

All participating staff were very positive, but pointed out that students don't always have realistic timelines, and the voice can be quite exclusive to those that participate, and there is debate over whether the roles need to be balanced/equal or not

Students had issues between online/in-person, they would have liked to learn more about students' roles, and did not feel like they were treated as colleagues, some felt less comfortable, and doubted they would stay in touch with staff they had met

\section{Quotes:}

Staff:

- It is an understanding we do want earnest student involvement

- All students at CSU that take on a leadership role are invited to training

- In the online SRC the amount of students is based on how many students we have on cap... but's funny, they've already started rocking the boat in the amount of finances that they have in their pool based on the number of students they have and what not

- It's right to question that it is quite static across the groups in terms of representative and quotas

- We don't want the entire decision body of the university to be decided by a bunch of online students

- There's a certain level of quality control that takes place in the student senate but the majority on that level are very capable

- I wouldn't say we're token with the students, but I would like to have us seeing more students on employment selection committee and whatnot

- Some of the negatives of that are obviously a student doesn't really understand the inner workings of a university

- If they get to the point where they can do the chairing of meetings those are invaluable skills they can into the workforce

- We usually find the participating students are high performers and they're already working several jobs full-time and this is their $3^{\text {rd }}$ or $4^{\text {th }}$ expectation above their studies

- Basically, the online SRC wanted to, you know, take full control of communication channels to students and as an institution we said, look, that's probably not a good idea

- We are not as politically charged as Melbourne or Sydney, sometimes a determent to us, but we don't want to see the shenanigans that happen there, because that's not a good look for anyone

- I think we see the dangers of the over-politicising the student voice

- We didn't want students to be so shocked when they got to the senate (are SRCs are much more lax) 
- We've been working with the students to get them to understand that they are not just here for fun, they are not just here to be a token

- Student enjoy it more when they feel listened to

- We always get the same type of student, the ones who are busy and want to be more busy

- With the voting now happening online, we saw the voting became more popular and more people nominated themselves and a different mix of students came forward, not just the students who were friends with students who were already on

- One student wrote about the SRCs, you get to plan events and you get to put in as much effort as you want... so if you don't have much time that's ok... I found that shocking. I mean with all the work that we're doing if someone still sees that they are just party planners and minimal effort is needed, that's when we realize we need to change the conversation and we need to change the message

- I have a lot of respect for what students can balance

- Very different from when I went to the university!

- Sometimes staff think, these guys are students, they are very busy, how are they going to have time for that? And you know what? They figure it out.

- Without students, we don't have a university. If it wasn't for them, we wouldn't have a job.

[Mixed]

- I also feel that academics have included the student voice as 'box ticking' exercise

- From my experience of the face to face environments, there could perhaps be more intentional effort to integrate students

- I think the rate of change that students expect foes not align with the reality of a university environment, knowing this early may help students to become more strategic in their input

Students:

- We as online students didn't feel like we had a strong enough voice

- It took us a long time to actually get the message through to them that we an equal voice in students rights

- I think there is between the online and face to face students a disconnect, part of our work is to integrate the two, and that has resonated with a few staff, but I'm not sure the students understand that

- As mature age students we come with a world of experience

- Our challenge was working with students, not the academics or staff

- You need to accept that a significant number of your students are online, you can't ignore them

- We were fight for more representation of online students based on the number of online students and that seemed to fall on deaf ears

- I felt they were a very clicky group, and perhaps that was just that they had the advantage of being on campus. Now I would see that as a failure of the student senate, to understand that 'these' people myself and the other SRCs memers are just as much a part of the groups as others 
- When I arrived at the VC leadership forum I got more acknowledgement and conversation with CSU staff than I did from any student member. Particularly, the president of student senate, and maybe that's just me being precious, but if I were to assume that role, knowing basic aspects of leadership, I would probably go out of my way to make sure I'm connected with the people I am responsible to

- The first training day, that really set the tone

- The impression when the online SRC was formed was that they were trying to include the presence of online students, but I wonder whether they actually asked themselves what that would look like

- The university probably needed to ask the question themselves, you know here's the token online students, I can't imagine what they are going to be whinging about again, let's give you chance to rant, but great, we've heard from you, let's move on

- I think there's a risk that universities see online students in a transactional way and the avenues of hearing the students voice is a way to mitigate that feeling and sentiment

- Universities think online students are a Band-Aid to fix all our funding issues... and I think the university is getting away with it, but if they are serious about capturing that market then they have to be serious about capturing those voices

- At first it was a little daunting, I felt like I was in a room of very professional and senior academics, however, they were open to hearing my opinions and they wanted to know the student perspective, and when I started to think of it like that, my role as a student, rather than being this kind of corporate type person, I found it a lot less stressful

- I think I added to the [university strategy plan] by talking about the students and we even added a new role to the vice chancellor portfolio, new deputy vice chancellor of students, which we never had before

- My sister did it at her university and I saw her role in that... so I thought I wanted to get involved in student leadership

- I try to give feedback at every meeting but probably not as much as I should, like one meeting I didn't say anything and afterwards I thought, oh, I should have said something

- I think there are a few who make an effort to help me join in, whereas sometimes there are others who just kind of shut it down and keep it to the couple of people who do most of the talking

- We had a discussion about online systems of education, and there were basically 3 options, and there were about 1 or 2 of them that I really knew, that they were not viable as a student, I gave my reasons why, and I think they did listen because they didn't go with those options, so I felt like I really did help in that sense

- Honestly, it really does feel like I am there to give feedback [rather than be a partner], that's why I feel anxious, and not on the same level as everyone

- I think because from meeting to meeting there is not much communication, it feels like I kind of just show up to the meeting, give my opinion and go home

- We should have more students [in these roles] because it's like the voice of the university, it's the people that receiving everything they are making decision about

- I think [this experience] made me really proud of my university, like I'm a part of it, and I don't want to leave or change universities, I feel like I belong there

- I don't really have much interaction with academic faculty except for when I sit on the academic board

- Me, personally, I don't have issue talking up at these meetings, I'm very vocal. I think I'm of the first student leaders to be so vocal, I was told

- Having a student who is willing to talk up and might be slightly controversial is something that we need at those levels 
- We recently just passed a class free period that is going to happen on Wednesday and we took the idea of wanting to better student representation and my stance on that was if we have an allotted time in which there is no class then students can get involved at those times

- I was involved in student governance in high school, and by family was always involved in governance... so it's something I kind of grew up with

- One of the biggest issues we're facing is the mindset of our faculty members, to them it's kind of student reps, having students on their boards, is just a token

- Really building the idea that student representation is not just a token, and it's something that can better the university, and if you have direct contact with students you're getting what's wrong with certain degree and finding areas where you can improve

- It's hard to say with $100 \%$ certainty that I represent all of the students, I could never do that

- There's a situation around me... I guess that staff aren't really happy with it, and I said to the staff you have the right to email me your concerns, but I said in my reply, I understand your concerns and fears, but as the student representative my position will always be for the students... and they turned around and said this doesn't affect the students so you shouldn't vote for students you should vote for staff, what's the point of having you if you don't have our backs?

- I'm not able to do my job properly to better the lives of students if I don't know how to properly change it

- I knew full well that getting into this role it was going to be mostly voluntary

- I am hoping to work on national accreditation boards and things, this looks really good on my resume

- The executives and management team what they experience when they were at university is different from what's going on now... you're not going to be able to do what's best for the university if you don't know what's going on

[Mixed]

- Students provide a front-line perspective that cannot be given by anyone else

- I often get the feeling that student senate has to be run by a 'responsible adult' who is employed by the university rather than students as change makers

- I am sometimes unsure if staff members are aware of students' responsibilities as a representative and if they place enough trust in the student perspective

- Sometimes I view close student/staff relationship as a negative as student representatives can get caught up in please staff they are close with, or listening to their ideas and viewing them as more valuable due to their position... 
Gioia Method

\begin{tabular}{|c|c|c|}
\hline $1^{\text {st }}$ Order Concepts & $2^{\text {nd }}$ Order Themes & Aggregate Dimension \\
\hline $\begin{array}{l}\text { At the end of the day who } \\
\text { can argue with the voice of } \\
\text { the customer? It's their } \\
\text { experience, and who's to say } \\
\text { its right or wrong, its just } \\
\text { their experience full stop. So } \\
\text { anyone arguing against that } \\
\text { wouldn't get any traction } \\
\text { (Staff, RESO) }\end{array}$ & & \\
\hline $\begin{array}{l}\text { Given that students } \\
\text { ultimately are the } \\
\text { beneficiaries of higher } \\
\text { education teaching and } \\
\text { learning activities, I believe } \\
\text { that every aspect of teaching } \\
\text { and learning stands to benefit } \\
\text { from some level of student } \\
\text { involvement (Student, } \\
\text { PROG) }\end{array}$ & Personal Outlook & Antecedents \\
\hline $\begin{array}{l}\text { University does not function } \\
\text { without students (Staff, } \\
\text { PROG) }\end{array}$ & & \\
\hline $\begin{array}{l}\text { So my high school had a } \\
\text { school magazine and in year } \\
11 \text { I was the deputy editor of } \\
\text { that magazine (Student, PUB) }\end{array}$ & Previous History & \\
\hline
\end{tabular}




\begin{tabular}{|c|c|}
\hline $\begin{array}{l}\text { I was involved in SRC } \\
\text { (student representative } \\
\text { committee) program in high } \\
\text { school... but my family was } \\
\text { always involved in } \\
\text { governance of sporting } \\
\text { committees so it's something } \\
\text { I kind of grew up with } \\
\text { (Student, GOV) }\end{array}$ & \\
\hline $\begin{array}{l}\text { So we had complete control } \\
\text { over that project. Actually } \\
\text { that's why I picked this } \\
\text { course because I wanted } \\
\text { more of that (Student, } \\
\text { RESO) }\end{array}$ & \\
\hline $\begin{array}{l}\text { And I wasn't sure but I } \\
\text { wanted to try something } \\
\text { outside of my comfort zone, } \\
\text { but it's actually been really } \\
\text { good (Student, RESO) }\end{array}$ & $\begin{array}{c}\text { Students' Initial Perceptions } \\
\text { and Motivations }\end{array}$ \\
\hline $\begin{array}{l}\text { I was working at a liquor } \\
\text { store and doing retail work } \\
\text { and I wanted to try and get } \\
\text { some other kind of job but I } \\
\text { didn't know where to start. I } \\
\text { liked the idea also of helping } \\
\text { other people because I do } \\
\text { like teaching and one of my } \\
\text { plans is maybe to get into } \\
\text { academia... so I thought this }\end{array}$ & \\
\hline
\end{tabular}




\begin{tabular}{|c|c|c|}
\hline $\begin{array}{l}\text { kind of thing would look } \\
\text { really good for future jobs } \\
\text { (Student, PEERA) }\end{array}$ & & \\
\hline $\begin{array}{l}\text { But we haven't been very } \\
\text { good at maintaining links } \\
\text { with students after they } \\
\text { finish. So I tried to think of } \\
\text { ways to create a sense of } \\
\text { community (Staff, PUB) }\end{array}$ & & \\
\hline $\begin{array}{l}\text { But another reason if there } \\
\text { are so much hock-ups in the } \\
\text { process now that any way I } \\
\text { can get some sense of the } \\
\text { pain points are and where I } \\
\text { think the gains are would be } \\
\text { good for me to know (Staff, } \\
\text { EXP) }\end{array}$ & & \\
\hline $\begin{array}{l}\text { My hope is that students will } \\
\text { feel as though their } \\
\text { perspectives and experiences } \\
\text { are seen as worthwhile, and } \\
\text { worthy of being shared on } \\
\text { our channels. Over time, I } \\
\text { hope that our Snapchat } \\
\text { takeovers can create a sense } \\
\text { of community amongst } \\
\text { students from across the } \\
\text { University (Staff, MEDIA) }\end{array}$ & Staff Aims and Motivations & \\
\hline
\end{tabular}

Table. Summary of Environmental Factors 


\begin{tabular}{|c|c|c|}
\hline $1^{\text {st }}$ Order Concepts & $2^{\text {nd }}$ Order Themes & Aggregate Dimension \\
\hline $\begin{array}{l}\text { Little more time spent } \\
\text { physically meeting one } \\
\text { another- whilst the online } \\
\text { aspect of submitting/editing } \\
\text { is time efficient, it doesn't do } \\
\text { too much for students who } \\
\text { would like to say, talk out } \\
\text { their ideas, before writing } \\
\text { them, or work through a } \\
\text { complexity (Student, PUB) }\end{array}$ & Online vs. In-Person & Environmental Factors \\
\hline $\begin{array}{l}\text { The physical environment } \\
\text { can most definitely improve, } \\
\text { it would improve the social } \\
\text { environment for students if } \\
\text { there were more areas to } \\
\text { study, hang out, interact with } \\
\text { the university (Student, CD) }\end{array}$ & & \\
\hline $\begin{array}{l}\text { It's not a simulation, it's not a } \\
\text { setup in any way, it's a } \\
\text { genuine business problem } \\
\text { and they have to research it } \\
\text { and provide recommendation } \\
\text { and report that is of some } \\
\text { strategic or operational value } \\
\text { to the client... (Staff, WIL) }\end{array}$ & Authentic & \\
\hline $\begin{array}{l}\text { One of the biggest issues } \\
\text { we're facing is the mindset of } \\
\text { our faculty members. To } \\
\text { them its kind of student reps, } \\
\text { having students on their }\end{array}$ & & \\
\hline
\end{tabular}




\begin{tabular}{|l|l|l|}
\hline $\begin{array}{l}\text { boards, is just a token } \\
\text { (Student, GOV) }\end{array}$ & \\
\hline $\begin{array}{l}\text { The ice breaker was good, } \\
\text { but we were a lot of people, } \\
\text { maybe 30-40 and the room } \\
\text { wasn't very big. Also, my } \\
\text { brain just doesn't work like } \\
\text { that, it was too fast, like } \\
\text { speed questions, and I } \\
\text { needed more time to think } \\
\text { (Student, EXP }\end{array}$ & \\
\hline $\begin{array}{l}\text { But there are elements of I } \\
\text { think she is running a whole } \\
\text { class by herself and there are } \\
\text { things she says that she } \\
\text { doesn't remember but we } \\
\text { remember and do. So, there } \\
\text { is a bit of miscommunication } \\
\text { I think (Student, CD) }\end{array}$ & & \\
\hline
\end{tabular}

Table. Summary of Barriers

\begin{tabular}{|l|l|l|}
\hline $1^{\text {st }}$ Order Concepts & $2^{\text {nd }}$ Order Themes & Aggregate Dimensions \\
\hline $\begin{array}{l}\text { However, the coordinator } \\
\text { was always a present figure in } \\
\text { putting the final touches } \\
\text { together (Student, PUB) }\end{array}$ & Need for Staff & Barriers \\
\hline $\begin{array}{l}\text { think especially from my } \\
\text { experience, having the } \\
\text { support staff really made it } \\
\text { possible... Without that extra }\end{array}$ & & \\
\hline
\end{tabular}




\begin{tabular}{|c|c|c|}
\hline \multicolumn{2}{|l|}{$\begin{array}{l}\text { support there, I don't think it } \\
\text { could've come together the } \\
\text { way it did (Student, PEERB) }\end{array}$} & \\
\hline $\begin{array}{l}\text { An awful lot of hard work! } \\
\text { The subject has a far greater } \\
\text { work load than a normal } \\
\text { subject (Staff, WIL) }\end{array}$ & & \\
\hline $\begin{array}{l}\text { They always want more time! } \\
\text { Which is difficult, because if } \\
\text { you add more time they } \\
\text { aren't under time pressure, } \\
\text { and it's only under time } \\
\text { pressure that they can be } \\
\text { most creative (Staff, EXP) }\end{array}$ & Time & \\
\hline $\begin{array}{l}\text { I think having the unknown } \\
\text { factor [as a part of the } \\
\text { course] adds excitement } \\
\text { engagement, fear, } \\
\text { challenge... (Staff, CD) }\end{array}$ & & \\
\hline $\begin{array}{l}\text { Giving a gentle amount of } \\
\text { responsibility I think would } \\
\text { be a good thing, to be able to } \\
\text { contribute to creation you } \\
\text { need to have a good } \\
\text { understanding of what it is } \\
\text { you are creating (Student, } \\
\text { PEERA) }\end{array}$ & Lack of Clarity & \\
\hline $\begin{array}{l}\text { But you know there were } \\
\text { people who weren't really }\end{array}$ & Wavering Motivation & \\
\hline
\end{tabular}




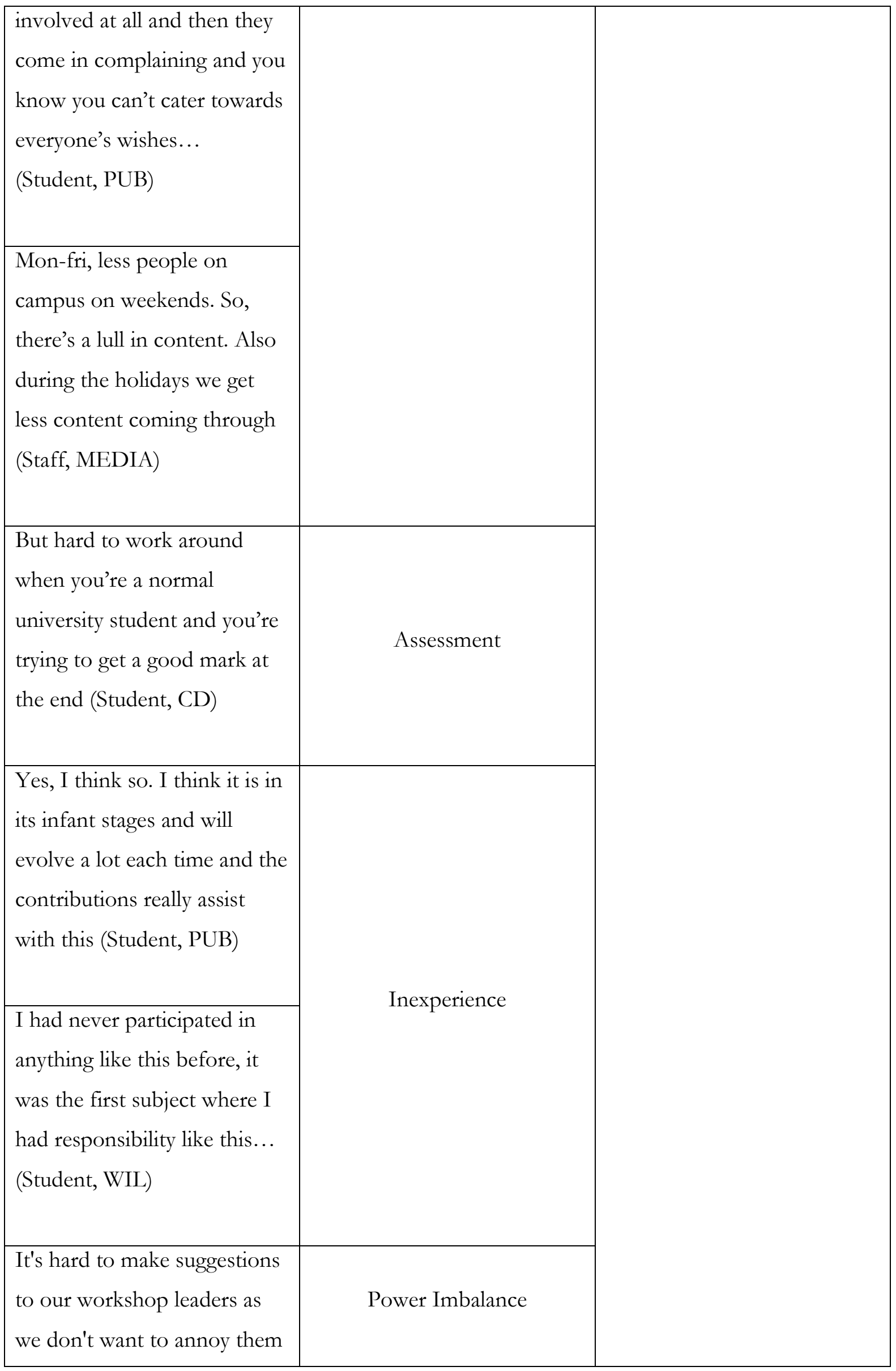




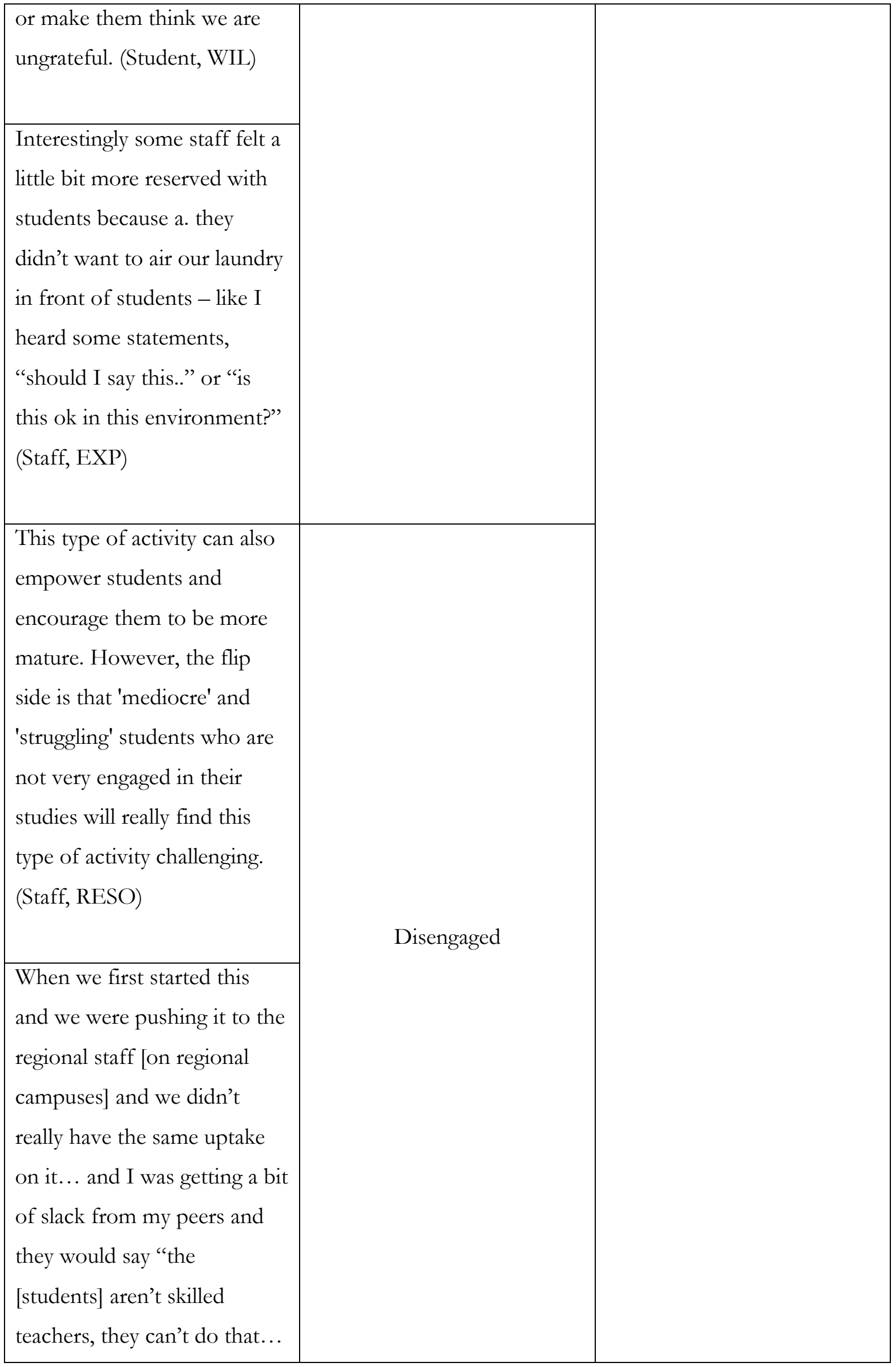


you don't realize they just aren't very good" and I just don't buy into that. (Staff, PEERA)

Table. Summary of Co-Production

\begin{tabular}{|c|c|c|}
\hline $1^{\text {st }}$ Order Concepts & $2^{\text {nd }}$ Order Themes & Aggregate Dimensions \\
\hline $\begin{array}{l}\text { This year we had a change } \\
\text { with SRC with all the voting } \\
\text { now happening online and } \\
\text { we saw that the voting } \\
\text { became more popular and } \\
\text { more people nominated } \\
\text { themselves and a different } \\
\text { mix of students came } \\
\text { forward, and not just the } \\
\text { students who were friends } \\
\text { with the students who are } \\
\text { already on. (Staff, GOV) }\end{array}$ & Equity & Co-Production \\
\hline $\begin{array}{l}\text { People in teaching roles } \\
\text { sometimes use words that are } \\
\text { confusing and there might be } \\
\text { a bit of a power thing, but } \\
\text { with pictures everyone is on } \\
\text { equal footing (Staff, EXP). }\end{array}$ & & \\
\hline $\begin{array}{l}\text { I think the project gave us a } \\
\text { chance to see each other } \\
\text { outside of class in terms of } \\
\text { our intellectual and creative } \\
\text { capacity, I also think it was }\end{array}$ & Interaction & \\
\hline
\end{tabular}




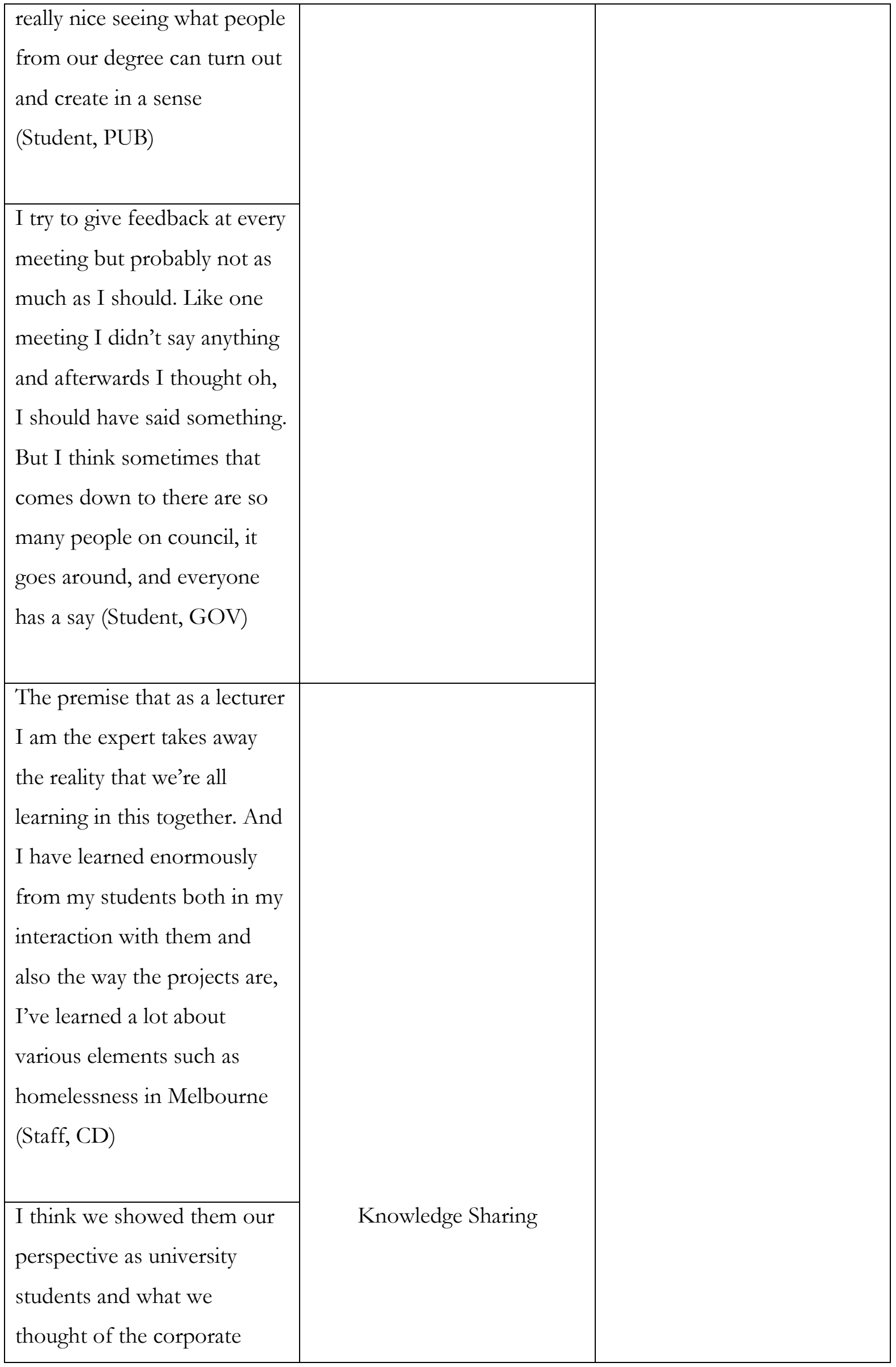




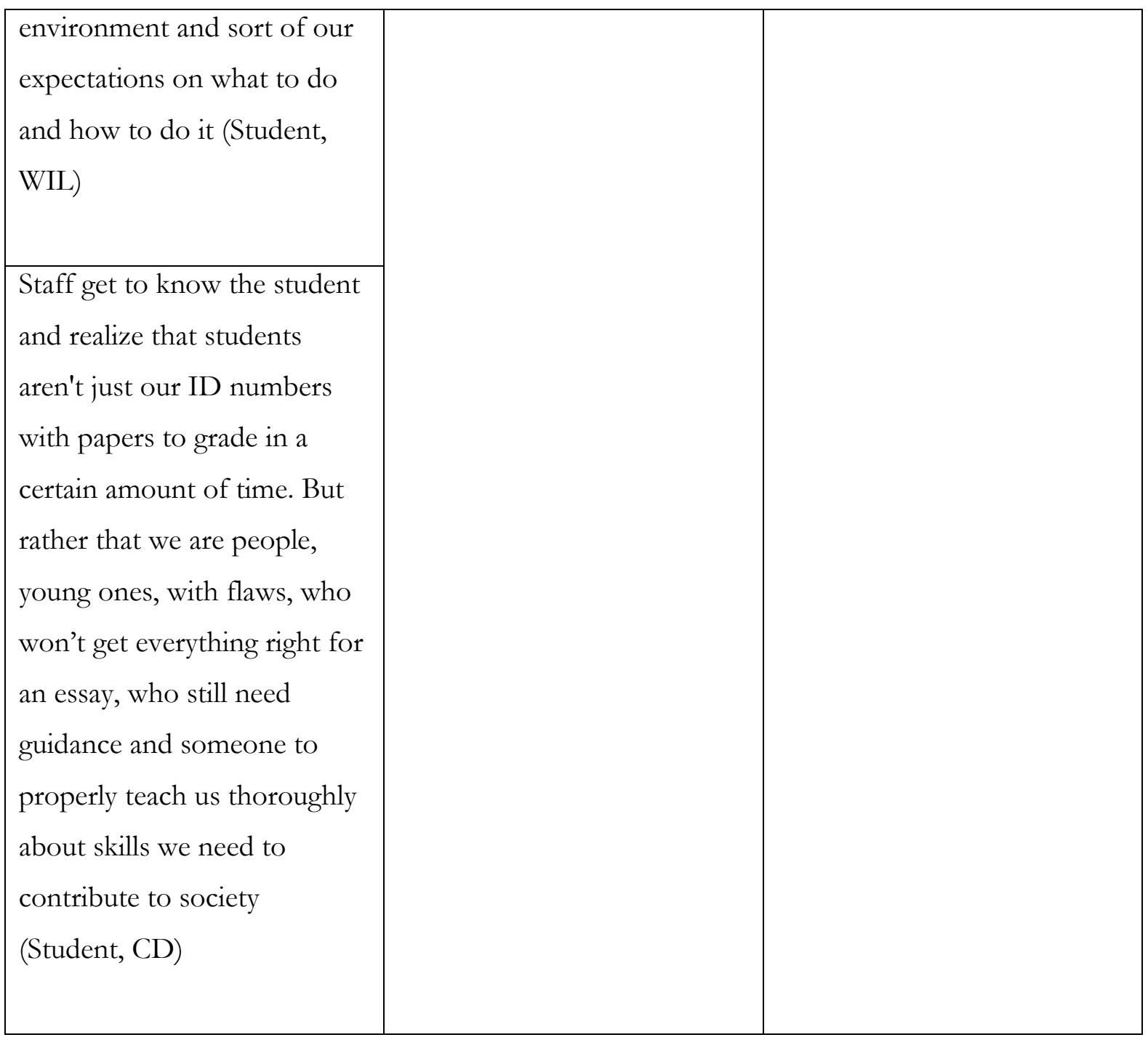

Table. Summary of Value-in-Use

\begin{tabular}{|c|c|c|}
\hline $1^{\text {st }}$ Order Concepts & $2^{\text {nd }}$ Order Themes & Aggregate Dimension \\
\hline $\begin{array}{l}\text { Anybody who asks me about } \\
\text { jobs around campus I'm } \\
\text { always like try peer } \\
\text { mentoring, if you can get in, } \\
\text { it's a really worthwhile thing } \\
\text { to do because it's a great } \\
\text { feeling when you help other } \\
\text { students and see the light of } \\
\text { realization when you see } \\
\text { students get it, it's a really }\end{array}$ & Experience & Value-in-Use \\
\hline
\end{tabular}




\begin{tabular}{|c|c|}
\hline $\begin{array}{l}\text { satisfying feeling (Student, } \\
\text { PEERA) }\end{array}$ & \\
\hline $\begin{array}{l}\text { I find more meaning in } \\
\text { engaging with students and } \\
\text { helping them realize their } \\
\text { awesomeness. This space } \\
\text { helps give my work a greater } \\
\text { sense of meaning (Staff, } \\
\text { PUB). }\end{array}$ & \\
\hline $\begin{array}{l}\text { Rather than adhering } \\
\text { specifically to a tight } \\
\text { assignment that may not } \\
\text { allow for too much freedom } \\
\text { (although this assignment did } \\
\text { allow for freedom regardless } \\
\text { of this voluntary experience), } \\
\text { students are able to be } \\
\text { creative on a wider scale if } \\
\text { that is what they think they } \\
\text { are able to manage (Staff, } \\
\text { RESO) }\end{array}$ & Personalization \\
\hline $\begin{array}{l}\text { I think that's one of the key } \\
\text { advantages of the program is } \\
\text { that I and I guess also the } \\
\text { students that attend get to } \\
\text { make the sessions their own } \\
\text { in their own way and finds } \\
\text { what works for them and for } \\
\text { the students that come along } \\
\text { regularly. And you get to } \\
\text { make it your own and do }\end{array}$ & \\
\hline
\end{tabular}




\begin{tabular}{|c|c|}
\hline $\begin{array}{l}\text { things that work for } \\
\text { everybody (Student, PEERB) }\end{array}$ & \\
\hline $\begin{array}{l}\text { Like she realizes that you just } \\
\text { a human trying to get a } \\
\text { degree. I think she has } \\
\text { respect for us as people, and } \\
\text { it's not like other tutors don't } \\
\text { but you don't feel it as much } \\
\text { (Student, CD) }\end{array}$ & Relational \\
\hline $\begin{array}{l}\text { Because from my personal } \\
\text { experience I had a strong } \\
\text { feeling after the co-creation } \\
\text { that I'm (finally) part of the } \\
\text { University of Melbourne } \\
\text { society (Student, MEDIA) }\end{array}$ & \\
\hline
\end{tabular}

Table. Summary of Benefits

\begin{tabular}{|l|l|l|}
\hline $1^{\text {st }}$ Order Concepts & Aggregate Dimension \\
\hline $\begin{array}{l}\text { For resume building this is a } \\
\text { point that I highlight, I } \\
\text { applied to a magazine and } \\
\text { showed this and I hope it will } \\
\text { be seen as a point of } \\
\text { difference... (Student, PUB) }\end{array}$ & Employability & \\
\hline $\begin{array}{l}\text { Students have first-hand } \\
\text { experience in their course and } \\
\text { can provide insight on } \\
\text { worked best for them in } \\
\text { achieving their goals or what }\end{array}$ & & \\
\hline
\end{tabular}




\begin{tabular}{|c|c|}
\hline $\begin{array}{l}\text { they have learned from other } \\
\text { successful individuals around } \\
\text { them (Student, WIL) }\end{array}$ & \\
\hline $\begin{array}{l}\text { For me the benefits have } \\
\text { been a huge boost in self- } \\
\text { efficacy and belief in my } \\
\text { capacity in my role as a } \\
\text { student regardless of it rather } \\
\text { than in spite of it (Student, } \\
\text { PROG) }\end{array}$ & Self-Efficacy \\
\hline $\begin{array}{l}\text { I think they feel that their } \\
\text { ideas are valued and they are } \\
\text { taken seriously. Also, they } \\
\text { come to understand that they } \\
\text { have something worthwhile } \\
\text { to contribute (Staff, PEERA) }\end{array}$ & \\
\hline $\begin{array}{l}\text { When I brought the idea up } \\
\text { with the staff member it was } \\
\text { conversational, rather than a } \\
\text { formal proposal, because I } \\
\text { can't pinpoint exactly when it } \\
\text { came about (Student, PUB) }\end{array}$ & Ownership \\
\hline $\begin{array}{l}\text { I feel proud. And when my } \\
\text { friends notice it and say } \\
\text { something to me I will feel } \\
\text { happy about it. Like it's an } \\
\text { achievement... (Student, } \\
\text { MEDIA). }\end{array}$ & \\
\hline
\end{tabular}




\begin{tabular}{|c|c|c|}
\hline $\begin{array}{l}\text { Yes, it has evolved! Each cohort } \\
\text { shapes it. It gives it depth and } \\
\text { breadth each time. (Staff, CD) }\end{array}$ & & \\
\hline $\begin{array}{l}\text { As a current student, I have a } \\
\text { much stronger understanding } \\
\text { of what students may be } \\
\text { struggling with, especially in } \\
\text { my field of study. As a result, } \\
\text { I can provide valuable insight } \\
\text { into the student mindset } \\
\text { (Student, PEERA) }\end{array}$ & Innovation & \\
\hline $\begin{array}{l}\text { Happier and more successful } \\
\text { students and a more } \\
\text { successful program and pass } \\
\text { rate. Increased status of the } \\
\text { uni for having programs in } \\
\text { place to look after students } \\
\text { (Student, PEERB) }\end{array}$ & & \\
\hline $\begin{array}{l}\text { The subject is also used in } \\
\text { promotional materials } \\
\text { feedback from clients that } \\
\text { will say things like, 'the } \\
\text { student work in the WIL } \\
\text { course was exceptional and } \\
\text { on par with contract work } \\
\text { that we've sent out to } \\
\text { professional consulting } \\
\text { organizations' and obviously } \\
\text { the faculty loves that kind of } \\
\text { feedback and uses that } \\
\text { strategically (Staff, WIL) }\end{array}$ & University Marketing & \\
\hline
\end{tabular}




\section{University Library}

\section{- M M N E R VA A gateway to Melbourne's research publications}

Minerva Access is the Institutional Repository of The University of Melbourne

\section{Author/s:}

Dollinger, Mollie Margaret

Title:

Co-creation in higher education

Date:

2018

Persistent Link:

http://hdl.handle.net/11343/217993

Terms and Conditions:

Terms and Conditions: Copyright in works deposited in Minerva Access is retained by the copyright owner. The work may not be altered without permission from the copyright owner. Readers may only download, print and save electronic copies of whole works for their own personal non-commercial use. Any use that exceeds these limits requires permission from the copyright owner. Attribution is essential when quoting or paraphrasing from these works. 